\title{
Anais do I Congresso Online em Doenças Negligenciadas e Emergentes
}

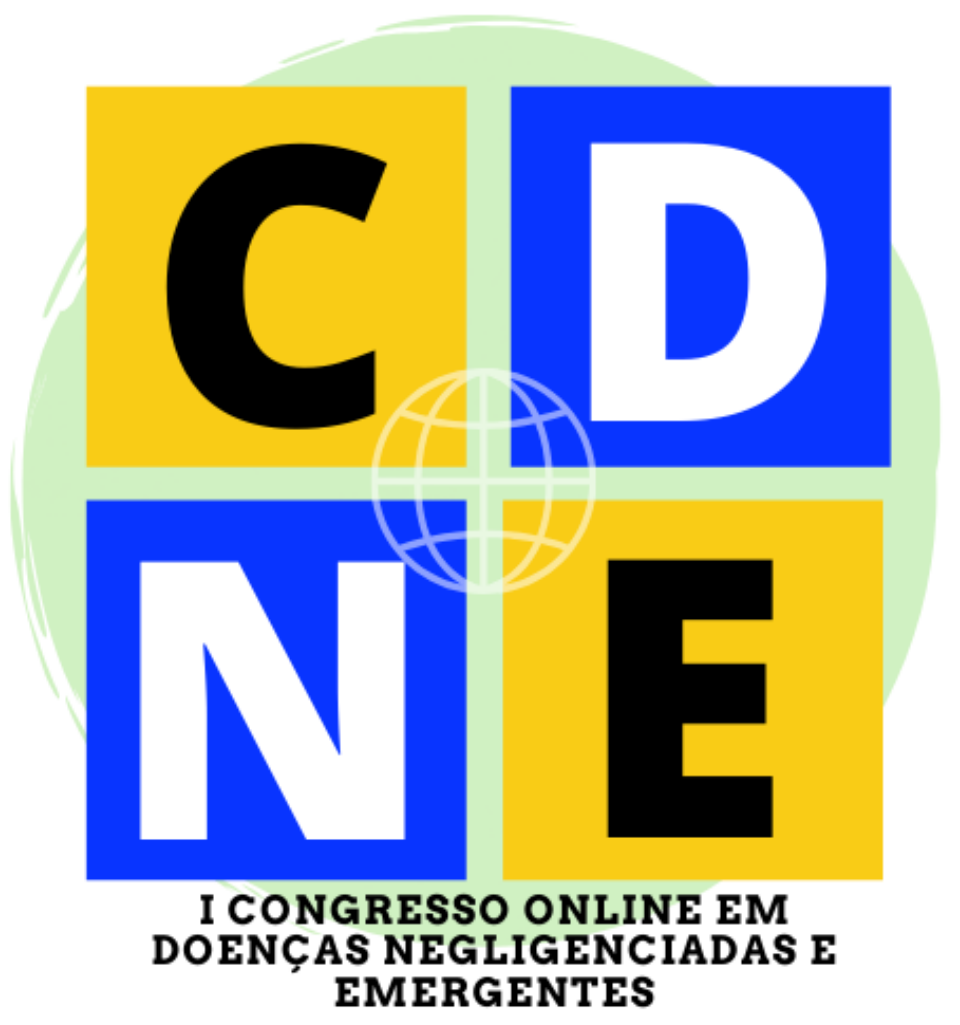

\section{Apoio:}

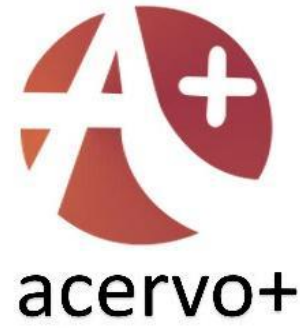

Eventos

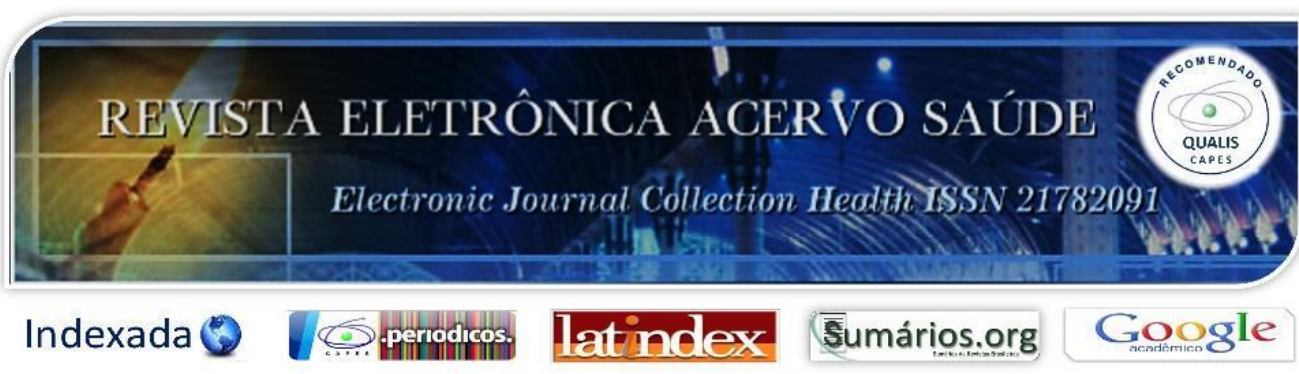




\section{SUMÁRIO}

SOBRE O EVENTO

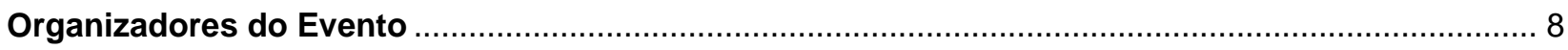

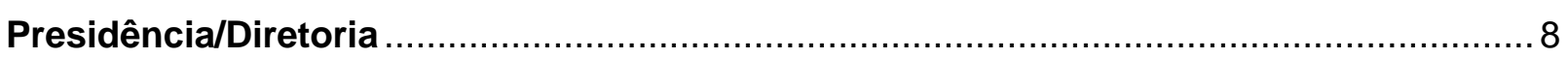

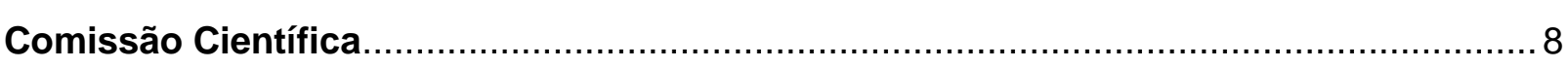

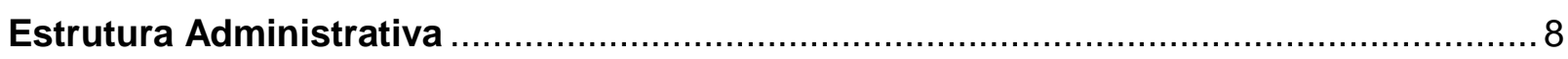

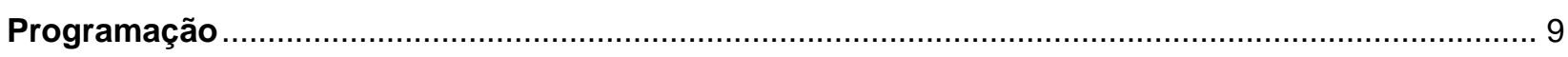

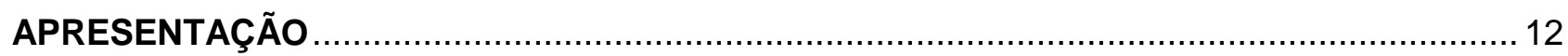

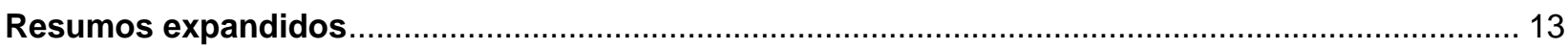

Título: Análise da presença de HIV e AIDS em casos confirmados de tuberculose no Brasil. 13

Título: Doença de Chagas no Nordeste Brasileiro: Perfil Epidemiológico entre os anos de

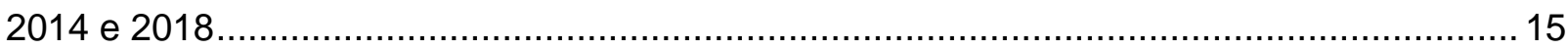

Título: Diagnóstico quantitativo da mortalidade por esquistossomose no Brasil ....................17

Título: Avaliação da atividade larvicida do extrato etanólico de Aristolochia trilobata frente a Aedes aegypti.....

Título: Da negligência ao óbito: análise da mortalidade por doença de Chagas no Brasil no período de 2008 a 2018.

Título: Avaliação quantitativa do nível de conhecimento sobre LTA de estudantes do ensino básico de escolas situadas em áreas endêmicas de Pernambuco

Título: Avaliação in vitro do potencial esquistossomicida da associação miltefosina/praziquantel em vermes adultos de Schistosoma mansoni .....

Título: Desenvolvimento de micropartículas contendo polissacarídeo sulfatado e avaliação da

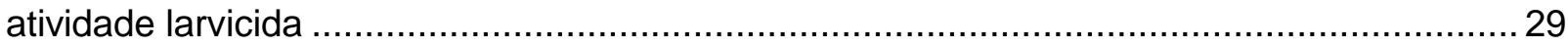

Título: Novos derivados 1,3-Tiazóis: síntese, caracterização e atividade leishmanicida .........32

Título: Aspectos Clínicos e Sociodemográficos de Leishmaniose Tegumentar Americana no

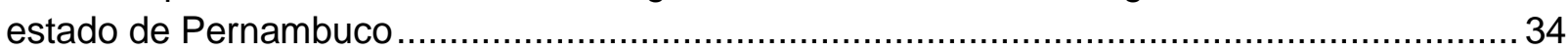

Título: Análise temporal da tuberculose no Estado da Bahia: o retrato de uma década .......... 36

Título: Análise epidemiológica da tuberculose no Estado de Rio Grande do Norte entre 2010 e 2019

Título: A importância da educação em saúde na prevenção de acidentes por animais peçonhentos: um enfoque ao escorpionismo.....

Título: Incidência de casos de Leishmaniose Tegumentar Americana no estado de Pernambuco no período de 2013 a 2018

Título: Leishmaniose Visceral: levantamento epidemiológico em Minas Gerais no período de 2017 a 2019. 
Título: Síntese e avaliação in silico da capacidade antileishmania do 2-ciano-3-fenilacrilamida

Título: Síntese e avaliação das propriedades anti- $T$. cruzi de inéditos 1,3-tiazóis derivados da

5-cloro-isatina 49

Título: Sífilis Gestacional e Sífilis Congênita: análise temporal dos casos no Brasil..... 52

Título: Série temporal de incidência de Dengue no estado da Bahia: Uma análise transversal

Título: Incremento da Atividade Antichagásica de uma Naftoquinona com a obtenção de Complexos de Inclusão com $\beta C D$ e metil- $\beta-C D$.

Título: Perfil Epidemiológico dos casos de Dengue no Brasil: Análise em um período de 5 anos.

Título: Análise das predições in silico da farmacocinética de novos candidatos LPSF/ZKC1115 antivirais contra o Zika

Título: Análise epidemiológica dos acidentes envolvendo serpentes no Rio Grande do Norte (2010-2016) .

Título: Aspectos sociodemográficos dos casos de tuberculose na Bahia de 2015 a 2019 ....

Título: Atividade antimicrobiana e antiformação de biofilme de extrato aquoso das folhas de Campomanesia dichotoma (O.Berg) Mattos em Gram-negativos

Título: Avaliação da atividade antileishmania de naftoimidazóis sintéticos derivados do lapachol

Título: Diferenças no processo de evolução da COVID-19 em comunidades ribeirinhas urbanas.

Título: Efeito inibitório de extratos vegetais (Jatropha mollissima) frente a hemorragia local induzida pela peçonha da jararaca (Bothrops jararaca)

Título: Estudo de estabilidade química das moléculas com atividade leishmanicida SB-83, SB200 e SB-44.

Título: Perfil epidemiológico da coinfecção de LV-HIV no Brasil, 2010-2018.

Título: Identificação de Staphylococcus aureus em goma de mandioca comercializada em feiras livres em um município localizado no estado do Piauí, Brasil

Título: Leishmaniose Tegumentar Americana em um município do leste de Minas Gerais, no período de 2008 a 2017.

Título: Nanodispositivo eletroquímico para diagnóstico presuntivo de leishmaniose visceral . 93

Título: Perfil epidemiológico das Leishmanioses no estado de Pernambuco..........................95

Título: Perfil de resistência de isolados clínicos de Enterococcus faecium (Recife, PE).........98

Título: Perfil das Gestantes Infectadas pelo T. pallidum segundo fatores sociodemográficos

Título: Saúde na escola: Parasitoses intestinais em adolescentes e medidas de biossegurança 
Título: Novos derivados híbridos ftalimido-tiazolinonas: síntese e atividade anti-T. cruzi ..... 106

Título: Novas dispersões sólidas poliméricas com atividade antileishmania obtidas do SB-83:

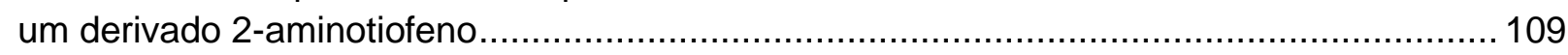

Título: Via de Hedgehog na esquistossomose: Revisão Narrativa da literatura.....................112

Título: Análise comparativa do perfil epidemiológico da Dengue em meio a pandemia do

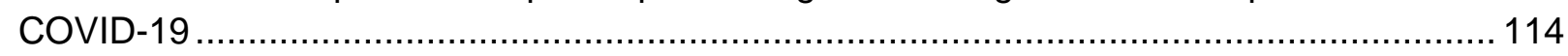

Título: Abordagem histórica e arqueológica da Entamoeba histolytica ................................ 116

Título: Perfil clínico-epidemiológico de pacientes com Esquistossomose no Nordeste brasileiro

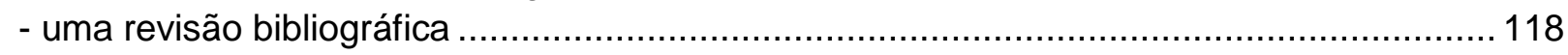

Título: Análise do pressuposto jurídico do direito à saúde de pacientes com tuberculose.... 120

Título: Estratégias terapêuticas para o tratamento da Hepatite C ....................................... 124

Título: Extratos de Plantas como Alternativa para o Tratamento da Esquistossomose

Mansônica: Uma Revisão Sistemática ....................................................................... 127

Título: Fatores de virulência do novo vírus da influenza $A(H 1 N 2)$ e seu potencial de evolução

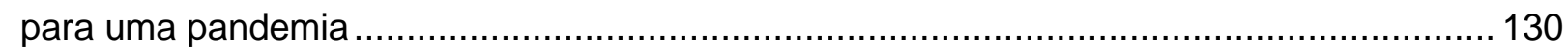

Título: Abordagens no desenvolvimento de vacinas multivalentes contra filariose linfática .. 132

Título: Abordagens da nanotecnologia no aprimoramento do tratamento da hanseníase .... 134

Título: Sistemas de liberação de benznidazol: uma revisão integrativa dos recentes esforços

para superar as limitações físico-químicas do principal agente antichagásico ......

Título: Relato de Experiência: Gestão de Resíduos de Serviços de Saúde Frente ao novo

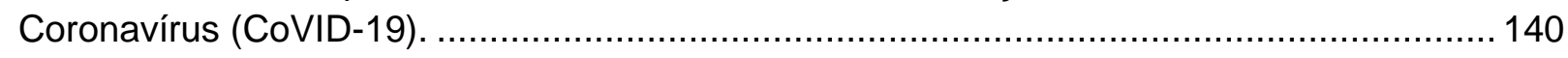

Título: Revisão Sistemática dos Parâmetros Farmacocinéticos da Dapsona ....................... 143

Título: Fatores de virulência do novo vírus da influenza A (H1N2) e seu potencial de evolução

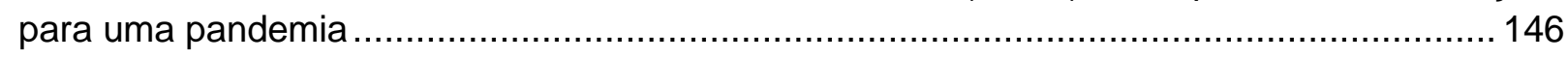

Título: Terapia combinada entre lectinas e antibióticos como uma estratégia promissora para superar a resistência bacteriana: uma revisão da literatura ........................................... 148

Título: Relevância da intervenção nutricional como estratégia para intervir no prognóstico de portadores de DCNT infectados por COVID-19: uma breve revisão ................................... 150

Título: Potencial antileishmanial de nanopartículas de prata: uma revisão.......................... 153

Título: Perspectivas farmacoterapêuticas para a COVID-19 ............................................ 155

Título: Perfil epidemiológico e estratégias de controle de arboviroses (dengue, zika e chikungunya) no Brasil - Uma revisão bibliográfica.................................................... 157

Título: A Importância do Acompanhamento Farmacêutico no Uso de Psicofármacos em

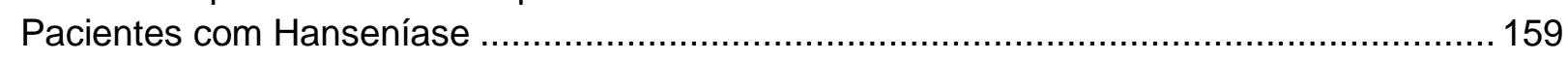

Título: Os Desafios Do Tratamento Da Tuberculose Em Pacientes Coinfectados Pelo Vírus Da Imunodeficiência Humana (Hiv): Uma Revisão Integrativa............................................. 162

Título: Nanossistemas no carreamento de fármacos para o tratamento tópico de lesões provocadas pela Leishmaniose cutânea ................................................................... 164 
Título: Avaliação dos métodos de diagnóstico para COVID-19

Título: Benznidazol para o tratamento da doença de Chagas: Efeitos e novas alternativas farmacológicas.

Título: Assistência de Enfermagem no Tratamento da Tuberculose: Uma Revisão Integrativa

Da Literatura.

Título: Ivermectina: Novos horizontes na farmacoterapia

Título: Nanosistemas contendo Benznidazol: um avanço tecnológico na terapêutica da Doença de Chagas....

Título:Métodos de diagnóstico da esporotricose felina - uma zoonose negligenciada.

Título: Dengue uma doença negligenciada tropical: Panorama, populações afetadas, fatores sociais e políticas de saúde pública para sua prevenção e tratamento

Resumos Simples.

Título: Perfil epidemiológico dos casos de sífilis congênita no Distrito Sanitário III do Recife entre 2015 a 2018

Título: Hepatites Virais em Governador Valadares, Minas Gerais: estudo descritivo

Título: Perfil epidemiológico, clínico, laboratorial e terapêutico de portadores de tuberculose atendidos na rede SUS em Pernambuco.

Título: Avaliação do potencial antifúngico de nanopartículas de quitosana associadas à peçonha da serpente Crotalus durissus cascavella.

Título: Avaliação da expressão de grupos de genes codificantes de proteínas parálogas GP63 ao longo do ciclo de vida de Leishmania braziliensis

Título: Cenário da tuberculose infanto-juvenil indígena: visão diagnóstica

Título: Leptospirose Humana em Pernambuco: Estudo Epidemiológico dos Dados do SINAN de 2018 e 2019.

Título: Perfil Epidemiológico dos casos de Hanseníase Virchowiana no Estado de

Pernambuco no período de 2013 a 2017: uma abordagem quantitativa

Título: Desafio do tratamento da tuberculose nos casos de coinfecção TB/HIV em um município prioritário da Amazônia ocidental

Título: Hidrazonas derivadas do lapachol com potencial antileishmania: determinação in silico e análise de ADME/T

Título: Prevalência da Doença de Chagas Aguda na Região Norte do Brasil no Período de 2015 a 2018.

Título: Perfil epidemiológico de pacientes acometidos por Tuberculose no estado de Mato Grosso entre 2009 e 2019

Título: Perfil epidemiológico de pacientes acometidos por Leishmaniose Tegumentar no estado de Mato Grosso entre 2009 e 2019

Título: Análise in silico do perfil farmacocinético de hidrazonas com potencial leishmanicida utilizando o PreADMET. 
Título: Desafios e enfrentamentos na dispensação de medicamentos para pacientes portadores de tuberculose em uma Farmácia da Família, em tempos de pandemia......

Título: Buscando estratégias de enfrentamento da COVID-19 por meio de experiência pregressa em surto da Chikungunya em 2017: Ações realizadas em um município do Leste de Minas Gerais

Título: Estratégias de saúde utilizadas para gestantes portadoras de HIV/AIDS na redução da transmissão vertical

Título: Desafios do enfrentamento da Influenza no Brasil durante a pandemia da Covid-19 213 Título: Avaliação da cromatografia de troca iônica como etapa de purificação na produção de soro antiofídico

Título: Aspectos Clínicos da Tripanossomíase Humana Africana ou Doença do Sono ........216

Título: Análise das internações por brucelose nos estados brasileiros

Título: Análise da situação epidemiológica da sífilis gestacional no Brasil: uma revisão .......218

Título: Assistência farmacêutica voltada a portadores de doenças crônicas associadas à hanseníase

Título: Análise das alterações comportamentais em animais infectados por Toxocara spp: uma revisão da literatura.

Título: Diagnósticos da Leishmaniose Visceral (LV): uma revisão de literatura......

Título: Resistência aos antimaláricos como fator preponderante contra a erradicação da Malária no Brasil: uma revisão integrativa.

Título: Desafios do manejo médico no tratamento da tuberculose: uma doença ainda negligenciada.

Título: Os serviços comunitários desenvolvidos pelo farmacêutico na pandemia da Covid-19

Título: Epidemiologia e fatores de risco da esquistossomose mansoni: uma revisão de literatura.

Título: Sintomas chagásicos podem ser potencializados pela COVID19.

Título: Hanseníase: Um problema de saúde pública

Título: Estudos in vitro e in vivo utilizando nanossistemas para aplicação anti-tuberculose .235

Título: HIV-1 subtipo F no Brasil: importância na dispersão da epidemia, patogênese e geração dos recombinantes $\mathrm{BF}$ do vírus.

Título: Distribuição geográfica e aspectos epidemiológicos da filariose linfática: Uma revisão de literatura.

Título: Novas estratégias para a terapia da Leishmaniose cutânea: uma revisão narrativa.. 240

Título: A influência da expressão gênica na virulência da paracoccidioidomicose

Título: Impacto na saúde mental da população brasileira causado pelo distanciamento social no enfrentamento a COVID-19. 


\section{SOBRE O EVENTO}

I Congresso Online em Doenças Negligenciadas e Emergentes surgiu da necessidade de ampliar o espaço de discussões e intercâmbio científico desta temática, com tamanha relevância dentro do cenário nacional. $O$ evento ocorreu entre os dias 15 e 17 de agosto de 2020, das 8 às 18 horas, e contou com a participação de profissionais e pesquisadores da área de saúde. Desde o início do processo de desenvolvimento de novas terapêuticas com o planejamento em química medicinal até a clínica atual dessas doenças, os diversos tópicos abordados agregaram ao evento um caráter multi e interdisciplinar dentro da área de saúde. Para cumprir as recomendações sanitárias de prevenção contra a COVID-19, todo o evento ocorreu de forma online, com palestras gravadas, minicursos, apresentações dos trabalhos e sessões de dúvidas no formato ao vivo. Os mais de 200 resumos submetidos foram avaliados pela comissão científica no sistema de revisão de pares, e os melhores foram escolhidos para apresentação oral, concorrendo a menção honrosa e premiação. $O$ congresso reverberou positivamente pela comunidade científica e pelos mais de 400 congressistas de todas as regiões do Brasil, e gerou uma reflexão complexa da temática por meio de diversos olhares, saberes e abordagens. 


\section{ORgANIZADORES DO EVENTO}

\section{PresidênCIA/Diretoria}

Ana Cristina Lima Leite (Presidente docente)

Mabilly Cox Holanda de Barros Dias (Presidente da Comissão)

Débora Lopes de Santana

\section{Comissão Científica}

lanca Karine Prudencio de Albuquerque (Coordenadora Científica)

Laysa Creusa Paes Barreto Barros Silva

Thaís Pachêco de Freitas

\section{Estrutura Administrativa}

Luiz Alberto Barros Freitas

Rayane Karine Santos Menino

Camila Gabriela Costa Ramos

Maria Gabriella Nunes de Melo

Maria José Cristiane

Miria Barbosa de Oliveira 


\section{Programação}

\begin{tabular}{|c|c|c|c|c|}
\hline \multicolumn{5}{|c|}{ Dia $1-15 / 08 / 2020$} \\
\hline Horário & \multicolumn{4}{|c|}{ Evento } \\
\hline $\begin{array}{l}\text { 08:00 - } \\
\text { 09:00 }\end{array}$ & $\begin{array}{l}\text { Mesa de } \\
\text { abertura }\end{array}$ & $\begin{array}{c}\text { Mesa de abertura I } \\
\text { Congresso Online em } \\
\text { Doenças Negligenciadas e } \\
\text { Emergentes }\end{array}$ & $\begin{array}{c}\text { Dr. Danilo César } \\
\text { Galindo Bedor } \\
\text { (Coordenador Farmácia } \\
\text { - UFPE) } \\
\text { Dr. Arimatéa da Rocha } \\
\text { Filho (Conselheiro } \\
\text { Regional de Farmácia - } \\
\text { CRF-PE) } \\
\text { Dra. Ana Cristina Lima } \\
\text { Leite (Professora } \\
\text { coordenadora do } \\
\text { evento) }\end{array}$ & Online \\
\hline $\begin{array}{l}\text { 09:00 - } \\
\text { 10:00 }\end{array}$ & Palestra & $\begin{array}{c}\text { Novos mecanismos para } \\
\text { acelerar a P\& D em } \\
\text { doenças tropicais e } \\
\text { negligenciadas }\end{array}$ & Dr. Jadel Müller Kratz & Online \\
\hline $\begin{array}{l}10: 00- \\
11: 00\end{array}$ & Palestra & $\begin{array}{c}\text { Panorama atual da filariose } \\
\text { linfática e a busca por } \\
\text { novas tecnologias de } \\
\text { diagnóstico }\end{array}$ & $\begin{array}{c}\text { Dr. André Filipe Pastor } \\
\text { da Silva }\end{array}$ & Online \\
\hline $\begin{array}{l}11: 00- \\
12: 00\end{array}$ & Palestra & $\begin{array}{l}\text { Malaria drug resistance: } \\
\text { what else? }\end{array}$ & Dra. Fátima Nogueira & Online \\
\hline \multicolumn{5}{|c|}{ Intervalo } \\
\hline $\begin{array}{l}13: 00- \\
14: 00\end{array}$ & Palestra & $\begin{array}{c}\text { Evolução da Fisiopatologia } \\
\text { da Covid-19 e principais } \\
\text { terapias em estudo }\end{array}$ & $\begin{array}{c}\text { PhD Lindomar José } \\
\text { Pena }\end{array}$ & Online \\
\hline $\begin{array}{l}14: 00- \\
15: 00\end{array}$ & Palestra & $\begin{array}{c}\text { Atual cenário da } \\
\text { Esquistossomose } \\
\text { Mansônica e prospecção } \\
\text { diagnóstica }\end{array}$ & $\begin{array}{l}\text { Msc Caroline Louise } \\
\text { Diniz Pereira }\end{array}$ & Online \\
\hline $\begin{array}{l}15: 00- \\
16: 00\end{array}$ & Palestra & $\begin{array}{c}\text { Desafios para a eliminação } \\
\text { da Hanseníase no Brasil }\end{array}$ & $\begin{array}{l}\text { Dr. Carlos Dornels } \\
\text { Freire de Souza }\end{array}$ & Online \\
\hline $\begin{array}{l}16: 00- \\
18: 00\end{array}$ & $\begin{array}{l}\text { Mesa } \\
\text { redonda }\end{array}$ & Mesa redonda & $\begin{array}{c}\text { Carolina } \\
\text { Medeiros/Enfermeira } \\
\text { Anne } \\
\text { Epalanga/Terapeuta } \\
\text { Ocupacional } \\
\text { Dolores Mais } \\
\text { Netto/Psicóloga } \\
\text { Cleide } \\
\text { Freire/Biomédica } \\
\text { Cristina } \\
\text { Carrazzone/Médica }\end{array}$ & Online \\
\hline \multicolumn{4}{|c|}{ Dia $2-16 / 08 / 2020$} & \\
\hline
\end{tabular}


Anais do I Congresso Online em Doenças Negligenciadas e Emergentes

\begin{tabular}{|c|c|c|c|c|}
\hline $\begin{array}{l}\text { 08:00 - } \\
09: 00\end{array}$ & Palestra & $\begin{array}{l}\text { Desafios farmacológicos na } \\
\text { busca de novos compostos } \\
\text { para o tratamento da } \\
\text { tuberculose sensível e } \\
\text { resistente }\end{array}$ & $\begin{array}{l}\text { MsC. Aline dos Santos } \\
\text { Peixoto }\end{array}$ & Online \\
\hline $\begin{array}{c}09: 00- \\
10: 00\end{array}$ & Palestra & $\begin{array}{c}\text { Coronavírus, Zika e } \\
\text { Chikungunya: Como o } \\
\text { desenvolvimento de testes } \\
\text { rápidos de diagnóstico } \\
\text { podem acelerar a resposta } \\
\text { frente a esses patógenos? }\end{array}$ & $\begin{array}{l}\text { Msc Severino Jefferson } \\
\text { Ribeiro da Silva }\end{array}$ & Online \\
\hline $\begin{array}{c}10: 00- \\
10: 30\end{array}$ & Palestra & $\begin{array}{l}\text { Diagnóstico laboratorial das } \\
\text { leishmanioses emserviços } \\
\text { de saúde pública: dos } \\
\text { métodos clássicos a } \\
\text { tecnologia molecular }\end{array}$ & $\begin{array}{c}\text { Dr. Rômulo Pessoa e } \\
\text { Silva }\end{array}$ & Online \\
\hline $\begin{array}{l}10: 30- \\
11: 10\end{array}$ & Palestra & $\begin{array}{l}\text { Desenvolvimento de um } \\
\text { novo teste rápido para } \\
\text { diagnóstico de } \\
\text { leishmaniose visceral }\end{array}$ & $\begin{array}{l}\text { Dr. Wagner José } \\
\text { Tenório dos Santos }\end{array}$ & \\
\hline $\begin{array}{l}11: 10- \\
12: 00\end{array}$ & Palestra & $\begin{array}{l}\text { Compostos naturais como } \\
\text { alternativa para o } \\
\text { tratamento da doença de } \\
\text { Chagas } \\
\end{array}$ & $\begin{array}{c}\text { MsC Isabella Coimbra } \\
\text { Vila Nova }\end{array}$ & Online \\
\hline \multicolumn{5}{|c|}{ Intervalo } \\
\hline $\begin{array}{c}13: 00- \\
14: 00\end{array}$ & Palestra & $\begin{array}{l}\text { Os possíveis impactos da } \\
\text { Covid-19 na produção de } \\
\text { Hemoderivados }\end{array}$ & $\begin{array}{l}\text { MsC Antonio Edson de } \\
\text { Souza Lucena }\end{array}$ & Online \\
\hline $\begin{array}{l}14: 00- \\
15: 00\end{array}$ & Palestra & $\begin{array}{l}\text { Epidemias virais e a corrida } \\
\text { pelo desenvolvimento de } \\
\text { vacinas }\end{array}$ & $\begin{array}{c}\text { PhD Isabelle Freire } \\
\text { Tabosa Viana }\end{array}$ & Online \\
\hline $\begin{array}{l}15: 00- \\
16: 00\end{array}$ & Palestra & $\begin{array}{c}\text { A importância do SUS no } \\
\text { combate às doenças } \\
\text { negligenciadas }\end{array}$ & Msc Catarina Cataldi & Online \\
\hline $\begin{array}{l}16: 00- \\
18: 00\end{array}$ & $\begin{array}{c}\text { Apresentação } \\
\text { dos melhores } \\
\text { trabalhos }\end{array}$ & $\begin{array}{l}\text { Apresentação oral de } \\
\text { trabalhos }\end{array}$ & Comissão avaliadora & Online \\
\hline \multicolumn{5}{|c|}{ Dia $3-17 / 08 / 2020$} \\
\hline $\begin{array}{l}08: 00- \\
12: 00\end{array}$ & Minicurso & $\begin{array}{c}\text { Princípios e aplicações da } \\
\text { técnica de PCR }\end{array}$ & $\begin{array}{l}\text { Msc Cíntia Nascimento } \\
\text { da Costa Oliveira }\end{array}$ & Online \\
\hline $\begin{array}{l}08: 00- \\
12: 00\end{array}$ & Minicurso & $\begin{array}{l}\text { Planejamento estrutural de } \\
\text { compostos nas doenças } \\
\text { negligenciadas: como } \\
\text { podemos fazer? }\end{array}$ & $\begin{array}{c}\text { Luciana Rabêlo Pessôa } \\
\text { de Siqueira }\end{array}$ & Online \\
\hline $\begin{array}{l}08: 00- \\
12: 00\end{array}$ & Minicurso & $\begin{array}{c}\text { Ensaios biológicos para o } \\
\text { estudo de doença de } \\
\text { Chagas e as } \\
\text { Leishmanioses }\end{array}$ & $\begin{array}{l}\text { PhD Maria Carolina } \\
\text { Accioly Brelaz de } \\
\text { Castro }\end{array}$ & Online \\
\hline
\end{tabular}


Anais do I Congresso Online em Doenças Negligenciadas e Emergentes

\begin{tabular}{|c|c|c|c|c|}
\hline $\begin{array}{l}08: 00- \\
12: 00\end{array}$ & Minicurso & $\begin{array}{c}\text { Desenvolvimento } \\
\text { tecnológico de novas } \\
\text { terapias para doenças } \\
\text { negligenciadas }\end{array}$ & $\begin{array}{l}\text { Dr. José Lamartine } \\
\text { Soares Sobrinho }\end{array}$ & Online \\
\hline $\begin{array}{l}08: 00- \\
12: 00\end{array}$ & Minicurso & $\begin{array}{l}\text { Novas abordagens } \\
\text { terapêuticas, de } \\
\text { diagnóstico e produção de } \\
\text { vacinas para dengue }\end{array}$ & $\begin{array}{c}\text { PhD Vivian } \\
\text { Vasconcelos Costas }\end{array}$ & Online \\
\hline $\begin{array}{l}08: 00- \\
12: 00\end{array}$ & Minicurso & $\begin{array}{c}\text { Inovações no diagnóstico e } \\
\text { perspectivas terapêuticas } \\
\text { na Esporotricose }\end{array}$ & $\begin{array}{c}\text { Dr. Reginaldo } \\
\text { Gonçalves de Lima } \\
\text { Neto }\end{array}$ & Online \\
\hline $\begin{array}{l}13: 00- \\
14: 00\end{array}$ & Palestra & $\begin{array}{l}\text { Avanços na Tecnologia } \\
\text { Farmacêutica e Analítica } \\
\text { para o tratamento de } \\
\text { doenças negligenciadas }\end{array}$ & $\begin{array}{l}\text { PhD Larissa Andrade } \\
\text { Rolim }\end{array}$ & Online \\
\hline $\begin{array}{l}14: 00- \\
15: 00\end{array}$ & Palestra & $\begin{array}{c}\text { Ensaios in vitro e in vivo de } \\
\text { ação de novos candidatos } \\
\text { á fármacos para doenças } \\
\text { negligenciadas }\end{array}$ & $\begin{array}{c}\text { Dra. Maria Nazaré } \\
\text { Correia Soeiro }\end{array}$ & Online \\
\hline $\begin{array}{l}16: 00- \\
17: 00\end{array}$ & Palestra & $\begin{array}{c}\text { Estruturas privilegiadas no } \\
\text { desenvolvimento de } \\
\text { protótipos para doenças } \\
\text { negligenciadas }\end{array}$ & $\begin{array}{l}\text { PhD Gevanio Bezerra } \\
\text { de Oliveira Filho }\end{array}$ & Online \\
\hline $\begin{array}{l}15: 00- \\
16: 00\end{array}$ & Palestra & $\begin{array}{l}\text { Sistemas de liberação de } \\
\text { fármacos com novas } \\
\text { moléculas para doença de } \\
\text { Chagas e Leishmaniose }\end{array}$ & $\begin{array}{l}\text { PhD Ádley Antonini } \\
\text { Neves de Lima }\end{array}$ & Online \\
\hline $\begin{array}{l}17: 00- \\
18: 00\end{array}$ & $\begin{array}{l}\text { Premiação de } \\
\text { trabalhos }\end{array}$ & $\begin{array}{l}\text { Premiação dos melhores } \\
\text { trabalhos }\end{array}$ & Comissão organizadora & Online \\
\hline
\end{tabular}




\section{APRESENTAÇÃO}

Devido a ascensão da doença emergente COVID-19 e os inúmeros desafios no combate das doenças negligenciadas, o I Congresso Online em Doenças Negligenciadas Emergentes tornou-se ainda mais relevante, e possibilitou o acréscimo de saberes desde à pesquisa e inovação até a clínica para os congressistas. Além disso, gerou contribuição para comunidade científica através da submissão de resumos simples e expandidos, na forma de estudo original, estudo de caso, relato de experiência e revisão bibliográfica. A presente publicação traz 104 resumos, sendo 37 simples e 68 expandidos aceitos, entre estes $9 \mathrm{com}$ aprovação pelo comitê de ética em pesquisa para realização de trabalhos com seres humanos. A avaliação dos resumos foi feita por revisão de pares e levou em consideração relevância, originalidade, qualidade da redação e organização do texto, atendimento às normas e encaixe no escopo do evento (doenças negligenciadas e emergentes) dentro das áreas temáticas: Assistência Farmacêutica/Farmácia Hospitalar; Síntese e Planejamento de Fármacos; Tecnologia Farmacêutica/Biotecnologia; Epidemiologia; Saúde Pública; Parasitologia/Microbiologia e Métodos de Diagnóstico. 


\section{RESUMOS EXPANDIDOS}

\section{RESUMOS EXPANDIDOS: Estudo Original}

Título: ANÁlise dA PRESENÇA dE HIV E AIDS EM CASOS CONFIRMADOS DE TUBERCULOSE NO BRASIL

Autor/coautores: Claudia de Lima Rodrigues Souza', Brenda Fernanda Guedes², Maria Vitoria Alves Vila Nova ${ }^{3}$, Sandy Guedes Pereira ${ }^{4}$ e Ronald Pereira Cavalcantis.

Instituição: Centro Universitário Tabosa de Almeida (ASCES), Caruaru - Pernambuco'. Universidade Federal de Pernambuco (UFPE) ${ }^{2,45}$, Vitória de Santo Antão - Pernambuco. Universidade de Pernambuco (UPE), Nazaré da Mata - Pernambuco ${ }^{3}$.

Palavras-chave: Tuberculose, HIV, Sorodiagnóstico da AIDS.

\section{INTRODUÇÃO}

A tuberculose é uma doença infecciosa causada pelo Mycobacterium tuberculosis hominis. Em países em desenvolvimento como o Brasil, ela se mantém uma doença infectocontagiosa prevalente. $O$ meio de transmissão da tuberculose ocorre a partir da eliminação de bacilos por via respiratória e sua infectividade está diretamente relacionada ao estado imunológico do indivíduo (ORME IM, et al., 2015).

O Vírus da Imunodeficiência Humana (HIV) e a Síndrome da Imunodeficiência Adquirida (AIDS) são fatores que contribuem para a transmissão e a manifestação da tuberculose e, quando presentes, a transforma de uma doença endêmica para epidêmica. A taxa de mortalidade por tuberculose aumenta de 2,4 a 19 vezes em pacientes com coinfecção tuberculose-HIV ou tuberculose-AIDS quando comparados a pacientes HIV negativos (GASPAR RS, et al., 2016).

Sendo a tuberculose uma doença tratável de controle prioritário no país, agravada quando associada ao HIV/AIDS, torna-se indispensável a análise de sua ocorrência no Brasil, possibilitando, dessa forma, o traçado de novos caminhos para o planejamento de ações de prevenção e combate.

\section{OBJETIVO}

Realizar análise da presença sincrônica de Síndrome da Imunodeficiência Adquirida e/ou Vírus da Imunodeficiência Humana em casos confirmados de tuberculose, no período de 2010 a 2019, presentes no território brasileiro.

\section{MÉTODO}

A presente pesquisa trata de um estudo observacional, descritivo, quantitativo e longitudinal, em um recorte temporal do período de 2010 a 2019. O intervalo analisado corresponde aos últimos dez anos disponíveis no sistema. Foram coletados dados secundários oriundos do sítio eletrônico do Departamento de Informática do Sistema Único de Saúde do Brasil (DATASUS), especificamente do Sistema de Informação de Agravos e Notificação (SINAN). Após a realização da coleta, os dados foram sistematizados em planilhas eletrônicas, utilizando o programa LibreOffice Calc. As variáveis foram padronizadas através de taxas por 100 mil, agregadas ano a ano, organizadas por tipo de agravo e analisados descritivamente por meio de valores absolutos e relativos.

\section{RESULTADOS}

Durante a observação dos resultados obtidos no banco de dados, viu-se que os casos isolados de tuberculose representam a maioria, somando $691.729(79 \%)$ do total registrado. Os coinfectados com HIV retratam $96.787(11 \%)$ e os casos de tuberculose sincrônicos com AIDS refletem $88.844(10 \%)$ do total. Os números que representam tuberculose acrescida de HIV iniciam com taxa de 4,5 por 100 mil, atingem o ápice em 2014 com taxa de 4,8, encerram o período com 4,3 em 2019. 
Quando verificada a tuberculose agregada a AIDS, o início do período demonstra taxa de 3,8 com elevação até o ano de 2014 chegando a 4,4 e cai para 3,9 em 2019. Os casos com presença de HIV e AIDS apresentam diminuição de 4,48\% e 4,90\% respectivamente quando comparados o ano de início e de fim do estudo. Os confirmados apenas com tuberculose terminam 2019 com crescimento de 6,65\% em relação a 2010.

\section{DISCUSSÃO}

Observou-se que o número de casos apenas com tuberculose teve estabilidade entre 2010 a 2014 , seguido de aumento até 2018 atingindo o pico, declinando em 2019. As duas categorias HIV e AIDS simultaneamente com a tuberculose demonstram comportamento semelhante. Possuem aumento do início até 2014, terminando o período em queda.

O mesmo não ocorre com os confirmados apenas com tuberculose, que terminam 2019 com crescimento de $6,65 \%$ em relação a 2010 .

Os dados observados corroboram com o estudo de Gaspar RS, et al. (2016) em que demonstra pacientes que apresentaram a doença da tuberculose e HIV no período de 2002 a 2012, apresentaram maiores taxas de abandono da terapia. Em 2014 o Ministério da Saúde ampliou o uso de medicamentos nos casos de infecção dupla, permitindo a redução da ocorrência de complicações durante o tratamento, explicando assim a diminuição dos casos verificados através da pesquisa a partir de 2014.

\section{CONSIDERAÇÕES FINAIS}

Por meio da análise dos resultados foi possível observar que apesar da diminuição dos casos de infecção dupla entre HIV e/ou AIDS com a tuberculose, os casos confirmados de tuberculose apresentam aumento, demonstrando assim a necessidade de estudos mais aprofundados sobre o tema e elaborações de estratégias mais efetivas na adesão e permanência no tratamento, e que apesar do avanço no tratamento e na prevenção do HIV e AIDS, é fundamental não negligenciar o contínuo avanço e expandir as ações do programa nacional de controle a tuberculose em todo o país.

\section{REFERÊNCIAS}

1. GASPAR RS, et al. Análise temporal dos casos notificados de tuberculose e de coinfecção tuberculoseHIV no Brasil entre 2002 e 2012. J. bras. pneumol., 2016; 42(6): 416-422.

2. ORME IM, et al. The balance between protective and pathogenic immune responses in the TB-infected lung. Nat Immunol. 2015;16(1):57-63. 
RESUMO EXPANDIDO: Estudo Original

Título: Doença de Chagas no Nordeste Brasileiro: Perfil Epidemiológico entre os anos de 2014 e 2018

Autor/coautores: Alessandra Toscano de Brito Pontes1, Kylma Kettly Gomes da Silva2, Jonatas Victor da Silva2, Wanessa Antonia Pereira de Sousa3, Thaise Queiroz de Melo4.

Instituição: ${ }^{1}$ Universidade de Pernambuco (UPE), Recife-PE; ${ }^{2}$ Centro Universitário Brasileiro (UNIBRA), Recife-PE; ${ }^{3}$ Universidade Federal do Rio Grande do Norte (UFRN), Natal-RN; ${ }^{4}$ Universidade Salgado de Oliveira (UNIVERSO), Recife-PE.

Palavras-chave: Doenças Negligenciadas, Epidemiologia, Doença de Chagas.

\section{INTRODUÇÃO}

A Doença de Chagas (DC), também conhecida como tripanossomíase é considerada pela Organização Mundial de Saúde (OMS) como uma das doenças negligenciadas, pois apesar de atingir de 8 milhões de pessoas por ano, é uma patologia tratável, com caráter endêmico em populações de baixa renda, porém, não tem investimento de saúde e social expressivos (FERREIRA AM, et al., 2018).

A transmissibilidade ocorre pela eliminação do protozoário Tripanosoma cruzi nas fezes e urina do "barbeiro", um inseto triatomíneo. Quando atinge a circulação sanguínea, acomete diversos órgãos e sistemas, sendo os gânglios, fígado, baço e coração mais frequentes, onde dentre as formas de contaminação não são restritas, estão associadas inclusive às transfusões sanguíneas, acidentes laboratoriais e transmissão vertical (FERREIRA AM, et al., 2018).

Apesar de ser um grave problema de saúde público, no Brasil, podemos perceber o desequilíbrio na distribuição de recursos dirigidos às doenças negligenciadas, assim como a precariedade nas condições de saúde, onde torna mais dificultosa a melhora do perfil epidemiológico desta infecção, além de ter relação com fatores socioeconômicos e culturais populacionais (BRASIL MS, 2020).

\section{OBJETIVO}

Descrever o perfil epidemiológico da doença de chagas no Nordeste brasileiro entre os anos de 2014 a 2018.

\section{MÉTODO}

Trata-se de um estudo epidemiológico, descritivo e retrospectivo dos casos de Doença de Chagas Aguda na região Nordeste do Brasil notificados de forma compulsória através do Sistema de Informação do Ministério da Saúde (SINAN-DATASUS). Não houve necessidade de submissão ao Comitê de Ética em Pesquisa (CEP), visto que estes dados secundários são de livre acesso em plataforma digital. Para a análise e obtenção dos dados, foram incluídas as seguintes variáveis: idade, sexo, zona de residência, modo provável de infecção, evolução do agravo, casos novos no Brasil e casos novos por estado do Nordeste Brasileiro, entre os períodos de 2014 e 2018.

\section{RESULTADOS}

A investigação se deu em todos os estados do Nordeste brasileiro, porém apenas quatro dos nove estados da região notificaram casos, sendo esta a segunda região brasileira com maior índice de casos notificados (53) no país entre os anos investigados neste estudo, e 2018 foi responsável pelo maior registro (29 casos). Ao todo foram notificados 53 casos novos de Doença de Chagas Aguda, a maior incidência se deu no estado do Maranhão $(71,7 \%)$ e não houve diferença considerável entre o acometimento de pessoas do sexo masculino ou feminino.

A faixa etária mais acometida foi entre 20 e 39 anos, seguida de 40 e 59 anos, não houve nenhum registro de gestantes confirmadas com o agravo em questão e a principal zona de residência foi a rural. Constatouse que o meio provável mais frequente de transmissão foi considerado o oral, por meio de alimentos, que 
representou $77,3 \%$ dos casos e apenas um dos casos teve como evolução e desfecho óbito em decorrência do agravo.

\section{DISCUSSÃO}

Os índices demostram uma resposta positiva frente às ações de controle vetorial, resultando, entretanto, no aumento da contaminação via oral. Evidenciando a importância de considerar critérios de boas práticas alimentares e medidas sanitárias (BRASIL MS, 2020). O estado do Maranhão possui um ambiente favorável a domiciliação do vetor da DC e teve aumento na incidência, através da ingestão de alimentos contaminados oriundos de região endêmica. Análises indicam que a faixa etária mais acometida é entre os mais jovens, pela correlação entre o tempo de vida nas regiões onde o habitat principal do vetor é intradomiciliar e a incidência da doença (MOURA EC, et al., 2018). Fica evidente a relevância das áreas rurais na epidemiologia da DC, visto que em sua maioria encontram-se em precárias condições de moradia e em deficiência de saneamento básico entre outros indicadores ambientais favorecendo o desenvolvimento do vetor e a predominação da doença.

\section{CONSIDERAÇÕES FINAIS}

Conclui-se que o perfil epidemiológico da Doença de Chagas no nordeste brasileiro, conforme discutido anteriormente, é influenciado por várias situações que devem ser consideradas, como a precariedade dos serviços de saúde, fatores culturais e socioeconômicos, que dificultam a melhora do quadro epidemiológico. Expondo assim, a importância de criação de mecanismos de encaminhamento para a assistência assim como o acompanhamento dos casos positivos da doença de Chagas, junto a necessidade de intervenções contínuas de caráter educativo de maneira coletiva e individual.

\section{REFERÊNCIAS}

1. BRASIL MS. Secretaria de Vigilância em Saúde. Doença de Chagas: 14 de abril - Dia Mundial. Bol Epidemiol [Internet]. 2020; 51:1-43. Disponível em: http://bvsms.saude.gov.br/ultimas-noticias/3173-14-4dia-mundial-da-doenca-de-chagas. Acessado em: 10 de julho de 2020.

2. FERREIRA AM, et al. Avaliação do conhecimento acerca do manejo clínico de portadores da doença de chagas em região endêmica no brasil. Prestação de Cuidados de Saúde, Rev. APS. 2018; ed. 21(3): 345354.

3. MOURA EC, et al. Casos de doença de chagas aguda no estado do Maranhão no período de 2007 a 2018. In: XXVI Jornada de Parasitologia e Medicina Tropical do Maranhão - São Luís - MA, 2018. 
RESUMO EXPANDIDO: Estudo Original

TíTULO: DIAGNÓSTICO QUANTITATIVO DA MORTALIDADE POR ESQUISTOSSOMOSE NO BRASIL

Autor/coautores: Andréia Monique Lermen, Naiara Jacinta Clerici, Dinalva Schein, Carolina Smaniotto Fronza. Instituição: Universidade Federal da Fronteira Sul (UFFS), Cerro Largo-Rio Grande do Sul; Universidade.

Federal de Santa Maria (UFSM), Santa Maria-Rio Grande do Sul.

Palavras-chave: Doenças negligenciadas, Esquistossomose, Mortalidade.

\section{INTRODUÇÃO}

Doenças negligenciadas são causadas por agentes infecciosos ou parasitas, sendo consideradas endêmicas em populações de baixa renda. Dentre elas, a esquistossomose é uma das mais importantes no Brasil, uma vez que é causadora de muitas mortes. Possui como agente etiológico o Schistosoma mansoni, tendo caramujos do gênero Biomphalaria como hospedeiros intermediários e humanos como hospedeiros definitivos (FIOCRUZ, 2020).

O portador da esquistossomose pode viver muitos anos sem apresentar qualquer sintoma, no entanto, ressalta-se que essa doença possui uma fase aguda, onde há manifestações clínicas como febre, dor de cabeça, mialgia, erupção cutânea e sintomas respiratórios e, uma fase crônica, com presença de diarreia, constipação e sangue nas fezes, podendo levar a casos mais graves e até a óbito.

A parasitose é responsável por cerca de 200 mil mortes anuais no mundo, destacando-se como a segunda doença parasitária, logo após à malária. Ainda, sabe-se que a mesma reflete negativamente na economia. Estima-se que no Brasil a esquistossomose gera um ônus econômico de, aproximadamente, $R \$ 155$ milhões de reais, pois além do tratamento para o indivíduo, este tem uma queda na sua produtividade (KATZ N, 2018; FIOCRUZ, 2020).

\section{OBJETIVO}

Analisar os casos de mortalidade por esquistossomose, nas diferentes regiões (Sul, Sudeste, CentroOeste, Nordeste e Norte) do Brasil, entre o período de 1996 a 2018, além de avaliar a mortalidade de acordo com o sexo.

\section{MÉTODO}

O presente trabalho trata-se de um estudo descritivo com delineamento transversal, com abordagem quantitativa, onde foram analisados os casos de mortalidade por esquistossomose. Os dados sobre estatísticas vitais em relação a esquistossomose foram buscados no Departamento de Informática do do Sistema Único de Saúde (DataSUS).

A amostra do estudo foi os casos de mortalidade devido a esquistossomose na população brasileira, sendo abordado todas as regiões do país, entre o período de 1996 a 2018. Adotou-se esse intervalo de tempo para englobar todos os dados fornecidos pelo sistema. Posteriormente, os dados foram organizados em planilhas do Excel e analisados, sendo discutidos com bases teóricas da literatura.

\section{RESULTADOS}

Através da tabulação dos dados, observa-se que no período estudado ocorreram mais óbitos na região Nordeste (7618), seguido da região Sudeste (3694). Já para as demais regiões do país, os números de mortalidade em função de esquistossomose, são extremamente baixos, sendo 209 para o Centro-Oeste, 96 para a região Sul e 69 para a região Norte. Além disso, é importante ressaltar que o estado do Amazonas e de Roraima não registraram nenhum óbito por esquistossomose.

A região Nordeste, especialmente, o estado de Pernambuco, apresenta maior mortalidade, com 3829 óbitos. Sendo seguido por Alagoas, com 1638 e Bahia, com 1151 óbitos. 
Em outros estados, como Maranhão, Piauí, Ceará, Rio Grande do Norte, Paraíba e Sergipe, também houve óbitos devido a esquistossomose, no entanto, o número é inferior aos citados anteriormente. Já a região Sudeste, tem como destaque o estado de São Paulo e Minas Gerais, com 1750 e 1326 óbitos, respectivamente.

No estudo, avaliou-se ainda a mortalidade em relação ao sexo, sendo maior para homens (6329) do que mulheres (5357), considerando todos os óbitos de todas as regiões no período estudado.

\section{DISCUSSÃO}

Acredita-se que a esquistossomose chegou a América do Sul com os escravos africanos, o que explica a maior ocorrência dessa doença e, por consequência mais óbitos, nas regiões Nordeste e Sudeste, ambas regiões litorâneas onde desembarcavam os navios (KATZ N, 2018).

O fato de o índice de mortalidade ser maior para homens, se dá possivelmente, por estes terem mais contato com água contaminada e menos hábitos de higiene, se comparados com mulheres. A ocorrência da esquistossomose está diretamente ligada a presença dos moluscos transmissores.

No entanto, há alguns condicionantes que favorecem a proliferação dessa doença, como falta de saneamento básico, tratamento inadequado de água e esgoto, contato do homem com águas contaminadas, condições de higiene precárias e ausência de educação.

Portanto, investimentos em saneamento e implementação de medidas de vigilância e controle são primordiais para minimizar a problemática da esquistossomose (KATZ N, 2018; FIOCRUZ, 2020).

\section{CONSIDERAÇÕES FINAIS}

Diante do exposto, observa-se que as regiões Nordeste e Sudeste são endêmicas para a esquistossomose, concentrando mais de $96 \%$ da mortalidade no país.

Portanto, é fundamental a divulgação sobre informações acerca deste tema e implementação de programas de educação sobre saúde, principalmente nas regiões nordeste e sudeste.

Ainda, é essencial cobrar as autoridades, para que estas realizem investimentos em saneamento básico, especialmente em tratamento de água e esgoto, a fim de diminuir casos de doença e por consequência, os óbitos causados por esta, melhorando assim a saúde pública em geral.

\section{REFERÊNCIAS}

1. DEPARTAMENTO DE INFORMÁTICA DO SUS (DATASUS). Mortalidade. Disponível em: <http:/tabnet.datasus.gov.br/cgi/deftohtm.exe?sim/cnv/obt10uf.def>. Acesso em 02 de julho de 2020.

2. FUNDAÇÃO OSWALDO CRUZ (FIOCRUZ). Esquistossomose. Disponível em: $<$ https://agencia.fiocruz.br/>. Acesso em 02 de julho de 2020.

3. KATZ N. Inquérito Nacional de Prevalência da Esquistossomose mansoni e Geo-helmintoses. Belo Horizonte: CPqRR, 2018; e79. 
RESUMO EXPANDIDO: Estudo Original

TítUlo: AVALIAÇÃO DA ATIVIDADE LARVICIDA DO EXTRATO ETANÓLICO DE ARISTOLOCHIA TRILOBATA FRENTE A AEDES AEGYPTI

Autor/coautores:Stéfani Ferreira de Oliveira, Rômulo Carlos Dantas da Cruz, Pedro José Rolim Neto, Ivone Antonia de Souza, Daniel Tarciso Martins Pereira.

Instituição: Universidade Federal de Pernambuco (UFPE), Recife -PE; Universidade Federal do Amazonas (UFAM), Itacoatiara -AM.

Palavras-chave: Arboviroses, Aristolochia trilobata, Inseticidas.

\section{INTRODUÇÃO}

As arboviroses são doenças causadas por vírus e transmitidas por artrópodes hematófagos durante o repasto sanguíneo. As principais arboviroses de importância epidemiológica são Chikungunya, Zika, Dengue e Febre Amarela, por se espalharem numa velocidade preocupante devido à exposição humana aos vetores. Dentre os mosquitos transmissores, o Aedes aegypti é o principal vetor (PAIXÃO E, 2018).

O tratamento dessas arboviroses é sintomático e vacinas ainda não estão disponíveis. A maneira eficaz de controlar é interromper o ciclo de transmissão através de métodos mecânicos, biológicos, ambientais, químicos e genéticos. O controle químico é uma das principais estratégias, o uso de inseticidas organossintéticos tem levado ao surgimento de populações resistentes.

Diante disso, inseticidas vegetais vem sendo uma alternativa, podendo ser obtidos de diversas partes das plantas (ZARA ALSA, et al., 2016).

A espécie Aristolochia trilobata é amplamente utilizada para fins terapeuticos e seu óleo essencial possui uma diversidade de constituintes bioativos e já demostrou atividade biologica contra as formigas cortadeiras Atta sexdens e Acromyrmex balzani, de forma sinergica e aditiva (OLIVEIRA BMS, et al., 2017 ).

A investigação da atividade inseticida de extratos vegetais contribui com programas de manejo para o controle do Aedes aegypti e a redução do número de doenças transmitidas por esse vetor.

\section{OBJETIVO}

Avaliar a atividade larvicida do extrato etanólico das folhas de Aristolochia trilobata L. (Aristolochiaceae), frente ao Aedes aegypti.

\section{MÉTODO}

As folhas da espécie Aristolochia trilobata L. foram coletadas no estado do Amazonas e submetidas à secagem em estufa de ar circulante $\left(45^{\circ} \mathrm{C}\right)$. Os extratos foram obtidos por Soxhlet, com solvente etanol, em seguida, sendo removido com auxílio de rotaevaporador. Para a realização dos ensaios com o Ae. aegypti, foram utilizadas larvas entre o terceiro e quarto instar oriundas de uma colônia de terceira geração estabelecida no Laboratório de Pesquisa de uma universidade a partir de ovos da linhagem Rockefeller. Para a realização dos ensaios biológicos, seguiu a metodologia adaptada de World Health Organization (1970).

\section{RESULTADOS}

O rendimento do extrato etanólico de Aristolochia trilobata L. foi de 22,92\%, considerando a relação da massa do extrato bruto resultante com a massa do material botânico utilizado no processo extrativo. $\mathrm{Na}$ atividade larvicida foram utilizadas 180 larvas, com 30 larvas por repetição, as quais foram expostas às diferentes proporções do extrato, cada proporção foi solubilizada com Dimetlsufoxido e água deionizada, essa mesma proporção foi utilizada para o grupo controle. As observações de mortalidade das larvas foram realizadas após $1,2,4,8,16$ e 24 horas, a partir do início do experimento. Na concentração de $5,0 \mathrm{mg} \mathrm{mL}^{-1}$ no período de $8 \mathrm{~h}$ de exposição apresentou mortalidade de $46,66 \%$, no período de $24 \mathrm{~h}$ a mortalidade das larvas foi de $98,88 \%$. Na concentração de $2,5 \mathrm{mg} \mathrm{mL}^{-1}$ no período de $16 \mathrm{~h}$ de exposição a mortalidade foi de $34,44 \%$ e no período de $24 \mathrm{~h}$ de $82,22 \%$. Na concentração de $1,0 \mathrm{mg} \mathrm{mL}^{-1}$ após $24 \mathrm{~h}$ de exposição a 
mortalidade foi de $12,22 \%$ e na concentração de $0,5 \mathrm{mg} \mathrm{mL}^{-1}$ apenas $2,4 \%$ após $24 \mathrm{~h}$. $\mathrm{O}$ grupo controle não apresentou mortalidade durante todo o experimento.

\section{DISCUSSÃO}

As arboviroses emergentes no Brasil continuam sendo um problema de saúde pública, tendo como principal estratégia de combate o controle do vetor. A resistência de Ae. aegypti a inseticidas, tem representado um enorme obstáculo ao controle deste vetor, uma alternativa é o uso de misturas complexas de compostos bioativos que mostram diferentes mecanismos e locais de ação, como os óleos essenciais das plantas (PAVELA R, 2015).

Estudos têm mostrado que populações de Ae. aegyptipodem ser controladas com uso desses produtos. O óleo essencial de Aristolochia trilobata destaca-se por seus efeitos em fungos, bactérias e insetos pragas. Compostos presentes em seu óleo essencial têm ação sinérgica e rápida nas formigas cortadeiras além de efeitos no comportamento da locomoção desses insetos (SILVA IMA, et al., 2018).

O potencial de mortalidade dos componentes encontrados no extrato de A. trilobata sobre larvas de Ae. aegypti, evidenciaram o potencial de utilização deste composto.

\section{CONSIDERAÇÕES}

O controle do Aedes tem constituído um importante desafio, especialmente nos países em desenvolvimento. Nossos resultados apontam possíveis alternativas ao controle de larvas de Ae. aegytpi por meio da utilização do extrato etanólico das folhas de Aristolochia trilobata L. o que demonstra a necessidade de continuar a pesquisa, no que diz respeito, a identificação das possíveis substâncias ativas presente no extrato, contribuindo para aumentar a compreensão do efeito de inseticidas de origem botânica sobre o comportamento de Ae. aegypti.

\section{REFERÊNCIAS}

1. OLIVEIRA BMS, et al. Aristolochia trilobata essential oil: exposure, routes of exposure, acute toxicity, binary fog and behavioral effects in sharp form. Molecules, 2017; 22(3): e335.

2. PAIXÃO E, et al. Zika, chikungunya and dengue: the causes and threats of new and remerging arboviral diseases. BMJ Glob Health, 2018; 14(3): 13-21.

3. PAVELA R. History, presence and perspective of the use of plant extracts as commercial botanical insecticides and agricultural products for protection against insects - A review. Plant Prot Sci, 2016; 52: 229-241.

4. SILVA IMA, et al. Alternative control of Aedes aegypti resistant to pyrethroids: lethal and sublethal effects of monoterpene bioinsecticides. Pest Manag Sci, 2018; 74: 1001-1012.

5. ZARA ALSA, et al. Estratégias de controle do Aedes aegypti: uma revisão. Epidemiologia e Serviços de Saúde, 2016; 25(2): 391-404. 


\section{RESUMO EXPANDIDO: Estudo Original}

Título: Da negligência ao óbito: análise da mortalidade por doença de Chagas no Brasil no período de 2008 a 2018

Autor/coautores: Luís Roberto da Silva1, Laís Eduarda Silva de Arruda1, Jonathan Willams do Nascimento1, Marcelo Victor de Arruda Freitas ${ }^{1}$, Emília Carolle Azevedo de Oliveira².

Instituição:'Universidade Federal de Pernambuco, Centro Acadêmico De Vitória (UFPE-CAV), Vitória de Santo Antão-PE; ${ }^{2}$ Instituto Aggeu Magalhães, Fundação Oswaldo Cruz (IAM-FIOCRUZ), Recife-PE.

Palavras-chave: Doença de Chagas, Doenças Negligenciadas, Registros de Mortalidade.

\section{INTRODUÇÃO}

A doença de Chagas (DC) é uma doença tropical negligenciada, descoberta pelo médico sanitarista Carlos Chagas em 1909, causada pelo protozoário Trypanosoma cruzi. É endêmica em diversos países da América Latina e, segundo a Organização Mundial da Saúde (OMS), está relacionada intrinsecamente com as condições socioeconômica dos indivíduos. Sua transmissão ocorre pelo contato da pele e mucosas com fezes contaminadas de hematófagos, principalmente, pelas espécies de Triatoma infestans e $T$. brasilienses, conhecidos popularmente como "Barbeiros" (SILVA AC, et al., 2019). Entretanto, mesmo descoberta há mais de 100 anos, a doença ainda é considerada um grave problema de saúde pública, pois, os casos são diagnósticados tardiamente e têm precários acessos aos tratamentos adequados (MORAES CA, 2017).

Assim, conhecer e analisar as estatísticas de saúde referentes à DC possibilita a gestão compreender o cenário epidemiológico do território, formular indicadores, definir prioridades e propor intervenções para o seu enfrentamento. No Brasil, esses dados são obtidos no Sistema de Informações sobre Mortalidade (SIM), bastante utilizado no planejamento em saúde, pois expressa indicadores sensíveis de atenção e condições de saúde. Entretanto, ainda existem falhas na cobertura e completude dos dados devido ao não preenchimento adequado das declarações de óbitos (OLIVEIRA ECA, et al., 2019).

\section{OBJETIVO}

Analisar o cenário epidemiológico dos óbitos com causa básica a doença de Chagas no Brasil, no período de 2008 a 2018, a partir do Sistema de Informações sobre Mortalidade (SIM).

\section{MÉTODO}

Estudo epidemiológico descritivo quantitativo, realizado com dados obtidos no SIM, referentes aos óbitos por DC no Brasil, no período de 2008-2018. Os dados foram tabulados no TabNet, disponibilizado pelo Departamento de Informática do Sistema Único de Saúde (DATASUS), organizados e analisados em planilhas eletrônicas do Excel $2016 \circledast$. As variáveis selecionadas foram: ano, região, sexo, faixa etária, cor/raça, estado civil, local de ocorrência do óbito e escolaridade.

Foram calculadas as frequências absolutas e relativas de cada variável, bem como, as variações percentuais e taxas de mortalidade do período.

Este estudo não foi submetido ao Comitê de Ética em Pesquisa (CEP), pois foi realizado exclusivamente com dados de domínio público, atendendo as orientações da Resolução №510/2016 do Conselho Nacional de Saúde (CNS).

\section{RESULTADOS}

Observou-se um total de 13.309.550 óbitos no Brasil (2008-2018), desses, 50.959 (0,39\%) tiveram como causa básica a doença de Chagas (2008-2018). A maioria dos casos foi na região Sudeste $(48,25 \%)$, em seguida Centro-Oeste $(22,74 \%)$, Nordeste $(22,19 \%)$, Sul $(4,86 \%)$ e Norte $(1,96 \%)$. Com relação as taxas de mortalidade por 100mil habitantes, o Centro-Oeste foi a região com as maiores taxas, superando as do país, seguida pelo Sudeste; enquanto Norte, Nordeste e Sul se mantiveram abaixo do Brasil (Figura 1). 
Figura 1- Taxas de mortalidade por DC no Brasil (2008-2018).

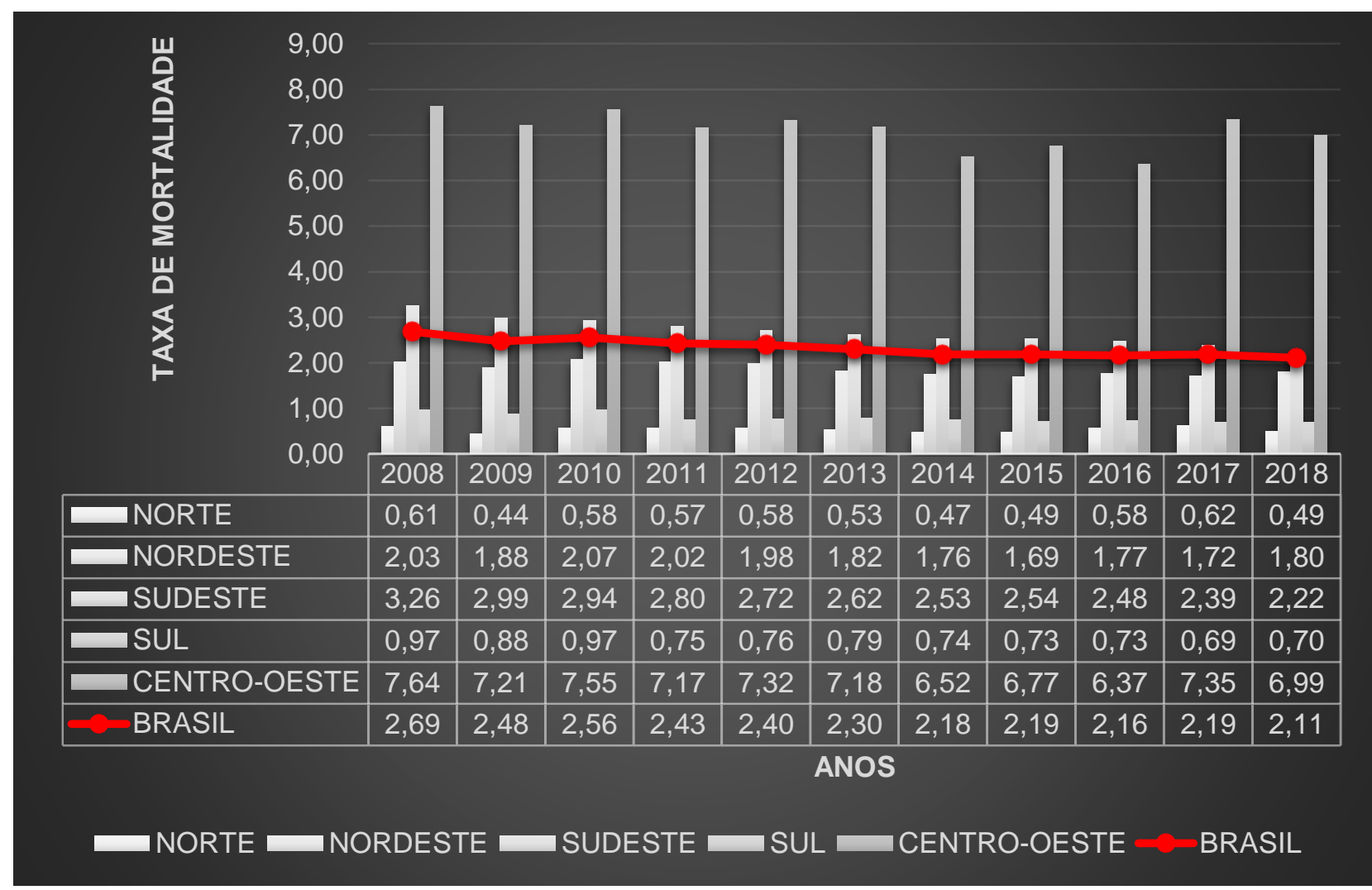

Fonte: SILVA LR, et al., 2020. Dados extraídos do Sistema de Informações sobre Mortalidade, 2008-2018.

$\mathrm{Na}$ variação percentual dos óbitos (2008-2018), observou-se uma redução no Brasil de $-13,83 \%$, destacando-se o Sudeste (-25,53\%), Sul $(-22,39 \%)$, Nordeste $(-5,11 \%)$ e Norte $(-2,17 \%)$. Enquanto a região Centro-Oeste demonstrou um aumento de $7,55 \%$ dos óbitos por DC.

Quanto ao perfil desses casos, identificou-se que a maioria ocorreu em indivíduos do sexo masculino (54,93\%), nas cores/raças parda $(40,72 \%)$ e branca $(40,44 \%)$, com faixas etárias de $70-79$ anos $(27,35 \%)$ e 60-69 $(24,40 \%)$, casados $(42,89 \%)$, escolaridade variando de " $1-3$ anos" $(28,10 \%)$ e ignorada $(26,11 \%)$, cujo desfecho para o óbito ocorreu em hospitais (69,97\%).

\section{DISCUSSÃO}

Visto o cenário epidemiológico dos óbitos por doença de Chagas no Brasil, é evidente a necessidade de fortalecer as pesquisas sobre tal problemática negligenciada, pois, mesmo tendo sido descoberta há mais de 100 anos, ainda há investimentos insuficientes na busca de procedimentos terapêuticos, produção de vacinas e de avanços nos métodos de diagnóstico.

Outro ponto preocupante é a qualidade dos dados ao considerar a problemática do mal preenchimento das declarações de óbitos (OLIVEIRA ECA, et al., 2019; SILVA AC, et al., 2019). Observou-se que a maioria dos óbitos ocorreram em pessoas com mais de 60 anos, podendo ser um reflexo do diagnóstico tardio da enfermidade. Além disso, grande parte dos casos foram nos indivíduos de baixa escolaridade, evidenciando sua inter-relação com as condições socioeconômicas.

Não foi possível estabelecer, concretamente, se há relação entre raça/cor, embora a maioria dos casos se concentre em brancos e pardos (MORAES CA, 2017). 


\section{CONSIDERAÇÕES FINAIS}

Esses achados preliminares evidenciam a necessidade de fortalecimento do trabalho com doenças negligenciadas no país, visto que afetam, principalmente, indivíduos de maior vulnerabilidade socioeconômica. E contribuem para um maior aprofundamento teórico sobre a DC e seu panorama nacional de óbitos.

Conhecer este cenário pode subsidiar a vigilância em saúde no planejamento das ações de prevenção desta enfermidade nos territórios e no controle do seu agravamento. Para fortalecer o enfrentamento dessa doença é preciso ultrapassar o paradigma biomédico, oportunizar intervenções intersetoriais com articulações que possibilitem empoderar a população e garantir a mudança do status quo das iniquidades em saúde.

\section{REFERÊNCIAS}

1. MORAES CA. Mortalidade por doença de chagas no estado de Goiás, Brasil, no período de 2006 a 2011. Biblioteca Digital de Dissertações e Teses, 2017. Dissertação (Mestrado em Ciências da Saúde) Universidade Federal de Goiás, Goiânia.

2. OLIVEIRA ECA, et al. Incompletude dos óbitos por esquistossomose no sistema de informação sobre mortalidade em Pernambuco, 2000-2014. Revista de Gestão e Sistemas de Saúde, 2019; 8(3), p. 343353.

3. SILVA AC, et al. Incidência dos casos de doença de Chagas aguda nas Regiões Brasileira no período de 2015-2017. In: Editora Poisson (org.). Tópicos em Ciências da Saúde, 2019; 1(14), p. 80-87. 
RESUMO EXPANDIDO: Estudo Original

TítULO: AVALIAÇÃO QUANTITATIVA DO NÍVEL DE CONHECIMENTO SOBRE LTA DE ESTUDANTES DO ENSINO BÁSICO DE ESCOLAS SITUADAS EM ÁREAS ENDÊMICAS DE PERNAMBUCO

Autor/coautores: Maria Gabriella Nunes de Melo, Milena de Paiva Cavalcanti, Rayana Carla Silva de Morais. Instituição: Fundação Oswaldo Cruz, Instituto Aggeu Magalhães (FIOCRUZ-PE), Recife-PE.

Palavras-chave: Leishmanioses, Educação em saúde, Epidemiologia.

\section{INTRODUÇÃo}

A Leishmaniose é uma das sete doenças tropicais mais importantes no mundo, causada por espécies de protozoários do gênero Leishmania (TORRES-GUERRERO E, et al., 2017). No Novo Mundo, a LT é conhecida como Leishmaniose Tegumentar Americana (LTA) e se caracteriza por um conjunto de doenças com manifestações clínicas e imunopatológicas distintas, nas quais o desenvolvimento e o agravamento dos sintomas relacionam-se com fatores diversos, tais como a espécie de parasito envolvida e a resposta imune do hospedeiro.

No Brasil, analisando a cronologia a LTA de 2007 até 2017, observou-se que atualmente existem 235.301 casos notificados de LTA nas cinco regiões e em todos os estados brasileiros, sendo o Nordeste uma das áreas mais acometidas pela doença, com 72.395 casos notificados. O conhecimento sobre a epidemiologia da LTA pode contribuir de forma positiva para o seu controle, mas tal conhecimento restringe-se às vítimas da infecção, dificultando o estabelecimento de medidas preventivas (CELOTO MG, et al., 2018). Deste modo, as atividades de prevenção através da educação em saúde podem proporcionar melhor qualidade de vida para as pessoas através do conhecimento podendo gerar mudança de hábitos relacionados ao processo de saúde-doença.

\section{OBJETIVO}

Avaliar, através de questionário quantitativo, o nível de conhecimento sobre LTA de escolares provenientes de áreas endêmicas do estado de Pernambuco, e realizar uma atividade de educação em saúde referente à doença.

\section{MÉTODO}

Foram inclusos no estudo, alunos do ensino básico, mais especificamente do $6^{\circ}$ ao $9^{\circ}$ ano do ensino fundamental, de duas escolas localizadas em cidades de Pernambuco, em 2018. A pesquisa obteve aprovação do Comitê de Ética em Pesquisa (CEP), com CAAE: 86346618.0.0000.5190 e Parecer: 2.819.852. O questionário teve abordagem quantitativa, com inclusão de dados de sexo, idade e série escolar, além de questões relativas ao conhecimento prévio sobre a LTA. O questionário foi dividido em duas partes (laudas distintas).

Os dados extraídos dos questionários foram analisados por meio de estatística descritiva, com distribuições absolutas e percentuais. Posterior a pesquisa, foram realizadas palestra e atividades lúdicas para educação sobre o tema.

\section{RESULTADOS}

Obteve-se um total de 46 estudantes participantes, 17 do $8^{\circ}$ ano e 29 do $9^{\circ}$ ano. Destes 46,19 (41,3\%) eram do sexo masculino e 27 (58,7\%) do sexo feminino, com média de idade de 14,5 anos. Verificou-se que apenas $13(28,3 \%)$ relataram saber "o que é leishmaniose?".

Quando foi exposta a imagem de uma úlcera, 10 marcaram já ter visto, destes, 3 viram no vizinho, 3 em uma pessoa na televisão, $3 \mathrm{em}$ um familiar e 1 no colega. Ao responder "como se pega essa ferida?", 22 marcaram através da picada de inseto e 5 por mordida de cachorro. Após exposição da imagem $B$ (flebotomíneo), 9 já tinham visto o inseto, destes, 1 encontrou em casa, 3 no quintal de casa, 3 na mata, 1 em 
outro lugar e 1 nunca viu. Ao "qual o nome do inseto?", 4 marcaram mosquito, 6 mosquito-palha, 6 dengue e 1 maruim. Dos 46, $12(26,1 \%)$ afirmaram que o cão tem alguma relação com a leishmaniose.

\section{DISCUSSÃO}

Realizou-se uma avaliação quantitativa do nível de conhecimento dos estudantes de colégios públicos em Pernambuco, observou-se que a maioria era do sexo feminino com faixa etária média de 14 anos, fase em que 0 adolescente tem a capacidade de raciocinar sobre o mundo com forma mais lógica e dedutiva, organizando ideias e propagando conceitos adquiridos na escola, para sua residência e comunidade. $O$ baixo número de indivíduos que informaram saber sobre a leishmaniose, indicou a falta de informação da população acometida pela LTA (CELOTO MG, et al., 2018). Dados semelhantes foram obtidos em área endêmica do Maranhão, também situado no Nordeste, o público do estudo apresentou um nível de conhecimento precário sobre a leishmaniose visceral, pois a maioria desconhecia as formas de transmissão da doença, $95 \%$ informaram que nunca assistiram palestras sobre a temática, nem em escolas, hospitais ou outro meio de divulgação (LOPES GS, et al., 2019).

\section{CONSIDERAÇÕES FINAIS}

Os dados obtidos indicam que mesmo sendo moradores de áreas endêmicas para LTA, estudantes não tem conhecimento sobre o tema. Também se nota que alguns já tiveram algum tipo de contato com a doença, e pela falta de informação envolve o cão como um dos transmissores da LTA. Dessa forma, o estudo revelou a constante necessidade de realização de atividades que promovam educação em saúde, como meio para difundir informações corretas para as populações acometidas, aplicando novos conceitos a realidade de cada comunidade, para atingir efetivamente mudança de hábitos, vigilância e controle da doença.

\section{REFERÊNCIAS}

1. CELOTO MG, et al. Nível de conhecimento sobre leishmaniose tegumentar americana de população residente no parque Itaipu, Maringá, PR. IX Mostra Interna de Trabalhos de Iniciação Científica e II Mostra Interna de Trabalhos de Iniciação em Desenvolvimento Tecnológico e Inovação 2018 - UNICESUMAR, 2018.

2. LOPES GS, et al. Nível de conhecimento e medidas de prevenção de moradores sobre a Leishmaniose Visceral em área endêmica no Maranhão, Brasil. Arch Health Invest, 2019; 8(6):285-289.

3. TORRES-GUERRERO E, et al. Leishmaniasis: a review. F1000research, 2017; 6; 750-755. 
RESUMO EXPANDIDO: Estudo Original

TÍTULO: AVALIAÇÃO IN VITRO DO POTENCIAL ESQUISTOSSOMICIDA DA ASSOCIAÇÃO

MILTEFOSINA/PRAZIQUANTEL EM VERMES ADULTOS DE SCHISTOSOMA MANSONI

Autor/coautores: Renan Andrade Fernandes de Souza, Mônica Camelo Pessôa de Azevedo Albuquerque, Victor Hugo Barbosa dos Santos, Eulália Camelo Pessôa de Azevedo Ximenes e André de Lima Aires.

Instituição: Universidade Federal de Pernambuco (UFPE), Recife-PE.

Financiamento: Fundação de Amparo à Ciência e Tecnologia do Estado de Pernambuco (FACEPE).

Palavras-chave: Esquistossomose, Miltefosina, Praziquantel.

\section{INTRODUÇÃO}

O Schistosoma mansoni, platelminto da classe Trematoda, é o agente causal da esquistossomose mansoni, doença negligenciada de importância epidemiológica e a segunda parasitose de maior prevalência no mundo. Nas Américas o Brasil é o país mais prevalente com maiores índices de infeção na região nordeste (KATZ N, 2018).

O quadro clínico da esquistossomose se apresenta de acordo com o desenvolvimento do parasito no hospedeiro, dividindo-se em duas fases: aguda e crônica. As reações inflamatórias, devido ao acúmulo de ovos nos tecidos hepático e intestinal, acarretam um estado fibrótico, alterando toda arquitetura e fisiologia do órgão (KATZ N, 2018).

O praziquantel, fármaco de escolha para o tratamento da doença, mesmo com características de um fármaco ideal, apresenta falhas terapêuticas que necessitam ser sanadas, dentre elas, riscos de resistência por ser a única droga disponível para a doença há quase meio século (KATZ N, 2018). A partir da descoberta da atividade esquistossomicida da miltefosina, apresentando vantagem quando comparada ao praziquantel, tornou-se uma droga atraente para o tratamento em associação com o praziquantel (EISSA MM, et al., 2015).

Associar diferentes medicamentos adotando dosagens inferiores às usuais, as quais são consideradas curativas, tem sido uma alternativa para aumentar a eficácia terapêutica e reduzir a exposição ao fármaco.

\section{OBJETIVO}

Avaliar a atividade esquistossomicida, in vitro, da associação Miltefosina (MTF)/Praziquantel (PZQ) sobre vermes adultos machos e fêmeas de Schistosoma mansoni (cepa $\mathrm{BH}$ ) e determinar a taxa de mortalidade, o índice de combinação (IC) e o índice de redução de dose (IRD) da associação MTF/PZQ.

\section{MÉTODO}

Camundongos fêmeas Swiss (Mus musculus) foram infectados com 120 cercárias de Schistosoma mansoni (cepa BH) por via percutânea. Após 45 dias, realizou-se a perfusão para coleta dos vermes. Devidamente lavados, os casais foram separados e transferidos para placas de 24 poços ( $n=8 /$ poço), em meio RPMI 1640 suplementado com soro bovino fetal (10\%). Foram adicionadas as diluições de cada droga em proporções específicas a partir da $\mathrm{CL}_{50}$ determinada previamente e em seguida incubados em estufa a $37^{\circ} \mathrm{C}$ e $5 \%$ de $\mathrm{CO}_{2}$. As análises foram feitas num período total de $24 \mathrm{~h}$, em microscópio invertido e processadas pelo software CompuSyn. O experimento foi aprovado pelo Comitê de Ética em Experimentação Animal, CAAE: 23076.011235/2018-86.

\section{RESULTADOS}

Durante $24 \mathrm{~h}$ os vermes adultos machos controles, sem exposição à associação, permaneceram com movimentos normais, aderidos ao fundo da placa através das ventosas e o tegumento intacto. No ensaio com vermes machos, 3 combinações mostraram sinergismo com uma taxa de mortalidade de $66,4 \%$. A associação 1/8CL50MTF+1/2CL50PZQ obteve o melhor índice de combinação (IC=0,5), com mortalidade próxima a 70\%. 
A combinação que obteve o maior índice de mortalidade foi 1/2CL50MTF+1/2CL50PZQ, matando $83 \%$ dos vermes, porém teve o IC relativamente maior $(I C=0,62)$ em relação aos demais por preservar menos as drogas, como as outras concentrações utilizadas. Os vermes adultos fêmeas apresentaram maior susceptibilidade à associação $M T F+P Z Q$. Apresentaram o melhor índice de combinação $(I C=0,14)$ em relação a todos os índices verificados, levando em consideração a efetividade contra $100 \%$ dos vermes expostos à combinação $1 / 2 C L 50 M T F+1 / 2 C L 50 P Z Q$, reduzindo em 10 vezes a miltefosina e em quase 22 vezes o praziquantel, quando comparadas às concentrações que seriam utilizadas de cada droga em modo isolado para obter o mesmo efeito. A Tabela 1 expressa os resultados dos ensaios com os vermes adultos machos e fêmeas.

Tabela 1 - Efeito da miltefosina com praziquantel sobre vermes adultos machos e fêmeas de $S$. mansoni (cepa $\mathrm{BH}$ ) após 24 horas, $\mathrm{n}=8$.

\begin{tabular}{|c|c|c|c|c|c|}
\hline \multirow{2}{*}{\multicolumn{2}{|c|}{$\begin{array}{l}\text { CL50 PZQ: } \\
2.92 \mu \mathrm{M} \\
\text { Diluição Testada }\end{array}$}} & \multicolumn{2}{|c|}{ Vermes Adultos Machos } & \multirow{2}{*}{\multicolumn{2}{|c|}{$\begin{array}{c}\text { CL50 MTF: } \\
187.7 \mu M \\
\text { Índice de Redução de } \\
\text { Dose (IRD) }\end{array}$}} \\
\hline & & \multirow[t]{2}{*}{$\begin{array}{c}\text { MTF+PZQ } \\
\text { (Vermes Mortos) }\end{array}$} & \multirow[t]{2}{*}{$I^{* \star \star \star}$} & & \\
\hline MTF & PZQ & & & MTF & $\mathbf{P Z Q}$ \\
\hline $0,5 \mathrm{CL}_{50}$ & $0,5 \mathrm{CL}_{50}$ & $\begin{array}{c}93,85+1,46 \\
(83 \%)^{* \star}\end{array}$ & 0,62 & 3,17218 & 3,23001 \\
\hline $0,5 \mathrm{CL}_{50}$ & $0,25 \mathrm{CL}_{50}$ & $\begin{array}{c}93,85+0,73 \\
(66,4 \%)\end{array}$ & 0,61 & 2,43853 & 4,92294 \\
\hline $0,125 C_{50}$ & $0,5 \mathrm{CL}_{50}$ & $\begin{array}{c}23,46+1,46 \\
(66,4 \%)\end{array}$ & 0,50 & 9,75517 & 2,246147 \\
\hline \multicolumn{2}{|c|}{$\begin{array}{c}\text { CL50 PZQ: } \\
79.9 \mu \mathrm{M}\end{array}$} & \multicolumn{2}{|c|}{ Vermes Adultos Fêmeas } & \multicolumn{2}{|c|}{$\begin{array}{c}\text { CL50 MTF: } \\
108.6 \mu \mathrm{M}\end{array}$} \\
\hline $\mathrm{CL}_{50}$ & $0,5 \mathrm{CL}_{50}$ & $\begin{array}{c}108,6+39,95 \\
(100 \%)\end{array}$ & 0,24 & 5,00435 & 21,8917 \\
\hline $\mathrm{CL}_{50}$ & $0,25 C_{50}$ & $\begin{array}{c}108,6+19,97 \\
(83 \%)\end{array}$ & 0,83 & 1,44788 & 6,93588 \\
\hline $0,5 C_{50}$ & $0,5 \mathrm{CL}_{50}$ & $\begin{array}{c}54,3+39,95 \\
(100 \%)\end{array}$ & 0,14 & 10,0086 & 21,8916 \\
\hline $0,5 \mathrm{CL}_{50}$ & $0,25 C_{50}$ & $\begin{array}{c}54,3+19,97 \\
(83 \%)\end{array}$ & 0,48 & 2,89577 & 6,93588 \\
\hline $0,25 C_{50}$ & $0,5 \mathrm{CL}_{50}$ & $\begin{array}{c}27,15+39,95 \\
(66,4 \%) \\
\end{array}$ & 0,60 & 4,69075 & 2,57472 \\
\hline
\end{tabular}

Legenda: *Valores de concentração expressos em $\mu \mathrm{M}$. **Percentagem de vermes mortos $(n=8)$ avaliados. ${ }^{* * *}$ Valor de índice de combinação menor que 1 indica sinergismo.

Fonte: SOUZA RAF, et al., 2020.

\section{DISCUSSÃO}

Apesar da Esquistossomose ser uma doença antiga, o caminho para a cura ainda é muito limitado. Com o avanço da biotecnologia, novas possibilidades vêm surgindo para o tratamento de doenças. A descoberta e uso de substâncias sintéticas, semissintéticas e naturais norteiam pesquisas frente a moléculas promissoras no tratamento das infecções causadas por espécies de Schistosoma (KATZ N, 2018). O uso de drogas em associação sinérgica reflete algumas vantagens no tratamento de doenças. Doses reduzidas de 2 a 20 vezes, em associação com outras drogas, podem trazer efeitos potencializados mesmo em baixa taxa de exposição (ALMEIDA GT, et al., 2015). Nos ensaios de associações com vermes adultos houve mais sinergismo nos 
testes com fêmeas em relação aos ensaios feitos com vermes adultos machos. Considerar a possibilidade do uso de associações de drogas com efeito esquistossomicida pode ser uma boa estratégia sobre cepas tolerantes ao tratamento monoterápico convencional da esquistossomose.

\section{CONSIDERAÇÕES FINAIS}

Neste estudo hipotetizamos que a miltefosina associada ao praziquantel possui promissora atividade esquistossomicida, bem como considerável efeito sinérgico, quando aliada ao PQZ sobre vermes adultos machos e, sobretudo, fêmeas de Schistosoma mansoni (cepa BH). Houve sinergismo em diferentes graus, a depender das concentrações utilizadas, como também da própria susceptibilidade da fase evolutiva avaliada. Nestas avaliações foram observadas lesões tegumentares mais severas que as lesões causadas pelas drogas isoladas, sendo nessas ocasiões, concentrações mais elevadas do que as concentrações utilizadas em associação. Por fim, estudos aprofundados devem ser realizados para que novas formas de tratamento possam ser utilizadas na prática.

\section{REFERÊNCIAS}

1. ALMEIDA GT, et al. Synergy of Omeprazole and Praziquantel In Vitro Treatment against Schistosoma mansoni Adult Worms. PLOS Neglected Tropical Diseases. 2015; 9(9), e0004086.

2. EISSA MM, et al., Miltefosine Lipid Nanocapsules for Single Dose Oral Treatment of Schistosomiasis Mansoni: A Preclinical Study. PloS One, 2015;10(11), e0141788.

3. KATZ, N. Inquérito Nacional de Prevalência da Esquistossomose mansoni e Geo-helmintoses. Belo Horizonte: CPqRR, 2018; 76. 
RESUMO EXPANDIDO: Estudo Original

TÍTULO: DESENVOLVIMENTO DE MICROPARTÍCULAS CONTENDO POLISSACARÍDEO SULFATADO E AVALIAÇÃO DA ATIVIDADE LARVICIDA

Autor/coautores: Júlia Rayanne Valentim de Lima, Ana Carla da Silva; Daniela Maria do Amaral Ferraz Navarro, Nereide Stela Santos Magalhães, Mariane Cajubá De Britto Lira Nogueira.

Instituição: Universidade Federal de Pernambuco (UFPE), Recife-PE.

Financiamento: Fundação de Amparo à Ciência e Tecnologia de Pernambuco (FACEPE).

Palavras-chave: Micropartículas, Larvicida, Fucana.

\section{INTRODUÇÃO}

A dengue é uma arbovirose que se tornou um problema de saúde pública no Brasil, semelhantemente em outras regiões tropicais e subtropicais do mundo. O Aedes aegypti é o principal vetor da dengue e transmite o vírus que causa Zika e Chikungunya, cujas infecções apresentam crescimento no número ao longo dos últimos anos (BARBOSA GL, et al., 2019).

A busca por alternativas, principalmente por produtos naturais com potencial uso no controle de vetores vem ganhando destaque. As algas marinhas são fontes de compostos bioativos, a exemplo de polissacarídeo sulfatado como a fucana, que apresentam atividades biológicas como: antioxidante, anti-inflamatória e antitumoral (FERNANDO IPS, et al., 2019). Trabalhos descrevem ação anti-dengue e larvicida de extratos de alga sendo compostos promissores contra o mosquito, com vantagem de não promover danos ao ecossistema.

Paralela à busca por novas moléculas bioativas, a microencapsulação vem sendo explorada por proporcionar vantagens desde a diminuição da frequência da dose ao aumento da atividade biológica do material, trazendo uma alternativa ecologicamente correta, econômica e segura. Neste sentido, o uso de moléculas bioativas, a exemplo da fucana, em conjunto com a microencapsulação pode constituir uma possível alternativa no combate ao $A$. aegypti para controle da dengue.

\section{OBJETIVO}

Extrair a fucana a partir de algas marrons da espécie Fucus vesiculosus. Desenvolver e caracterizar micropartículas contendo fucana e avaliar a ação larvicida das micropartículas visando uma possível aplicação no controle do Aedes aegypti.

\section{MÉTODO}

Inicialmente, o polissacarídeo (fucana) foi extraído, purificado e em seguida utilizado para o desenvolvimento das micropartículas. As micropartículas contendo diferentes concentrações de fucana $(0,5$, 1 e $2 \%(p / v))$ foram preparadas utilizando um microencapsulador (BUCHI B-390) onde foi acoplado uma seringa com uma mistura alginato-fucana e gotejada em uma solução de $\mathrm{CaCl}_{2} \mathrm{com}$ imediata formação das micropartículas. Após formação, as micropartículas foram lavadas para remoção dos componentes que não reagiram e foram armazenadas a $4^{\circ} \mathrm{C}$. A caracterização foi realizada analisando-se o aspecto macroscópico, microscópico e tamanho médio das partículas. A avaliação da atividade larvicida foi realizada a partir do contato das formulações com larvas do mosquito em estágio $L 3$, e contagem da letalidade mediana após $24 \mathrm{~h}$ e 48h.

\section{RESULTADOS}

A extração e purificação da fucana foi realizada a partir de algas da espécie Fucus vesiculosus, na qual foi obtido um pó com coloração marrom, que foi utilizado para o desenvolvimento das micropartículas. As micropartículas foram preparadas com três concentração diferentes de fucana, $0,5,1$ e $2 \%(p / v)$. Os parâmetros do equipamento foram ajustados até a obtenção das micropartículas permanecendo em $1500 \mathrm{~Hz}$ de frequência, $1500 \mathrm{v}$ de potência, agitação $100 \%$ e de pump $20 \mathrm{~mL} / \mathrm{min}$. 
As formulações analisadas tanto no aspecto macroscópico como microscópico, apresentaram forma esféricas, uniformes, com coloração marrom e uma borda bem delimitada. As micropartículas obtiveram tamanho médio que variou de $395,2 \pm 68,7 \mu \mathrm{m}$ para $539,4 \pm 59,3 \mu \mathrm{m}$ nas concentrações de 0,5 a $2 \%$, e o $\mathrm{K}_{\mathrm{G}}$ foi 1,5, indicando uma distribuição mais leptocúrtica (Figura 1).

Figura 1 - Formulações de micropartículas contendo fucana em diferentes concentrações (0,5, 1,0 e 2\%). Aspectos macro e microscópicos (microscopia de fluorescência de campo invertido), tamanho das partículas e KG.

\begin{tabular}{|c|c|c|c|c|c|}
\hline \multirow[t]{2}{*}{ FORMULAÇÃO } & \multirow{2}{*}{$\begin{array}{l}\text { CONCENTRAÇÃo } \\
\text { DE FuCANA (\%) }\end{array}$} & \multicolumn{2}{|c|}{ ASPECTO } & \multirow{2}{*}{$\begin{array}{c}\text { TAMANHO } \\
(\mu \mathrm{m})\end{array}$} & \multirow{2}{*}{$\begin{array}{c}\mathrm{K}_{\mathbf{G}} \\
\text { (PICO) }\end{array}$} \\
\hline & & MACROSCÓPICO & MICROSCÓPICO & & \\
\hline Micro-Fuc 0.5 & 0,5 & & & $395,2 \pm 68,7$ & 1,5 \\
\hline Micro-Fuc 1 & 1,0 & & & $461,7 \pm 65,6$ & 1,5 \\
\hline Micro-Fuc 2 & 2,0 & & & $539,4 \pm 59,3$ & 1,5 \\
\hline
\end{tabular}

Fonte: LIMA JRV, et al., 2020.

Para avaliação da atividade larvicida foi utilizada a formulação Micro-Fuc2 em diferentes concentrações. Após avaliação não foi observada ação larvicida em nenhuma das concentrações e tempos utilizados, tanto para a fucana na forma livre como microencapsulada.

\section{DISCUSSÃO}

No presente trabalho, descrevemos pela primeira vez a obtenção de micropartículas com fucana a partir da utilização do microencapsulador. Segundo Cunha L, et al. (2018), a fucana pode ser utilizada como matriz na obtenção de micropartículas. Os autores desenvolveram micropartículas de fucana por spray dry obtendo partículas convolutas e de superfície lisa. No nosso trabalho, micropartículas contendo fucana em três diferentes concentrações foram obtidas, apresentando também superfície lisa, mas com formato esférico. Observou-se que com o aumento da concentração da fucana, as micropartículas apresentaram coloração bege-marrom mais intensa e mais densa. Quanto ao $\mathrm{K}_{\mathrm{G}}$ os valores permaneceram constante indicando distribuição homogênea no tamanho das partículas. Não foi observada ação larvicida em nenhuma das concentrações testadas, e mesmo após $48 \mathrm{~h}$ as larvas não apresentaram percentual de mortalidade significativo. Apesar deste resultado, as micropartículas com fucana desenvolvidas podem ser utilizadas para avaliar outras atividades biológicas, a exemplo da ação antiviral.

\section{CONSIDERAÇÕES FINAIS}

A fucana, polissacarídeo sulfatado, foi extraída de algas marrons da espécie Fucus vesiculosus, purificada e utilizada na obtenção das micropartículas. As micropartículas contendo fucana foram desenvolvidas com êxito em todas as concentrações testadas, apresentando aspecto esférico, uniforme e com coloração bege- 
marrom, com coloração mais intensa com o aumento da concentração de fucana utilizada. Não foi observada ação larvicida para a fucana livre e microencapsulada nas concentrações do experimento. Porém, as micropartículas contendo fucana serão testadas frente a outras atividades biológicas.

\section{REFERÊNCIAS}

1. BARBOSA GL, et al. Influência de pontos estratégicos na dispersão de Aedes aegypti em áreas infestadas. Revista de saúde pública, 2019; 53: 29.

2. FERNANDO IPS, et al. Advances in functionalizing fucoidans and alginates (bio)polymers by structural modifications: A review. Chemical Engineering Journal, 2019; 355: e33-48.

3. CUNHA L, et al. Inhalable fucoidan microparticles combining two antitubercular drugs with potential application in pulmonary tuberculosis therapy. Polymers, 2018; 10: 636. 
RESUMO EXPANDIDO: Estudo Original

TítUlo: Novos dERIVAdos 1,3-TIAZÓIS: SíNTESE, CARACTERIZAÇÃO E ATIVIDADE LEISHMANICIDA

Autor/coautores: Beatriz de Fatima Maia Santana1, Juliana Maria da Conceição', Regina Célia Bressan Figueredo ${ }^{1}$, Ana Carla da Silva ${ }^{1}$, Ana Cristina Lima Leite'.

Instituição: Universidade Federal de Pernambuco' ${ }^{1}$ (UFPE), Recife-PE.

Palavras-chave: Doenças negligenciadas, Leishmania spp., 1,3-Tiazóis.

\section{INTRODUÇÃO}

A Leishmaniose é um conjunto de doenças crônicas provocadas pelo protozoário do gênero Leishmania spp., sendo de caráter endêmico e mais observada, em países de clima tropical e subtropical, sendo notificados vários casos todos os anos (SINGH K, et al., 2016). O tratamento da leishmaniose oferece desvantagens já que promove toxicidade acentuada levando, além de existirem relatos de cepas resistentes a tais medicações (SINGH K, et al., 2016).

Neste contexto, as estruturas privilegiadas podem servir como inspiração para o planejamento e descoberta de novos fármacos. Os compostos derivados do heterocíclico 1,3-tiazol vêm despertando bastante interesse, uma vez que apresentam uma diversidade de atividade biológica (ALIANÇA, et al., 2017). Logo, a nossa proposta consistiu em desenvolver uma série de novos derivados 1,3-tiazóis com potencial atividade leishmanicida frente à forma promastigota do parasita.

\section{OBJETIVO}

Identificar protótipos a fármacos com atividade anti-leishmania frente as formas evolutivas promastigotas de Leishmania amazonensis, por meio da síntese, caracterização e avaliação biológica de novos derivados do anel heterocíclico 1,3-tiazol.

\section{MÉTODO}

A síntese dos derivados 1,3-tiazois realizou-se em três etapas: a primeira compreende a síntese das acetofenonas. Na segunda etapa, reagiu-se as acetofenonas com tiossemicarbazidas, sob refluxo em meio etanólico, produzindo tiossemicabazonas com altos rendimentos. E finalmente, a ciclização das tiossemicarbazonas em derivados 1,3-tiazóis substituídos e obtenção dos 9 compostos finais. As moléculas finais tiveram rendimentos entre 59-85\%. A estrutura química dos compostos foi confirmada por espectroscopia de Ressonância Magnética Nuclear de Hidrogênio (RMN 1H) e de carbono (RMN 13C). Para a avaliação biológica, foram realizados testes de concentração citotóxica (CC50) em MTT frente a macrófagos peritoneais de camundongos Balb/C e a concentração inibitória $(I C=50)$ em promastigotas do parasita $L$. amazonensis. Esses procedimentos foram aprovados pelo Comitê de Ética (CEUA/FIOCRUZ 119/2017).

\section{RESULTADOS}

Em todas as etapas houve a necessidade de purificação dos produtos com lavagem simples, obtendo-se compostos sólidos com rendimentos satisfatórios. A estrutura química das moléculas, foi confirmada por dados espectroscópicos $\mathrm{RMN}^{1} \mathrm{H}$ e $\mathrm{RMN}^{13} \mathrm{C}$.

A avaliação da atividade leishmanicida revelou que todos os compostos foram capazes de inibir o crescimento da forma promastigota, com valores de IC50 variando entre 41,4 e 484 $\mu \mathrm{M}$ (Tabela 1).

O composto que promoveu a maior inibição do crescimento foi o derivado JM.07, tendo ainda o melhor índice de seletividade (IS) para a célula do parasito que para a célula de mamíferos (IS=4,93). Os compostos JM.01 e JM.09 também se mostraram hábeis em inibir o crescimento das promastigotas com (IS =1,12 e 1.98) respectivamente. Os compostos com menor valor de IC50 foram o JM.07(41,4 $\mu \mathrm{M})$, e JM.06 $(87,4 \mu \mathrm{M})$. Já os valores de CC50 para as células de macrófagos variaram entre 112,7 e 543,1 $\mu \mathrm{M}$. 
Tabela 1 - Resultados obtidos para atividade leishmanicida dos derivados de 1,3-Tiazóis.

\begin{tabular}{llll}
\hline Composto & $\begin{array}{l}\mathbf{I C}_{\mathbf{5 0}}(\boldsymbol{\mu M}) \\
\text { (Promastigota) }\end{array}$ & Citotoxicidade $\left(\mathbf{C C}_{\mathbf{5 0}}\right) \boldsymbol{\mu M}$ & IS \\
\hline JM.01 & ND & 379,5 & \\
JM.02 & 484,8 & 543,1 & ND \\
JM.03 & 150,1 & ND & 1,12 \\
JM.04 & 274,8 & 112,7 & ND \\
JM.05 & 335,6 & 153,6 & 0,41 \\
JM.06 & 87,4 & ND & 0,46 \\
JM.07 & 41,4 & 204,4 & ND \\
JM.08 & 326,1 & ND & 4,93 \\
JM.09 & 257,3 & 508,3 & ND \\
\hline
\end{tabular}

Fonte: SANTANA BFMS, et al., 2020.

Legenda: $\mathbf{C C}_{50}=$ Concentração Citotóxica para $50 \%$ das Células; $\mathbf{I C}_{50}=$ Concentração Inibitória para $50 \%$ da População; IS(prom) = Índice de Seletividade.

\section{DISCUSSÃO}

Os compostos JM.06 e JM.07 que apresentaram atividade leishmanicida possuíam o radical fenil (Ph) e Naftil na porção C4 do anel tiazol. Tal resultado sugere que a ciclização e a presença de grupamentos volumosos estão envolvidos na atividade anti-leishmanial. Esses dados também corroboram com trabalhos de Gomes et al. (2016), os quais relatam a presença do radical naftil nos compostos mais eficazes. A presença deste radical torna o composto mais hidrofóbico, facilitando a penetração do composto na membrana parasitária. De forma geral, todas as moléculas apresentaram baixos valores de citotoxicidade em macrófago, o que as tornam bem toleráveis às células saudáveis de mamíferos. Para escolha de composto com potencial quimioterápico deve-se levar em consideração sua ação frente ao micro-organismo, assim como, a sua citotoxicidade.

\section{CONSIDERAÇÕES FINAIS}

As comprovações de dados estruturais através de análise de $\mathrm{RMN}{ }^{1} \mathrm{H}, \mathrm{RMN}{ }^{13} \mathrm{C}$, apontaram que os nove tiazóis sintetizados, foram efetivamente formados. Todos os compostos foram testados enquanto sua atividade leishmanicida frente as formas promastigotas, assim como a citotoxicidade para macrófagos. $O$ composto JM.07 foi o que mais se destacou evidenciando uma maior seletividade (IS=4,93; IC $\mathrm{F}_{50}=41,4 \mu \mathrm{M}$; $\mathrm{CC}_{50}=204 \mu \mathrm{M}$ ). Embora ensaios adicionais sejam necessários, diante desses resultados, os compostos derivados 1,3-tiazóis mostraram ser fármacos em potenciais para o combate à leishmaniose.

\section{REFERÊNCIAS}

1. ALIANÇA ASS, et al. In vitro evaluation of cytotoxicity and leishmanicidal activity of phthalimido-thiazole derivatives. European Journal of Pharmaceutical Sciences, 2017; 105: 1-10.

2. GOMES PAT, et al. Phthalimido-thiazoles as building blocks and theire ffectsonthe growth and morphologyof Trypanosoma cruzi. Eur. J. Med. Chem., 2016; 10: 1-12.

3. SINGH K, et al. Current Therapeutics, Their Problems and Thiol Metabolism as Potential Drug Targets in Leishmaniasis. Current Drug Metabolism, 2016; 17: 1-23. 


\section{RESUMO EXPANDIDO: Estudo Original}

Título: Aspectos Clínicos e Sociodemográficos de LeISHMANIOSE TEGUMENTAR

\section{Americana no ESTAdo de PeRnambuco}

Autor/coautores: Décio Henrique Araújo Salvadôr de Mello', Ananda Carolina Barros da Silva², Stella Cristina Cabral da Silva, Paloma Lima da Costa, Priscila da Silva Soares'.

Instituição: ${ }^{1}$ Universidade de Pernambuco (UPE), Recife-Pernambuco; ${ }^{2}$ Universidade Federal de Pernambuco (UFPE), Recife-Pernambuco.

Palavras-chave: Doenças negligenciadas, Epidemiologia, Variáveis clínicas.

\section{INTRODUÇÃO}

A Leishmaniose Tegumentar Americana (LTA) é uma doença causada por protozoários do gênero Leishmania (BRASIL, 2017). As espécies Leishmania braziliensis e Leishmania amazonensis apresentam maior interesse médico devido à prevalência e patogenicidade mais elevada em relação às outras espécies, causando desde a forma cutânea simples até a forma grave destrutiva da mucosa (ROCHA TJM, et al., 2015).

A Organização Mundial de Saúde considera a LTA como uma das seis doenças infecciosas mais importantes, tanto pelo número de casos como pela capacidade de acarretar danos e deformidades (BRASIL, 2017). No Brasil os maiores números de casos são nas regiões Norte, Nordeste e Centro-Oeste, mas são encontrados casos em todas regiões do país (PACHIEGA J, et al., 2020).

Antigamente a doença era restrita a regiões de florestas e os indivíduos infectados eram aqueles que a adentravam, tendo contato com o mosquito Lutzomyia longipalpis, popularmente conhecido como "mosquitopalha", "tatuquira" ou "cangalhinha", dependendo da região. Atualmente, o mosquito se adaptou ao ambiente urbano (BRASIL, 2017; ROCHA TJM, et al., 2015; PACHIEGA J, et al., 2020).

\section{OBJETIVO}

Compreender características e o perfil clínico-sociodemográfico dos casos notificados nos Sistema de Informação de Agravos de Notificação (SINAN) para LTA no estado de Pernambuco, no período de 20082018, contribuindo para o direcionamento das medidas profiláticas e de controle no estado e reduzir impactos das formas graves da doença nos pacientes.

\section{MÉTODO}

O estudo é descritivo com abordagem qualitativa, realizado por meio de análise de dados disponibilizados pelo SINAN, no mês de julho de 2020. A categorização das variáveis epidemiológicas e clínicas contendo a porcentagem e a frequência relativa foi feita no programa Microsoft Office Excel. Foram analisados o número de casos, sexo, raça, escolaridade, faixa etária, zona de residência, tipo de entrada do paciente, critério para confirmação, forma clínica da doença e evolução dos casos. As informações utilizadas e apresentadas nesse estudo são públicas e disponibilizadas virtualmente pelo Departamento de Informática do Sistema Único de de (DATASUS), não sendo necessário submissão do projeto à aprovação por um Comitê de Ética em Pesquisa (CEP).

\section{RESULTADOS}

No período de 2008 a 2018 foram identificados 4.098 casos de LTA no estado de Pernambuco, uma média de 372,55 casos por ano. $O$ ano com maior percentual de casos foi 2011 com 466 casos $(11,37 \%)$ e o menor foi o ano de 2016 com 257 casos (6,27\%). A incidência média no período foi de 4,08/100000 habitantes. Sendo registrada a maior incidência de 6,12/100000 habitantes em 2009, e a menor a de 2,65/100000 habitantes em 2014.

De acordo com o estudo, viu-se que $59,88 \%$ dos casos ocorreram em indivíduos do sexo masculino, $54,29 \%$ ocorreu em indivíduos analfabetos ou que não concluíram o ensino fundamental. 53,07\% dos casos ocorreram em indivíduos entre 20 e 59 anos. $62,25 \%$ dos indivíduos diagnosticados eram pardos e 69,33\% dos casos ocorreu em habitantes das zonas rurais do estado. $92,95 \%$ das notificações foram para novos 
casos, $96,75 \%$ dos casos se manifestaram na forma cutânea, e $70,38 \%$ dos casos o diagnóstico se deu de forma clínico-epidemiológica. Observou-se ainda que $71,33 \%$ dos casos evoluíram para a cura dos indivíduos.

\section{DISCUSSÃO}

Semelhante observado em estudos de outros pesquisadores a maior prevalência dos casos de LTA se deu em indivíduos do sexo masculino, de baixa escolaridade sendo estes analfabetos ou com ensino fundamental incompleto e moradores de zonas rurais e faixa etária entre 20 a 59 anos (PACHIEGA J, et al., 2020), podendo estes resultados terem relação com atividades laborais no setor da agricultura. Observou-se ainda que a alta taxa de manifestações cutâneas se encontra de acordo com indicado pelo Ministério da Saúde que afirma que apenas 3-6\% das manifestações ocorrem pela forma mucosa da doença (BRASIL, 2017) .

A alta taxa de cura e pode ser indicativa de bom funcionamento dos protocolos para a doença. Faz-se necessária uma ampliação do conhecimento da população, principalmente a mais exposta sobre a doença, como sua transmissão e tratamento, podendo esta ser feita através intervenção da Unidade Básica de Saúde do local.

\section{CONSIDERAÇÕES FINAIS}

Os resultados preliminares apontam que a baixa porcentagem de óbitos por esta doença pode indicar eficiência dos protocolos de abordagem para a mesma, como políticas e programas que existam para esta ou demais doenças negligenciadas. É necessária uma maior análise destes fatores fazendo-se correlação com a possível existência destes programas, como seu período de implantação, podendo ainda esta observação ser sugestiva para uma possível redução de casos. A prevalência de casos na zona urbana, seguida pela zona rural pode ser sugestiva de alterações nos padrões de transmissão da doença, como desmatamento, migração da população, vulnerabilidade socioeconômica, entre outros.

\section{REFERÊNCIAS}

1. BRASIL. Ministério da Saúde. Secretaria de Vigilância em Saúde. Departamento de Vigilância das Doenças Transmissíveis. Manual de Vigilância da Leishmaniose Tegumentar [Internet]. Brasília: Ministério da Saúde; $2017 . \quad$ Disponível em: http://bvsms.saude.gov.br/bvs/publicacoes/manual_vigilancia_leishmaniose_tegumentar.pdf. Acessado em: 10 de julho de 2020.

2. PACHIEGA J, et al. Incidência da Leishmaniose Tegumentar Americana no Centro-Sul de Mato Grosso, Brasil entre 2000 a 2019. Revista Ibero-Americana de Ciências Ambientais, [s. I.], , 2020; 11.

3. ROCHA TJM, et al. Aspectos epidemiológicos dos casos humanos confirmados de Leishmaniose Tegumentar Americana no Estado de Alagoas, Brasil. Rev Pan-Amaz de Saúde. 2015;6(4):49-54. 
RESUMO EXPANDIDO: Estudo Original

TÍTULO: ANÁLISE TEMPORAL DA TUBERCULOSE NO ESTADO DA BAHIA: O RETRATO DE UMA DÉCADA

Autor/coautores: Milena Roberta Freire da Silva, Karolayne Silva Souza, Maria Betânia Melo de Oliveira.

Instituição: Universidade Federal de Pernambuco (UFPE), Recife-Pernambuco.

Palavras-chave: Epidemiologia, Morbimortalidade, Tuberculose.

\section{INTRODUÇÃo}

A tuberculose (TB) é uma doença infectocontagiosa que tem como agente causador o Mycobacterium tuberculosis (SANTOS ÁN, et al., 2020). Segundo o Ministério da Saúde é um agravo na saúde pública, de grande magnitude, transcendência e vulnerabilidade, sendo considerada uma das maiores causas de morbimortalidade entre as doenças infectocontagiosas no mundo, dado que a cada ano cerca de 8 milhões de pessoas adoecem e 2 milhões evoluem para o óbito. No Brasil estima-se uma prevalência de 110.000 infectados, com cerca de 70.000 casos novos e 5.000 mortes anuais. O estado da Bahia é o terceiro em casos de TB notificados no Brasil, com cerca de 7.000 novos casos por ano (JÚNIOR EVS, et al., 2018; OLIVEIRA LGF, et al., 2020).

Diante da importância epidemiológica desta doença é necessário considerar que além das questões biológicas, a TB possui uma dinâmica associada principalmente às condições precárias de vida, como por exemplo: moradia inadequada, e dificuldade de acesso da população mais carente aos serviços de saúde. No entanto, o processo de subnotificação da doença constitui uma preocupação, uma vez que, dificulta as medidas de prevenção e controle, como a detecção precoce e o tratamento efetivo (RODRIGUES R e LOBÃO JSB, 2019).

\section{OBJETIVO}

Analisar epidemiologicamente o número de casos notificados e com diagnóstico confirmado para tuberculose no Estado da Bahia, no período de 2010 a 2019, utilizando a plataforma de Sistema de Informação de Agravos e Notificação (SINAN).

\section{MÉTODO}

Trata-se de um estudo retrospectivo, transversal, epidemiológico com abordagem quantitativa, realizado por meio dos dados disponíveis no Departamento de Informática do Sistema Único de Saúde (DATASUS) através do SINAN. Foram analisados os dados de número de casos notificados e com diagnóstico confimado para tuberculose em residentes do estado da Bahia, no período de 2010 a 2019, de acordo com sexo (masculino/feminino), faixa etária que variou de menor de 1 ano e 80 anos mais, forma clínica da doença, tipo de entrada e tipo de saída. Após a coleta dos dados foi realizada a análise descritiva simples utilizando o software de planilha eletrônica Excel.

\section{RESULTADOS}

No período de 2010 a 2019 foram notificados e com diagnósticos confirmados para tuberculose 57.857 casos no Estado da Bahia. Observou-se cerca de 65\% (37.827) dos casos para o sexo masculino, e os demais $35 \%$ (20.030) dos casos para o sexo feminino. Das faixas etárias analisadas, as populações mais acometidas foram os de $30-39$ anos representando $21 \%$ (12.089) dos casos, seguidos dos de $40-49$ com 19\% (10.866), em contraposto os menos acometidos foram aqueles de $1-4$ anos com $0,5 \%$ (240) dos casos.

Quanto a forma clínica dos casos, a maioria apresentou-se como pulmonar 86\% (49.946), tendo como principal forma de entrada a de casos novos $80 \%$ (46.426) e a maior parte das formas de saída foi a evolução para cura com $61 \%$ (35.343), no entando, $12 \%$ (6.736) dos casos foram ignorados por parte do sistema de notificação quanto a essa análise. Dentre os anos avaliados, o de 2010 registrou $11 \%$ (6.554) dos casos, sendo este considerado o de maior prevalência quando comparado aos demais, como mostrado no Gráfico 1.

REAS | Vol.Sup.n.54 | DOI: https://doi.org/10.25248/anais.e4798.2020 Página 36 de 245 
Gráfico 1 - Casos de tuberculose no Estado da Bahia, no período de 2010 a 2019.

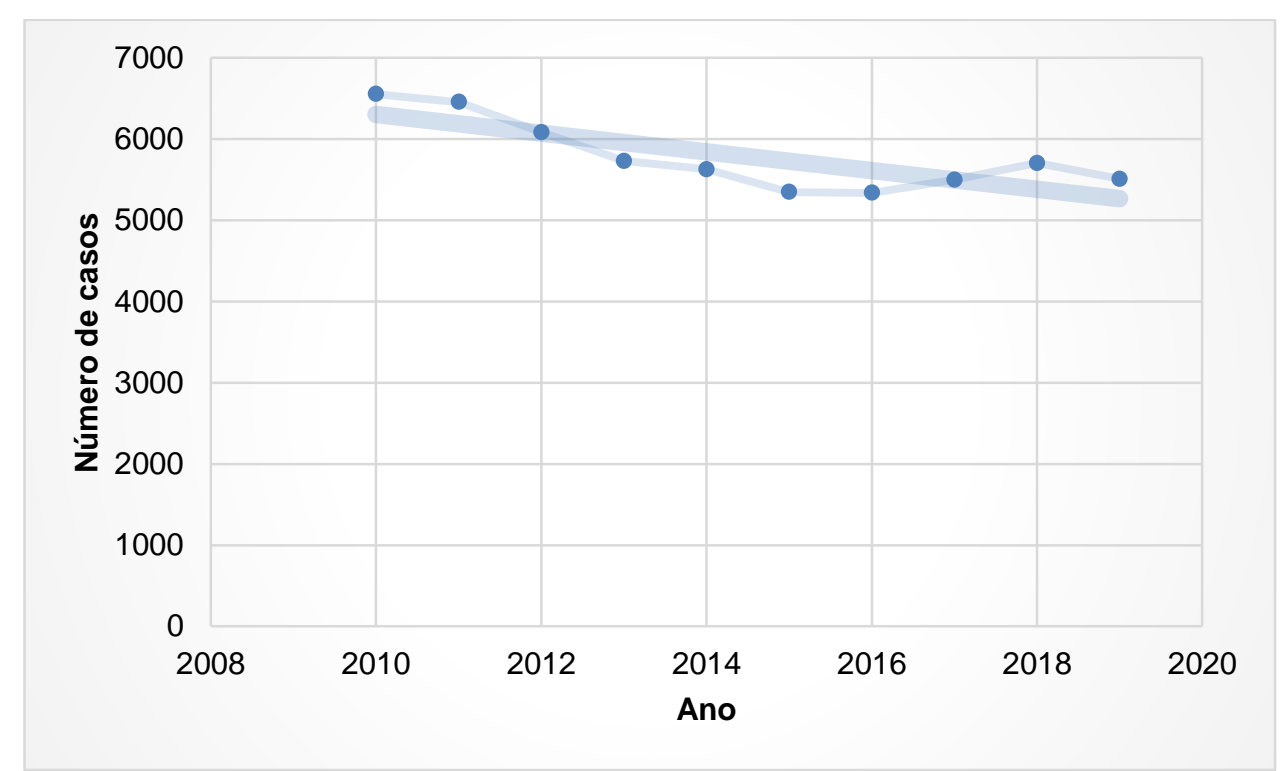

Fonte: SILVA MRF, et al., 2020.

\section{DISCUSSÃO}

No presente estudo observou-se uma oscilação entre o número de casos confirmados de tuberculose no período analisado, todavia, nota-se que houve um descréscimo destes, assim como foi observado em um estudo realizado no estado do Maranhão no ano de 2006 a 2016 (MACEDO LR, et al., 2017). A respeito da variável "sexo", houve predomínio da população masculina, como demonstrado por Santos BA et al (2020), em um estudo realizado em uma microrregião da Bahia, notificados em $68,60 \%$ dos casos. Essa situação pode ser explicada pelas condições e estilo de vida que estes individuos possuem, além da baixa procura pelo serviço de saúde quando comparados aos indivuduos do sexo feminino (HAYNE LMP, et al., 2018). A faixa etária que se apresentou com maior ocorrencia, corresponde as pessoas economicamente ativas, com idades variando de 30-49. Resultados semelhantes são encontrados em um estudo ocorrido no Piauí, no recorte temporal de 2010 a 2014 (SILVA WA, et al., 2017).

\section{CONSIDERAÇÕES FINAIS}

O presente estudo evidenciou, durante o período avaliado, que o Estado da Bahia apresentou decréscimo no número de casos, tendo a população masculina como principal acometida e indivíduos da faixa etária economicamente ativa de 30-49 anos. No que se refere ao controle e combate da tuberculose, acredita-se que essa diminuição ocorreu devido a implementação do Plano Nacional de Controle da Tuberculose, estabelecido pelo Ministério da Saúde. Todavia, ainda é necessário o desenvolvimento de ações e estratégias com abordagem multiprofissional, como o diagnóstico precoce, para que se promova maior adesão do tratamento pelo paciente, possibilitando êxito no controle desta doença.

\section{REFERÊNCIAS}

1. HAYNE LMP, et al. Perfil clínico-epidemiológico de coinfecção por tuberculose e HIV no município de Salvador, Bahia, no período de 2008 a 2017. 2018.

2. JÚNIOR EVS, et al. Internamientos hospitalarios e impacto financiero por Tuberculosis Pulmonar em Bahía, Brasil. Revista Enfermería Actual, 2018; 35: e3851.

3. MACEDO LR, et al. Tuberculose na população privada de liberdade do Brasil, 2007-2013. Epidemiologia e Serviços de Saúde, 2017, 26(4): 783-794. 
4. OLIVEIRA LGF, et al. Incidência da tuberculose na Bahia. Revista Integrativa em Inovações Tecnológicas nas Ciências da Saúde, 2019, 4(0): 79-88.

5. RODRIGUES R, LOBÃO JSB. Distribuição espacial da tuberculose e a relação com as condições socioeconômicas no município de Feira de Santana-2005 a 2016. Hygeia-Revista Brasileira de Geografia Médica e da Saúde, 2019, 15(34): 1-10.

6. SANTOS ÁN. Perfil epidemiológico da tuberculose em uma microrregião da Bahia (2008-2018). Revista Brasileira de Saúde Funcional, 2020; 10(1): e2929.

7. SANTOS BA, et al. Tuberculose em crianças e adolescentes: uma análise epidemiológica e espacial no estado de Sergipe, Brasil, 2001-2017. Ciência \& Saúde Coletiva, 2020, 25(8): 2939-2948.

8. SILVA WA, et al. Perfil epidemiológico dos casos notificados de tuberculose no Piauí nos anos de 2010 a 2014. Revista Interdisciplinar 2017; 10(3): e3138. 
RESUMO EXPANDIDO: Estudo Original

Título: ANÁlise EPIDEMIOLÓGICA DA TUbeRCULOSE No ESTADO DE RIO GRANDE DO NORTE ENTRE 2010 E 2019

Autor/coautores: José Nyedson Moura de Gois, Luanne Eugênia Nunes.

Instituição: Faculdade Nova Esperança (Facene/RN), Mossoró-Rio Grande do Norte

Palavras-chave: Epidemiologia, Mycobacterium tuberculosis, Tuberculose/HIV.

\section{INTRODUÇÃO}

A Tuberculose (TB) é considera uma doença transmissível reemergente tão antiga quanto a humanidade. Essa infecção oportunista causada pelo bacilo Mycobacterium tuberculosis está entre as 10 principais causas de morte no mundo, sendo a primeira provocada por um único agente infeccioso. Desde a década de 60, é disponibilizado um tratamento eficaz, porém aproximadamente um quarto da população mundial permanece infectada com o bacilo, e, portanto, poderá desenvolver a doença (OLIVEIRA LB, et al., 2018).

O panorama epidemiológico mundial demonstra mais de 7 milhões de casos de TB por ano, dos quais cerca de $15 \%$ evoluem a óbito. O Brasil encontra-se na lista dos 30 países com alta incidência de TB, bem como da coinfecção da TB/HIV, condição agravante devido ao aumento da carga viral e diminuição da contagem de linfócitos T CD4 em indivíduos com HIV. Nesse sentido, desde 2003, a TB é uma prioridade do Ministério da Saúde (MS) no Brasil na tentativa de minimizar os fatores que predispõe à aquisição da comorbidade. Contudo, o Rio Grande do Norte (RN) tem demonstrado aumento gradativo de notificações nos últimos anos, revelando a magnitude da TB como uma séria problemática de saúde pública (MARQUES CC, et al., 2020).

\section{OBJETIVO}

Analisar o perfil epidemiológico da tuberculose no recorde temporal de 2010 a 2019 na área geográfica do Estado do Rio Grande do Norte, dividindo-o em suas respectivas Regiões de Saúde (RS) delimitadas pelo Ministério da Saúde.

\section{MÉTODO}

Este estudo descritivo epidemiológico embasou-se em dados secundários disponibilizados no Sistema de Informações de Agravos de Notificação (SINAN) através da plataforma do Departamento de Informática do Sistema Único de Saúde (DATASUS) do MS, onde buscou-se por estatísticas do RN entre 2010-2019. Realizou-se o levantamento de dados na aba "tuberculose", aplicando variáveis como: forma, sexo, HIV, região de saúde e ano de notificação. Após isso, procedeu-se com a tabulação dos dados no Microsoft Exceß® 2019 para aplicação de técnicas de estatística como: média, porcentagem e desvio padrão (DP).

Em seguida, analisou-se cada uma das tabelas estruturadas, de forma individual. Os preceitos éticos brasileiros permitem a utilização desses dados secundários de dominío público, dispensando apreciação pelo Comitê de Ética em Pesquisa (CEP).

\section{RESULTADOS}

O RN divide-se nas seguintes RS: São José de Mipibu (I), Mossoró (II), João Câmara (III), Caicó (IV), Santa Cruz (V), Pau dos Ferros (VI), Metropolitana (VII) e Açu (VIII).

Nesse período, o RN registrou 12.693 casos de TB, possuindo em média 1.269,3 notificações/ano. Em relação ao sexo e a forma, a prevalência foi de pacientes do sexo masculino (70\%) e de infecção de forma pulmonar (86\%). Ainda, $11 \%$ são apontados positivos para HIV, havendo uma coinfecção entre tuberculose e HIV.

A região com maior taxa de notificação foi a Metropolitana, possuindo 7.874 casos (62\%). A mesma região ainda exibe uma média igual a 787,4 casos por ano ( $D P=52,2)$. Em contrapartida, a região de Santa Cruz constatou o menor índice de notificação, entre 16-33 novos casos/ano, valor mínimo e máximo, 
respectivamente, totalizando 239 casos (2\%). Já os casos das regiões de Mossoró (13\%) e de São José de Mipibu (10\%) estão próximos da média estadual. Em todas as regiões, o sexo masculino foi prevalente, em consonância com a média estadual.

Gráfico 1- Número de casos de TB notificados por Região de Saúde no RN.

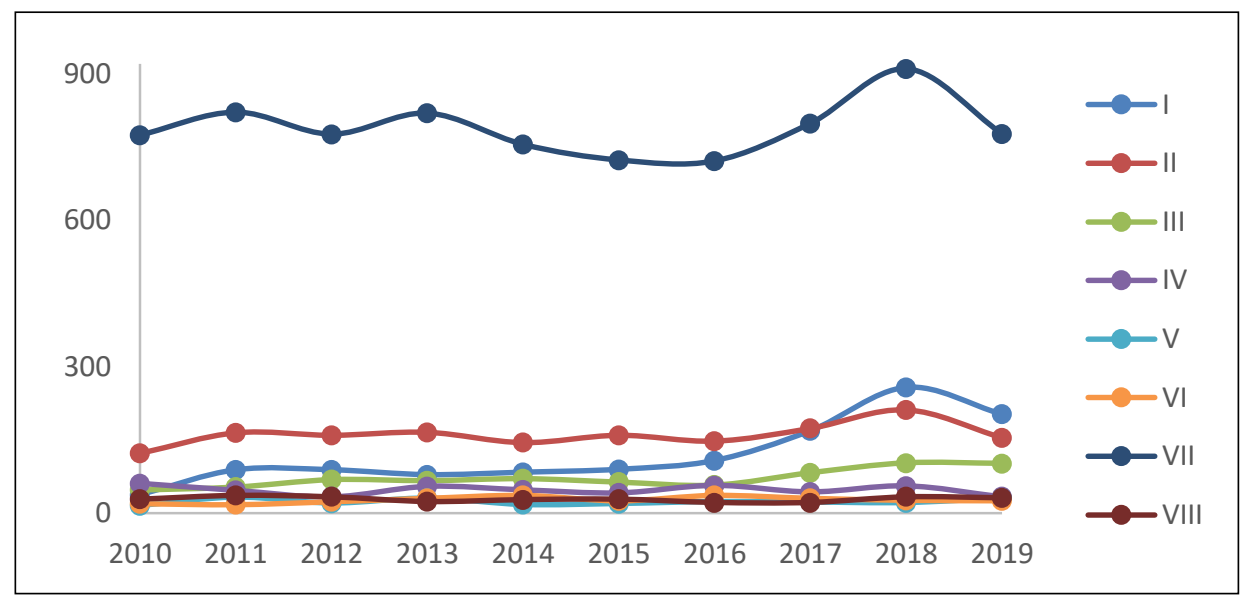

Fonte: GOIS JNM e NUNES LE, 2020 [dados extraído de SINAN, 2020].

\section{DISCUSSÃO}

Nota-se que as regiões mais afetadas são: Metropolitana, Mossoró e São José de Mipibu. O somatório das demais regiões contabilizam 16\% (BRASIL, 2020). A TB apresenta fatores de agravamento como: a vulnerabilidade social, o alcoolismo, o diabetes e a Síndrome da Imunodeficiência Humana Adquirida (AIDS) (OLIVEIRA LB, et al., 2018).

Assim, a prevalência de casos de TB na região Metropolitana, que abrange a capital do Estado, poderá associar-se ao nível de desenvolvimento socioeconômico. O índice de coinfecção no RN também é pauta de precupação pública, visto que é superior à média nacional (9,6\%) (MARQUES CC, et al., 2019).

Portanto, os dados levantados apontam a necessidade de interveção e acompanhamento dessa população passível de transmissão devido às elevadas notificações, bem como de mensurar índices mais detalhados no que tange à TB, pois não foram reportadas taxa de mortalidade e cura, parâmetros relevantes para pesquisas nessa dimensão.

\section{CONSIDERAÇÕES FINAIS}

A incidência dos casos de TB pode estar associada aos determinantes sociais de saúde. Dessa forma, verificou-se que a prevalência de notificações na região Metropolitana constitui um possível indicativo das situações de vulnerabilidade social existente. Logo, este estudo poderá favorecer ao desenvolvimento de estratégias de prevenção da citada afecção, proporcionando melhores esclarecimentos para minimizar a transmissão e propagação da TB. Ademais, foi possivel identificar, de forma abrangente, o perfil epidemiológico do RN, sendo, portanto, um dado de interesse público.

\section{REFERÊNCIAS}

1. BRASIL. Casos de Tuberculose - Desde 2001. Sistema de Informações de Agravos de Notificação (SINAN), 2020. Disponível em: http://tabnet.datasus.gov.br/cgi/tabcgi.exe?sinannet/cnv/tubercrn.def. Acessado em: 08 de julho de 2020.

2. MARQUES CC, et al. Casos de tuberculose coinfectados por HIV em um estado do nordeste brasileiro. Enfermería Actual de Costa Rica, 2019; 36.

3. OLIVEIRA LB, et al. Análise epidemiológica da coinfecção tuberculose/HIV. Cogitare Enfermagem, 2018; 23, 1: e51016. 
RESUMO EXPANDIDO: Estudo Original

TÍTULO: A IMPORTÂNCIA DA EDUCAÇÃO EM SAÚDE NA PREVENÇÃO DE ACIDENTES POR ANIMAIS PEÇONHENTOS: UM ENFOQUE AO ESCORPIONISMO

Autor/coautores: Amanda Fernanda da Silva, Guilherme Gomes Freire, Juliana Félix da Silva.

Instituição: Centro Universitário Facex (UNIFACEX), Natal-Rio Grande do Norte.

Palavras-chave: Escorpionismo, Farmacêutico, Educação em Saúde.

\section{INTRODUÇÃo}

Os acidentes por animais peçonhentos constituem um importante problema de saúde pública. Dentre eles, destacam-se os acidentes provocados por escorpiões, que em virtude de sua incidência crescente ano após ano, são considerados pela Organização Mundial de Saúde (OMS) um problema de saúde pública negligenciado, por mais que não esteja incluso oficialmente na lista de Doenças Tropicais Negligenciadas da OMS, ao contrário do que acontece com o ofidismo (PUCCA MB, et al., 2015).

No Brasil, os acidentes por escorpiões são a segunda maior causa de intoxicação humana, ficando atrás apenas dos medicamentos (BRASIL, 2019). A peçonha produz desde efeitos locais, como intensa dor local, parestesia e edema, que podem evoluir, nos casos mais graves, para efeitos sistêmicos, que incluem alterações cardiovasculares, edema pulmonar, choque, hipertensão arterial e morte (PUCCA MB, et al., 2015).

O escorpionismo se torna um problema ainda mais grave pelo fato de o escorpião ser um animal cujo habitat é próximo às residências, fazendo com que a população esteja ainda mais vulnerável devido à grande falta de informação que se observa tanto no reconhecimento do animal, quanto em relação ao tratamento, fazendo com que, muitas vezes, as vítimas sejam socorridas a partir de conhecimentos empíricos pouco eficazes.

\section{OBJETIVO}

Avaliar o nível de conhecimento dos estudantes de uma Instituição de Ensino Superior (IES) do Estado do Rio Grande do Norte (RN) sobre os riscos de acidentes por animais peçonhentos, com enfoque no escorpionismo, com o propósito de traçar um plano educativo de orientação sobre prevenção, cuidados e tratamento.

\section{MÉTODO}

Trata-se de um estudo descritivo, abordando o nível de conhecimeto de acadêmicos de uma IES do RN. Mediante preenchimento do "Consentimento de Pós-Informação", disponibilizado junto ao formulário on-line, onde o participante declara ser maior de 18 anos e que foi informado e esclarecido sobre o Termo de Consentimento Livre e Esclarecido (TCLE) virutal, foi aplicado um questionário estruturado, com questões fechadas, via Google Forms, de forma on-line, buscando mensurar o nível de conhecimento destes indivíduos acerca do escorpionismo.

Os dados coletados foram analisados por meio de estatística descritiva. Este trabalho foi realizado conforme os preceitos éticos vigentes, mediante aprovação pelo Comitê de Ética em Pesquisa (CEP), cujo Certificado de Apresentação para Apreciação Ética (CAAE) é 33758920.6.0000.5537.

\section{RESULTADOS}

Um total de 33 alunos responderam ao formulário compartilhado on-line. Todos eram alunos da área da saúde, sendo a maiora do sexo feminino (66,7\% dos entrevistados), das faixas etárias de $21-25$ anos $(42,4 \%)$ e $26-30$ anos (39,4\%), caracterizando um perfil de jovens adultos, majoritariamente feminino. Dentre as questões de múltipa escolha constantes no questionário, será dado destaque aqui ao resultado obtido referente às questões que abordam o uso de compressas no local da picada como forma de primeiro cuidado em caso de acidentes com escorpiões. 
Conforme apresentado na Tabela 1, é evidente a divergência do conhecimento nos participantes entrevistados. A maioria dos estudantes $(51,5 \%)$ informou que não deveria ser aplicada nenhuma compressa no local, enquanto $21,2 \%$ alegaram não saber a resposta para a pergunta. Dos que responderam que tipo de compressa deveria ser aplicado, $6(18,2 \%)$ acreditam que deve ser utilizada compressa morna, enquanto 3 $(9,1 \%)$ alegaram que compressa gelada deveria ser utilizada. Nenhum dos entrevistados escolheu compressa quente como resposta.

Tabela 1 - Tipos de compressas que se deve aplicar no local da picada, segundo os entrevistados. $n=33$

\begin{tabular}{lcc}
\hline Variável & N & $\%$ \\
\hline Tipo de compressa & & \\
Gelada & 3 & 9,1 \\
Quente & 0 & 0 \\
Morna & 6 & 18,2 \\
Não aplicar & 17 & 51,5 \\
Não sei & 7 & 21,2 \\
\hline Total & $\mathbf{3 3}$ & $\mathbf{1 0 0}$ \\
\hline
\end{tabular}

Fonte: SILVA AF, et al., 2020.

\section{DISCUSSÃO}

Uma picada de escorpião, em geral, pode provocar dor intensa, parestesia e sinais de inflamação. Diante desse quadro, é comum dúvidas acerca dos cuidados imediatos para aliviar tais sintomas, enquanto se aguarda ajuda médica especializada. É preconizado o uso de compressas mornas no local da picada em associação com analgésicos para alívio da dor, enquanto não existem evidências clínicas de benefício do uso de compressas geladas (CUPO P, 2015).

Com base nos resultados preliminares obtidos, é nítida a falta de conhecimento acerca dessa abordagem, o que foi também observado em outros parâmetros que ainda estão sob análise, como por exemplo uso de torniquetes e o próprio conhecimento acerca de qual a sintomatologia mais comum no escorpionismo. Também chama atenção se tratar de alunos da área da saúde.

Sendo assim, fica evidente a necessidade crescente de se traçar planos educativos de orientação sobre prevenção, cuidados e tratamento no escorpionismo.

\section{CONSIDERAÇÕES FINAIS}

Tendo em vista os dados apresentados, e considerando-se o quanto o escorpionismo pode gerar complicações e/ou desconforto se não tratados de acordo com o recomendado, fica evidente o quão é importante a educação em saúde para a população na temática do escorpionismo. Profissionais da saúde como o farmacêutico, que é muitas vezes protagonista na linha de frente ao cuidado comunitário, tem seu papel essencial como mediador de orientações corretas e eficazes, mostrando seu importante papel na saúde pública.

\section{REFERÊNCIAS}

1. BRASIL. Vigilância em saúde no Brasil 2003|2019: da criação da Secretaria de Vigilância em Saúde aos dias atuais. Boletim Epidemiológico. 2019. Disponível em:

https://portalarquivos2.saude.gov.br/images/pdf/2019/setembro/25/boletim-especial-21ago19-web.pdf.

Acessado em: 10 de agosto 2020.

2. CUPO P. Clinical update on scorpion envenoming. Revista da Sociedade Brasileira de Medicina Tropical, 2015; 48:642.

3. PUCCA MB, et al. Tityus serrulatus venom - a lethal cocktail. Toxicon, 2015; 108:272. 
RESUMO EXPANDIDO: Estudo Original

TÍTULO: INCIDÊNCIA DE CASOS DE LEISHMANIOSE TEGUMENTAR AMERICANA NO ESTADO DE Pernambuco no PERÍOdo DE 2013 A 2018

Autor/coautores: Rosana Maria da Conceição Silva ${ }^{1}$, Cleber José da Silva ${ }^{1}$, Thales Willys do Nascimento Gomes $^{2}$, Fabricia Karla da Silva².

Instituição: ${ }^{1}$ Universidade Federal de Pernambuco (UFPE), Recife-Pernambuco. ${ }^{2}$ Centro Universitário Mauricio de Nassau (UNINASSAU), Recife-Pernambuco.

Financiamento: Fundação de Amparo a Ciência e Tecnologia do Estado de Pernambuco (FACEPE).

Palavras-chave: Leishmaniose Tegumentar Americana, Incidência, Epidemiologia.

\section{INTRODUÇÃO}

A Leishmaniose Tegumentar Americana (LTA) é classificada pela Organização Mundial de Saúde (OMS) como uma doença tropical negligenciada causada por parasitos intracelulares do gênero Leishmania sendo transmitida através da picada de insetos-vetor fêmea do gênero Lutzomiya (continente americano) (TORRESGUERRERO E, et al., 2017). As principais apresentações clínicas da LTA são as formas cutânea e mucosa caracterizadas por lesões difíceis de serem tratadas e que podem causar deformações na face do indivíduo acometido (TORRES-GUERRERO E, et al., 2017).

A LTA é considerada um grave problema de saúde pública e sanitária em países emergentes, como o Brasil, e segundo dados recentes da OMS, estima-se que, anualmente, $0.6-1$ milhão de pessoas residentes nas áreas endêmicas do planeta são infectadas por essa doença. No Brasil, a LTA possui uma alta incidência e, anualmente, são notificados de $15-20$ mil novos casos. As áreas mais afetadas são as regiões norte e nordeste, pois, aproximadamente, $73,14 \%$ dos casos são registrados nessas regiões (GONÇALVES AFLS, et al., 2020).

Tendo em vista a importância dos estudos epidemiológicos na promoção de políticas públicas voltadas à saúde, o presente estudo propõe-se a analisar a incidência de LTA no estado de Pernambuco e os principais dados epidemiológicos relacionados a essa doença no período de 2013 a 2018 utilizando bancos de dados de saúde pública como base de pesquisa.

\section{OBJETIVO}

Verificar a incidência de casos de Leishmaniose Tegumentar Americana no estado de Pernambuco e analisar os principais dados epidemiológicos relacionados a essa doença no período de 2013 a 2018 registrados em bancos de dados de domínio público.

\section{MÉTODO}

Tratou-se de uma pesquisa descritiva e documental, de corte transversal com abordagem quantitativa. A amostra do estudo foram todos os novos casos notificados para Leishmaniose tegumentar americana no estado de Pernambuco, incluídos na base de dados do DATASUS entre 2013 a 2018. Após a coleta dos dados foi realizada uma tabulação quantitativa com estatística descritiva simples e análise fatorial, apresentando os resultados em números absolutos e percentuais. Como esta pesquisa tratou-se apenas de análises de dados secundários, não lidando diretamente com pacientes, não foi necessário submissão para Comitê de Ética em Pesquisa (CEP) ou Termo de Consentimento Livre e Esclarecido (TCLE).

\section{RESULTADOS}

O estado de Pernambuco registrou 1.845 casos de LTA no período de 2013 a 2018, possuindo a média de 307,5 novos casos por ano. Os municípios mais incidentes estão localizados no litoral e zona da mata pernambucano, onde $31,79 \%$ dos casos de LTA foram registrados na Região de Saúde I (Recife), seguido da Região de Saúde II (Palmares) com 29,72\% dos casos dessa parasitose. 
Dentre todos os novos casos, foi observado que $61,03 \%$ eram do sexo masculino, com faixa etária predominante de 20 a 39 anos (28,15\%) e 40 a 59 anos (25,49\%). A raça/etnia declarada predominante foi de $66,83 \%$ para pardos. Enquanto ao nível de escolaridade $29,37 \%$ dos pacientes possuíam ensino fundamental incompleto.

Com relação a doença $97,40 \%$ dos pacientes desenvolveram a forma de Leishmaniose cutânea, enquanto apenas $2,60 \%$ dos indivíduos apresentaram a forma clínica mucosa. Para critérios de diagnósticos, os médicos se basearam em 70,46\% exames clínico-epidemiológico e 29,54\% clínico-laboratorial.

\section{DISCUSSÃO}

O presente estudo demonstrou que, em Pernambuco, os municípios endêmicos são localizados em áreas urbanas, periurbana, rurais ou próximos a resquícios de mata atlântica, esse indício pode justificar a presença e adaptação de insetos-vetores (gênero Lutzomiya spp.) em áreas peridomiciliares, necessitando-se de políticas públicas de prevenção e educação sobre a doença à populações residentes nessas localidades (CORDEIRO EL, et al., 2018).

Os dados sociodemográficos mostram que indivíduos do sexo masculino em idade laboral (20 - 59 anos) são mais suscetíveis a infecção por Leishmania spp, esse risco pode estar correlacionado as suas ocupações e tempo de exposição aos vetores (GONÇALVES AFLS, et al., 2020). Sobre a LTA, observamos que a forma clínica predominante é a forma cutânea e o padrão de diagnóstico adotado nas áreas endêmicas de Pernambuco é o critério clínico-epidemiológico, vale ressaltar que inúmeras doenças dermatológicas possuem lesões semelhantes a LTA, sendo necessários exames laboratoriais para conclusão de diagnóstico.

\section{CONSIDERAÇÕES FINAIS}

Através de uma análise, podemos verificar que, em Pernambuco, são registrados 307,5 novos casos de LTA por ano. As áreas endêmicas dessa doença estão localizadas, principalmente, nas Regiões de Saúde I e II do estado. Os indivíduos do sexo masculino e na faixa etária de 20 a 59 anos dessas regiões possuem um alto risco de serem infectados devido a suas atividades profissionais e a exposição ao inseto-vetor. A forma cutânea é a manifestação clínica comum no estado e o critério de diagnóstico clínico-epidemiológico pode se sobressair ao critério clínico-laboratorial nas áreas endêmicas.

\section{REFERÊNCIAS}

1. CORDEIRO EL, et al. Nursing activities in the prevention of american tegumentary leishmaniasis in the Vicência/PE municipality. International Journal of Family \& Community Medicine, 2018; 2(5): 266-271.

2. GONCALVES AFLS, et al. Spatial dynamics and socioeconomic factors correlated with American cutaneous leishmaniasis in Pernambuco, Brazil from 2008 to 2017. Revista da Sociedade Brasileira de Medicina Tropical, 2020; 53: e20190373.

3. TORRES-GUERRERO E, et al. Leishmaniasis: a review [version 1; referees: 2 aproved]. F1000Research 2017; 6 (F1000 Faculty Review): 1-15. 
RESUMO EXPANDIDO: Estudo Original

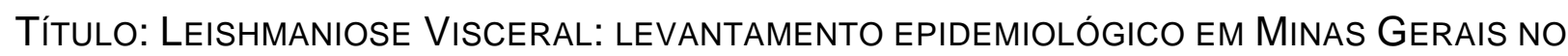
PERÍODO DE 2017 A 2019

Autor/coautores: Gabrielly Pelegrini Domingues, Brenda Gersanti Borba, Guilherme dos Santos Fontes Macedo, Ivana Araújo.

Instituição: Universidade José do Rosário Vellano (UNIFENAS), Alfenas - Minas Gerais.

Palavras-chave: Doença negligenciada, Vigilância, Zoonoses.

\section{INTRODUÇÃo}

As Leishmanioses, doenças tropicais, infecciosas, negligenciadas, de notificação compulsória, constituem um grave problema de saúde pública, dentre as principais formas clínicas encontra-se a Leishmaniose Visceral (LV), causada por protozoários tripanossomatídeos do gênero Leishmania (BRASIL, 2015). É uma doença que acomete mais as populações com baixa condição socioeconômica, uma doença de curso crônico e sistêmico. Segundo Guia de Vigilância em saúde, a LV quando não recebe tratamento e diagnóstico adequados, pode evoluir para óbito em mais de 90\% dos casos (BRASIL, 2019).

Assim sendo, é de suma importância as ações da vigilância em saúde associadas a identificação de LV precoce, por meio de ações profiláticas e terapêuticas, objetivando-se a redução da progressão e da letalidade da doença. $A$ atenção à Leishmaniose Visceral tem caráter complexo e diversificado envolvendo ações que atuarão sobre o vetor, o reservatório e o hospedeiro. Portanto, torna-se fundamental avaliar a prevalência, incidência e letalidade da doença no estado de Minas Gerais a fim de, posteriormente, realizar ações de combate a mesma (BRASIL, 2014).

\section{OBJETIVO}

Analisar o perfil epidemiológico da Leishmaniose Visceral no período entre 2017 a 2019 no estado de Minas Gerais, baseando em variáveis tais como idade, sexo, zona de residência, evolução da doença e coinfecção Leishmania-HIV.

\section{MÉTODO}

Foi realizado um estudo descritivo utilizando dados obtidos do Sistema de Informação de Agravos de Notificação (SINAN). A população analisada foi a dos casos notificados e confirmados de Leishmaniose Visceral no estado de Minas Gerais, Brasil.

O período selecionado, de 2017 a 2019, deve-se às notificações terem sido intensificadas em 2017. Ademais, 3 anos é o tempo preconizado para subsidiar gestores na elaboração e execução de propostas para enfrentamento da doença.

Os dados foram organizados no software Excel computando-se a frequência percentual, obtida a partir da frequência absoluta para as variáveis relacionadas aos casos notificados e confirmados de LV. Doravante, será realizado o estudo analítico segundo o sexo, a faixa etária, taxa de letalidade, número de óbitos e LVHIV.

\section{RESULTADOS}

Entre 2017 a 2019, 5145 casos novos de Leishmaniose Visceral foram notificados no estado, dos quais 1563 confirmados, com redução gradativa, uma vez que houve 869 casos confirmados em 2017, 412 casos em 2018 e 282 casos em 2019. Houve maior percentual na zona urbana (72\%), seguida da zona rural (21\%). Destes casos confirmados, $63 \%$ são de homens e $37 \%$, de mulheres. As faixas etárias predominantes foram a inferior a 5 anos (23\%) e entre 20 e 69 anos (55\%). A letalidade no período foi de $10 \%$, sendo os óbitos mais frequentes no sexo masculino (64\%) e na faixa etária de 50 a 59 anos $(21 \%)$.

Ademais, observou-se coinfecção LV-HIV, identificada em $11 \%$ dos pacientes com LV, predominante no sexo masculino (78\%) e na faixa etária de 30 a 49 anos (61\%). Os óbitos em pacientes com coinfecção LV-

REAS | Vol.Sup.n.54 | DOI: https://doi.org/10.25248/anais.e4798.2020 Página 45 de 245 
HIV (15\%) ocorreram com maior frequência em indivíduos do sexo masculino (71\%), na faixa etária de 30 a 49 anos $(67 \%)$.

\section{DISCUSSÃO}

No presente estudo, a Leishmaniose Visceral acometeu mais a população do sexo masculino, o que pode ser explicado pelo fato do homem estar exposto a trabalhos em maior contato com o flebotomíneo. Como observado, as faixas etárias mais acometidas foram inferiores a 5 anos e entre 20 e 69 anos.

A idade, pode representar um importante fator de risco para a ocorrência da LV, cuja susceptibilidade é aumentada devido a imaturidade celular e por possível imunodepressão agravada, geralmente por um estado de desnutrição, em áreas com baixa condição socioeconômica (BRASIL, 2014).

Nos últimos anos, a LV inicialmente possuia caráter rural e progressivamente vem passando por uma transição urbana, promovida pela urbanização (BRASIL, 2015). Ademais, os pacientes portadores de HIV apresentam maior risco de manifestar a doença LV, além da coinfecção LV-HIV acelerar o curso clínico da infecção por HIV, configurando-se em importante infecção oportunista (BRASIL, 2015).

\section{CONSIDERAÇÕES FINAIS}

A Leishmaniose Visceral mantém-se como grave problema de saúde pública no estado de Minas Gerais, cujo diagnóstico deve ser feito precocemente, assim como a coinfecção LV-HIV. A análise epidemiológica da LV auxilia no planejamento das ações coletivas e individuais e na atuação das políticas públicas de saúde, como o Programa de Vigilância e Controle da Leishmaniose Visceral (PVCLV) do Ministério da Saúde, o qual prevê ações para a redução da transmissão e da morbimortalidade. O presente estudo mostrou redução gradativa dos casos confirmados de LV no estado, enfatizando, portanto, a importância das ações da vigilância em saúde e controle ambiental.

\section{REFERÊNCIAS}

1. BRASIL. Guia de Vigilância em Saúde. Ministério da Saúde, 2019. Disponível em: https://portalarquivos2.saude.gov.br/images/pdf/2019/junho/25/guia-vigilancia-saude-volume-unico3ed.pdf. Acessado em: 13 de junho de 2020.

2. BRASIL. Manual de recomendações para diagnóstico, tratamento e acompanhamento de pacientes com a coinfecção leishmania-HIV. Ministério da Saúde, 2015. Disponível em: https://www.who.int/leishmaniasis/burden/manual-recomendacoes-diagnostico-leishmania-hivBRA.pdf?ua=1. Acessado em: 13 de junho de 2020.

3. BRASIL. Manual de vigilância e controle da leishmaniose visceral. Ministério da Saúde, 2014. Disponível em: $\quad$ http://nhe.fmrp.usp.br/wp-content/uploads/2018/08/Manual-de-vigil\%C3\%A2ncia-e-controle-daleishmaniose-visceral-1\%C2\%AA-Edi\%C3\%A7\%C3\%A3o.pdf. Acessado em: 13 de junho de 2020. 
RESUMO EXPANDIDO: Estudo Original

TÍTULO: SíNTESE E AVALIAÇÃO IN SILICO DA CAPACIDADE ANTILEISHMANIA DO 2-CIANO-3FENILACRILAMIDA

Autor/coautores: Agnis Pâmela Simões do Nascimento; Lucas Linhares de Lócio; Joilly Nilce Santana Gomes; Michelangela Suelleny de Caldas Nobre; Ricardo Olímpio de Moura.

Instituição: Universidade Estadual da Paraíba (UEPB), Campina Grande-Paraíba.

Palavras-chave:EstudosComputacionais,QuímicaMedicinal,Antileishmania.

\section{INTRODUÇÃO}

Mais de um milhão de pessoas vivem em áreas endêmicas da Leishmaniose, estas regiões são predominantemente pobres. Nas Américas, em 2018, 97\% dos casos de Leishmaniose Visceral (LV) foram no Brasil. Além deste, outros continentes são fortemente relacionados com esta doença parasitária como a região Africana onde os surtos são frequentes, e a região Mediterrânea Oriental que detém $70 \%$ dos casos da Leishmaniose Cutânia (LC) de todo o mundo (SOORARAEI M, et al., 2018).

Testes presuntivos in silico podem auxiliar na descoberta de novos quimioterápicos direcionados para alvos específicos, como a Leishmania spp. Compostos carbonilados $\alpha, \beta$ insaturados podem atuar como aceptores ou doadores de Michael, os quais puderam ser testados por Silva et al. (2016) como inibidores irreverssíveis da protease de Leishmaniose. Desta forma, pôde-se propor possíveis mecanismos de ação in silico para a interação com as enzimas de Leishmania spp: piruvato quinase (PDB ID: 3PP7), tripanotriona redutase (PDB ID: 2JK6) e pteridina redutase (PDB ID: 1E7W) (SILVA WAV, et al., 2016).

\section{OBJETIVO}

Sintetizar composto carbonílico $\alpha, \beta$-insaturado (2-ciano-3-fenilacrilamida) por meio da reação do tipo Knoevenagel e avaliar sua capacidade inibitória in silico através da ferramenta de docking molecular frente aos alvos referentes a Leishmania mexicana, Leishmania majore Leishmania infantum, propondo um provável perfil quimioterápico.

\section{MÉTODO}

A sintetise ocorreu por reação de Knoevenagel, a partir do 2-cianoacetamida e benzaldeído, em etanol e catalizada por trietilamina. Por fim, a solução pôde ser precipitada com água e em seguida filtrada. $A$ capacidade inibitória in silico do APC-01 foi obtida por docking. A Leishmania mexicana (PDB ID: 3PP7), testada nas coordenadas 29,482; 21,949; 45,944; dimensão 60x60x60Á. Leishmania major (PDB ID: 1E7W) em -6,140; 21,210; 26,307; 40x40x50Á. Leishmania infantum (PDB ID: 2JK6) em 32,051; 55,534; -6,760; $60 \times 60 \times 60 \AA$. Os espaçamentos foram de 0,375 . Os ligantes co-cristalizados com o alvo foram utilizados como padrão para checagem do sítio ativo, GridBox, e comparativo energetico e inibitório, sendo eles: metotrexato (PDB ID: 1E7W), dinucleotídeo flavina-adenina (PDB ID: 2JK6) e suramina (PDB ID: 3PP7).

\section{RESULTADOS}

O composto APC-01 pôde ser sintetizado, resultando em um rendimento de 33,06\% e estruturalmente caracterizado por Ressonância Magnética Nuclear de Hidrogênio $1\left(\mathrm{RMN}{ }^{1} \mathrm{H}\right)$ e Carbono $13\left(\mathrm{RMN}{ }^{13} \mathrm{C}\right)$. No RMN ${ }^{1} \mathrm{H}$, a insaturação característica da condensação pode ser identificada pelo deslocamento químico de $8,19 \mathrm{ppm}$ (singleto, $1 \mathrm{H}$ ) e a amina primária em $7,80 \mathrm{ppm}$. No RMN ${ }^{13} \mathrm{C}$, a insaturação gerou um sinal em 107,16 ppm, o carbono ligado a nitrila em 151,05 ppm.

Para os alvos testados, os valores de energia livre $(\Delta G)$ e a constante de inibição estimada (Ki) foram para a tripanotriona redutase $-7,69 \mathrm{Kcal} . \mathrm{mol}^{-1}$ e $6,39 \mathrm{nM}$, respectivamente; para o piruvato quinase, $-4,78 \mathrm{Kcal}_{\text {.mol- }}$ ${ }^{1}$ e $311,40 \mathrm{nM}$; pteridina redutase, $-6,74 \mathrm{Kcal}_{\mathrm{mol}}^{-1}$ e 11,54 nM; e arginase, -6,35 Kcal. $\mathrm{mol}^{-1}$ e 22,13 nM. Dos ligantes co-cristalizados tiveram-se $-8,28 \mathrm{Kcal} \mathrm{mol}^{-1}$ e $846,03 \mathrm{nM}$ para o metotrexato; $-13,73 \mathrm{Kcal} . \mathrm{mol}^{-1}$ e 0,086 nM para p dinucleotídeo flavina-adenina; e -9,60 Kcal.mol-1 e 91,39 nM para a suramina. 
Tabela 1 - Resultados de Docking molecular.

\begin{tabular}{|c|c|c|c|c|c|c|c|}
\hline $\begin{array}{l}\text { Estrutura } \\
\text { Composto } \\
\text { Sintetizado }\end{array}$ & do & $\begin{array}{l}\text { Código } \\
\text { do } \\
\text { Alvo }\end{array}$ & $\begin{array}{l}\Delta G \\
\left(K_{c a l} \text { Mol}^{-1}\right) \\
(\text { APC-01) }\end{array}$ & $\begin{array}{l}\mathrm{Ki} \\
(\mathrm{nM}) \\
(\mathrm{APC}-01)\end{array}$ & $\begin{array}{l}\Delta G \\
\text { (Kcal. Mol-1) } \\
\text { (ligante) }\end{array}$ & $\begin{array}{l}\text { Ki } \\
\text { (nM) } \\
\text { (ligante) }\end{array}$ & $\begin{array}{l}\text { Desvio } \\
\text { quadrático } \\
\text { médio } \\
\text { (RMSD) (Á) }\end{array}$ \\
\hline & & $1 \mathrm{E} 7 \mathrm{~W}$ & $-6,74$ & 11,54 & $\begin{array}{l}-8,28 \\
\text { (metotrexato) }\end{array}$ & 846,03 & 1,04 \\
\hline C & $\mathrm{NH}$ & 2JK6 & $-7,69$ & 6,39 & $\begin{array}{l}-13,73 \\
\text { (dinucleotíde } \\
\text { o flavina- } \\
\text { adenina) }\end{array}$ & 0,086 & 1,10 \\
\hline & & 3PP7 & $-4,78$ & 311,40 & $\begin{array}{l}-9,60 \\
\text { (suramina) }\end{array}$ & 91,39 & 0,93 \\
\hline
\end{tabular}

Fonte: NASCIMENTO APS, et al., 2020.

\section{DISCUSSÃO}

Os RMSD's inferiores a 2,0 Á validadam a metodologia utilizada. Dos alvos selecionados a interação com o 2JK6 foi a de $\Delta \mathrm{G}\left(-7,69 \mathrm{Kcal}^{\mathrm{mol}}{ }^{-1}\right)$ e Ki $(6,39 \mathrm{nM})$ mais favoráveis, de forma a mostrar-se como um potencial inibidor da tripanotriona redutase. Se tratando do efeito inibitório, apesar de possuir maior energia $(-6,74$ $\left.\mathrm{Kcal} \cdot \mathrm{mol}^{-1}\right)$, em relação ao metotrexato $\left(-8,28 \mathrm{Kcal}^{\mathrm{mol}}{ }^{-1}\right)$, o APC-01 possui melhor ação inibitória $(11,54 \mathrm{nM})$ em relação ao metotrexato (1E7W) $(846,03 \mathrm{nM})$.

Comparando-se os resultados obtidos para o 1E7W com os estudos realizados por Araújo JL, et al. (2020) para o Epiruno (derivado do metabolito secundário do Jaborandi) $\left(-10,68 \mathrm{Kcal}_{\text {.mol }}{ }^{-1} ; 14,8 \mathrm{nM}\right)$, que em testes in vitro inibiram $50,53 \%$ do crescimento de promastigota em uma concentração de $800 \mu \mathrm{g} \cdot \mathrm{mL}^{-1}$, o APC-01 se sobressai em termos de capacidade inibitória in silico por possuir um menor valor de $(11,54 \mathrm{nM})$.

\section{CONSIDERAÇÕES FINAIS}

Pôde-se sintetizar e avaliar a capacidade de inibição de diferentes alvos. Apesar de não ser energeticamente favorável aos ligantes co-cristalizados testados neste experimento, o APC-01 por se tratar de um composto carbonílico $\alpha, \beta$ insaturado pode atuar como doador/aceptor de Michael sendo bons inibidores enzimático, favorecendo sua ação. A obtenção de resultado satisfatório de Ki para pteridina redutase (PDB ID: 1E7W), em detrimento ao metotrexato, e a comparação com resultados in silico, proveniente de revisão de literatura, indicam possibilidade de haver inibição do crescimento de promastigota por meio de testes in vitro, de acordo com a comparação dos resultados do Ki.

\section{REFERÊNCIAS}

1. ARAÚJO JL, et al. Molecular Docking and Evaluation of Antileishmania Activity of a Ruthenium Complex with Epiisopiloturine and Nitric Oxide. Journal of Biosciences and Medicines, 2020; 8(5): 85005.

2. SILVA WAV, et al. Synthesis and activity of novel homodimers of Morita-Baylis-Hillman adducts against Leishmania donovani: A twin drug approach. Bioorganic \& medicinal chemistry letters, 2016; 26(18): 07022.

3. SOOSARAEI M, et al. A decade bibliometric analysis of global research on leishmaniasis in Web of Science database. Annals of medicine and Surgery, 2018; 26: 12014. 
RESUMO EXPANDIDO: Estudo Original

TíTULO: SíNTESE E AVALIAÇÃO DAS PROPRIEDADES ANTI-T. CRUZI DE INÉDITOS 1,3-TIAZÓIS DERIVADOS DA 5-CLORO-ISATINA

Autor/coautores: Luiz Alberto Barros Freitas ${ }^{1}$, Paulo André Teixeira de Moraes Gomes ${ }^{1}$, Valéria Pereira Hernandes$^{2}$, Aline Caroline da Silva Santos², Ana Cristina Lima Leite1.

Instituições: ${ }^{1}$ Universidade Federal de Pernambuco (UFPE), Recife-Pernambuco; ${ }^{2}$ Instituto Aggeu Magalhães - Fundação Oswaldo Cruz (IAM/Fiocruz-PE), Recife-Pernambuco.

Financiamento: Fundação de Amparo à Ciência e Tecnologia do Estado de Pernambuco (FACEPE).

Palavras-chave: Doenças de Chagas, Trypanosoma cruzi, Tiazolil-isatinas.

\section{INTRODUÇÃO}

Doenças negligenciadas são um conjunto de doenças infecciosas que afetam regiões tropicais e subtropicais de países com economias em desenvolvimento. Dentre as doenças negligenciadas, destaca-se a Doença de Chagas, causada pelo protozoário Trypanosoma cruzi, no qual o tratamento da doença é feito com o benznidazol. Esse fármaco, porém, não é eficaz em estágios mais avançados da doença, além de apresentar muitos efeitos adversos. Por tais motivos, o desenvolvimento de novos fármacos para a terapêutica da doença de Chagas é de fundamental importância (SCARIM CB, et al., 2018).

Nesse contexto, a utilização de estruturas privilegiadas para obtenção de moléculas bioativas é recorrente devido a essas estruturas possuírem um amplo espectro de atividades farmacológicas (LEITE ACL, et al., 2019). Uma estratégia empregada para a obtenção de novos fármacos é a hibridização molecular, onde há a junção de dois grupos com conhecida atividade biológica. Isatina e o tiazol são importantes grupos farmacofóricos com um amplo espectro de atividades farmacológicas, dentre elas a atividade anti-T. cruzi. Baseado nessas características, o objetivo deste trabalho foi sintetizar uma série de novas isatinas de tiazolil e avaliar as propriedades anti-T.cruzi (GOMES PATM, et al., 2016).

\section{OBJETIVO}

Identificar moléculas promissoras com potencial atividade anti- $T$. cruzi frente a forma tripomastigota do parasita, por meio do planejamento estrutural, síntese e avaliação biológica de uma série de novos 1,3-tiazóis derivados da 5-cloro-isatina.

\section{MÉTODO}

A síntese dos novos 1,3-tiazóis foi realizada em duas etapas. Inicialmente ocorreu a condensação entre a 5-cloro-isatina e a tiossemicarbazida. Em seguida, ocorreu a ciclização em tiazol a partir da reação com diferentes $\alpha$-halo-cetonas para ser obtida a série final. Com a série sintetizada e purificada, a estrutura química foi confirmada por meio de espectroscopia na região do infravermelho (IV) e por Ressonância Magnética Nuclear de Hidrogênio $\left(R M N{ }^{1} \mathrm{H}\right)$ e de carbono $\left(R M N{ }^{13} \mathrm{C}\right)$.

Para a avaliação farmacológica, foram realizados testes de concentração citotóxica $\left(\mathrm{CC}_{50}\right)$ frente a macrófagos da linhagem RAW 264.7 e concentração inibitória $\left({ } C_{50}\right)$ frente a forma tripomastigota de Trypanossoma cruzi (Cepa Y). Os valores foram determinados por análise de regressão linear utilizando o software GraphPad Prism.

\section{RESULTADOS}

Os derivados 1,3-tiazóis foram obtidos em forma de sólidos e ao final das reações, houve necessidade de purificação dos produtos através de recristalização em THF. Os rendimentos alcançados para cada produto na etapa final da síntese se encontraram entre $86 \%$ e $94 \%$. A estrutura química dos compostos foi confirmada por dados espectroscópicos de $\mathrm{RMN}^{1} \mathrm{H}$ e $\mathrm{RMN}^{13} \mathrm{C}$ e Infravermelho. 
De acordo com a Tabela 1, seis compostos apresentaram concentração inibitória para $50 \%$ da população (IC50) menor que o fármaco de referência benznidazol $\left(\mathrm{IC}_{50}=14,6 \mu \mathrm{M}\right)$, com destaque para os compostos PA$3 A\left(\mathrm{IC}_{50}=4,21 \mu \mathrm{M}\right), \mathrm{PA}-3 \mathrm{~B}\left(\mathrm{IC}_{50}=5,8 \mu \mathrm{M}\right)$ PA-3G $\left(\mathrm{IC}_{50}=5,12 \mu \mathrm{M}\right)$ e PA-3J $\left(\mathrm{IC}_{50}=5,54 \mu \mathrm{M}\right)$. Quando testado a concentração citotóxica $\left(\mathrm{CC}_{50}\right)$ dois compostos se destacaram, o PA-3D $\left(\mathrm{CC}_{50}=175,11 \mu \mathrm{M}\right)$ e PA-3E $\left(C_{50}=239,49 \mu \mathrm{M}\right)$, sendo o composto PA-3E cerca de duas vezes menos tóxico que o benznidazol $\left(C_{50}=123,54 \mu \mathrm{M}\right)$. Quanto ao índice de seletividade, o maior valor foi observado para o composto PA-3J (IS=3,5), embora menos seletivo comparado ao BZD $(I S=8,46)$.

Tabela 1 - Resultados obtidos para atividade anti-T. cruzi dos 1,3-tiazóis derivados da 5-cloro-isatina.

\begin{tabular}{|c|c|c|c|c|}
\hline CÓDIGO & $\mathbf{R}$ & Citotoxicidade $\left(\mathrm{CC}_{50}\right) \mu \mathrm{M}$ & $\mathrm{IC}_{50}$ tripomastigotas $\mu \mathrm{M}$ & IS \\
\hline PA-Int3 & - & 91,42 & 23,61 & 0,98 \\
\hline PA-3A & $\mathrm{Ph}$ & 31,74 & 4,21 & 2,67 \\
\hline PA-3B & 4-Me-Ph & 30,42 & 5,8 & 1,93 \\
\hline PA-3C & 4-MeO-Ph & 43,06 & 12,48 & 1,33 \\
\hline PA-3D & 3-NO2-Ph & 175,11 & 26,33 & 2,66 \\
\hline PA-3E & 4-NO2-Ph & 239,49 & 51,40 & 1,86 \\
\hline PA-3F & 4-F-Ph & 32,99 & 8,49 & 1,45 \\
\hline PA-3G & 4-Cl-Ph & 40,62 & 5,12 & 3,09 \\
\hline PA-3J & 2,4-DiCl-Ph & 45,95 & 5,54 & 3,50 \\
\hline PA-3L & 4-Ph-Ph & 93,43 & 18,31 & 2,20 \\
\hline Benznidazol & - & 123,54 & 14,6 & 8,46 \\
\hline
\end{tabular}

Fonte: FREITAS LAB, et al., 2020.

\section{DISCUSSÃO}

De acordo com os valores obtidos de Citotoxicidade $\left(\mathrm{CC}_{50}\right)$, Concentração Inibitória $\left(\mathrm{IC}_{50}\right)$ e Índice de Seletividade (IS) os compostos PA-3G e PA-3J se mostraram promissores. Nesse caso, pode-se inferir que a inserção do cloro, na posição 4 do anel ligado ao tiazol, pode ser responsável pelo incremento da atividade biológica. O composto PA-3J, que além do cloro na posição 4, tem um cloro na posição 2 do anel ligado ao tiazol apresentou a maior seletividade. Os compostos PA-3D e PA-3E, que se mostraram menos tóxicos que o Benznidazol apresenta um grupo nitro na estrutura. Assim, inferimos que a inserção do grupo $\mathrm{NO}_{2}$ possa estar relacionada ao resultado.

Com base nos resultados de Gomes PATM, et al. (2016), realizar modificações estruturais nos derivados 1,3-tiazóis pode gerar moléculas bioativas contra o Trypanossoma cruzi. Assim, outras opções de substituicões pode auxiliar na busca de novas moléculas ativas.

\section{CONSIDERAÇÕES FINAIS}

As comprovações de dados estruturais através de análise de $\mathrm{RMN}^{1} \mathrm{H}$ e $\mathrm{RMN}^{13} \mathrm{C}$ e Infravermelho, mostram que os inéditos 1,3-tiazóis propostos foram efetivamente sintetizados. Além disso, todos os derivados foram testados enquanto sua atividade anti-T. cruzi, frente a forma tripomastigota e citotoxicidade para macrófagos. Os valores obtidos nesse trabalho indicam que os compostos PA-3G e PA-3J são compostos promissores 
quanto a atividade anti- $T$. cruzi frente a forma tripomastigota do parasita. Esses resultados nos motivam a realizar testes contra outras formas evolutivas.

\section{REFERÊNCIAS}

1. GOMES PATM, et al. New 1,3-thiazole derivatives and their biological and ultrastructural effects on Trypanosoma cruzi. European Journal of Medicinal Chemestry, 2016; 121: 387-398.

2. LEITE ACL, et al. Privileged Structures in the Design of Potential Drug Candidates for Neglected Diseases. Current Medicinal Chemistry, 2019; 26: 4323.

3. SCARIM CB, et al. Current advances in drug discovery for Chagas disease. European Journal of Medicinal Chemestry, 2018; 155: 824-838. 
RESUMO EXPANDIDO: Estudo Original

TíTULO: SífILIS GESTACIONAL E SíFILIS CONGÊNITA: ANÁLISE TEMPORAL dOS CASOS NO

BRASIL

Autor/coautores: Brenda Fernanda Guedes ${ }^{1}$, Claudia de Lima Rodrigues Souza ${ }^{2}$, Maria Vitoria Alves Vila Nova $^{3}$, Sandy Guedes Pereira ${ }^{4}$ e Ronald Pereira Cavalcanti ${ }^{5}$.

Instituição: Universidade Federal de Pernambuco (UFPE), Vitória de Santo Antão - Pernambuco 1,4,5. Centro Universitário Tabosa de Almeida ASCES, Caruaru - Pernambuco². Universidade de Pernambuco (UPE), Nazaré da Mata - Pernambuco ${ }^{3}$.

Palavras-chave: Doenças Sexualmente Transmissíveis, Sífilis, Sífilis Congênita.

\section{INTRODUÇÃO}

A sífilis é uma doença infecciosa e sistêmica que possui como agente etiológico o Treponema Pallidum. A transmissão pode ocorrer através do contato com lesões ou transfusão sanguínea na fase inicial da doença, no entanto a principal forma de transmissão é através da relação sexual. Sua ocorrência na gravidez pode resultar na sífilis congênita (SC). A SC ocorre quando a gestante com sífilis não faz tratamento ou é tratada de forma inadequada, transmitindo a infecção ao feto de forma transplacentária (GUERRERO M e LUCIANI K, 2019).

Apesar da eficácia do diagnóstico e tratamento para prevenção da sífilis congênita devido aos baixos custos e efetividade, a transmissão da mãe para o filho ainda é um problema de saúde pública. A eliminação da SC é uma prioridade mundial estabelecida pela Organização Mundial de Saúde (OMS) e a Organização Pan-Americana de Saúde (OPAS), pois a maioria das infecções maternas por sífilis permanece não identificada e/ ou não tratada adequadamente (CARDOSO ARP, et al., 2018).

\section{OBJETIVO}

Realizar análise dos casos confirmados de sífilis em gestantes e sífilis congênita em crianças menores de um ano de idade, registrados durante o período de cinco anos no território brasileiro.

\section{MÉTODO}

A presente pesquisa trata de um estudo observacional, descritivo, quantitativo e longitudinal, em um recorte temporal do período de 2015 a 2019. O intervalo analisado corresponde aos últimos cinco anos disponíveis no sistema. Foram coletados dados secundários oriundos do sítio eletrônico do Departamento de Informática do Sistema Único de Saúde do Brasil (DATASUS), especificamente do Sistema de Informação de Agravos e Notificação (SINAN). Após a realização da coleta, os dados foram sistematizados em planilhas eletrônicas, utilizando o programa LibreOffice Calc. As variáveis foram agregadas ano a ano e organizadas por trimestre gestacional, analisados descritivamente por meio de valores absolutos e relativos.

\section{RESULTADOS}

Em 2015 o número de casos de gestantes com sífilis era de 32.774, 2016 (38.268), 2017 (49.796), 2018 (62.599) e 2019 (25.794), apresentando uma queda de mais de 50\% em relação ao ano anterior. O estudo também observou que durante o período gestacional, o número de gestantes infectadas oscilou durante os trimestres de gravidez, em 2015 no $1^{\circ}$ trimestre gestacional registrou 10.559, o $2^{\circ}$ (9.767) e no $3^{\circ}$ (10.469), em 2016 no $1^{\circ}$ trimestre foram 14.207, no $2^{\circ}$ (11.000) e no $3^{\circ}$ (10.751), em 2017 no $1^{\circ}$ o trimestre foram 19.792 casos, no $2^{\circ}$ (13.897) e no $3^{\circ}$ (13.388), em 2018 no $1^{\circ}$ trimestre foram 24.390 casos, no $2^{\circ}$ (15.771) e no $3^{\circ}$ (18.530) e em 2019 no $1^{\circ}$ trimestre foram 9.962 , no $2^{\circ}$ (6.573) e no $3^{\circ}$ (7.532). O número de casos de sífilis congênita em menores de um ano de idade em 2015 era de 19.647, em 2016 (21.254), 2017 (24.933), 2018 (26.219), sofrendo uma diminuição no número de casos em 2019 com 11.759, apresentando uma queda de mais de $50 \%$ em relação ao ano anterior. 
Tabela 1 - Gestantes com sífilis segundo idade gestacional no Brasil, 2015-2019.

\begin{tabular}{llllllllllll}
\hline $\begin{array}{l}\text { Idade } \\
\text { Gestacional }\end{array}$ & $\mathbf{2 0 1 5}$ & & $\mathbf{2 0 1 6}$ & & $\mathbf{2 0 1 7}$ & & $\mathbf{2 0 1 8}$ & & $\mathbf{2 0 1 9}$ & \\
& $\mathbf{N}$ & $\%$ & $\mathbf{N}$ & $\%$ & $\mathbf{N}$ & $\%$ & $\mathbf{N}$ & $\%$ & $\mathbf{N}$ & $\%$ \\
\hline $1^{\circ}$ Trimestre & 10.559 & 34,3 & 14.207 & 39,5 & 19.792 & 42,0 & 24.390 & 41,6 & 9.962 & 41,4 \\
$2^{\circ}$ Trimestre & 9.767 & 31,7 & 11.000 & 30,6 & 13.897 & 29,5 & 15.771 & 26,9 & 6.573 & 27,3 \\
$3^{\circ}$ Trimestre & 10.469 & 34,0 & 10.751 & 29,9 & 13.388 & 28,4 & 18.530 & 31,6 & 7.532 & 31,3 \\
\hline Total & $\mathbf{3 0 . 7 9 5}$ & $\mathbf{1 0 0}$ & $\mathbf{3 5 . 9 5 8}$ & $\mathbf{1 0 0}$ & $\mathbf{4 7 . 0 7 7}$ & $\mathbf{1 0 0}$ & $\mathbf{5 8 . 6 9 1}$ & $\mathbf{1 0 0}$ & $\mathbf{2 4 . 0 6 7}$ & $\mathbf{1 0 0}$ \\
\hline
\end{tabular}

Fonte: GUEDES BF, et al., 2020. Dados extraídos do SINAN/ DATASUS, 2020.

\section{DISCUSSÃO}

Durante a análise dos cinco anos pôde ser observado que o número de casos cresceu quase todo período, exceto no ano de 2019 no qual ele sofreu uma diminuição em relação a 2018 , o mesmo se aplica a sífilis congênita em menores de um ano de idade que cresceu sem oscilar até 2018 , tendo uma diminuição em 2019. Lima VC, et al. (2017) atribui o crescente no número de casos a alguns fatores sendo essas ações de vigilância epidemiológica voltadas para uma abordagem mais eficiente e a diminuição do número de subregistros que leva consequentemente ao aumento das notificações. Outra hipótese, levantada através do estudo de Cardoso ARP, et al. (2018), para o aumento de gestantes infectadas é a falta de tratamento do parceiro sexual de uma boa parte das gestantes, ocasionando a reinfecção e falhas durante o tratamento dessas mulheres.

\section{CONSIDERAÇÕES FINAIS}

De acordo com o resultado do estudo foi possível observar um crescimento no número de gestantes com sífilis, entretanto no ano de 2019 ocorreu uma diminuição na quantidade dos casos registrados, o que pode ser reflexo da volta de sub-registros. A redução do número de gestante com sífilis entre os trimestres gestacionais foi observada em alguns anos, mas em outros o $3^{\circ}$ trimestre apresentou mais casos, o que pode indicar falha no pré-natal.

\section{REFERÊNCIAS}

1. CARDOSO ARP, et al. Análise dos casos de sífilis gestacional e congênita nos anos de 2008 a 2010 em Fortaleza, Ceará, Brasil. Ciência \& Saúde Coletiva, Ceará, 2018; 23(2): 563-574.

2. GUERRERO M, LUCIANI K. Sífilis congénita: características y calidad de atención en el Complejo Hospitalario Metropolitano Dr. Arnulfo Arias Madrid Dr. Arnulfo Arias Madrid. Pediátr. Panamá, 2019; 48(1): 5-11.LIMA VC, et al. Perfil epidemiológico dos casos de sífilis congênita em um município de médio porte no nordeste brasileiro. J. Health Biol Sci, 2017; 5(1): 56-61. 
RESUMO EXPANDIDO: Estudo Original

TíTULO: SÉRIE TEMPORAL DE INCIDÊNCIA DE DENGUE NO ESTADO DA BAHIA: UMA ANÁLISE TRANSVERSAL

Autor/coautores: Karolayne Silva Souza, Milena Roberta Freire da Silva, Maria Betânia Melo de Oliveira. Instituição: Universidade Federal de Pernambuco (UFPE), Recife-Pernambuco.

Palavras-chave: Saúde Pública, Epidemiologia, Emergente.

\section{INTRODUÇÃO}

A dengue é uma doença causada por uma infecção viral, transmitida por insetos artrópodes do gênero Aedes. Ela é considerada emergente principalmente em regiões tropicais e subtropicais, sendo uma das doenças mais frequente no mundo, resultando em um problema socioecômico para as regiões afetadas. A transmissão percorre principalmente desde regiões do Mediterrâneo Oriental, Americana, Sudeste Asiático, Pacífico Ocidental e África, assim, estima-se que de 2000-2013 houve um aumento de aproximadamente $400 \%$, o que resultou em sua classificação como uma doença tropical negligenciada (SMITH AW, et al., 2019).

Ao decorrer dos anos tornou-se uma das mais relevantes morbidades causando mortalidades entre as pessoas, com isso, o Brasil é um dos principais países endêmicos dessa arbovirose, dos quais, enfrentam surtos dessa doença ocasionados por distintos sorotipos do vírus, que são divididos em quatro tipos: DENV1, DENV-2, DENV-3 e DENV-4. Estes sorotipos resultam em manifestações clínicas que podem ser um dos principais e importantes predições de gravidade clínica e prognóstico de pacientes (GUZMAN MG, et al., 2016; LOPES TRF, et al., 2018).

\section{OBJETIVO}

Analisar a incidência de casos da Dengue através dos casos notificados entre os anos de 2013 a 2017 no estado da Bahia, coletados do Departamento de Informática do Sistema Único de Saúde (DATASUS).

\section{MÉTODO}

É um estudo transversal de série temporal de incidência de casos de Dengue no período de 2013 a 2017 no estado da Bahia. Este trabalho, baseou-se em dados secundários coletados através do Sistema de Informação de Agravos de Notificação (SIAN) vinculado a plataforma do DATASUS.

Foram analisados dados de notificações confirmadas para dengue segundo a faixa etária de $<1$ Ano, 1-4, 5-9, 10-14, 15-19, 20-39, 40-59, 60-64, 65-69, 70-79 e 80 anos mais e por sexo (masculino e feminino), e dados de critérios de confirmação diagnóstica (Laboratorial, clínico-epidemiológico, ignorado/branco e em investigação) sobre a dengue no período supracitado.

Ao final da coleta de dados realizou-se a análise descritiva simples utilizando o software de planilha eletrônica Excel.

\section{RESULTADOS}

Entre o período de 2013 a 2017 houve a notificação de 146.997 novos casos prováveis de dengue no estado da Bahia, sendo que, 15.511 casos tiveram o diagnóstico de pacientes confirmados laboratorialmente, 52.016 foram confirmados através de exames clínico-epidemiológico e 73.009 tiveram o critério de confirmação ignorado/branco, restando 6.461 casos que ficaram em investigação. Assim, observou-se que dos 140.536 casos confirmados da doença, cerca de 81.205 (58\%) acometeram o sexo feminino e restante $59.016(42 \%)$ o sexo masculino.

Na Figura 1, pode-se observar um gráfico de série temporal de incidência de novos casos da dengue no período investigado, na qual, percebe-se que o pico (maior índice de casos novos) ocorreu entre os anos de $2015(36 \%)$ e $2016(47 \%)$, e as faixas etárias mais acometidas pela dengue foram as de 20-39 anos 
diagnosticadas em 53.251 pessoas, representando $38 \%$ e $40-49$ anos em 33.174 com $24 \%$ do valor total entre as faixas etárias estudadas.

Figura 1 - Série Temporal de Incidência no estado da Bahia de 2013-2017.

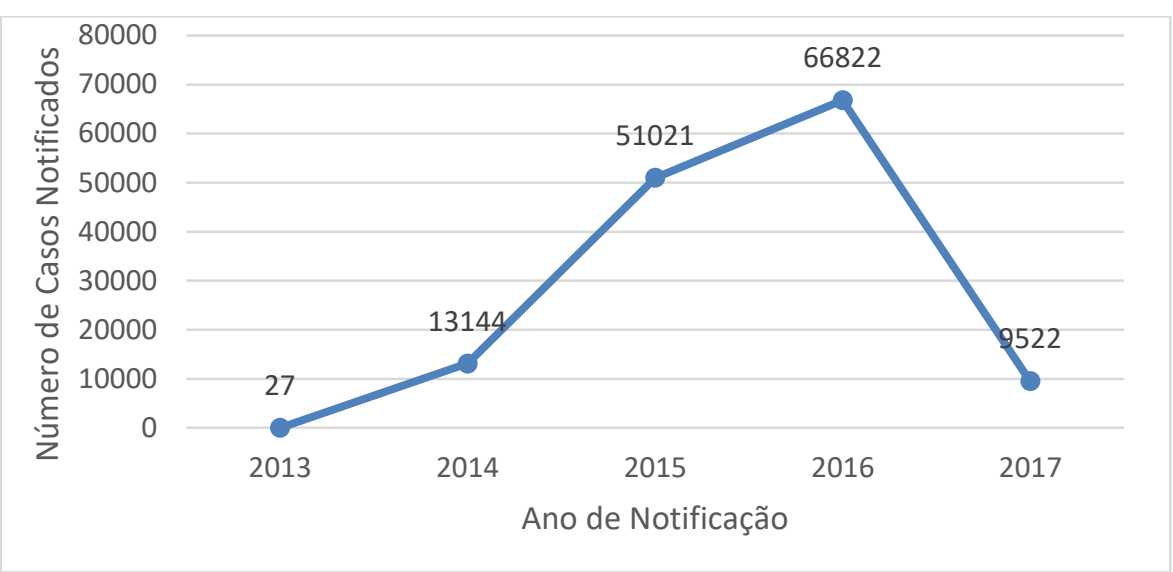

Fonte: SOUZA KS, et al., 2020 [dados extraído do Departamento de Informática do Sistema Único do Saúde, 2020].

\section{DISCUSSÃO}

Foi verificado um aumento de incidência da dengue entre 2015 e 2016, conforme detectado no trabalho de Pacheco DG, et al. (2019). Em relação aos casos notificados por sexo, os dados revelaram maior prevalência no sexo feminino (58\%), tendo, Monteiro ESC, et al (2009) relacionado isso ao fato de maior permanência de mulheres em residências, já que nestes locais há maior predominância, e assim a transmissão da dengue.

Em relação as faixas etárias, este estudo corroborou com dados da literatura, como por exemplo, o estudo de Ferreira AC et al (2018), sendo possivel perceber que a faixa etária mais acometida pela doença incluiu individuos com 20-49 anos de idade, provavelmente pelo fato de ser uma faixa etária mais economicamente ativa.

Os dados de incidência estavam disponíveis no DATASUS somente até o ano de 2017, visto que, foram atualizados até julho de 2018 e publicados em fevereiro de 2019, sujeitos a revisões e atualizações.

\section{CONSIDERAÇÕES FINAIS}

Conclui-se que no período estudado houve um aumento de incidência de Dengue no estado da Bahia, inclusive na faixa etária de 20-49.

O elevado número de notificações ignorado/branco e em investigação, indica um possível erro na vigilância epidemiológica em exames confirmatórios da doença.

Todavia, o baixo número de casos em 2013 refere-se ao fato da disponibilidade de um banco de dados único para dengue apenas a partir de 2014, o que dificultou anteriormente o monitoramento dos casos ocorridos.

Este trabalho demonstra a importancia da realização de estudos epidemiológicos para as estratégias de medidas de controle na redução de casos de arboviroses.

\section{REFERÊNCIAS}

1. FERREIRA AC, et al. Dengue em Araraquara, SP: epidemiologia, clima e infestação por Aedes aegypti. Revista de Saúde Pública, 2018, 52: 18.

2. GUZMAN MG, et al. Dengue infection. Nature reviews Disease primers, 2016, 2(1): 1-25. 
3. LOPES TRF, et al. Dengue no Brasil em 2017: o que aconteceu?. Revista do Instituto de Medicina Tropical de São Paulo, 2018, 60, e43: 1-3.

4. MONTEIRO ESC, et al. Aspectos epidemiológicos e vetoriais da dengue na cidade de Teresina, PiauíBrasil, 2002 a 2006. Epidemiologia e Serviços de Saúde, 2009, 18(4): 365-374.

5. PACHECO DG, et al. Aspectos epidemiológicos da dengue em Araçuaí, médio Vale do Jequitinhonha, Minas Gerais. Revista Espinhaço, 2019, 8 (1): 43-51.

6. SMITH AW, et al. Dengue. The Lancet, 2019, 393 (10169): 350-363. 


\section{RESUMOS EXPANDIDOS: Estudo Original}

TítUlo: INCREMENTO da ATIVIDADE ANTICHAGÁsica DE UMA NAFTOQUINONA COM A OBTENÇÃO DE COMPLEXOS DE INCLUSÃO COM BCD E METIL-B-CD

Autor/coautores: Amanda Silva de Almeida ${ }^{1}$, Verônica da Silva Oliveira ${ }^{1}$, Marcelo de Sousa da Silva ${ }^{1}$, Vitor Francisco Ferreira², Ádley Antonini Neves de Lima

Instituição: ${ }^{1 U n i v e r s i d a d e ~ F e d e r a l ~ d o ~ R i o ~ G r a n d e ~ d o ~ N o r t e ~(U F R N), ~ N a t a l-R i o ~ G r a n d e ~ d o ~ N o r t e . ~}{ }^{2}$ Universidade Federal Fluminense (UFF), Niterói-Rio de Janeiro.

Financiamento: Coordenação de Aperfeiçoamento de Pessoal de Nível Superior (CAPES) e Conselho Nacional de Desenvolvimento Científico e Tecnológico (CNPq).

Palavras-chave: Complexos, Naftoquinona, Atividade antichagásica.

\section{INTRODUÇÃO}

A baixa solubilidade de ativos nos fluidos biológicos interfere de modo direto na biodisponibilidade oral, contestando-se a viabilidade do composto nessa via de administração e, sobretudo, a sua eficácia terapêutica. Neste contexto, os complexos de inclusão se mostram como uma alternativa eficaz para o desenvolvimento de sistemas de liberação de fármacos, permitindo a incorporação de ativos de natureza hidrofóbica e com relevância terapêutica (MARIAN E, et al., 2020). As ciclodextrinas são constituídas por unidades de Dglucopiranose unidas por ligações a-glicosídicas, em que a parte interna é hidrofóbica e, por isso, permite acomodação de compostos de mesma natureza, conferindo, por exemplo, aumento de solubilidade e proteção frente a enzimas hidrolisantes (MARIAN E, et al., 2020).

O IVS 320 (3a,10b-di-hidro-1H-ciclopenta[b]nafto[2,3-d]furan-5,10-diona) é uma naftoquinona com potencial antifúgico e antichagásico (DANTAS ED, et al., 2017). No entanto, este composto apresenta baixa solubilidade em água, limitação que pode ser superada a partir de sua incorporação com as ciclodextrinas, originando os complexos de inclusão. Desse modo, torna-se viável a obtenção de uma nova alternativa terapêutica, segura e eficaz voltada para o tratamento da doença de Chagas, que consiste em uma doença tropical negligenciada que afeta 8 milhões de pessoas (ROBELLO C, et al., 2019).

\section{OBJETIVO}

Desenvolver complexos de inclusão com a naftoquinona (IVS320) utilizando as ciclodextrinas (CDs) $\beta C D$ e metil- $\beta-C D(M \beta C D)$, bem como caracterizar os compostos empregando análises físico-químicas e investigar o potencial antichagásico in vitro do IVS320 nesses novos sistemas de liberação.

\section{MÉTODO}

Para o desenvolvimento dos complexos de inclusão utilizou-se a razão molar 1:1 (IVS320:CDs) e empregou-se o método de malaxagem, que consistiu na pesagem e homogeneização do IVS320 e das CDs ( $\beta C D$ ou $M \beta C D$ ), seguida da adição da mistura de solventes água/acetona (50:50, v/v). E posterior secagem das amostras em estufa a temperatura de $50^{\circ} \mathrm{C}$ durante 8 horas. Para a caracterização dos complexos empregou-se as técnicas de infravermelho, calorimetria exploratória diferencial (DSC) e difração de raios-X (DR-X). A atividade antichagásica in vitro foi realizada em triplicatas utilizando cepas epimastigotas de T.cruzi (concentração $1 \times 10^{7}$ parasitas $/ \mathrm{mL}$ ), e a inibição parasitária foi avaliada através do ensaio de redução da resazurina, com incubação de $24 \mathrm{~h}$ dos compostos analisados.

\section{RESULTADOS}

No infravermelho dos complexos, os $v(\mathrm{O}-\mathrm{H})$ foram verificados em 3326 (IVS320- $\beta$ CD) e $3400 \mathrm{~cm}^{-1}$ (IVS320- $\beta C D$ ), enquanto nas CDs, observados em 3304 ( $\beta C D$ ) e $3394 \mathrm{~cm}^{-1}$ (M $\beta C D$ ). Também ocorreram alterações nos $v(C=O)$ e $v(C=C)$, entre 1700 a $1500 \mathrm{~cm}^{-1}$, comparativamente ao IVS320 isolado.

Adicionalmente, o IVS320 exibiu processo endotérmico ( $T_{\text {pico }} 189^{\circ} \mathrm{C}$ - fusão) e exotérmico $\left(T_{\text {pico }} 203^{\circ} \mathrm{C}\right.$ recristalização). Nos complexos os eventos exotérmicos foram deslocados para menores temperaturas, 198

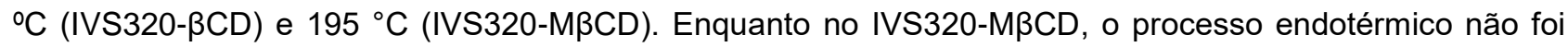
constatado. 
No DR-X os complexos apresentaram tanto reduções nas intensidades quanto ausência de algumas reflexões cristalinas em comparação ao IVS320 (cristalinidade de 99,19\%). Assim, o IVS320-MBCD exibiu menor valor $(26,74 \%)$, enquanto o IVS320- $\beta C D$ teve $86,06 \%$ de cristalinidade.

Para a atividade antichagásica (Fig.1), o IVS320- $\beta C D$ exibiu maior percentual de inibição frente as cepas epimastigotas, 70,87\%. Já o IVS320-MBCD apresentou 54,53\% para concentração de $100 \mu \mathrm{g} / \mathrm{mL}$. Em contrapartida, para essa mesma concentração, o IVS320 isolado e o Benznidazol, exibiram valores de $47,75 \%$ e $51,88 \%$, respectivamente. Os complexos também mostraram atividades inibitórias mesmo quando administrados em menores concentrações.

Figura 1 - Atividade antichagásica in vitro com $24 \mathrm{~h}$ de incubação.

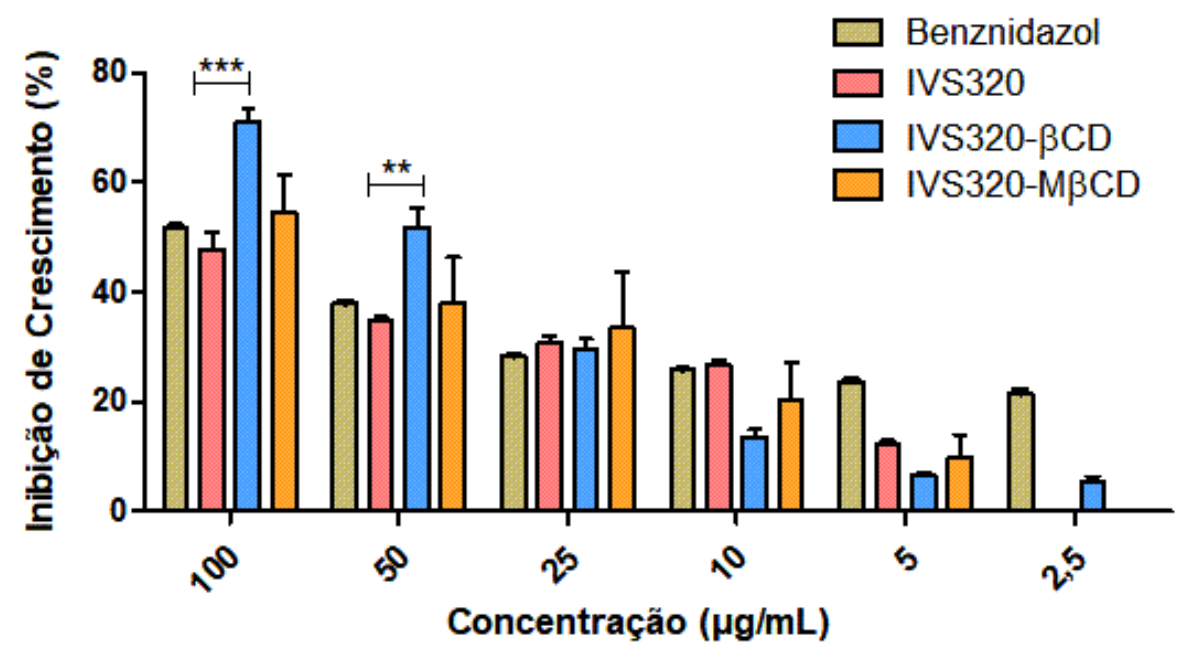

Fonte: ALMEIDA AS, et al., 2020.

\section{DISCUSSÃO}

$\mathrm{Na}$ caracterização físico-química no infravermelho e na análise térmica (DSC), as alterações evidenciadas ocorreram devido à interação do IVS320 com as CDs, sugerindo a formação dos complexos. Já no DR-X o desaparecimento das reflexões cristalinas, também indicam fortemente a formação dos sistemas, propondo a incorporação do IVS320 nas CDs (SANTANA A, et al., 2019). A redução da cristalinidade pode acarretar incremento na solubilidade do IVS320, e por sua vez, melhor performance nos ensaios in vitro. O aumento da atividade antichagásica também pode ser devido ao efeito sinérgico do IVS320 com CDs, podendo se tornar uma alternativa no combate à doença de Chagas, já que existem poucos fármacos disponíveis comercialmente, e estes possuem efeitos adversos relevantes. Como perspectiva a continuidade do estudo, almeja-se avaliar a toxicidade dos sistemas obtidos, bem como realizar ensaios in vitro usando as formas amastigotas e tripomastigotas do $T$. cruzi.

\section{CONSIDERAÇÕES FINAIS}

Os complexos de inclusão formados pela incorporação do IVS320 pelas ciclodextrinas, podem se tornar um promissor sistema de liberação de fármaco para a atividade antichagásica, quando comparados ao IVS320 isolado e ao fármaco de referência (benznidazol). Ficou evidenciado que, mesmo em menores concentrações do princípio ativo, os complexos com ciclodextrina, possibilitaram uma melhora das propriedades físico-químicas do IVS320, acarretando melhor desempenho ou incremento no seu potencial antichagásico. Dessa forma, esses sistemas constituem uma alternativa para melhorar a liberação do IVS320, conferindo aumento na solubilidade, e consequentemente podendo interferir na biodisponibilidade e viabilidade terapêutica do composto para o tratamento de Chagas. 


\section{REFERÊNCIAS}

1. DANTAS ED, et al. Characterization and Trypanocidal Activity of Novel Pyranaphthoquinone. Molecules 2017; 22: 1631.

2. MARIAN E, et al. Synthesis, characterization of inclusion compounds of amygdalin with $\beta$-cyclodextrin and sod-like activity and cytotoxicity on hela tumor cells. Arabian Journal of chemistry, 2020.

3. ROBELLO C, et al. The fecal, oral, and skin microbiota of children with Chagas disease treated with benznidazole. PLoS ONE, 2019.

4. SANTANA A, et al. Influence of cyclodextrin on posaconazole stability, release and activity: Improve the utility of the drug. Journal of Drug Delivery Science and Technology, 2019; 53. 
RESUMO EXPANDIDO: Estudo Original

Título: Perfil EpidemiolóGico dos casos de Dengue no Brasil: ANÁlise EM UM

PERÍODO DE 5 ANOS

Autor/coautores: Daniel Oliveira da Costa1, Davi Gabriel Barbosa1, Luiz Fernando Leite da Silva Neto1, Victor Oliveira da Costa2, Marcela Natalia Rocha de Castro2.

Instituição: 'Universidade do Estado do Pará (UEPA); ${ }^{2}$ Universidade Federal do Pará (UFPA), Belém-Pará.

Palavras-chave: Doenças Negligenciadas, Dengue, Epidemiologia.

\section{INTRODUÇÃO}

As doenças negligenciadas são enfermidades prevalentes em condições de pobreza nas quais acentuam as desigualdades sociais, afetando o desenvolvimento dos países. No Brasil, os arbovírus de doenças negligenciadas, como a dengue, têm emergido e reemergido nas últimas décadas, ocasionando um ônus constante para a saúde pública (OSSA DPS, et al., 2019). Transmitidos por mosquitos que atuam como vetores, são umas das principais causas de problemas de saúde global principalmente em países tropicais e subtropicais.

A doença e a carga econômica são de grande relevância para prevenção de epidemias, a fim de evitar maior ocorrência de formas agravantes e, consequentemente, crescimento no número de óbitos (CASTRO MC, et al., 2017). Atualmente, no país, a dengue se apresenta como um dos principais agravos de saúde pública, devido se tratar de uma doença multifatorial e com significativo aumento no número de casos. Nesse sentido, estudos que auxiliem na elucidação dos principais determinantes da dengue, principalmente aqueles relacionados com a epidemiologia se mostram extremamente úteis para uma melhor compreensão e futuro auxílio na criação de mecanismos de controle de epidemias, para a definição de políticas públicas e a alocação oportuna de recursos nas ações de prevenção.

\section{OBJETIVO}

Traçar o perfil epidemiológico dos casos da arbovirose Dengue no Brasil, durante o período de 2016 a 2020, avaliando a distribuição anual das notificações com base nos boletins epidemiológicos disponibilizados pelo Ministério da Saúde.

\section{MÉTODO}

Trata-se de um estudo do tipo transversal, prospectivo e descritivo. Avaliou-se quantitativamente os dados contidos nos Boletins Epidemiológicos do Ministério da Saúde, referentes às notificações da arbovirose Dengue no período de 2016 a 2020, de acordo com as semanas epidemiológicas.

Até o momento, analisaram-se aspectos relacionados aos anos de 2016 à $23^{\text {a }}$ semana epidemiológica de 2020, obtendo-se uma população amostral de 4.357.671 indivíduos. Buscou-se avaliar a distribuição anual dos casos, relacionando-os de forma comparativa e identificando as características da doença em janelas temporais.

Ademais, estão sendo analisados os números de notificações de acordo com as regiões brasileiras, bem como as taxas de incidência e de óbitos decorrentes da doença.

\section{RESULTADOS}

Observou-se, até o presente momento, que o período em que houve maior número de casos de Dengue no Brasil, foi o ano de 2019, com 1.544.987 indivíduos acometidos. Em seguida, encontra-se 2016 com 1.483.623 notificações, sendo que nos anos de 2017 e 2018, notou-se uma redução significativa na quantidade de infectados pelo vírus Aedes aegypti, havendo diminuição em cerca de $83 \%$ dos casos em 2018 quando comparado ao ano inicial do estudo. Ao se analisar os dados referentes de 2020 até a sua 23a semana, percebe-se que os números já somam 823.738 casos, equivalendo a mais da metade dos casos notificados no ano anterior. 
Tratando-se da distribuição regional, a região que mais se destacou foi o Sudeste com 2.285.297 notificações, seguido do Centro-Oeste, Nordeste, Sul e Norte (Tabela 1). Outrossim, as taxas de incidência também variaram no decorrer dos anos, sendo que em 2020, o valor já se encontra em 392 casos por 100.000 habitantes, com cerca de 374 óbitos apenas no primeiro semestre. Quanto ao número total de óbitos durante o período de estudo, computaram-se 2.194 mortes.

Tabela 1 - Distribuição dos casos de Dengue no Brasil de acordo com as Regiões da Federação, no período de 2016 a 23를 semana epidemiológica de 2020, n=4.357.671.

\begin{tabular}{lll}
\hline Variável & $\mathbf{N}$ & $\%$ \\
\hline Região & & \\
Centro-Oeste & 775.041 & 17,79 \\
Nordeste & 771.966 & 17,71 \\
Norte & 131.539 & 3,02 \\
Sudeste & 2.285 .297 & 52,44 \\
Sul & 393.828 & 9,04 \\
\hline Total & 4.357 .671 & 100
\end{tabular}

Fonte: COSTA DO, et al., 2020. Dados extraídos a partir dos Boletins Epidemiológicos disponibilizados pelo Ministério da Saúde, 2020.

\section{DISCUSSÃO}

A partir dos resultados obtidos, verifica-se que, entre os anos analisados, 2019 e, proporcionalmente, 2020 foram os mais impactados pela Dengue no Brasil, sendo diferente em 2017 e 2018 que apresentaram uma realidade contrária.

Essa disparidade de notificações ocorre devido à sazonalidade dessa doença, permitindo a oscilação quantitativa de acometidos ao longo do tempo. Além disso, é válido pontuar que os dados de casos confirmados e do número de mortes referentes a 2020 podem ser maiores em relação aos que já foram registrados devido à possibilidade do aumento de subnotificações de Dengue, ocasionada pela realidade pandêmica da COVID-19 que impacta negativamente os recursos da saúde pública (MASCARENHAS MDM, et al., 2020).

Concernente à regionalização das notificações, nota-se a concentração de acometidos pela Dengue no Sudeste. Esse resultado converge com o desordenado crescimento populacional, que é considerado uma das causas entre os processos multifatoriais de transmissão (OSSA DPS, et al., 2019).

\section{CONSIDERAÇÕES FINAIS}

Segundo o estudo, houve uma distribuição anual desigual dos casos de Dengue no Brasil, apresentando picos significativos nos últimos anos, e afetando, sobretudo, as regiões com maior crescimento populacional desordenado, como o Sudeste brasileiro.

Ademais, fica evidente o impacto da arbovirose nos sistemas de saúde, oferecendo potenciais riscos de sobrecarga e desgaste dos recursos públicos no cenário atual.

Tal realidade, aponta a necessidade do direcionamento de políticas públicas de controle e vigilância da doença com enfoque a nível local, atuando de forma ferrenha no processo de educação e sensibilização da população, e considerando as especificidades de cada localidade. 


\section{REFERÊNCIAS}

1. CASTRO MC, et al. Disease and economic burdens of dengue. The Lancet Infectious Diseases, 2017; 17 (3): e70 - e78.

2. MASCARENHAS MDM, et al. Ocorrência simultânea de COVID-19 e dengue: o que os dados revelam?. Cadernos de Saúde Pública, 2020; 36 (6): e00126520.

3. OSSA DPS, et al. Arbovírus circulantes no Brasil: fatores associados com a disseminação e estratégias terapêuticas. Revista eletrônica Acervo Saúde, 2019. (33): e1067. 
RESUMO EXPANDIDO: Estudo Original

TÍTULO: ANÁLISE DAS PREDIÇÕES IN SILICO DA FARMACOCINÉTICA DE NOVOS CANDIDATOS

\section{LPSF/ZKC11-15 ANTIVIRAIS CONTRA O ZIKA}

Autor/coautores: José Arion da Silva Moura, Gutembergmann Batista Coutinho, Ana Beatriz Lima Martiniano de Oliveira, Ivan da Rocha Pitta, Marina Galdino da Rocha Pitta.

Instituição: Universidade Federal de Pernambuco (UFPE), Recife-Pernambuco.

Financiamento: Fundação de Amparo à Ciência e Tecnologia de Pernambuco (FACEPE); Conselho Nacional de Desenvolvimento Científico e Tecnológico (CNPq).

Palavras-chave: Vírus Zika, Tiazolidina-2,4-diona, Farmacocinética.

\section{INTRODUÇÃO}

O vírus Zika (ZIKV) foi relatado primeiramente em macacos rhesus em 1947, na floresta Zika da Uganda, e em 1954 em humanos, na Nigéria. No Brasil, o primeiro relato ocorreu em 2015, e posteriormente causou um grande problema de saúde pública, pois além de apresentar sintomas similares a outras arboviroses, quando sintomático, a infecção foi associada a problemas neurológicos, como a síndrome de Guillain-Barré e microcefalia em neonatos. Atualmente, não existem tratamentos nem vacinas, sendo necessária a busca por medidas eficazes de combate à doença (WHITE MK, et al., 2017).

A hibridização molecular é um método eficaz no desenvolvimento de novas moléculas. Logo os novos derivados tiazolidínicos da série LPSF/ZKC surgem como uma possível alternativa farmacológica para a enfermidade. A estrutura desses compostos possui o núcleo da tiazolidina-2,4-diona, que possui destacadas atividades anti-inflamatória, antitumoral, antimicrobiana, antiviral, dentre outras, e está presente na estrutura de antidiabéticos comercializados (MANJAL SK, et al., 2017).

A avaliação da farmacocinética, por sua vez, permite compreender mecanismos envolvidos na administração, distribuição, metabolismo e excreção do fármaco no organismo, sendo de suma importância no desenvolvimento de um novo fármaco, permitindo inclusive a realização de uma triagem in silico para redução de custos em ensaios posteriores.

\section{OBJETIVO}

Analisar através de três métodos in silico, em plataformas on-line e gratuitas, parâmetros farmacocinéticos de absorção, distribuição, metabolização e excreção de cinco novos derivados antivirais contra o ZIKV codificados LPSF/ZKC.

\section{MÉTODO}

Foram utilizadas as plataformas on-line e gratuitas SwissADME, admetSAR e pkCSM, onde foram plotadas as estruturas da LPSF/ZKC-11 a LPSF/ZKC-15 a partir dos códigos SMILES correspondentes. A partir disso, foram selecionados e analisados os parâmetros de absorção intestinal, volume de distribuição teórico, permeabilidade à barreira hematoencefálica, interações com Glicoproteína P (Pgp), enzimas da superfamília do Citocromo P450 (CYP) e Clearence total.

Foi verificada a absorção intestinal, permeabilidade à barreira hematoencefálica e interações Pgp, com as três plataformas e comparado os resultados. Já nas interações com as CYP foram utilizadas apenas o admetSAR, assim como volume de distribuição teórico e Clearence total utilizando o pkCSM.

\section{RESULTADOS}

Considerando os resultados das predições, foi verificado que todos derivados apresentaram elevada absorção intestinal. Enquanto a permeação à barreira hematoencefálica para atingir o sistema nervoso central, os LPSF/ZKC-11 e LPSF/ZKC-14 apresentaram propriedade no SwissADME, o pkCSM reconhece os 
LPSF/ZKC-13 e LPSF/ZKC-15, como não permeáveis, ademais o admetSAR reconhece como todos permeáveis. $O$ volume de distribuição teórico calculado pelo pkCSM de todos compostos foi baixo.

Utilizou-se apenas o admetSAR para verificar a interação com as CYP, importante complexo enzimático na metabolização de fármacos e xenobióticos. Nenhum derivado inibiu a CYP2D6. Todos compostos inibiram a CYP2C9 e a CYP2C19. Os LPSF/ZKC-13, LPSF/ZKC-15, não inibiram a CYP1A2. Apenas ZKC-13 inibiu a CYP3A4.

Os substratos calculados para CYP3A4 são LPSF/ZKC-12, LPSF/ZKC-13 e LPSF/ZKC-15. Não foram apresentados nenhum substrato para a CYP2C9, da mesma forma para CYP2D6. Nenhum composto é substrato da Pgp em SwissADME e admetSAR, ainda no pkCSM, são substratos LPSF/ZKC-13-LPSF/ZKC15. Ademais, utilizando o admetSAR, nenhum composto foi inibidor da Pgp. O menor resultado para o Clearance Total foi $-0.456 \mathrm{log} \mathrm{ml} / \mathrm{min} / \mathrm{kg}$ (LPSF/ZKC-12) e o maior $-0.245 \mathrm{log} \mathrm{ml} / \mathrm{min} / \mathrm{kg}$ (LPSF/ZKC-14).

Tabela 1 - Resultado das predições farmacocinéticas dos potenciais novos antivirais da série PSF/ZKC.

\begin{tabular}{|c|c|c|c|c|c|c|c|c|c|c|c|c|c|c|c|}
\hline & \multicolumn{2}{|c|}{ LPSF/ZKC-11 } & \multicolumn{3}{|c|}{ LPSF/ZKC-12 } & \multicolumn{3}{|c|}{$\begin{array}{l}\text { LPSF/ZKC- } \\
13\end{array}$} & \multicolumn{3}{|c|}{$\begin{array}{l}\text { LPSF/ZKC- } \\
14\end{array}$} & \multicolumn{3}{|c|}{$\begin{array}{l}\text { LPSF/ZKC- } \\
15\end{array}$} \\
\hline & & $\alpha$ & $Y$ & $\alpha$ & $\beta$ & $\mathbf{Y}$ & $\alpha$ & $\beta$ & $Y$ & $\alpha$ & $\beta$ & $\mathbf{Y}$ & & $\beta$ & $\mathbf{Y}$ \\
\hline \multicolumn{2}{|c|}{ Absorção Intestinal } & + & + & + & + & + & + & + & + & + & + & + & + & + & + \\
\hline \multicolumn{2}{|c|}{$\begin{array}{l}\text { Permeação à barreira } \\
\text { hematoencefálica }\end{array}$} & + & + & - & + & + & - & - & + & + & + & + & - & - & + \\
\hline \multicolumn{2}{|c|}{ Substrato de Pgp } & - & - & - & - & - & - & + & - & - & + & - & - & + & - \\
\hline \multicolumn{2}{|c|}{ Inibidor de Pgp } & \multicolumn{2}{|l|}{-} & \multicolumn{3}{|l|}{-} & \multicolumn{3}{|l|}{-} & \multicolumn{3}{|l|}{-} & \multicolumn{3}{|l|}{-} \\
\hline \multicolumn{2}{|c|}{$\begin{array}{lr}\text { Volume } & \text { de } \\
\text { distribuição } & \text { teórico } \\
(\log \mathrm{L} / \mathrm{Kg}) & \end{array}$} & \multicolumn{2}{|l|}{0.115} & \multicolumn{3}{|c|}{-0.019} & \multicolumn{3}{|c|}{-0.048} & \multicolumn{3}{|c|}{-0.018} & \multicolumn{3}{|c|}{-0.14} \\
\hline \multirow{5}{*}{$\begin{array}{l}\text { Inibição } \\
\text { de CYP }\end{array}$} & CYP2D6 & \multicolumn{2}{|l|}{-} & \multicolumn{3}{|l|}{-} & \multicolumn{3}{|l|}{-} & \multicolumn{3}{|l|}{-} & \multicolumn{3}{|l|}{ - } \\
\hline & CYP2C9 & \multicolumn{2}{|l|}{+} & \multicolumn{3}{|l|}{+} & \multicolumn{3}{|l|}{+} & \multicolumn{3}{|l|}{+} & \multicolumn{3}{|l|}{+} \\
\hline & CYP2C19 & \multicolumn{2}{|l|}{+} & \multicolumn{3}{|l|}{+} & + & & & + & & & + & & \\
\hline & CYP1A2 & + & & + & & & - & & & + & & & - & & \\
\hline & CYP3A4 & - & & - & & & + & & & - & & & - & & \\
\hline Substrato & CYP3A4 & - & & + & & & + & & & - & & & + & & \\
\hline de CrP & CYP2C9 & - & & - & & & - & & & - & & & - & & \\
\hline & CYP2D6 & - & & - & & & - & & & - & & & - & & \\
\hline $\begin{array}{l}\text { Clearance } \\
\mathrm{ml} / \mathrm{min} / \mathrm{kg} \text { ) }\end{array}$ & total $(\log$ & -0.335 & & -0.4 & & & -0.4 & & & -0. & & & -0.3 & & \\
\hline
\end{tabular}

Legenda: Os símbolos $\alpha, \beta$ e $\mathrm{y}$ representam as plataformas SwissADME, pkCSM e admetSAR, respectivamente, assim como + resultados positivos e - resultados negativos.

Fonte: MOURA JAS, et al., 2020.

\section{DISCUSSÃO}

De acordo com o mecanismo de infecção do ZIKV, particularidades em novos derivados devem ser observados para garantir a eficácia, principalmente na farmacocinética, como ser permeáveis a barreira placentária e hematoencefálica, não reportar interações com outras drogas (BERNATCHEZ JA, et al., 2019) 
sendo interações com as CYP as principais formas de ocorrência, características que podem ser observadas nos derivados da série LPSF/ZKC nos métodos in silico.

O estudo apresenta limitações e por utilizar metodologias in silico, o resultado é previsto e não o real, servindo de idealização para delineamento de estudos posteriores.

Portanto, de acordo com o método calculado das diferentes plataformas e da quantidade de moléculas conhecidas utilizadas em cada método, é possível obter resultados diferentes.

Para a prospecção dos estudos, então a avaliação da administração das novas moléculas LPSF/ZKC nos estudos in vitro e in vivo, planejamento de novos derivados, e desenvolvimento de novos medicamentos.

\section{CONSIDERAÇÕES FINAIS}

Os métodos in silico de verificação de parâmetros farmacocinéticos apresentam uma grande vantagem no desenvolvimento de novos compostos e triagem de novos estudos na transição do in silico para o in vivo.

Nesse estudo foi apresentado que alguns derivados da série LPSF/ZKC têm resultados favoráveis de absorção, distribuição, metabolização e excreção característica.

Portanto de acordo com os parâmetros farmacocinéticos as moléculas são interessantes para estudos posteriores com intuito de se tornarem medicamentos ou servirem para desenvolvimento de novos protótipos, pois até o momento não há tratamento para a enfermidade causada pelo ZIKV.

\section{REFERÊNCIAS}

1. BERNATCHEZ JA, et al. Drugs for the Treatment of Zika Virus Infection. Journal Of Medicinal Chemistry, 2019; 63(2).

2. MANJAL SK, et al. Synthetic and medicinal perspective of thiazolidinones: a review. Bioorganic Chemistry, 2017; 75.

3. WHITE MK, et al. Zika virus: An emergent neuropathological agent. Annals of Neurology, 2017; 80(4). 
RESUMO EXPANDIDO: Estudo Original

TítULO: ANÁLISE EPIDEMIOLÓGICA DOS ACIDENTES ENVOLVENDO SERPENTES NO RIO GRANDE DO NORTE (2010-2016)

Autor/coautores: Guilherme Gomes Freire, Kerzea Miguel de Oliveira, Amanda Fernanda da Silva, Renato Bruno D'Samontesy Dantas Martinho, Juliana Félix da Silva.

Instituição: Centro Universitário FACEX (UNIFACEX), Natal - Rio Grande do Norte.

Palavras-chave: Acidente Ofídico, Rio Grande do Norte, Epidemiologia.

\section{INTRODUÇÃO}

Os envenenamentos causados por serpentes peçonhentas são considerados um importante problema de saúde pública, sobretudo em países tropicais ou subtropicais, sendo incluídos na lista de Doenças Tropicais Negligenciadas pela Organização Mundial da Saúde (OMS). Estes tipos de acidentes têm grande importância clínica em virtude de sua elevada incidência, gravidade e potencial letalidade (WHO, 2019).

No Brasil, são conhecidas 62 espécies de serpentes peçonhentas, das quais as de importância médica podem provocar quatro tipos de acidentes: botrópico (gêneros Bothrops e Bothrocophias - "jararacas"); crotálico (gênero Crotalus - "cascaveis"); laquético (gênero Lachesis - "surucucus") e elapídico (gênero Micrurus - "corais-verdadeiras") (MOTA DA SILVA A, et al., 2015).

Estudos que abordem o padrão de ocorrência dos acidentes por serpentes e suas características epidemiológicas podem subsidiar o entendimento da dinâmica desse agravo, bem como importantes ações de vigilância em saúde. Nesse contexto, visa-se, neste estudo, descrever o perfil dos acidentes ofídicos no Estado do Rio Grande do Norte (RN), notificados no período de 2010 a 2016 no banco de dados on-line do Sistema de Informação de Agravos de Notificação (SINAN).

\section{OBJETIVO}

Descrever e analisar as características epidemiológicas e clínicas dos casos de acidentes ofídicos notificados no Estado do Rio Grande do Norte, entre os anos de 2010 a 2016.

\section{MÉTODO}

Foi realizada uma análise epidemiológica retrospectiva dos acidentes ofídicos no $\mathrm{RN}$, ocorridos entre janeiro de 2010 a dezembro de 2016, notificados na base de dados do SINAN. Analisou-se a distribuição dos acidentes de acordo com variáveis epidemiológicas como gênero de serpente, sazonalidade, faixa etária, sexo, local da picada, tempo entre o acidente e o atendimento, e classificação clínica do caso. Os dados foram tabulados e analisados através de estatística descritiva no Microsoft Excel. Uma vez que os dados foram coletados através de um sistema de notificação e sem identificação dos sujeitos envolvidos, não houve necessidade de apreciação por Comitê de Ética (CEP), conforme as normas nacionais vigentes.

\section{RESULTADOS}

Entre 2010 a 2016 foram registrados 2.583 acidentes ofídicos no $\mathrm{RN}$, representando $1,32 \%$ dos acidentes registrados no Brasil. Desses, $1.228(47,54 \%)$ foram provocados pelo gênero Bothrops; 198 (7,67\%), por Crotalus; 45 (1,74\%), por Micrurus; e 4 (0,15\%), por Lachesis. Em 599 casos (23,19\%), no entanto, não havia identificação da serpente. As serpentes não-peçonhentas causaram $19,71 \%$ dos acidentes $(n=509)$ (Tabela 1).

Quanto à sazonalidade, observa-se que os acidentes acontecem durante todo o ano, com significativas variações mensais, principalmente nos meses chuvosos (junho, julho e agosto).

O sexo masculino foi o mais acometido, com um percentual de $74,76 \%$ dos acidentes ( $n=1931$ ). A faixa etária mais afetada foi a de 20 a 39 anos de idade, com o total de 861 casos. As regiões anatômicas mais frequentemente atingidas foram os membros inferiores, seguidos pelos superiores, tronco e cabeça. Em 
relação ao atendimento das vítimas, 53,23\% foram atendidas em até três horas após o acidente e 83,66\% dos acidentes foram classificados clinicamente como leves ou moderados (Tabela 1).

Tabela 1 - Características epidemiológicas dos casos de acidentes ofídicos registrados no $\mathrm{RN}(2010-2016), \mathrm{n}=2.583$.

\begin{tabular}{lll}
\hline Variável & $\mathbf{N}$ & $\%$ \\
\hline Tipo de Acidente Ofídico & & \\
Botrópico & 1.228 & 47,54 \\
Crotálico & 198 & 7,67 \\
Elapídico & 45 & 1,74 \\
Laquético & 4 & 0,15 \\
Não-peçonhenta & 509 & 19,71 \\
Ignorado & 599 & 23,19 \\
\hline Total & $\mathbf{2 . 5 8 3}$ & $\mathbf{1 0 0} \%$ \\
\hline Classificação do Caso & & \\
Leve & 1.607 & 62,21 \\
Moderado & 554 & 21,45 \\
Grave & 87 & 3,37 \\
Ignorado & 335 & 12,97 \\
\hline Total & $\mathbf{2 . 5 8 3}$ & $\mathbf{1 0 0} \%$
\end{tabular}

Fonte: FREIRE GG, et al., 2020. Dados extraídos do SINAN NET. DATASUS, 2020.

\section{DISCUSSÃO}

Apesar de serem dados ainda preliminares, devido o grande percentual de dados "ignorados" e falta de atualização, é possível observar que o perfil epidemiológico e clínico no RN reflete, em geral, a situação nacional. A predominância de acidentes botrópicos demonstra o quanto é necessário o investimento em pesquisas por terapias cada vez mais eficazes contra essas serpentes.

Outro ponto a ser destacado é o tempo entre a picada e o atendimento, que é crucial para um bom prognóstico.

Este estudo demonstrou que o tempo médio no RN é menor que o recomendado pelo Ministério da Saúde, corroborando com a maioria dos acidentes serem classificados como leves. No entanto, apesar de positivo, esse resultado deve ser analisado com cautela, pois é importante que se mantenham crescentes os esforços para melhorar cada vez mais a distribuição de soros em regiões de alta incidência (MOTA DA SILVA A, et al., 2015).

\section{CONSIDERAÇÕES FINAIS}

Acidentes com serpentes peçonhentas expressam grande importância na Saúde Pública brasileira.

É importante destacar que estes dados, embora sejam preliminares, demonstram a relevância dos acidentes ofídicos na morbimortalidade da população norte-riograndese e a necessidade de realização de constantes e atualizados estudos que avaliem os aspectos epidemiológicos envolvidos nesta problemática, afim de que sejam criadas políticas públicas direcionadas a diminuição dos desfechos negativos a partir destes acidentes.

Além disso, intervenções relacionadas a educação e orientação da população sobre medidas de prevenção de acidentes envolvendo animais peçonhentos são medidas que podem contribuir de maneira significativa na diminuição destes. 


\section{REFERÊNCIAS}

1. BRASIL. Acidente por animais peçonhentos - notificações registradas no Sistema de Informação de Agravos de Notificação (SINAN) - SINAN NET. DATASUS, Tecnologia da Informação a Serviço do SUS. 2019. Disponível em: http://tabnet.datasus.gov.br/cgi/tabcgi.exe?sinannet/cnv/animaisbr.def. Acessado em: 02 de junho de 2020.

2. MOTA DA SILVA A, et al. Acidentes com animais peçonhentos no brasil por sexo e idade. Revista Brasileira de Crescimento e Desenvolvimento Humano, 2015; 25(1).

3. WORLD HEALTH ORGANIZATION. Snakebite envenoming. 2019. Disponível em: https://www.who.int/news-room/fact-sheets/detail/snakebite-envenoming. Acessado em: 05 de junho de 2020. 
RESUMO EXPANDIDO: Estudo Original

TítUlo: Aspectos SOCIODEMOGRÁficos dos CASOS DE TUBERCULOSE NA BAHIA DE 2015 A 2019

Autor/coautores: Yuri Messias Lisboa, Raiana Rodrigues Xavier, Késia Carvalho da Silva, Lua Naya de Oliveira Souza e Meire Núbia Santos de Santana.

Instituição: Faculdade Santo Agostinho de Itabuna (FASA-Itabuna), Itabuna-Bahia.

Palavras-chave: Tuberculose, Perfil de Saúde, Doenças Negligenciadas.

\section{INTRODUÇÃO}

A tuberculose (TB) é uma doença infectocontagiosa e crônica que tem como principal agente etiológico o bacilo aeróbico Mycobacterium tuberculosis, também intitulado de bacilo de Kock (BK), uma bactéria aeróbica, ácido álcool resistente, fotossensível e sensível ao calor (LIMA SM DE A, et al., 2019).

A TB é um agravo de notificação compulsória, possui elevada taxa de mortalidade e permanece sendo considerada, pela Organização Mundial da Saúde (OMS), um problema de saúde pública mundial. Assim, o Brasil ocupa a $20^{\circ}$ posição quanto à carga da doença e a 19 posição quanto a coinfecção TB-HIV na lista de países prioritários para abordagem da tuberculose, no período de 2016 a 2020 (LIMA SM DE A, et al., 2019).

Em Minas Gerais, durante 2001 e 2016, ocorreram 73.837 casos de TB. Foi observada maior incidência entre homens de 20 e 39 anos, das raças branca e parda (OLIVA HNP, et al., 2018).

Com relação aos fatores de risco para doença, observa-se que essa está fortemente ligada a fatores socioeconômicos. Logo, torna-se imperativo conhecer o perfil das pessoas atingidas com o objetivo de conter o avanço desse agravo (DA SILVA K DE O, et al., 2020).

\section{OBJETIVO}

Analisar o perfil sociodemográfico e aspectos econômicos dos casos de tuberculose, notificados ao Sistema de Informação de Agravos de Notificação (SINAN) do estado da Bahia, durante os anos de 2015 a 2019.

\section{MÉTODO}

Trata-se de um estudo quantitativo, descritivo, com uso de dados secundários. Foram analisadas as variáveis: sexo, faixa etária, raça/cor, se o caso notificado era de profissional da saúde, se fazia parte da população privada de liberdade em unidade prisional e se era beneficiário de programa de tranferência de renda do governo federal.

Os dados foram coletados do SINAN em de julho de 2020. Para análise foi utilizado o programa Microsft Office Excel.

Por se tratar de um trabalho com uso de dados de uma base pública, de acesso universal com informações agregadas e sem possibilidade de identificação individual, não foi submetido ao Comitê de Ética em Pesquisa (CEP) conforme resolução de nº 510/16 do Conselho Nacional de Saúde.

\section{RESULTADOS}

Foram notificados, durante o período analisado (2015 a 2019), 30.375 casos de TB no estado da Bahia. Desses casos, houve uma maior concentração entre os homens $(65,9 \%)$, e com relação à raça/cor a população negra possui elevado número de casos $(89,7 \%)$. Já em relação à faixa etária, houve maior número de notificações em pessoas acima de 30 anos (73,8\%). Buscou-se, também, conhecer a quantidade de casos de TB entre profissionais de saúde e na população privada de liberdade, tendo em vista a possibilidade alta de exposição à doença. Observou-se que $1,3 \%$ dos casos ocorreram em profissionais da saúde e 4,8\% na população privada de liberdade. 
Em relação aos aspectos econômicos, tem-se que dos infectados, 2.566 pessoas são beneficiários de algum programa de transferência de renda do governo federal, correspondendo a $12,5 \%$ dos casos. Com relação a todas as variáveis, com exceção a variável sexo, houve um número considerável de dados ignorados.

Tabela 1 - Aspectos sociodemográficos dos casos de Tuberculose notificados no SINAN - Bahia, de 2015 a 2019, $\mathrm{n}=30375$.

\begin{tabular}{lll}
\hline Variável & $\mathbf{N}$ & $\%$ \\
\hline Sexo & & \\
$\quad$ Feminino & 10.352 & 34,1 \\
Masculino & 20.004 & 65,9 \\
Faixa etária & & \\
O a 14 anos & 785 & 2,6 \\
15 a 29 anos & 7.162 & 23,6 \\
$\quad 30$ anos ou mais & 22.427 & 73,8 \\
Raça & & \\
$\quad$ Branco & 2624 & 9,7 \\
$\quad$ Negro & 24.197 & 89,7 \\
$\quad$ Indígena & 143 & 0,5 \\
Profissional de saúde & & 1,3 \\
$\quad$ Sim & 336 & 98,7 \\
$\quad$ Não & 25.337 & 4,8 \\
População privada de liberdade & & 95,2 \\
Sim & 1.244 & 12,5 \\
$\quad$ Não & 24.810 & 87,5 \\
Beneficiário programa de distribuição de renda & & 2.566 \\
$\quad$ Sim & 17.952 & \\
Não & &
\end{tabular}

Fonte: LISBOA YM, et al., 2020. Dado extraído de SESAB/SUVISA/DIVEP/SINAN - Sistema de Informação de Agravos de Notificação, 2020.

\section{DISCUSSÃO}

Os altos índices da tuberculose no grupo de homens, negros e com mais de 30 anos justifica-se por fatores econômicos, culturais e sociais.

Esses são mais acometidos por maior exposição na vida social e pelo fato da menor procura dos serviços de saúde, assim, sendo mais propensos às infecções com o bacilo (OLIVA HNP, et al., 2018).

Ressalta-se também que os casos de tuberculose na população privada de liberdade despertam interesse visto que o presídio é um local favorável para a disseminação, devido às más condições sanitárias, além de aglomerações e pouca ventilação.

Nesse ínterim, é importante observar que uma pequena porcentagem das pessoas que tiveram tuberculose é beneficiária de programas de transferência de renda, é importante tendo em vista a relação entre fatores econômicos e a adesão ao tratamento da TB, configurando como um dos principais obstáculos encontrados para cura da doença (DA SILVA K DE O, et al., 2020).

\section{CONSIDERAÇÕES FINAIS}

A realização dessa pesquisa permitiu observar que a tuberculose acomete majoritariamente as populações masculina, negra e em idade economicamente ativa no estado da Bahia.

Dessa forma, é necessário analisar qual a população mais afetada para auxiliar na criação de estratégias de prevenção e promoção da saúde de forma a garantir maior controle da doença, além de novas pesquisas a fim de elucidar quais fatores tem levado esse grupo ao adoecimento; a importância dessa ação exacerbase devido a elevada taxa de incidência e de morbimortalidade da tuberculose no território. 


\section{REFERÊNCIAS}

1. DA SILVA K DE O, et al. Análise das metas de controle da tuberculose no Brasil: uma revisão narrativa. Revista Eletrônica Acervo Saúde, 2020; 12(5): e3063.

2. LIMA SM DE A, et al. Caracterização dos casos de tuberculose notificados em um município prioritário do Brasil, de 2011-2015. Revista Eletrônica Acervo Saúde, 2019; 11(13): e482.

3. OLIVA, HNP, et al. Estudo epidemiológico da tuberculose no estado de Minas Gerais. Revista Eletrônica Acervo Saúde, 2018; 18: e78.

4. BAHIA. Secretária de Saúde. Sistema de Informação de Agravos de Notificação. Salvador, BA: SESAB; 2020. Disponível em: http://www.saude.ba.gov.br/suvisa/vigilancia-epidemiologica/sistema-deinformacao-de-agravos-de-notificacao-sinan/. Acessado em: 10 de junho de 2020. 
RESUMO EXPANDIDO: Estudo Original

TÍTULO: ATIVIDADE ANTIMICROBIANA E ANTIFORMAÇÃO DE BIOFILME DE EXTRATO AQUOSO DAS FOLHAS DE CAMPOMANESIA DICHOTOMA (O.BERG) MATTOS EM GRAM-NEGATIVOS

Autor/coautores: Rafael Artur de Queiroz Cavalcanti de Sá, Tainara Fernandes Dantas, Amanda Virginia Barbosa, Maria Tereza dos Santos Correia, Bárbara de Azevedo Ramos.

Instituição: Universidade Federal de Pernambuco, UFPE, Recife-Pernambuco

Palavras-chave: Plantas medicinais, Klebsiella pneumoniae, Pseudomonas aeruginosa.

\section{INTRODUÇÃO}

Nos últimos anos, o índice de infecções causadas por microrganismos, principalmente bactérias, têm aumentado.

Além disso, muitas dessas infecções causadas por Gram-negativas estão diretamente relacionadas com a capacidade desses microrganismos possuirem resistência às drogras convencionais (Antibióticos), o que tem dificultado o tratamento dessas infecções (BREIJYEH Z, et al., 2020). Adicionalmente, esses microrganismos possuem a capacidade de expressar fatores de virulência, os quais estão associados a severidade das infecções, destacando-se a formação de biofilme, que é caracterizado por ser um aglomerado de bactérias embebidas em uma matriz exopolissacarídica (EPS) e fixas a uma superfície (biótica ou abiótica) (VERT M, et al., 2012).

Consequentemente, as buscas por alternatinativas que possam superar ou minimizar essa resistência, bem como a formação de biofilme, têm se intensificado.

Dentre essas alternativas, estudos com plantas têm ganhado destaque, pois as plantas têm ampla utilização no âmbito medicial para diversas enfermidades, sendo uma delas, as infecções bacterianas.

\section{OBJETIVO}

Avaliar o extrato aquoso das folhas da $C$. dichotoma sobre microrganismos Gram-negativos, visando a capacidade do extrato em agir como agente inibidor do crescimento, bem como agente inibidor da formação de biofilme dos mesmos.

\section{MÉTODO}

As folhas da C. dichotoma foram coletadas na Usina Coruripe - AL (1007'16.3"S 36 $\left.16^{\prime} 01.6^{\prime \prime} \mathrm{W}\right)$. O extrato aquoso foi obtido por banho de ultrassom e posteriormente liofilizado. As cepas de Escherichia coli, Klebsiella pneumoniae e Pseudomonas aeruginosa foram doadas pelo Departamento de Antibióticos da Universidade Federal de Pernambuco (UFPEDA) onde foi testado a capacidade de formação de biofilme das cepas em Caldo Triptona de Soja (TSB), Sigma-Aldrich ${ }^{\circledR}$.

Para a determinação da concentração mínima inibitória (CMI) foi utilizado o método de microdiluição em caldo seguindo as diretrizes do CLSI (2018) e para atividade antibiofilme foi utilizado o método de coloração por cristal violeta proposto por Trentin DDS, et al. (2011), onde as concentrações dos extratos para este método foram de 2,0 e 0,2 mg/mL.Para isso, os experimentos foram realizados em quadruplicatas.

\section{RESULTADOS}

Os dados obtidos no presente trabalho para a atividade de formação de biofilme revelaram que todas as cepas tiveram a capacidade de formar biofilme no meio TSB.

O extrato aquoso de $C$. dichotoma foi bactericida para a cepa Escherichia ecoli, atigindo $100 \%$ de inibição do crecimento na concentração de $0,0625 \mathrm{mg} / \mathrm{mL}$. Contudo, o extrato não obteve resultados significativos para K. pneumoniae e $P$. aeruginosa. 
Em relação a atividade antiformação de biofilme contra a cepa de $K$. pneumoniae, o extrato mostrou-se promissor, foi observado que o extrato inibiu em torno de $86,5 \%$ a $2,0 \mathrm{mg} / \mathrm{mL}$. Contudo, ao ser testado a $0,2 \mathrm{mg} / \mathrm{mL}$, o extrato possuiu um resultado bastate expressivo, havendo uma inibição em torno de $98 \%$.

Em relação à $P$. aeruginosa, o extrato inibiu em torno de $67,6 \%$ a $2,0 \mathrm{mg} / \mathrm{mL}$. No entano, em $0,2 \mathrm{mg} / \mathrm{mL}$ ocorreu estímulo da formação de biofilme. $O$ extrato não apresentou atividade antibiofilme contra $E$. coli nas concentrações testadas.

Tabela 1: Atividade antimicrobiana e antiformação de biofilme do extrato aquoso das folhasde $C$. dichotoma

\begin{tabular}{|c|c|c|c|c|c|c|c|}
\hline \multirow[b]{2}{*}{ Extrato } & \multirow{2}{*}{ Bactérias } & \multicolumn{2}{|l|}{ CMI } & \multicolumn{2}{|l|}{ CMB } & \multicolumn{2}{|c|}{ Antibiofilme (\%) } \\
\hline & & Extrato & $(\mathrm{mg} / \mathrm{mL})$ & Extrato & $(\mathrm{mg} / \mathrm{mL})$ & $2,0 \mathrm{mg} / \mathrm{mL}$ & $0,2 \mathrm{mg} / \mathrm{mL}$ \\
\hline \multirow{3}{*}{$\begin{array}{l}\text { C. } \\
\text { dichotoma }\end{array}$} & $\begin{array}{l}\text { K. } \\
\text { pneumoni } \\
a e\end{array}$ & - & - & - & - & $86,5 \pm 6,8$ & $98,3 \pm 3,6$ \\
\hline & $\begin{array}{l}P . \\
\text { aeruginos } \\
a\end{array}$ & - & - & - & - & $67,6 \pm 2,2$ & ec \\
\hline & E. coli & - & - & - & 0,06 & - & - \\
\hline
\end{tabular}

Legenda: CMI - concetração mínima inibitória, CMB - concetração mínima bactericida, ec - estimulação do biofilme.

Fonte: DE SÁ RAQC, 2020.

\section{DISCUSSÃO}

SÁ S, et al. (2018), testaram diferentes frações do extrato das folhas de outra espécie do gênero Campomanesia (C. adamantium (Cambess.) O. Berg.).

Onde, obteveram uma atividade antimicrobiana da fração aquosa do extrato de $C$. adamatium sobre a cepa de E. coli, porém, em uma concentração superior $(>1,0 \mathrm{mg} / \mathrm{mL})$ que a do extrato testado no presente estudo.

Com relação a isto, o extrato de $C$. dichotoma teve um resultado bastante significativo, pois foi bactericida numa concetração quatro vezes menor $(0,0625 \mathrm{mg} / \mathrm{mL})$.

O trabalho de Barbosa AV (2017), que está diretamente relacionado a espécie, revela atividade antimicrobiana da $C$. dichotoma sobre cepas de Staphylococcus aureus, utilizando o oléo essencial desta especie. Ademais, o estudo mostrou a ação do extrado de $C$. dichotoma na redução da formação de biofilme, visto que a formação do biofilme está diretamente relacionada com o aumento da dificuldade no tratamento das infecções bacterianas.

\section{CONSIDERAÇÕES FINAIS}

O extrato de $C$. dichotoma, mostrou ser uma execelente escolha para tratamento de infecções causadas por E. coli, pois apresentou uma atividade antimicrobiana bastante significativa, apresentando capacidade bactericida, além de apresentasar uma execlente atividade antiformação de biofilme sobre as cepas de $K$. pneumoniae e $P$. aeruginosa.

Interessantemente, o presente trabalho mostrou ser o primeiro a reportar a capacidade de inibição da formação de biofilme tanto para para C. dichotoma quato o seu gênero Campomanesia sobre as espécies de microrganismos gram-negativos. 


\section{REFERÊNCIAS}

1. BARBOSA AV. Caracterização química e atividadeantimicrobiana e antioxidante de óleosessenciais de plantas da Mata Atlântica. Attena.ufpe.br. Orientador: Marcia Vanusa da Silva. Dissertação (Mestre em Ciências biológicas) - Universidade Federal de Pernambuco, Recife, 2017; 91.

2. BREIJYEH Z, et al. Resistance of Gram-Negative Bacteria to Current Antibacterial Agents and Approaches to Resolve It. Molecules, 2020; 25(6), 1-23.

3. CLSI. Performance Standards for Antimicrobial Susceptibility Testing. Clinical and Laboratory Standards Institute. Supplement M100, Wayne, PA, 29th ed, 2018.

4. SÁ S, et al. Phytochemistry and antimicrobial activity of Campomanesia adamantium. RevistaBrasileira de Farmacognosia, 2018; 28, 303-311.

5. TRENTIN DDS, et al. Potential of medicinal plants from the Brazilian semi-arid region (Caatinga) against Staphylococcus epidermidis planktonic and biofilm lifestyles. Journal of Ethnopharmacology, 2011; 137(1), 327-335.

6. VERT M, et al. Terminology for biorelated polymers and applications (IUPAC Recommendations 2012). Pure and applied Chemistry, 2012; 84(2), 377-410. 
RESUMO EXPANDIDO: Estudo Original

TÍTULO: AVALIAÇÃO DA ATIVIDADE ANTILEISHMANIA DE NAFTOIMIDAZÓIS SINTÉTICOS DERIVADOS DO LAPACHOL

Autor/coautores: Victória Laysna dos Anjos Santos, Sabrina M. P. Carneiro, Valéria C. Sousa, Arlan Gonsalves de Assis, Clêonia Roberta Melo Araújo.

Instituição: Universidade Federal do Vale do São Francisco (UNIVASF), Petrolina-Pernambuco; Universidade Federal do Piauí (UFPI), Teresina-Piauí.

Financiamento: Fundação de Amparo à Ciência e Tecnologia do Estado de Pernambuco (FACEPE).

Palavras-chave: Leishmaniose, Naftoimidazóis, Lapachol.

\section{INTRODUÇÃO}

A leishmaniose é uma doença zoonótica e infecciosa causada por protozoários do gênero Leishmania. A sua manifestação clínica depende de fatores relacionados a espécie do protozoário, a distribuição geográfica e as características genéticas do hospedeiro. A leishmaniose é considerada uma doença negligenciada de ocorrência principalmente em países com clima tropical, como o Brasil, acometendo cerca de 350 milhões de pessoas/ano (EMAMI S, et al., 2017). O seu tratamento é realizado através do uso de antimoniatos e anfotericina $B$, medicamentos que apresentam limitações farmacocinéticas, toxicológicas e de resistência protozoária, resultando em tratamentos prejudiciais para o paciente (SHOKRI A, et al., 2018).

O lapachol é uma naftoquinona natural, produzida por plantas do gênero Tabebuia, com atividade antileishmania destacada, sendo um núcleo base atraente para o desenvolvimento de novos agentes leishmanicidas (ARAÚJO IAC, et al., 2019). Estruturas que contém o núcleo imidazol, também exibem atividade contra o parasita, devido a capacidade deste heterociclo de inibir a biossíntese de ergosterol, produzindo alternativas terapêuticas mais seletivas (SHOKRI A, et al., 2018). Dessa forma, o desenvolvimento de compostos capazes de combinar a atividade antiprotozoária do lapachol e do núcleo imidazol, torna-se atraente para o desenvolvimento de fármacos eficazes e seletivos para o tratamento da leishmaniose.

\section{OBJETIVO}

Avaliar a atividade leishmanicida e citotóxica, in vitro, de quatro análogos naftoimidazólicos derivados do lapachol, previamente planejados e sintetizados.

\section{MÉTODO}

Foram planejados e sintetizados quatro naftoimidazóis, empregando o lapachol como núcleo base e material de partida para inserção do núcleo imidazol. A atividade antileishmania desses derivados foi avaliada in vitro frente a formas promastigotas das espécies Leishmania amazonensis e Leishmania major. A

Concentração Inibitória média $\left(\mathrm{Cl}_{50}\right)$ foi determinada, empregando doze diluições seriadas, realizadas em duplicatas e utilizando Anfotericina $B(A n f B)$ como fármaco de referência. Para avaliação da atividade citotóxica empregou-se o ensaio de viabilidade celular pelo método do MTT frente a macrófagos RAW onde obteve-se a Concentração Citotóxica média $\left(\mathrm{CC}_{50}\right)$ de cada composto.

O Índice de Seletividade (IS) foi calculado através da razão entre a $\mathrm{CC}_{50}$ (macrófagos) e $\mathrm{Cl}_{50}$ (protozoários) exibida pelos compostos testados.

\section{RESULTADOS}

Com base na potencialidade terapêutica antileishmania apresentada pelo núcleo imidazol, assim como as atividades farmacológicas atribuídas ao lapachol, quatro naftoimidazóis foram estruturalmente planejados, sintetizados e avaliados como agentes leishmanicidas e citotóxicos (Tabela 1). 
Tabela 1 - Atividade antileishmania e citotóxica dos derivados naftoimidazólicos sintetizados.

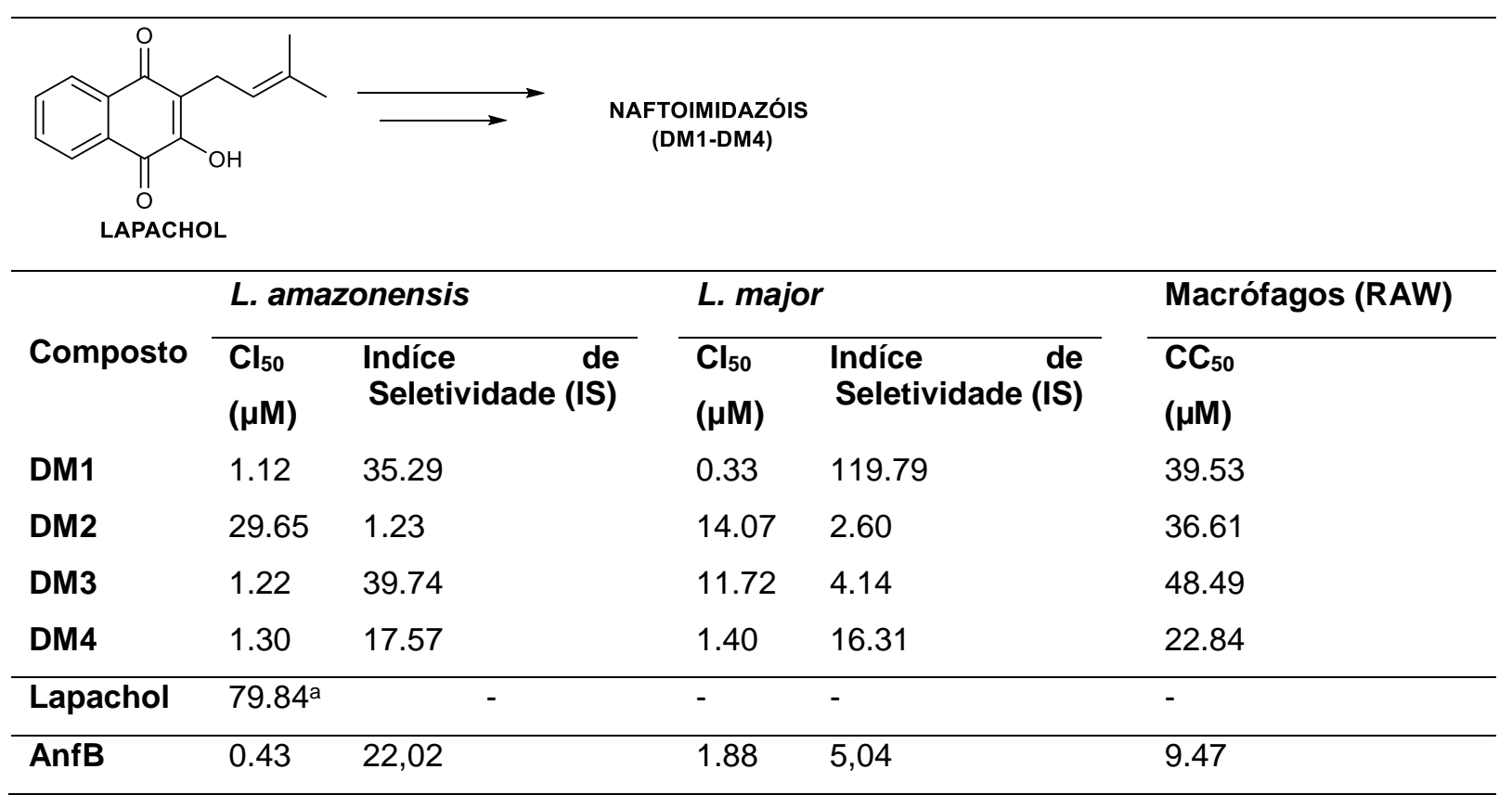

Fonte: SANTOS VLA, et al., 2020; a dado extraído de Araujo IAC, et al., 2019.

Os naftoimidazóis sintetizados apresentaram elevada atividade leishmanicida frente as duas espécies testadas, com $\mathrm{Cl}_{50}$ compreendidas entre 1.12-29.65 (L. amazonensis) e 0.33-14.07 $\mu \mathrm{M}$ ( $L$. major). Frente aos protozoários $L$. amazonensis, destaca-se a atividade antileishmania de DM1, DM3 e DM4, que exibiram $\mathrm{Cl}_{50}$ menor que $2.0 \mu \mathrm{M}$, enquanto que para $L$. major destacaram-se os naftoimidazóis DM1 $(0.33 \mu \mathrm{M})$ e DM4 (1.40 $\mu \mathrm{M})$, sendo estes mais eficazes que a $\operatorname{AnfB}(1.88 \mu \mathrm{M})$.

Ao analisar os IS dos compostos testados, verificou-se que DM1 (IS 35.29) e DM3 (IS 39.74) apresentaram maior IS que a AnfB para protozoários $L$. amazonensis, enquanto que para $L$. major, os derivados mais seletivos pelos protozoários foram os naftoimidazóis DM1 e DM4 com IS igual a 119.79 e 16.31, respectivamente. Em adição, destaca-se o elevado IS apresentado por DM1 frente aos protozoários $L$. major, superior aos demais derivados testados, assim como a AnfB (5.04).

\section{DISCUSSÃO}

Observou-se que os naftoimidazóis exibiram moderada e elevada atividade antileishmania, com destaque para o derivado DM1 que apresentou menor $\mathrm{Cl}_{50}$ para as duas espécies de leishmania testadas, sendo mais ativo que a AnfB frente a $L$. major. A inserção do heterociclo imidazol na estrutura do lapachol proporcionou um incremento da atividade leishmanicida, onde todos o naftoimidazóis sintetizados mostraram-se mais ativos que o lapachol ( $\mathrm{Cl}_{50}$ L. amazonensis-79.84 $\left.\mu \mathrm{M}\right)$, segundo os resultados obtidos por Araújo IAC, et al. (2019). Além da elevada atividade antileishmania, DM1 também exibiu elevados IS, 35.29 (L. amazonensis) e 119.79 ( $L$. major), sendo este último superior a AnfB em aproximadamente vinte e cinco vezes.

O aumento da seletividade observada para a maioria dos naftoimidazóis sintetizados pode ser associada ao mecanismo de ação leishmanicida do núcleo imidazol presente em suas estruturas, uma vez que apenas os protozoários são capazes de realizar a biossíntese do ergosterol (SHOKRI A, et al., 2018).

\section{CONSIDERAÇÕES FINAIS}

Os naftoimidazóis testados foram racionalmente planejados e sintetizados para exibirem atividade leishmanicida, fato comprovado após avaliação in vitro de suas atividades. Os naftoimidazóis sintetizados 
mostraram-se promissores agentes antileishmania frente a protozoários das duas linhagens testadas, com destaque para DM1, o derivado mais ativo e seletivo dentre os sintetizados.

Destaca-se ainda a elevada afinidade exibida por estes compostos pelos protozoários, sugerindo a obtenção de agentes potencialmente mais seguros quando comparado a AnfB. Dessa forma, os naftoimidazóis sintetizados mostram-se como promissores agentes antileishmania para o desenvolvimento de novos fármacos mais eficazes e seletivos para o tratamento da leishmaniose.

\section{REFERÊNCIAS}

1. ARAÚJO IAC, et al. Efficacy of lapachol on treatment of cutaneous and visceral leishmaniasis. Experimental Parasitology, 2019; 199: e67.

2. EMAMI S, et al. An overview of azoles targeting sterol $14 \alpha$-demethylase for antileishmanial therapy. European Journal of Medicinal Chemistry, 2017; 135: e241

3. SHOKRIA A, et al. Promising antileishmanial activity of novel imidazole antifungal drug luliconazole against Leishmania major: In vitro and in silico studies. Journal of Global Antimicrobial Resistance, 2018, 14: e260. 
RESUMO EXPANDIDO: Estudo Original

TíTULO: DIFERENÇAS NO PROCESSO DE EVOLUÇÃO DA COVID-19 EM COMUNIDADES

RIBEIRINHAS URBANAS

Autor/coautores: Maria Alice de Lira Borges, Ana Lúcia Bezerra Candeias.

Instituição: Universidade Federal de Pernambuco (UFPE), Recife- Pernambuco.

Financiamento: Fundação de Amparo a Ciência e Tecnologia de Pernambuco (FACEPE).

Palavras-chave: Recurso Hídrico, Pernambuco, Coronavírus.

\section{INTRODUÇÃO}

Para compreender e gerir a saúde dentro do ambiente urbano é necessário evidenciar que esse local é heterogêneo em aspectos sociais, econômicos, ambientais, históricos e culturais. Todos esses fatores interagem e influenciam entre si. Um bairro, por exemplo, pode ter aspectos socioeconômicos totalmente diferentes dos outros bairros circunvizinhos e isso, remete a importância de estudos cada vez mais detalhados e locais, para que seja compreendida não somente a dinâmica local mas, como ela influencia e é influenciada em uma dinâmica mais global (PARDO I, et al.,2020).

A pandemia da COVID-19 (Coranavirus disease) já contaminou mais de 12.507 .849 pessoas no mundo até a data 12/07/2020 (DATASUS,2020). O que traz esforços de estudos nas mais variadas áreas de conhecimento de forma interdisciplinar e esforços voltados para gerir a população de forma com que diminua a contaminação por esta doença.

Pensando a pandemia no contexto urbano, existem comunidades próximas a recursos hídricos, em que muitas vezes são ambientes de contaminação por doenças endêmicas e são marcadas por outros conflitos como as inundações frequentes, o que torna o ambiente ainda mais vulnerável para vivenciar a pandemia. Por isso, este trabalho analisa cinco comunidades riberinhas que margeiam o Rio Camaragibe, rio intermuncipal de Pernambuco para visualizar o impacto da COVID-19 nessas áreas.

\section{OBJETIVO}

Analisar as diferenças no processo de contaminação e evolução da doença COVID-19 nas comunidades riberinhas urbanas que margeiam o recurso hídrico intermunicipal Pernambucano: Rio Camaragibe.

\section{MÉTODO}

Os dados de contaminados e sua evolução (óbito e recuperados) estão sendo extraídos diariamente do Painel de Casos de Doença pelo Coronavírus 2019 (SEPLAG-PE), onde são filtradas as informações da área de estudo e são tabuladas no Excel para comparar dados. Esses dados são confrontados com análises bibliográficas históricas para caracterização da situação das condições socioambientais da população. Para o mapeamento estão sendo utilizadas imagens livres do Google que são processadas no Software livre Qgis. Ressalta-se que a metodologia é baseada em dados e arquivos livres, o que permite que outros pesquisadores possam replicar a metodologia de maneira acessível.

\section{RESULTADOS}

Os primeiros casos de contaminados por COVID-19 no entorno do Rio Camaragibe (PE) foram datados em 12/04/2020 com dois casos, até o dia 12/07/2020 a área obteve um aumento de 97,33\% casos confirmados pela doença. E dentre as cinco comunidades existentes nas margens deste recurso hídirco, notase que esta doença está dispersa da seguinte maneira ns bairros em que estão iseridas: $27 \%$ no Lotemento Nova Morada, 23\% na Caxangá, 21\% Inabi , 15\% Sítio São Brás e 14\% em Nazaré, onde também, fica possível identificar as áreas com maior quantidade de casos até o momento.

Quanto a letalidade presente nas comunidades foi identificados os seguintes percentuais: $15 \%$ Loteamento Nova Morada, 17,64\% Caxangá, 36,56\% Inabi, 36,36\% Sítio São Brás e 0\% Nazaré. E referente a recuperação da população os percentuais identificados foram: 34\% Loteamento Nova Morada, 31\% Caxangá, 
14\% Inabi, 12\% Sítio São Brás e 9\% Nazaré. E ainda existem 32\% do contaminados com a doença de forma ativa na área.

\section{DISCUSSÃO}

As comunidades do estudo possuem o Índice de Desenvolvimento Municipal (IDHM) abaixo de 0,6. Este indíce calculado por bairro inclui três categorias que são longevidade, renda e educação. Sendo possível identificar que essas áreas são vulneráveis socioeconomicamente. $\mathrm{E}$ em comparação com outras comunidades ribeirinhas urbanas dos municípios estudados, nota-se, que a forma como está ocorrendo a evolução dos casos de COVID está seguindo o mesmo parâmetro onde as taxas de letalidade são mais elevadas (adaptado MENDONÇA M, et al., 2020).

Além dessa questão, é importante relembrar que moradores desses locais vivenciam os efeitos da pandemia de COVID-19 e estão inseridos em um contexto de área inundável. As inundações ocorrem com frequencia, o que aumenta a possibilidade de contaminação por doenças endêmicas locais e a necessidade de deslocamento de pessoas para outros bairros. A limitação é a falta de informações censitárias atuais das populações para um maior aprofundamento no tocante social.

\section{CONSIDERAÇÕES FINAIS}

Conclui-se que o avanço da doença nas comunidades riberinhas do Rio Camargibe começou depois de 30 dias em relação aos municipios em que estão inseridas, mas, houve um crescimento acelerado de contaminados. Sendo possível notar que todos os bairros possuem a presença da doença e atualmente ainda existe uma parcela de $32 \%$ de casos ativos na área.

Quanto a comparação entre bairros é possível identificar que o bairro com maior quantidade de contaminados e recuperados é o Loteamento Nova Morada e com maior quantidade de óbitos é Inabi.

\section{REFERÊNCIAS}

1. BRASIL. Ministério da Saúde. Departamento de Informática do Sistema Único de Saúde (DATASUS) [online]. Brasília [s.d.]. Disponível em: http:// www.datasus.gov.br. Acessado em: 26 de julho de 2020.

2. PARDO I, et al. Spatial analysis and GIS in the study of COVID-19. A review. Science of The Total Environment, 2020; 140033.

3. MENDONÇA, M et al. A pandemia COVID-19 no Brasil: ecos e reflexos nas comunidades periféricas. APS EM REVISTA, 2020; (2)2, 162-168. 


\section{RESUMO EXPANDIDO: Estudo Original}

TÍTULO: EFEITO INIBITÓRIO DE EXTRATOS VEGETAIS (JATROPHA MOLLISSIMA) FRENTE A HEMORRAGIA LOCAL INDUZIDA PELA PEÇONHA DA JARARACA (BOTHROPS JARARACA)

Autor/coautores: Júlia Gabriela Ramos Passos, Jacyra Antunes dos Santos Gomes, Jacinthia Beatriz Xavier dos Santos, Juliana Félix da Silva, Matheus de Freitas Fernandes Pedrosa.

Instituição: Universidade Federal do Rio Grande do Norte (UFRN), Natal-Rio Grande do Norte.

Palavras-chave: Jatropha mollissima, Bothrops jararaca, Hemorragia.

\section{INTRODUÇÃO}

Acidentes ofídicos são considerados um grande problema de saúde pública em diversos países, principalmente em países tropicais e subtropicais (RIBEIRO AE, et al., 2019), sendo considerada uma doença tropical negligenciada na lista da Organização Mundial da Saúde (OMS). Neste contexto, o gênero Bothrops é responsável por cerca de $90 \%$ dos acidentes causados por serpentes.

Atualmente o principal tratamento disponível para envenenamentos ofídicos consiste no soro antiofídico, porém este possui algumas limitações, como: baixa eficácia frente aos efeitos locais, além da dificuldade de acesso (FÉLIX-SILVA J, et al., 2017). Plantas medicinais são utilizadas de forma milenar para diversos fins, inclusive para quadros de envenenamento por animais peçonhentos. Jatropha mollissima, conhecida popularmente como "pinhão bravo", é uma espécie vegetal endêmica em regiões semiáridas do nordeste brasileiro, e apresenta diversos usos na medicina popular, como: antiofídico, anti-inflamatório e cicatrizante. Alguns estudos da literatura demonstraram que J. mollissima possui atividade antioxidante, antimicrobiana, anti-helmíntica e antiofídica (GOMES JA, et al., 2016).

\section{OBJETIVO}

O objetivo deste estudo é avaliar e comparar o potencial antiofídico de três extratos hidroetanólicos obtidos a partir de diferentes partes da espécie vegetal $\mathrm{J}$. mollissima (folhas, raízes e caules) frente a hemorragia induzida pela peçonha de Bothrops jararaca.

\section{MÉTODO}

Os extratos das folhas, raízes e caules de J. mollissima foram preparados pelo método de maceração utilizando solução hidroetanólica (70\% etanol).

O potencial antiofídico destes extratos foi avaliado através da atividade hemorrágica in vivo, com quantificação de hemoglobina como marcardor da hemorragia (FÉLIX-SILVA J, et al., 2017). Camundongos swiss foram separados em grupos e injetados de forma intradérmica com a peçonha de $B$. jararaca, e logo após foram tratados por via oral com os diferentes extratos ou por via intraperitoneal com o soro antiofídico. Após três horas da indução da hemorragia, os animais foram sacrificados e seus halos hemorrágicos coletados.

O protocolo experimental foi aprovado pela Comissão de Ética no Uso de Animais da UFRN (CEUA-UFRN) (protocolo no. 053/2014).

\section{RESULTADOS}

O efeito hemorrágico provocado por envenamentos botrópicos altera a homeostase das paredes dos vasos sanguíneos e causa sua ruptura.

Sabe-se que a hemoglobina é uma proteína encontrada no interior dos eritrócitos do sangue. Neste sentido, a concentração de hemoglobina foi quantificada neste estudo como marcardor bioquímico a fim de analisar a hemorragia local induzida no dorso dos camundongos.

Como pode ser visto na Figura 1, ao avaliar a concentração de hemoglobina extraída dos halos hemorrágicos formados no dorso dos animais, foi observado que houve uma diminuição significativa do conteúdo de hemoglobina nos grupos tratados com os três extratos hidroetnólicos obtidos a partir de folhas 
$\left({ }^{* *} p<0,01\right)$, raízes $\left({ }^{* *} p<0,01\right)$ e caules $\left({ }^{* * *} p<0,001\right)$ da $J$. mollissima por via oral em comparação ao grupo que recebeu somente a injeção da peçonha de Bothrops jararaca (Bja), observando-se também que estes extratos obtiveram resultados semelhantes ao soro antibotrópico-crotálico $(S A B C)\left({ }^{* * *} p<0,001\right)$, utilizado como principal tratamento para envenenamentos.

Figura 1 - Efeito dos extratos hidroetanólicos de J. mollissima (modelo de pós-tratamento, via oral) no teor de hemoglobina no tecido de camundongos injetados de forma intradérmica com a peçonha de Bothrops jararaca, $\mathrm{n}=03$.

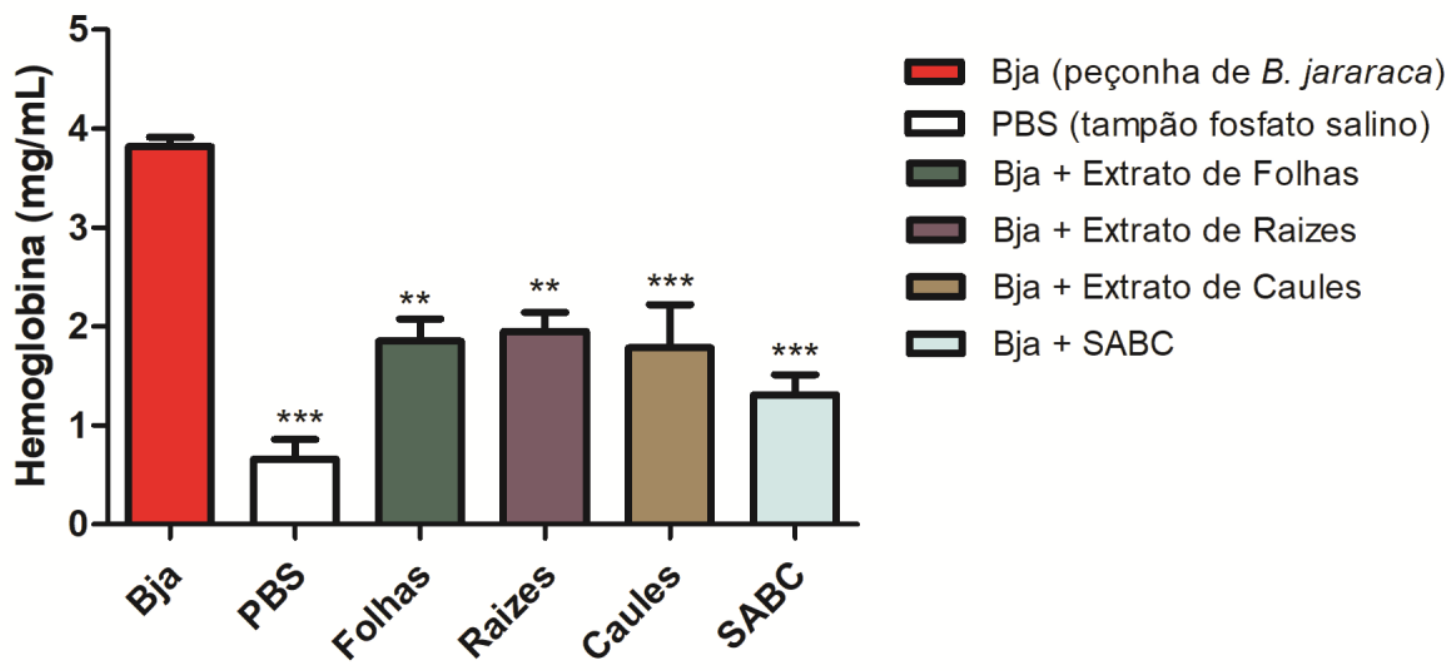

Legenda: Resultados experimentais. Dados apresentados como média \pm erro médio padrão. ${ }^{*} P<0,05$, ${ }^{* *} P<0,01$ e ${ }^{* * *} P<0,001$ quando comparados ao grupo controle (ANOVA, seguido de teste de Tukey).

Fonte: PASSOS JG, et al., 2020.

\section{DISCUSSÃO}

Metaproteinases dependentes de zinco são as principais enzimas presentes em peçonhas botrópicas responsáveis pela hemorragia gerada nestes acidentes. Plantas apresentam diversos mecanismos que neutralizam toxinas de peçonhas ofídicas, através de inativação enzimática, degradação proteolítica e quelação de metais.

Estudos anteriores demonstraram que o extrato aquoso das folhas da $J$. gossypiifolia inibiu a hemorragia in vivo pela B. erythromelas (FÉLIX-SILVA J, et al., 2017). Também foi evidenciado que o extrato aquoso das folhas da J. mollissima inibiu a hemorragia in vivo por B. erythromelas e B. jararaca (GOMES JA, et al., 2016).

O presente estudo obteve resultadores promissores quanto a três extratos hidroetanólicos de J. mollissima como anti-hemorrágicos frente ao envenenamento por $B$. jararaca. Serão necessários mais estudos para avaliar a atividade antiofídica destes extratos frente a outros danos locais provocados por serpentes botrópicas (atividades edematogênica, miotóxica, dermonecrótica), além da identificação/isolamento de compostos que seriam responsáveis por essas atividades.

\section{CONSIDERAÇÕES FINAIS}

Em conclusão, o estudo apresentado aponta que os extratos hidroetanólicos obtidos a partir de folhas, raízes e caules de $\mathrm{J}$. mollissima apresentam potencial anti-hemorrágico frente ao envenenamento por $B$. jararaca quando adminsitrados por via oral, visto através da diminuição significativa do teor de hemoglobina na hemorragia local de animais tratados com estes extratos, sendo semelhante ao soro antiofídico. Sugerese que estes extratos podem possuir um importante potencial antiofídico como alternativa complementar de fácil acesso e baixo custo ao tratamento dos efeitos locais induzidos pelo envenenamento botrópico. 


\section{REFERÊNCIAS}

1. FELIX-SILVA J, et al. Inhibition of local effects induced by Bothrops erythromelas snake venom: Assessment of the effectiveness of Brazilian polyvalent bothropic antivenom and aqueous leaf extract of Jatropha gossypiifolia. Toxicon, 2017; 125: e74.

2. GOMES J, et al. Aqueous Leaf Extract of Jatropha mollissima (Pohl) Bail Decreases Local Effects Induced by Bothropic Venom. BioMed Research International, 2016; 2016: e13.

3. RIBEIRO A, et al. Inhibitory effects of Morus nigra L. (Moraceae) against local paw edema and mechanical hypernociception induced by Bothrops jararacussu snake venom in mice. Biomedicine \& Pharmacotherapy, 2019; 111: e1046. 
RESUMO EXPANDIDO: Estudo Original

TíTULO: ESTUDO DE ESTABILIDADE QUÍMICA DAS MOLÉCULAS COM ATIVIDADE LEISHMANICIDA SB-83, SB-200 E SB-44

Autor/coautores: Fernanda da Costa Ferreira Guerra1, Amanda Rocha dos Santos ${ }^{1}$, Diego Torres Ramos Roberto de Lima ${ }^{1}$, Francisco Jaime Bezerra Mendonça Junior ${ }^{2}$ e Michel Leandro Campos ${ }^{1}$.

Instituição: 'Instituto de Ciências da Saúde - Universidade Federal de Mato Grosso (UFMT), Sinop-Mato Grosso do Sul; '2Laboratório de Síntese e Vetorização de Moléculas, Universidade Estadual da Paraíba (UEPB), João Pessoa-Paraíba.

Palavras-chave: Estabilidade, Leishmaniose, Farmacocinética.

\section{INTRODUÇÃO}

A leishmaniose é uma doença causada por diversas espécies do gênero Leishmania, considerada, atualmente, uma doença negligenciada no Brasil.

O tratamento de primeira linha para tal patologia é constituído pelos antimoniais pentavalentes como o Glucantime $\AA$, classe com efeitos adversos importantes como pancreatite, efeitos gastrintestinais significativos e artralgia (CAETANO DCDS, 2016).

Como segunda linha de medicamentos tem-se a Anfotericina $B$, fármaco utilizado, principalmente, em casos refratários e resistentes com efeitos adversos importantes como nefrotoxicidade, alterações cardíacas e anorexia (CAETANO DCDS, 2016).

Tal contexto levou pesquisadores a busca de novas moléculas com ação leishmanicida e mais segurança, de modo que os derivados do tiofeno, em espacial o grupo SB-83, SB-44 e SB-200, obtiveram resultados muito positivos (RODRIGUES KADF, et al., 2015).

Nesse sentido, mediante a inexistência de estudos sobre a disposição in vivo dessas moléculas e sendo a estabilidade em diferentes $\mathrm{pHs}$ uma das etapas iniciais para o estudo de um novo fármaco, o presente estudo visa entender e avaliar essa propriedade do SB-83, SB-44 e SB-200; cuja farmacodinâmica mostrouse promissora.

\section{OBJETIVO}

Avaliar a estabilidade química in vitro nos pHs 1,2 e 7,4 das moléculas SB-83, SB-200, SB-44, candidatas à fármaco com atividade leishmanicida.

\section{MÉTODO}

As moléculas foram obtidas pelo Laboratório de Síntese e Vetorização de Moléculas (LSVM) da Universidade Estadual da Paraíba (UEPB).

O ensaio de estabilidade foi realizado em pH 1,2 (tampão Clark-Lubs) e em pH 7,4 (tampão fosfato salino). As soluções foram adicionadas de SB-44, SB-83 e SB-200 para concentração de $1500 \mathrm{ng} / \mathrm{mL}$ a partir de uma intermediária em acetonitrila a $150 \mu \mathrm{g} / \mathrm{mL}$. Alíquotas de $50 \mu \mathrm{L}$, da mistura, foram coletadas nos tempos $0,0,5$, 1, 2, 4, 8, 12 e 24 horas e analisadas.

As análises foram execultadas por cromatografia líquida de ultra eficiência acoplada a espectrometria de massas de alta resolução.

\section{RESULTADOS}

O ensaio de estabilidade realizado em pH 1,2 não permitiu a elaboração de uma curva de decaimento, visto que, no primeiro tempo de coleta analisado, a concentração já se encontrava abaixo do limite de quantificação.

Testes também foram realizados em tempos mais curtos que os pré-estabelecidos no planejamento, e mesmo com apenas 5 minutos de exposição ao ambiente ácido, não foi possível quantificar as moléculas. $O$ 
ensaio de estabilidade realizado em $\mathrm{pH} 7,4$ sob agitação e controle de temperatura a $37^{\circ} \mathrm{C}$ permitiu a elaboração de uma curva de decaimento (Figura 1).

Como pode ser observado na Figura 1, apenas em 12 horas alguns dos compostos alcançaram uma degradação de 25\%. Após 24 horas, a degradação observada foi de $45 \pm 6,1,41 \pm 7,6$ e $45 \pm 7,3 \%$ para SB44, SB-83 e SB-200, respectivamente. Esse resultado indica que após absorção, em fluídos biológicos, o fator $\mathrm{pH}$, isoladamente, não deve ser o responsável se observada uma degradação elevada.

Figura 1 - Estabilidade dos candidatos a fármaco em tampão PBS pH 7,4 a 37 ․ C. Média $(\mathrm{n}=3) \pm$ desvio padrão.

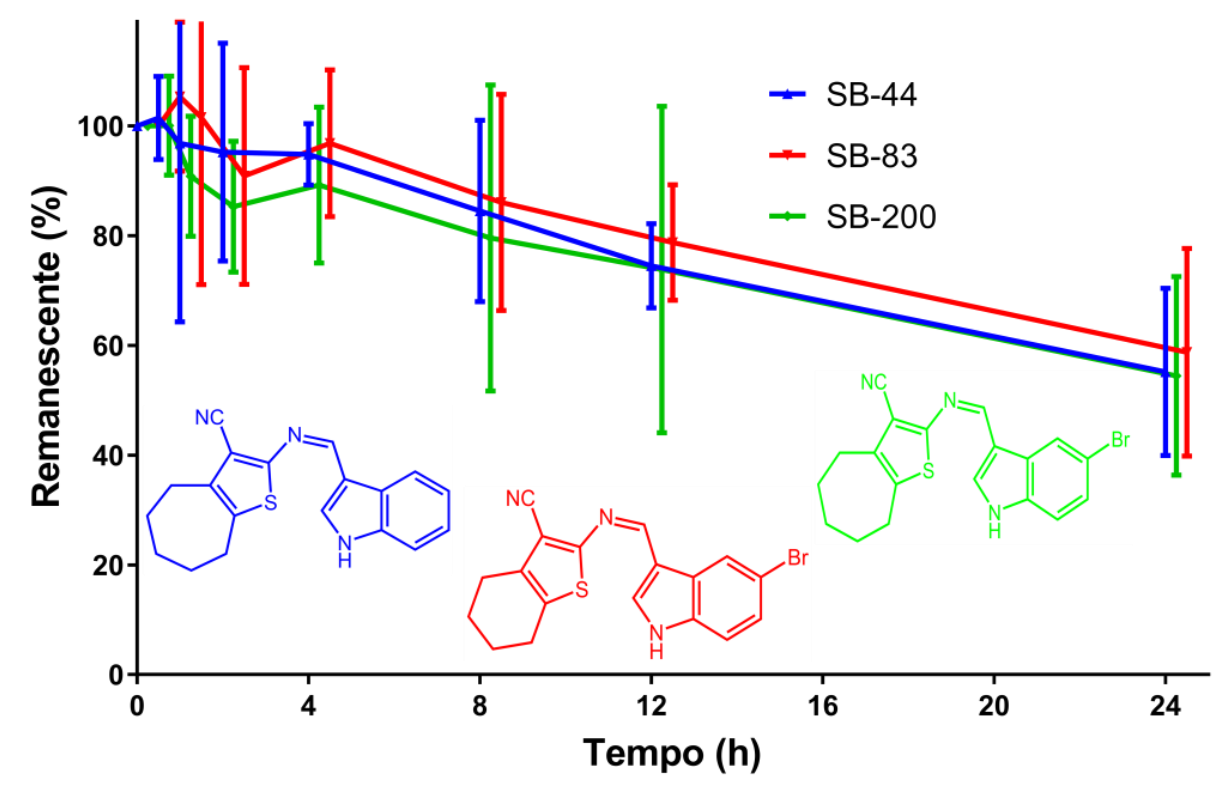

Fonte: GUERRA FCF, et al., 2020.

\section{DISCUSSÃO}

No ensaio de estabilidade executado em pH 1,2 havia expectativa de uma alta susceptibilidade da ligação imina ao meio com alta disponibilidade de prótons e água. Assim, a observação de instabilidade em condição ácida não foi surpreendente.

Enquanto essa instabilidade é um fator a se considerar devido ao ambiente estomacal da absorção oral, é importante ressaltar que o composto já mostrou atividade por esta via. Em pH 7,4 observa-se similaridade entre os decaimentos das moléculas SB-83, SB-200 e SB-44.

Esse comportamento em pH alcalino e em pH ácido condiz com o observado para iminas. (SEDLÁK M, et al., 2007) relatou estabilidade da ligação imina entre a anfotericina e um carreador polietilenoglicol em $\mathrm{pH}$ alcalino, com perda de apenas $5 \%$ em $24 \mathrm{~h}$.

Por outro lado, em pH 5,5 houve rápida liberação da anfotericina livre por rompimento da ligação imina, com meia-vida menor que 5 minutos para todos os derivados testados.

\section{CONSIDERAÇÕES FINAIS}

Pelo estudo de estabilidade em tampão dos compostos SB-44, SB-83 e SB-200 conclui-se que todos são altamente sensíveis ao pH ácido. Assim, para garantir máxima administração oral, modificações estruturais ou farmacotécnicas poderão ser necessárias. 
Por outro lado, em pH fisiológico de 7,4 foi possível elaborar uma curva de decaimento em que foi observado resultados similares entre as moléculas com estabilidade suficiente para continuidade de estudos. Essas informações são fundamentais para iniciar os estudos de farmacocinética dessas novas moléculas promissoras com ação leishmanicida, que a longo prazo podem tornar-se importantes opçoes terapêuticas.

\section{REFERÊNCIAS}

1. CAETANO DCDS. Prevalência e efeitos adversos no tratamento de pacientes com leishmaniose no ambulatório do hospital de referência em Cuiabá-MT. 2016. Dissertação (Mestrado em Farmácia) Universidade Anhanguera de São Paulo, São Paulo.

2. RODRIGUES KADF, et al. 2-Amino-thiophene derivatives present antileishmanial activity mediated by apoptosis and immunomodulation in vitro. European Journal of Medicinal Chemistry, 2015; 106, pp.1-14

3. SEDLÁK M, et al. Synthesis of pH-sensitive amphotericin B-poly (ethylene glycol) conjugates and study of their controlled release in vitro. Bioorganic \& Medicinal Chemistry, 2007. 15(12): p. 4069-4076. 


\section{RESUMO EXPANDIDO: ESTUDO ORIGINAL}

TítULO: PERFIL EPIDEMIOLÓGICO DA COINFECÇÃO DE LV-HIV NO BRASIL, 2010-2018

Autor/coautores: Ludmila Sandy Alves Moura, Luisa Bagette Rocha, Talita Gabriele de Queiroz Plácido, Thiago Felipe de Melo Dias, Ayla Maritcha Alves Silva Gomes.

Instituição: Centro Universitário Maurício de Nassau (UNINASSAU), Recife-Pernambuco

Palavras-chave: Leishmaniose Visceral, Infecções por HIV, Coinfecção.

\section{INTRODUÇÃO}

A Leishmaniose Visceral (LV) é uma doença tropical negligenciada. Com mais de 3.000 novos casos por ano, o Brasil tem destaque de caráter mundial pela alta incidência. Nas áreas urbanas, números aumentam, o que traz uma série de implicações e valor epidemiológico (HENN GAL, et al., 2018).

Com o intuito de conter o avanço da leishmaniose visceral e reduzir morbimortalidade por ela causada, o Ministério da Saúde criou o Programa de Vigilância e Controle da Leishmaniose Visceral (PVCLV) com medidas baseadas no diagnóstico e tratamento precoces, redução da população de vetores, eliminação de reservatórios e atividades de educação em saúde.

Nesse contexto, conhecer os fatores associados ao processo de doença, em especial a sua coinfecção com o vírus da imunodeficiência humana (HIV), é fundamental para o planejamento de políticas que visem diminuir a incidência da leishmaniose visceral. Sendo um agravo de notificação compulsória registrada pelo Sistema de Informação de Agravos e Notificação (SINAN), é possível a identificação do panorama da LV e planejamento de estratégias de controle.

\section{OBJETIVO}

Descrever epidemiologicamente os casos notificados de Leishmaniose Visceral sendo coinfectados com o vírus HIV no Brasil durante o período de 2010 a 2018, segundo o SINAN.

\section{MÉTODOS}

Estudo descritivo de prevalência de todos os casos de coinfecção LV-HIV diagnosticados e notificados em território brasileiro no período de 2010 a 2018. Foram utilizados como fonte de dados epidemiológicos o banco de dados do SINAN do Departamento de Informática do Sistema Único de Saúde (DATASUS).

Foram incluídas as variáveis: prevalência por Unidade Federativa de notificação, sexo, faixa etária, raça, escolaridade, critério confirmatório, evolução, tipo de entrada, zona de residência e diagnóstico. Os dados coletados foram tabulados através de uma planilha eletrônica (programa Excel versão 2010).

Por utilizar dados de domínio público, esta pesquisa é dispensada da aprovação por um Comitê de Ética em Pesquisa (CEP), conforme a resolução do Conselho Nacional de Saúde (CNS) no 466/12.

\section{RESULTADOS}

No período do estudo, no Brasil foram notificados 33.605 casos de leishmaniose visceral, sendo que $10,96 \%$ (2.891) foram de coinfectados com HIV. Ao verificar as características do infectados, a coinfecção é mais frequente nos homens ( $78,3 \%$ dos casos) e na faixa etária dos 20 a 39 anos (48,49\%). Cerca de $85,5 \%$ dos casos concentram-se em área urbana e $55,44 \%$ deles são dos estados de Minas Gerais (16,43\%), Ceará (14,04\%), Piauí (12,59\%) e Maranhão (12,38\%).

Quanto à raça, pardos são 4,83 mais prevalentes que brancas e 7,77 mais que pretas. Quanto à escolaridade, $32,84 \%$ apresentam o ensino fundamental incompleto e apenas $7,7 \%$ completou o ensino médio. 
Para confirmação diagnóstica, o método mais utilizado foi o laboratorial $(89,34 \%)$ e, destes, o diagnóstico parasitológico foi o mais prevalente, sendo realizado em $62,02 \%$ dos casos, com positividade em $86,16 \%$.

A imunofluorescência indireta foi realizada em $33,58 \%$ deles, positivando em $73,01 \%$ dos indivíduos. $77,2 \%$ foram casos novos, enquanto $20,8 \%$ destas foram recidivas. A taxa de cura da coinfecção é $66 \%$ e o abandono por pessoas com HIV foi de $1,45 \%$.

\section{DISCUSSÃO}

A expansão territorial da LV associada à infecção pelo HIV, citada pela literatura, também foi evidenciada através desta análise, na qual a área urbana concentrou $85,5 \%$ dos casos, fator importante já que a LV é considerada uma zoonose de perfil rural ou periurbano (LUZ JGG, et al., 2018).

O sexo masculino obteve destaque pela elevada frequência, tanto nos casos isolados de LV como de coinfecção HIV-TB. A letalidade por LV é mais elevada comparando com indivíduos sem infecção pelo HIV, no entanto a morte por outras causas é cerca de 5 vezes maior em pacientes vivendo com HIV. Também, é importante ressaltar que na variável escolaridade, o campo ignorado/branco representou cerca de $37 \%$ dos dados analisados, o que denota falha na notificação sociodemográfica do agravo.

\section{CONSIDERAÇÕES FINAIS}

Apesar dos esforços para ser contida, a Leishmaniose Visceral permanece incidente na atualidade. Além disso, humanos coinfectados por vírus da imunodeficiência (HIV) merecem atenção como um fator associado a um aumento de abandono do tratamento, recidiva e letalidade da LV. Fundamental para controlar esse agravo, é compreender os contextos social, demográfico, político e econômico, associados ao processo de doença para, assim, planejar e executar políticas eficientes que visem diminuir sua incidência.

\section{REFERÊNCIAS}

1. HENN GAL, et al. Is Visceral Leishmaniasis the same in HIV-coinfected adults?. Brazilian Journal of Infectious Diseases, 2018; 22: 92-98.

2. LUZ JGG, et al. Visceral leishmaniasis in a Brazilian endemic area: an overview of occurrence, HIV coinfection and lethality. Revista do Instituto de Medicina Tropical de São Paulo, 2018; 60: e12.

3. SILVA RV, et al. Leishmaniose Visceral Crónica em Paciente com Infeção Avançada pelo Vírus da Imunodeficiência Humana. Medicina Interna, 2017; 24: 40-41. 


\section{RESUMO EXPANDIDO: Estudo Original}

TÍTULO: IDENTIFICAÇÃO DE STAPHYLOCOCCUS AUREUS EM GOMA DE MANDIOCA COMERCIALIZADA EM FEIRAS LIVRES EM UM MUNICÍPIO LOCALIZADO NO ESTADO DO PIAUÍ, BRASIL Autor/coautores: Rute Emanuela da Rocha; Juliana Barros Bezerra; Emanuel Victor Cordeiro da Costa Silva; Vanessa Maria Matias Rocha; Thially Braga Gonçalves.

Instituição: Universidade Federal do Piauí (UFPI), Campus Senador Helvídio Nunes de Barros (CSHNB), Picos-Piauí.

Palavras-chave: Staphylococcus aureus, Goma de mandioca, Contaminação de alimentos.

\section{INTRODUÇÃO}

Staphylococcus aureus são bactérias esféricas, pertencentes ao grupo dos cocos gram-positivos, coagulase e catalse positiva, com alto poder de virulência e resistência, sendo capaz de causar enfermidades, pois são microrganismos frequentemente associados a surtos de doenças transmitidas por alimentos, pela sua alta capacidade de produzir e excretar enterotoxinas além de ser geralmente encontados na pele e nas cavidades nasais de indivíduos sadios como os manipuladores de alimentos (SOUSA LVNF, et al., 2020).

A mandioca (Manihot esculenta Crantz) é utilizada em grande escala no Brasil, em especial nas regiões Norte e Nordeste, derivando subprodutos, onde, um deles, a goma, é obtida através de processo de decantação (estando crua, é descascada, ralada e misturada à água).

A goma é o principal ingrediente da tapioca, prato bastante consumido pela população nordestina, e que, por advir, geralmente, de ambientes com poucos cuidados higiêncos durante sua cadeia produtiva (já que a mandioca é cultivada por muitas famílias em pequenas propriedades de forma rústica e artesanal), bem como por possuir alta umidade, torna-se propício para o crescimento microbiano (SHINOHARA NKS, et al., 2018).

\section{OBJETIVO}

Realizar investigação microbiológica, especificamente de bactérias da espécie Sthapyloccus aureus, em amostras de goma de mandioca comercializadas em feiras livres em um municipio localizado no estado do Piauí, Brasil.

\section{MÉTODO}

Coletou-se 12 amostras de goma de mandioca obtidas em feiras livres em um municipio localizado no estado do Piauí, Brasil, onde estas foram acondicionadas em caixas isotérmicas para análise microbiológica. Preparou-se suspensões com $25 \mathrm{~g}$ de cada amostra juntamente a $225 \mathrm{~mL}$ de solução salina peptonada a $0.1 \%$, e estas foram incubadas a $37^{\circ} \mathrm{C}$ por 24 horas. Feito isto, estas foram semeadas em Placas de Petri contendo Ágar Manitol e levadas à estufa a $37^{\circ} \mathrm{C}$ por 48 horas.

Em seguida, colônias com carecteristicas macroscópicas e de reação ao meio de cultivo típicas foram inoculadas em tubos de ensaio contendo Caldo $\mathrm{BHI}$ e incubadas a $37^{\circ} \mathrm{C}$ por 24 horas, onde, decorrido este tempo, realizaram-se as seguintes provas: Coloração de Gram, Prova da catalase e Prova da coagulase.

\section{RESULTADOS}

Após realização da metodologia descrita anteriormente, foram tabulados os resultados obtidos, onde constatou-se a presença de Staphylococcus aureus em 11 das 12 amostras pesquisadas, perfazendo um total de $91,6 \%$ de amostras positivas para este microorganismo. Tal resultado gerou preocupação, levandose em consideração que é um produto amplamente consumido pela população.

Observou-se que a maioria dos vendedores das feiras que comercializavam as gomas de mandioca utilizadas para amostragem, não possuíam equipamentos adequados para higiene e manipulação de alimentos (como uso de luvas, toucas ou máscara, bem como a ausência de refrigeradores para controle da temperatura específica destes alimentos, além de não possuírem rótulo ou dados de fabricação e validade) facilitando a contaminação dos mesmos. 
A imagem abaixo (Figura 1) representa os resultados obtidos nas etapas de identificação de $S$. aureus nas amostras pesquisadas, a saber: Observação de colônias típicas (colônias brancas e rodeadas de uma zona amarela), microscopia após Coloração de Gram (cocos Gram positivos), prova da catalase em lâmina (formação imediata de bolhas) e prova da coagulase (formação de coágulo).

Figura 1 - Etapas de identificação de Staphylococccus aureus em amostras de goma de mandioca comercializdas em feiras livres no município de Picos/PI.
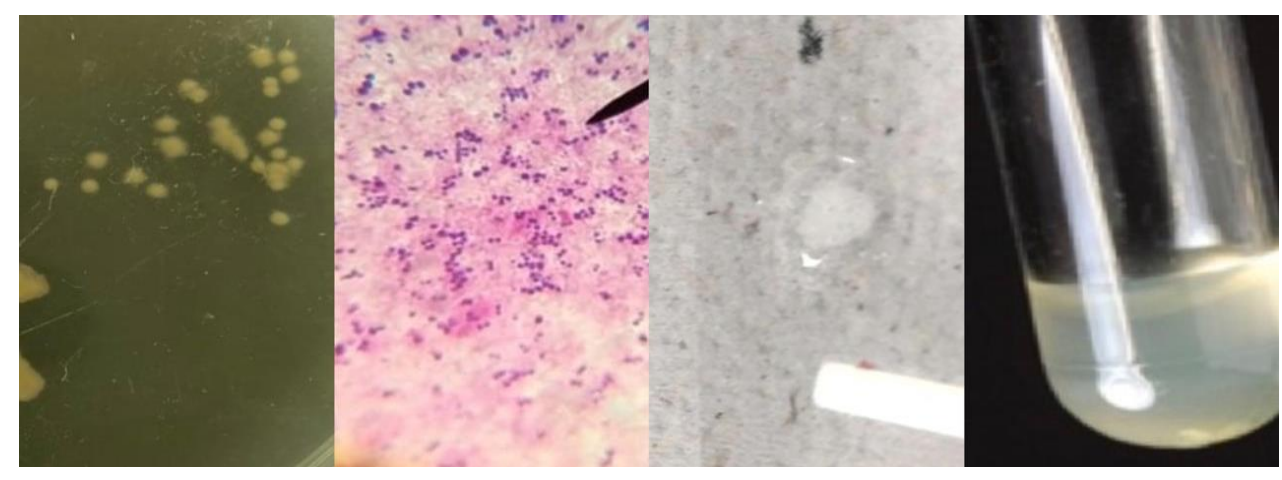

Fonte: ROCHA RE, et al., 2020.

\section{DISCUSSÃO}

O alto número de amostras contaminadas pode ser explicado por diversos fatores que envolvem toda sua cadeia produtiva até o momento da comercialização das mesmas. MENDES TIL, et al. (2019), associa essa contaminação por $S$. aureus a promoção do aumento de casos de intoxicação alimentar pelas toxinas formadas nos alimentos em decorrência da presença deste patógeno.

O manipulador é fundamental no que diz respeito à segurança dos alimentos, já que, em contato com os mesmos, da origem até o momento da comercialização, pode se tornar um transmissor viável de agentes patogênicos de doenças alimentares, quando falhas e erros são cometidos.

Assim sendo, o ser humano também possui uma alta capacidade para veicular patógenos de pessoa a pessoa, com graves riscos à saúde (MEDEIROS MGGA, et al., 2017).

\section{CONSIDERAÇÕES FINAIS}

Observou-se que a maioria das amostras pesquisadas apresentaram colônias de $S$. aureus, o que é preocupante, já que sua comercialização é feita em larga escala, portanto há uma alta probabilidade de intoxicação alimentar de consumidores das mesmas. Faz-se necessário além de uma fiscalização mais intensa por parte dos órgãos responsáveis, atenção por parte dos manipuladores e dos consumidores, visando a diminuição de casos de contaminação.

Estudos posteriores serão realizados a fim de identificar se outros alimentos comercializados nessas feiras livres apresentam contaminação por $S$. aureus ou se outros microrganismos patogênicos também são encontrados na goma de tapioca comercializada nessa feira.

\section{REFERÊNCIAS}

1. MEDEIROS MGGA, et al. Percepção sobre a higiene dos manipuladores de alimentos e perfil microbiológico em restaurante universitário. Ciência \& Saúde Coletiva, 2017; 22(2): 383-392.

2. MENDES TIL, et al. Condições higiênicas e sanitárias de unidades de alimentação e nutrição de escolas em tempo integral. Revista Eletrônica Acervo Saúde, 2019; 31: e1150.

3. SHINOHARA NKS, et al. Análise microbiológica em goma de mandioca industrializada. Journal of Environmental Analysis and Progress, 2018; 3(2): 226-231.

4. SOUSA LVNF, et al. Prevalencia de Staphylococcus aureus islado en manos de profesionales de la salud en un hospital del estado de Minas Gerais, Brasil (2018). Revista Eletrônica Acervo Saúde, 2020; 12: e2464. 
RESUMO EXPANDIDO: Estudo Original

Título: Leishmaniose Tegumentar Americana em um municíPIO do LeSte de Minas

GERAIS, NO PERÍODO DE 2008 A 2017

Autor/coautores: Débora de Souza Pazini, Gustavo Henrique Coelho de Pinho, Julia Fernandes Parenti de Almeida, Waneska Alexandra Alves, Alexandra Paiva Araújo Vieira.

Instituição: Universidade Federal de Juiz de Fora - Campus Avançado Governador Valadares (UFJF-GV), Governador Valadares - MG.

Palavras-chave: Leishmaniose Tegumentar Americana, Epidemiologia, Estudo descritivo.

\section{INTRODUÇÃO}

A leishmaniose tegumentar americana (LTA) é uma doença infectoparasitária de caráter crônico, causada por protozoários do gênero Leishmania (RIBEIRO MD, et al., 2018). Apresenta um complexo ciclo epidemiológico e acomete pele e mucosas, com importante espectro clínico (RIBEIRO MD, et al., 2018).

Sua transmissão é vetorial e ocorre durante o repasto sanguíneo de várias espécies de flebotomíneos fêmeas infectadas (VASCONCELOS JM, et al., 2018). O diagnóstico laboratorial é feito pelo encontro do parasito através do exame parasitológico ou de alterações teciduais pelo exame histopatológico, podendo ser complementado por testes imunológicos como a Intradermorreação de Montenegro (IDRM) (VASCONCELOS $\mathrm{JM}$, et al., 2018). O tratamento é feito preferencialmente pelo antimonial pentavalente, que pode causar graves efeitos adversos, especialmente em pacientes acima de 50 anos, exigindo rigoroso acompanhamento clínico e laboratorial (VASCONCELOS JM, et al., 2018).

A LTA é considerada uma antropozoonose negligenciada, representando um importante problema de saúde pública (VASCONCELOS JM, et al., 2018). Nesse contexto, um município no Leste de Minas Gerais se destaca como área endêmica, justificando esforços contínuos para a compreensão da doença, bem como para a sua prevenção e para o seu adequado manejo clínico (TANURE A, et al., 2015).

\section{OBJETIVO}

Estudar todos os casos confirmados e notificados de LTA residentes em um município do leste mineiro no período de 2008 a 2017, caracterizando-os de acordo com variáveis sociodemográficas, clínicas e epidemiológicas.

\section{MÉTODO}

Sendo esta a primeira etapa da pesquisa, foram utilizados dados secundários retirados do Sistema de Informação de Agravos de Notificação (SINAN), do Ministério da Saúde, sendo selecionados os casos confirmados, notificados e residentes em um município endêmico do leste de Minas Gerais, no período de 2008 a 2017.

As variáveis utilizadas foram: faixa etária, raça, sexo, forma clínica, coinfecção com HIV, critério de confirmação, testes diagnósticos, tratamento e evolução do caso. Para as análises foi utilizado o software Epilnfo versão 7.2 .

O projeto foi aprovado pelo Comitê de Ética em Pesquisa Humana (Certificado de Apresentação para Apreciação Ética: 89528118.5.0000.5147).

\section{RESULTADOS}

De acordo com os resultados obtidos no SINAN durante a primeira etapa da pesquisa, ocorreram no período de estudo 152 casos, a maioria em indivíduos a partir de 31 anos $(65,12 \%)$, brancos $(41,45 \%)$ e pardos $(40,79 \%)$. Tanto mulheres (46,05\%) quanto homens $(53,95 \%)$ foram afetados. A forma cutânea (FC) foi a mais prevalente, com $86,18 \%$ dos casos. 
De todos os casos, $97,37 \%$ foram confirmados laboratorialmente. Nos pacientes que realizaram os testes, observou-se um índice positivo de $83,81 \%$ na Intradermorreação de Montenegro, $94,95 \%$ no exame histopatológico e 46,38\% no exame parasitológico direto.

Em relação a coinfecção com HIV, 82,24\% das notificações foram preenchidas como ignorados. Casos em indivíduos acima de 51 anos corresponderam a 26,97\%, sendo que dois deles evoluíram para óbito e utilizaram o antimonial pentavalente. Esse medicamento foi utilizado como tratamento de escolha em $94,24 \%$ dos pacientes.

Houve $79,61 \%$ de cura e $10,53 \%$ dos pacientes abandonaram o tratamento. Observou-se que $92,10 \%$ dos casos ocorreram na zona urbana. Notou-se uma diminuição do número de casos ao longo dos anos, $63,15 \%$ no primeiro triênio e $12,5 \%$ no último (Gráfico 1).

Gráfico 1 - Casos confirmados de LTA em um município do Leste de Minas por ano, no período de 2008 a 2017.

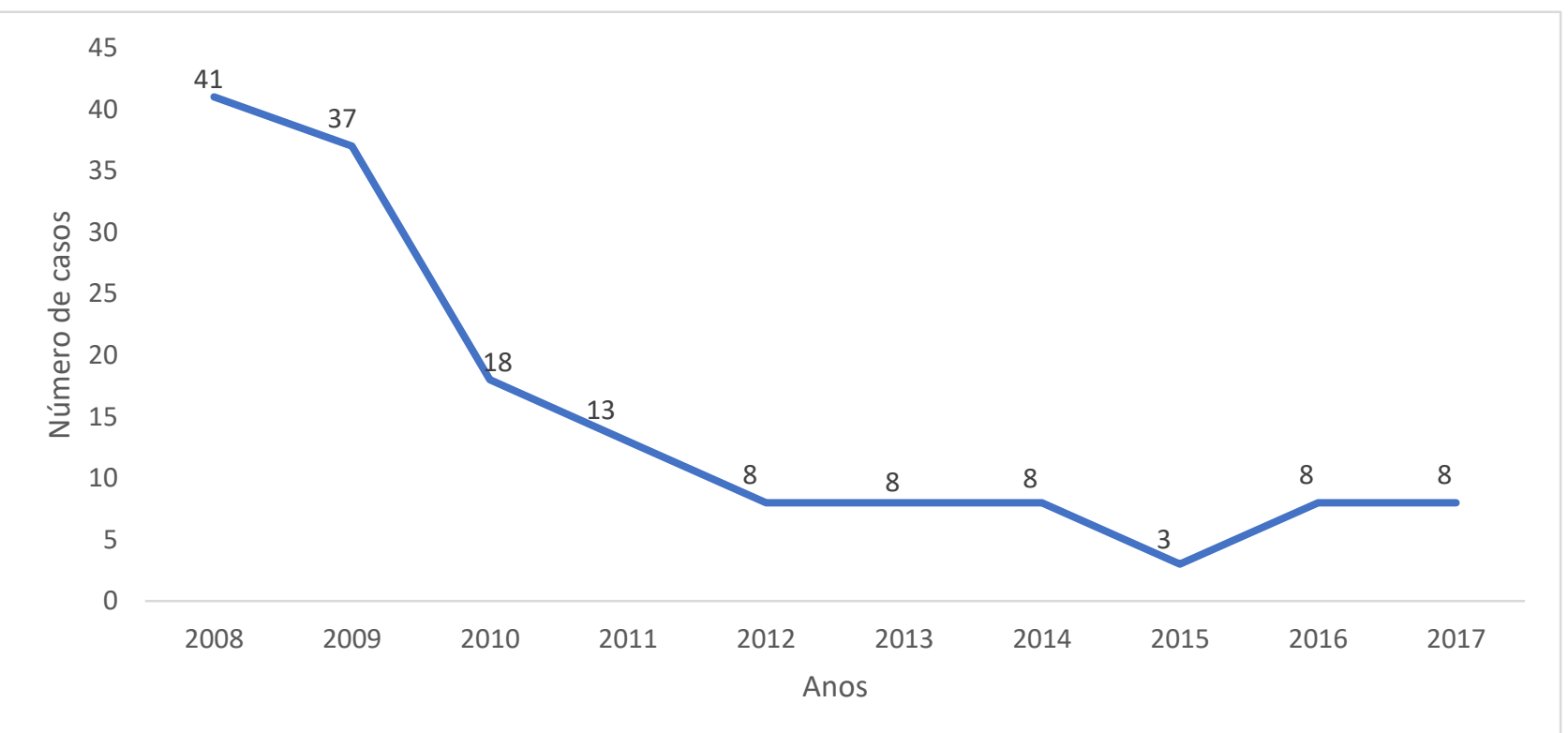

Fonte: PAZINI DS, et al., 2020.

\section{DISCUSSÃO}

O alto percentual de casos em indivíduos acima de 51 anos exige cuidados adicionais no tratamento com antimonial pentavalente pela alta toxicidade. A elevada taxa de abandono pode estar relacionada ao uso prolongado e às reações adversas.

O alto percentual de ignorados na coinfecção com HIV atesta a necessidade de um manejo clínico diferenciado. A maior incidência na zona urbana pode estar relacionada com a imprecisão da definição das áreas periurbanas no município ou com a urbanização, diferindo do apresentado em outro estudo (RIBEIRO MD, et al., 2018).

A predominância da FC, correlacionada a bom prognóstico, com elevada taxa de cura, reafirma o padrão epidemiológico descrito (VASCONCELOS JM, et al., 2018). Algumas limitações são: utilização de dados secundários e elevada proporção de notificações incompletas. Recomenda-se realizar pesquisas relacionadas à baixa adesão ao tratamento da LTA, pelo obstáculo que representa, e sensibilizar os profissionais quanto a importância de uma notificação completa. 


\section{CONSIDERAÇÕES FINAIS}

O conhecimento do perfil dos casos é essencial na elaboração de estratégias locais de assistência e de prevenção eficazes.

Apesar de observada uma redução do número de casos ao longo do período estudado, percebe-se uma mudança no perfil epidemiológico da doença, predominando casos na área urbana e atingindo uma parcela considerável de indivíduos com idade superior a 60 anos.

Dessa forma, fica evidente a necessidade de uma educação continuada dos profissionais de saúde para o manejo adequado desses pacientes, especialmente em relação ao tratamento dos grupos com maior probabilidade de ocorrência de efeitos adversos.

\section{REFERÊNCIAS}

1. RIBEIRO MD, et al. Perfil da leishmaniose cutânea americana na Amazônia Sul-Ocidental brasileira: uma abordagem multivariada. Revista de Epidemiologia e Controle de Infecção, 2018; 8(4).

2. TANURE A, et al. Identification of Sandflies (Diptera: Psychodidae: Phlebotominae) blood meals in na endemic leishmaniasis area in Brazil. Revista do Instituto de Medicina Tropical de São Paulo, 2015; 57(4):321-324.

3. VASCONCELOS JM, et al. Leishmaniose tegumentar americana: perfil epidemiológico, diagnóstico e tratamento. Revista Brasileira de Análises Clínicas, 2018; 50(3):221-7. 


\section{RESUMO EXPANDIDO: Estudo Original}

\section{TíTULO: NANODISPOSITIVO ELETROQUÍMICO PARA DIAGNÓSTICO PRESUNTIVO DE}

\section{LEISHMANIOSE VISCERAL}

Autor/coautores: Maria Luiza Salustiano Bandeira; Alberto Galdino da Silva Júnior; Fábio Lopes Melo; Maria Danielly Lima de Oliveira; César Augusto Souza de Andrade.

Instituição: Laboratório de Biodispositivos Nanoestruturados (BIONANO), Universidade Federal de Pernambuco, Recife-Pernambuco; Laboratório de Doenças Transmissíveis, Centro de Pesquisas Aggeu Magalhães, Recife-Pernambuco.

Financiamento: Conselho Nacional de Desenvolvimento Científico e Tecnológico (CNPq).

Palavras-chave: Biossensor, Eletroquímica, Leishmania.

\section{INTRODUÇÃO}

A Leishmaniose Visceral (LV) é uma zoonose causada pelo protozoário da espécie Leishmania chagasi, sendo reconhecida como a segunda causa de mortalidade entre doenças parasitárias. Os métodos de diagnóstico utilizados atualmente possuem limitações relacionadas ao tempo de análise, reações cruzadas com outras parasitoses e elevado custo de equipamentos e reagentes (KHATUN R, et al., 2017). Desta forma, a busca por alternativas inovadoras para detecção de $L$. chagasi se faz necessária.

Biossensores eletroquímicos representam uma boa alternativa para o diagnóstico presuntivo por possuirem características valiosas como alta sensibilidade, precisão e acurácia, com análises rápidas e de fácil manuseio (YÁÑEZ-SEDENÕ P, et al., 2019). Os métodos eletroquímicos apresentam destaque entre os demais devido à facilidade no desenvolvimento de dispositivos portáteis, podendo aplicá-lo em medicina diagnóstica. $O$ uso de nanopartículas na contrução de biossensores auxiliam consideravelmente na interface onde ocorre o reconhecimento biológico do analito (TERESHCHENKO A, et al., 2016).

Assim, o presente estudo objetiva o desenvolvimento de uma plataforma biossensora nanoestruturada para a biodetecção de $L$. chagasi, representando um inovador potencial para aplicação em análises clínicas.

\section{OBJETIVO}

Desenvolver um nanodispositivo para identificação de Leishmania chagasie avaliar a interação do sistema proposto frente a diferentes concentrações de amostras contaminadas, utilizando análise eletroquímica por meio das técnicas de Voltametria Cíclica (VC) e Espectroscopia de Impedância Eletroquímica (EIE).

\section{MÉTODO}

As medidas eletroquímicas foram realizadas em um potenciostato/galvanostato com gerador de frequência utilizando uma célula eletroquímica contendo três eletrodos e solução $10 \mathrm{mM} \mathrm{K}\left[\mathrm{Fe}(\mathrm{CN})^{6}\right] / \mathrm{K}_{3}\left[\mathrm{Fe}(\mathrm{CN})^{6}\right](1: 1)$, usada como sonda redox em solução tampão fosfato-salina (PBS) pH 7,0. A limpeza da superfície do eletrodo de trabalho com disco de ouro $(\varnothing=2 \mathrm{~mm})$ é necessária antes da montagem da plataforma, garantindo que as interações químicas sejam feitas sem interferências.

As análises EIE foram registradas na faixa de frequência de $100 \mathrm{mHz}$ a $100 \mathrm{kHz}$. As análises $\mathrm{VC}$ foram realizadas com potencial de varredura de entre $+0.7 \mathrm{a}-0.2 \mathrm{~V}$ com uma taxa de varredura de $50 \mathrm{mV} \mathrm{s}^{-1}$.

\section{RESULTADOS}

Com o eletrodo de trabalho limpo, a montagem da plataforma biossensora na sua superfície é iniciada com a aplicação de $4 \mu \mathrm{L}$ de uma solução de ácido 4-mercaptobenzóico (MBA) até total adsorção, com o objetivo de formar monocamada automontada (MAM) pela ligação covalente do grupamento tiol (-SH) com a superfície de ouro. Posteriormente, uma suspensão de nanopartículas de óxido de zinco modificadas (NpsZnO-NH2) por (3-aminopropil) trietoxissilano (APTES) diluídas em metanol $(1 \mathrm{mg} / \mathrm{mL})$ foi aplicada ao eletrodo. A montagem da plataforma nanossensora é finalizada com a aplicação de $3 \mu \mathrm{L}$ do primer leishmania R332 (GGCCGGTAAAGGCCGAATAG). 
A análise eletroquímica composta por VC e EIE destacam-se como excelentes ferramentas para o estudo do processo de detecção de genossensores baseados no processo de hibridização. A plataforma demonstrou uma resposta eletroquímica estável, tanto na VC quanto na EIE, indicando a deposição dos componentes no eletrodo.

O biosensor teve sua eficácia testada frente a três diferentes concentrações $\left(10 \mathrm{pg} \cdot \mathrm{mL}^{-1}, 5 \mathrm{pg} \cdot \mathrm{mL}^{-1} \mathrm{e} 1\right.$ pg. $\mathrm{mL}^{-1}$ ) da sequência alvo do DNA genômico complementar de L. chagasi.

\section{DISCUSSÃO}

A conformação da MAM permite maior precisão da plataforma por permitir melhor controle molecular das substâncias imobilizadas com uma preparação simples. Já a adição das nanopartículas eleva consideravelmente a magnitude de espécies eletroativas na superfície do eletrodo, elevando a sensibilidade. A funcionalização química dessas nanopartículas possibilita a formação de ligações covalentes com os demais componentes da plataforma (TERESHCHENKO A, et al., 2016).

A empregabilidade dessas manobras de modificação da superfície assegura uma diminuição nos limites de deteç̧ão, sendo possível detectar o analito em concentrações mínimas, como $1 \mathrm{pg} \cdot \mathrm{mL}^{-1}$. Mesmo com suas vantagens, o uso de biossensores não é muito explorado, com poucos estudos sendo feitos para validar a aplicação desses dispositivos (YÁÑEZ-SEDENÕ P, et al., 2019).

O estudo deve prosseguir com a utilização de amostras clínicas. Com a detecção bem sucedida, a plataforma poderá ser miniaturizada, transformando-a em um dispositivo portátil de fácil uso.

\section{CONSIDERAÇÕES FINAIS}

Os resultados obtidos no presente estudo demonstram a excelente resposta eletroquímica por medidas voltamétricas e impedimétricas. Os resultados comprovam que houve a imobilização correta de todas as camadas que compõe a plataforma biossensora nanoestruturada, atestando o desenvolvimento do nanodispositivo.

Além disso, as técnicas de VC e EIE também indicaram a detecção bem-sucedida da sequência alvo nas concentrações estudadas. Assim, o sistema desenvolvido está apto para iniciar o estudo de interação da plataforma frente a amostras clínicas.

\section{REFERÊNCIAS}

1. KATHUN M, et al. Novel PCR primers to diagnose visceral leishmaniasis using peripheral blood, spleen or bone marrow aspirates. Asian Pacific Journal of Tropical Medicine, 2017; 10(8), 753-759.

2. TERESHCHENKO A, et al. Optical biosensors based on $\mathrm{ZnO}$ nanostructures: Advantages and perspectives a review. Sensors and Actuators, B: Chemical, 2016; 229, 664-677.

3. YÁÑEZ-SEDENÕ $P$, et al. What electrochemical biosensors can do for forensic science? Unique features and applications. Biosensors, 2019; 9. 
RESUMO EXPANDIDO: Estudo Original

Título: Perfil epidemiológico das Leishmanioses no estado de Pernambuco

Autor/coautores: Marcos Lorran Paranhos Leão, Ana Isabel Barros Porpino do Prado, Fábio Henrique Cavalcanti de Oliveira.

Instituição: Universidade de Pernambuco (UPE), Recife - Pernambuco.

Palavras-chave: Leishmaniose Cutânea, Leishmaniose Visceral, Epidemiologia.

\section{INTRODUÇÃO}

A Leishmaniose Tegumentar Americana (LTA) é um grupo de doenças negligenciadas causadas por protozoários intracelulares do gênero Leishmania. Os casos desta patologia vêm aumentando nos últimos vinte anos. A LTA é uma doença infecciosa, com baixa mortalidade, mas que afeta muitas pessoas. (VASCONCELOS JM, et al., 2018).

A Leishmaniose Visceral (LV), popularmente conhecida como calazar, febre dundun ou esplenomegalia tropical, é uma zoonose, em geral negligenciada, que acomete seres humanos e outras espécies de animais domésticos e silvestres. A LV é uma doença grave crônica e, sistêmica, caracterizada por febre de longa duração, perda de peso, astenia, anemia, hepatoesplenomegalia, entre outras manifestações. Quando não tratada, pode evoluir para óbito em mais de 90\% dos casos (LIMA ME, et al., 2018; SANTOS ESM, et al., 2019).

O Brasil apresentou mais de 17 mil casos de LTA, em 2018, sendo que o estado de Pernambuco possui $1,8 \%$ desses casos. Se tratando de LV o número brasileiro é de 3.851 casos, e 5,2\% no estado pernambucano (SINAN, 2019). Assim, se torna essencial analisar o perfil epidemiológico atual da LV e da LTA nesse estado.

\section{OBJETIVO}

Analisar os últimos dados públicos acerca dos diagnósticos da leishmaniose tegumentar americana e da leishmaniose visceral no estado de Pernambuco. Além disso, traçar um perfil epidemiológico mais frequente para ambos os quadros no estado.

\section{MÉTODO}

Trata-se de uma pesquisa exploratória e quantitativa, de caráter descritivo, feita a partir das informações do domínio eletrônico oficial do DataSUS, Informações em Saúde (TabNET), ligado ao Ministério da Saúde.

Os dados são referentes aos casos confirmados de Leishmaniose Tegumentar Americana e Leishmaniose Visceral confirmados notificados no Sistema de Informação de Agravo de Notificação - SINAN, no estado de Pernambuco no ano de 2018. Ainda, se tratando de uma pesquisa que utiliza informações de acesso público, nos termos da Lei no 12.527, 18 de novembro de 2011, não precisa de autorização em Comitê de Ética em Pesquisa (CEP), respaldada pelo parágrafo único do Art $1^{\circ}$ da resolução 510/2016, da Comissão Nacional de Ética em Pesquisa (CONEP), do Conselho Nacional de Saúde (CNS).

\section{RESULTADOS}

A análise preliminar dos dados mostrou que, quando se trata do sexo, a LTA apresenta-se mais prevalente no masculino $(59,2 \%)$. Levando em conta a faixa etária, essa doença apresenta-se mais frequente de 40 a 59 anos $(27,5 \%)$. Com relação a raça, é predominante na parda $(68,3 \%)$. No que se refere à escolaridade, a maior taxa é de $1^{\circ}$ a $4^{\circ}$ série incompleta (15,2\%). Ainda $97,4 \%$ dos casos são da forma cutânea, e apenas $2,6 \%$ da forma mucosa. 
O critério confirmatório mais utilizado é o clínico-epidemiológico $(68,3 \%)$ e a evolução, na maior parte das vezes (77\%), é a cura.

Com relação a LV, a prevalência nos sexos é no masculino $(68,2 \%)$. Com relação à faixa etária, se apresenta mais frequente de 20 a 39 anos $(25,9 \%)$. Já, com relação a raça, é maior na parda $(74,1 \%)$. Referindo-se a escolaridade, a maior taxa está de $1^{\circ}$ a $4^{\circ}$ série incompleta $(16,5 \%)$. O critério confirmatório mais frequente é o laboratorial (84,7\%). A evolução mais frequente é a cura $(65,9 \%)$.

Tabela 1 - Algumas variáveis mais frequentes no diagnóstico de Leishmaniose Tegumentar Americana (LTA) e de Leishmaniose Visceral (LV) em Pernambuco no ano de 2018.

\begin{tabular}{|c|c|c|c|c|}
\hline Variável & $\mathbf{N}$ (LTA) & $\%$ (LTA) & $N(L V)$ & $\%(L V)$ \\
\hline \multicolumn{5}{|l|}{ Sexo } \\
\hline Masculino & 183 & 59,2 & 116 & 68,2 \\
\hline \multicolumn{5}{|l|}{ Faixa etária } \\
\hline $40-59$ anos & 85 & 27,5 & & \\
\hline $20-39$ anos & & & 44 & 25,9 \\
\hline \multicolumn{5}{|l|}{ Escolaridade } \\
\hline $\begin{array}{l}1^{\mathrm{a}} \text { a } 4^{\mathrm{a}} \text { série } \\
\text { incompleta }\end{array}$ & 47 & 15,2 & 28 & 16,5 \\
\hline \multicolumn{5}{|l|}{ Raça } \\
\hline Pardo & 211 & 68,3 & 126 & 74,1 \\
\hline \multicolumn{5}{|l|}{ Evolução } \\
\hline \multirow[t]{2}{*}{ Cura } & 238 & 77 & 112 & 65,9 \\
\hline & valor absoluto & porcentagem & valor absoluto & porcentagem \\
\hline Total & 309 & 100 & 170 & 100 \\
\hline
\end{tabular}

Fonte: LEÃO MLP, et al., 2020. Dados coletados no site do Sistema de Informação de agravos de Notificação - SINAN, 2020.

\section{DISCUSSÃO}

Os achados deste trabalho corroboram com a literatura já existente na medida que apontam os índices crescentes dos casos das doenças estudadas, e nos dados das baixas mortalidades de ambas.

O perfil epidemiológico da LV em Pernambuco é do sexo masculino, com faixa etária de 20 a 39 anos de idade, de raça parda e com grau de escolaridade até a $4^{\text {a }}$ série do ensino fundamental. Na LTA, também é do sexo masculino, mas na faixa etária de 40 a 59 anos, raça parda e até 4⿳亠丷厂 série do ensino fundamental. Quanto a evolução da doença, ambas evoluem majoritariamente para a cura. 
Este estudo limitou-se a analisar e traçar um perfil mais frequente de infectados de LTA e LV, utilizando os dados de acesso público, disponíveis no site do SINAN. Assim, alguns dados apresentaram grande número das variáveis ignorados/brancos e que não se aplicavam, prejudicando uma análise mais segura de sua totalidade.

\section{CONSIDERAÇÕES FINAIS}

Assim, concluímos que, de acordo com os últimos dados, o perfil epidemiológico atual da LTA, no estado de Pernambuco, é de homens pardos, de 40 a 59 anos e que tenham de $1^{\circ}$ a $4^{\circ}$ série incompleta.

Com relação a doença, apresenta, predominantemente, a forma cutânea, tem o critério clínicoepidemiológico como confirmação e evolui para a cura. Já, com relação a LV, o perfil que prevalece é o de homens pardos, de 20 a 39 anos e que tenham de $1^{\circ}$ a $4^{\circ}$ série incompleta.

A doença é diagnosticada por via laboratorial e evolui para a cura. Ainda, novas pesquisas devem ser feitas para atualização dos dados de casos de LTA e de LV no estado de Pernambuco. Também, estudos epidemiológicos baseados nesses dados são necessários para reger e embasar políticas públicas de combate profilático à tais enfermidades.

\section{REFERÊNCIAS}

1. LIMA ME, et al. Epidemiological profile of injured children with visceral leishmaniosis in a Maranhão University Hospital. Rev Soc Bras Enf Ped, 2018; 18(1).

2. SANTOS ESM, et al. Aspectos Epidemiológicos da Leishmaniose Visceral. Revista Eletrônica Acervo Saúde, 2019; (23): e959.

3. VASCONCELOS JM, et al. Leishmaniose tegumentar americana: perfil epidemiológico, diagnóstico e tratamento. RBAC, 2018; 50(3). 
RESUMO EXPANDIDO: Estudo Original

TítULO: PERFIL DE RESISTÊNCIA DE ISOLADOS CLíNICOS DE ENTEROCOCCUS FAECIUM (RECIFE, PE)

Autor/coautores: Bárbara de Azevedo Ramos ${ }^{1}$, Sivoneide Maria da Silva ${ }^{1}$, Maria Betânia Melo de Oliveira ${ }^{1}$, Túlio Diego da Silva², Maria Tereza dos Santos Correia¹.

Instituição: ${ }^{1}$ Universidade Federal de Pernambuco (UFPE), Recife-Pernambuco; ${ }^{2}$ Centro de Tecnologias do Nordeste (CETENE), Pernambuco.

Financiamento: Fundação de Amparo a Ciência e Tecnologia do Estado de Pernambuco (FACEPE).

Palavras-chave: Gram-positiva, Vancomicina resistente, Enterococos.

\section{INTRODUÇÃO}

Resistência aos antimicrobianos é uma das maiores preocupações mundiais. Isso faz com que aumente as taxas de Infecções Relacionadas a Assistência à Saúde (IRAS), e assim aumenta também as chances de mortalidade dos pacientes.

Essas infecções resultam de alguns fatores como a existência do microrganismo no ambiente hospitalar, a presença do hospedeiro em condições imunocomprometidas e a cadeia de transmissão que existe dentro do hospital. No geral o uso de cateteres são as principais portas de entrada do patógeno no hospedeiro (BROOKS GF, et al., 2014).

Segunda a Organização Mundial de Saúde (OMS, 2017), Enterococcus é o segundo gênero mais frequente envolvidos em infecções hospitalares entre os Gram-positivos, atrás somente do gênero Staphylococcus. A resistência associada ao gênero Enterococcus é preocupante principalmente por causa da presença de genes intrínsecos que causam a persistência ao efeito de alguns antimicrobianos de uso comum.

Assim como, a capacidade de adquirir resistência através de plasmídeos ou transposons que carregam genes responsáveis pela resistência a outros grupos de antimicrobianos. Desde a década de 90 houve um aumento das IRAS enterocócicas, e principalmente de E. faecium resistente à vancomicina (VRE) (HOLLENBECK BL e RICE LB, 2012).

\section{OBJETIVO}

Avaliar o perfil de susceptibilidade/resistência de isolados clínicos de Enterococcus faecium, coletados em um hospital da cidade do Recife, bem como correlacionar este perfil com os locais e sítios de infecções do qual foram isolados.

\section{MÉTODO}

Foram utilizados nove isolados clínicos de E. faecium, coletados em um hospital público do Recife (Comitê de Ética em Pesquisa - CEP, n² 2.581.568 / CAAE: 84015517.7.0000.5208).

A identificação dos isolados, o perfil de susceptibilidade e a determinação da Concentração Inibitória Mínima (CIM) dos antibióticos foi realizado através do equipamento de automação Phoenix (BD). A interpretação dos critérios de sensibilidade antimicrobiana foi realizada conforme recomendado pelo Clinical Laboratory Standards Institute (CLSI, 2018) utilizando os antibióticos Ampicilina (AMP), Penicilina G (PEN G), Daptomicina (DAP), Linezolida (LIN) e Vancomicina (VAN). Foram utilizados neste trabalho, além do perfil de susceptibilidade o número de identificação dos microrganismos, o sítio de coleta/infecção e o setor hospitalar.

\section{RESULTADOS}

É possível observar na Tabela 1 que os nove isolados clínicos de E. faecium foram provinientes de amostras de swab retal. Quanto ao setor hospitalar de onde essas amostras foram obtidas, $22,2 \%$ foram coletados da Unidade coronariana, 22,2\% da Cardiologia e 55,6\% da Unidade de tratamento intensivo (UTI).

REAS | Vol.Sup.n.54 | DOI: https://doi.org/10.25248/anais.e4798.2020 Página 98 de 245 
Através do perfil de susceptibilidade foi possível analisar a sensibilidade/resistência aos antibióticos. Todos os isolados foram resistentes a ampicilina, penicilia $G$ e vancomicina. A CIM da ampicilina e da penicilina $G$ não variou entre eles, contrário do que ocorreu com a CIM da vancomicina, no qual variou de > 32 a 256 $\mu \mathrm{g} / \mathrm{mL}$.

Da mesma forma, todos os isolados foram sensíveis a Daptomicina (CIM entre 1 e $4 \mu \mathrm{g} / \mathrm{mL}$ ), sendo esse antibiótico a última alternativa para alguns desses isolados clínicos, pois $3(33,3 \%)$ dos 9 isolados foram resistentes a Linezolida e $1(11,1 \%)$ apresentou resistência intermediária.

A CIM da linezolida para a cepa de resistência intermediária foi de $4 \mu \mathrm{g} / \mathrm{mL}$ e para as cepas resistentes acima de $4 \mu \mathrm{g} / \mathrm{mL}$.

Tabela 1 - Características gerais dos isolados de E. faecium, $\mathrm{n}=9$.

\begin{tabular}{|c|c|c|c|c|c|c|c|c|c|c|c|c|}
\hline \multirow{3}{*}{$\begin{array}{l}\text { Identificação } \\
00821\end{array}$} & \multirow{3}{*}{$\begin{array}{l}\text { Local de } \\
\text { coleta }\end{array}$} & \multirow{3}{*}{$\begin{array}{l}\text { Sítio de } \\
\text { coleta/infecção }\end{array}$} & \multicolumn{10}{|c|}{ Perfil de susceptibilidade (SIR / CIM $\mu \mathrm{g} / \mathrm{mL}$ ) } \\
\hline & & & \multicolumn{2}{|c|}{ AMP } & \multicolumn{2}{|c|}{ PEN G } & \multicolumn{2}{|c|}{ DAP } & \multicolumn{2}{|c|}{ LIN } & \multicolumn{2}{|c|}{ VAN } \\
\hline & & & $\mathrm{R}$ & $>16$ & $\mathrm{R}$ & $>8$ & $S$ & 4 & $\mathrm{R}$ & $>4$ & $\mathrm{R}$ & $>32$ \\
\hline 10656 & UCO & Swab retal & $\mathrm{R}$ & $>16$ & $\mathrm{R}$ & $>8$ & $S$ & 2 & s & 2 & $\mathrm{R}$ & $>32$ \\
\hline 11167 & UTI & Swab retal & $\mathrm{R}$ & $>16$ & $\mathrm{R}$ & $>8$ & S & 2 & $\mathrm{~s}$ & 2 & $\mathrm{R}$ & 96 \\
\hline 11170 & UTI & Swab retal & $\mathrm{R}$ & $>16$ & $\mathrm{R}$ & $>8$ & S & 2 & $\mathrm{R}$ & $>4$ & $\mathrm{R}$ & 96 \\
\hline 11601 & UTI & Swab retal & $\mathrm{R}$ & $>16$ & $\mathrm{R}$ & $>8$ & S & 2 & $\mathrm{~s}$ & 1 & $\mathrm{R}$ & 96 \\
\hline 12805 & UTI & Swab retal & $\mathrm{R}$ & $>16$ & $\mathrm{R}$ & $>8$ & s & 4 & $\mathrm{R}$ & $>4$ & $\mathrm{R}$ & $>32$ \\
\hline 16583 & UTI & Swab retal & $\mathrm{R}$ & $>16$ & $\mathrm{R}$ & $>8$ & $S$ & 2 & S & 1 & $\mathrm{R}$ & 256 \\
\hline 16599 & UCO & Swab retal & $\mathrm{R}$ & $>16$ & $\mathrm{R}$ & $>8$ & $S$ & 1 & $S$ & 1 & $\mathrm{R}$ & $>32$ \\
\hline 18258 & Cardiologia & Swab retal & $\mathrm{R}$ & $>16$ & $\mathrm{R}$ & $>8$ & s & 4 & 1 & 4 & $\mathrm{R}$ & $>32$ \\
\hline
\end{tabular}

Legenda: SIR - Sistema de Identificação de Resistência. CIM - Concentração inibitória mínima. UCO Unidade coronariana. UTI - Unidade de tratamento intensivo. AMP - Ampicilina. PEN G - Penicilina G. DAP - Daptomicina. LIN - Linezolida. VAN - Vancomicina.

Fonte: RAMOS BA, et al., 2020.

\section{DISCUSSÃO}

De acordo com a Organização Mundial da Saúde (OMS), os isolados de E. faecium VRE são mais frequentes em surtos hospitalares (OMS, 2017). A coleta com swab retal de pacientes que são encaminhados ao internamento, é uma prática de vigilânica epidemiológica indicada pela Agência Nacional de Vigilância Sanitária (ANVISA, 2004), o que é preocupante nesse estudo, pois de acordo com os dados as amostras coletadas são cepas multidroga resistentes que já vieram com o paciente do ambiente externo. 
Outra preocupação é a disseminação dessas cepas dentro dos setores hospitalares, principalmente para pacientes imunocomprometidos. Linezolida e Daptomicina, representam as alternativas aos VREs, no entanto nesse estudo observamos cepas resistenres a linezolida.

A preocupação é que já existe cepas daptomicina resistentes isoladas em outros locais. Dessa forma, a aquisisão da resistência a esse antibiótico nos hospitais do Recife é altamente preocupante (ARIAS CA e MURRAY BE, 2012).

\section{CONSIDERAÇÕES FINAIS}

A alta incidência de isolados clínicos de E. faecium multidroga resistente dentro do ambiente hospitilar é de grande preocupação, principalmente quando esses isolados já colonizam pacientes que vêm do ambiente externo.

Cepas resistentes a vancomicina e linezolida, apresentam como última alternativa a daptomicina, sendo necessária a prevenção do uso deste antibiótico a fim de diminuir as taxas de resistência a ele, pois como já se sabe a resistencia aos antimicrobianos dificulta o tratamento da infecção e aumenta as taxas de morbimortalidade do paciente hospitalizado.

\section{REFERÊNCIAS}

1. AGÊNCIA NACIONAL DE VIGILÂNCIA SANITÁRIA. In: Manual de Microbiologia Clínica para o Controle de Infecção em Serviços de Saúde. Procedimentos Laboratoriais: da Requisição do Exame à Análise Microbiológica. Módulo III. 2004: e1. Disponível em: https://bvsms.saude.gov.br/bvs/publicacoes/manual_microbiologia_completo.pdf. Acesso em: 25 maio. 2020.

2. ARIAS CA, MURRAY BE. The rise of the Enterococcus: Beyond vancomycin resistance. Nat Rev Microbiol, 2012; 10(4).

3. BROOKS GF, et al. In: Microbiologia médica de Jawetz, Melnick e Adelberg. Estreptococos, enterococos e outros gêneros relacionados. ARTMED. Porto Alegre; 2014: e26.

4. CLINICAL AND LABORATORY STANDARDS INSTITUTE. In: Performance Standards for Antimicrobial Susceptibility Testing. CLSI supplement M100. Wayne, PA.; 2018: e29.

5. HOLLENBECK BL, RICE LB. Intrinsic and acquired resistance mechanisms in Enterococcus Virulence. Landes Bioscience, 2012; 3(5).

6. ORGANIZAÇÃO MUNDIAL DA SAÚDE. In: Prioritization of pathogens to guide discovery, research, and development of new antibiotics for drug-resistant bacterial infections, including tuberculosis. Geneva, 2017. Disponível em: https://www.who.int/gho/mortality_burden_disease/causes_death/en/. Acesso em: 15 junho. 2020 
RESUMO EXPANDIDO: Estudo Original

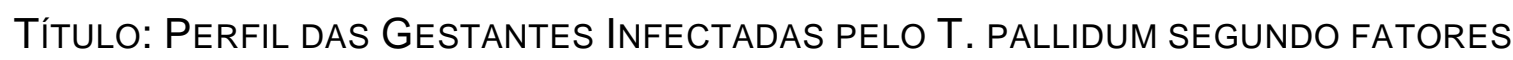
SOCIODEMOGRÁFICOS

Autor/coautores: Maria Vitoria Alves Vila Nova ${ }^{1}$, Brenda Fernanda Guedes ${ }^{2}$, Sandy Guedes Pereira ${ }^{3}$, Claudia de Lima Rodrigues Souza ${ }^{4}$, Ronald Pereira Cavalcanti5.

Instituição: Universidade de Pernambuco UPE, Nazaré da Mata - Pernambuco ${ }^{1}$. Universidade Federal de Pernambuco UFPE, Vitória de Santo Antão - Pernambuco ${ }^{2,3,5}$. Centro Universitário Tabosa de Almeida ASCES ${ }^{4}$.

Financiamento: Próprio.

Palavras-chave: Doenças Sexualmente Transmissíveis, Sífilis, Gestantes.

\section{INTRODUÇÃo}

A sífilis é uma doença de notificação compulsória desde 1986, causada pela bactéria Treponema pallidium. Pode ser transmitida na fase inicial através de transfusão sanguínea ou contato com lesões, entretanto sua principal forma de disseminação é pela via sexual. A sífilis em gestantes é detectada pela realização de exames durante os pré-natais ocorridos no $1^{\circ}$ e $3^{\circ}$ trimestre em torno da $30^{\circ}$ semana gestacional. Quando detectada é necessário tratamento imediato para redução da possibilidade de transmissão vertical, podendo gerar complicações como aborto por sífilis, óbito fetal e a sífilis congênita (ARAÚJO AGR, et al., 2018).

A despeito da eficácia em diagnosticar e realizar o tratamento para prevenção de sífilis, decorrente do seu baixo custo e efetividade, a transmissão transplacentária ainda é um problema de saúde pública. A sífilis materna é de simples rastreio e evitável, mas a implementação de medidas práticas no sistema de saúde ainda é difícil de serem integradas, como por exemplo, a realização de testes rápidos (FREITAS JLG, et al., 2019).

Decorrente desses aspectos, o estudo sobre a caracterização do perfil das gestantes infectadas, colabora no conhecimento do perfil dessas pacientes e possibilita a criação de estratégias de intervenção mais efetivas.

\section{OBJETIVO}

Realizar a descrição do perfil das gestantes com casos confirmados de infecção pela bactéria treponema pallidum de acordo com os fatores sociodemograficos, durante o corte temporal de 2010 a 2019 no território brasileiro.

\section{MÉTODO}

Esta pesquisa trata-se de um estudo descritivo, observacional e longitudinal que analisou os dados quantitativos, de um recorte temporal do período de 2010 a 2019, sendo analisados os casos de sífilis em gestantes, de acordo com os fatores de raça/cor, faixa etária e escolaridade.

Os dados utilizados nesse estudo foram extraídos via internet a partir de fonte secundária de acesso público, retirados do sítio eletrônico da base de dados do Departamento de Informática do Sistema Único de Saúde (DATASUS), especificadamente do Sistema de Informação de Agravos e Notificação (SINAN). Os dados foram sistematizados em planilhas eletrônicas, utilizando-se o programa eletrônico LibreOffice Calc e realizadas análises descritivas, por meio de valores absolutos e relativos.

\section{RESULTADOS}

A faixa etária que apresenta o maior número de casos de gestantes com sífilis está entre 20 a 29 anos, de acordo com os anos: 2010 (5.229), 2011 (6.990), 2012 (8.275), 2013 (10.547), 2014 (13.407), 2015 (16.859), 2016 (20.074), 2017 (26.251), 2018 (33.677) e 2019 (14.159). Em relação ao nível de escolaridade, ignorados se sobressaem em todos os anos observados (2010 a 2019) com o maior número de casos; em segundo lugar destaca-se a 5a a 8aㅡ série incompleta, que apresenta em 2010 (2.174), 2011 (3.025), 2012 (3.498), 2013 (4.279), 2014 (5.531), 2015 (6.508), 2016 (7.710) e 2017 (9.691) e nos dois últimos anos do estudo (2018 e 
2019) o nível de escolaridade que demonstra o maior número de casos é o Médio Completo com 12.055 e 5.310, respectivamente.

De acordo com raça ou cor, o maior número de casos de sífilis ocorre em mulheres pardas, apresentando em 2010 (4.703), 2011 (6.359), 2012 (7.633), 2013 (9.713), 2014 (12.443), 2015 (15.313), 2016 (18.031), 2017 (24.186), 2018 (31.786) e 2019 (13.310).

\section{DISCUSSÃO}

Através do estudo foi possível observar que o perfil epidemiológico de gestantes com sífilis é de mulheres jovens de 20 a 29 anos, com grau de escolaridade em sua maioria ignorada (no qual a paciente não quis informar o nível de escolaridade ou houve incompletude no preenchimento da ficha de notificação), também destacam-se as mulheres gestantes com ensino fundamental incompleto, com o segundo maior número de casos tendo como predominância de raça ou core parda.

Os resultados apresentados corroboram com o estudo de Saback MC, et al. (2019) em relação a faixa etária, baixa escolaridade e prevalências de cor parda.

O perfil de gestantes com sífilis se manteve durante o período de estudo, essa constante nos faz refletir sobre a falta de informação entre esse grupo de gestantes que pode estar relacionada com o nível de escolaridade baixa e a ausência de estratégias para esse perfil específico de mulheres.

\section{CONSIDERAÇÕES FINAIS}

Através do resultado obtido pelo estudo, foi visto a importância em determinar o perfil das gestantes infectadas pela sífilis, pois o mesmo permite a reflexão sobre a necessidade de um acompanhamento maior e contínuo dessas gestantes por profissionais da saúde.

Contribuindo assim para a elaboração de estratégias de prevenção da doença, sendo imprescindível a criação de um plano de ação junto aos profissionais que registram as notificações pra que haja uma melhora na qualidade dos dados.

\section{REFERÊNCIAS}

1. ARAÚJO AGR, et al. Estudo Epidemiológico Dos Casos De Sífilis Em Gestantes Em Uma Cidade Do Norte De Minas Gerais. Revista Eletrônica Acervo Científico, 2018; 11: e143.

2. FREITAS JLG, et al. Sífilis Materna E Congênita Em Rondônia: Casos Notificados De 2010 a 2015. Revista Eletrônica Acervo Científico, 2019; 11: e1631.

3. SABACK MC, et al. Perfil epidemiológico da sífilis gestacional e congênita na Maternidade Ana Braga Manaus, Amazonas. Revista Eletrônica Acervo Saúde, 2019; 5: e299. 


\section{RESUMOS EXPANDIDO: Estudo Original}

\section{TíTULO: SAÚdE NA ESCOLA: PARASITOSES INTESTINAIS EM ADOLESCENTES E MEDIDAS DE}

\section{BIOSSEGURANÇA}

Autor/coautores: Amanda de Oliveira Bernardino, Joêmia Maria de Lima, Edvânia do Nascimento Leite, Priscila Nilma Rodrigues de Albuquerque Soares, Andrea Rosane Souza Silva.

Instituição: Centro Universitário Tiradentes (UNIT), Recife-Pernambuco.

Financiamento: Centro Universitário Tiradentes (UNIT), Recife-Pernambuco.

Palavras-chave: Adolescente, Doenças Parasitárias, ENITducação em saúde.

\section{INTRODUÇÃO}

Adolescência é uma etapa evolutiva peculiar ao ser humano caracterizado por profundas alterações somáticas, como também, psicossocial. A pobreza, o saneamento básico e moradia precária, contribuem para um aumento do índice de parasitados, afetando o desenvolvimento físico, psicossomático e social dos adolescentes escolares.

Com o surgimento do Programa de Saúde da Família (PSF), os adolescentes passam a ser vistos como membros da família e redirecionados para o atendimento geral, desconsiderando suas especificidades e identidades.

Nesse contexto, as ações de educação em saúde podem favorecer o desenvolvimento de medidas profiláticas como já vem sendo apontadas outros trabalhos de prevenção às parasitoses e de promoção à saúde (BRASIL EGM, 2017).

O enfermeiro e demais profissionais de saúde estão diretamente a frente destas atividades de promoção e prevenção da saúde, com atribuições como: as equipes de Saúde da Família realizarão visitas periódicas e permanentes às escolas participantes do Programa Saúde na Escola (PSE) para avaliar as condições de saúde dos educandos, bem como para proporcionar o atendimento à saúde ao longo do ano letivo, de acordo com as necessidades locais de saúde identificadas (BRAGAGNOLLO G, et al., 2019).

\section{OBJETIVO}

Avaliar o impacto das ações educativas como medida de prevenção das enteroparasitoses em adolescentes escolares.

\section{MÉTODO}

Trata-se de um estudo descritivo de abordagem qualitativa, realizada em uma escola da rede estadual com regime integral dois dias por semana. A avaliação da ação educativa foi desenvolvida no período de agosto a novembro de 2016, com 16 educandos, todos $1^{\circ}$ ano do ensino médio, com idade entre 15 e 17 anos.

O estudo foi aprovado pelo Comitê de Ética em Pesquisa (CEP), CAEE protocolo de no57510416.6.0000.5191. Para coleta de dados foi utilizado a aplicação de questionário estruturado em Círculos de Cultura para avaliação do conhecimento pré e pós da ação educativa. Na análise dos dados foi realizada através das Técnicas de análise de conteúdo e do Discurso do Sujeito Coletivo (DSC). 


\section{RESULTADOS}

Quadro 1: Comparativo Pré e Pós discurso do sujeito coletivo.

\begin{tabular}{|c|c|}
\hline PRÉ & ÓS \\
\hline $\begin{array}{l}\text { Posso dizer que era tipo meio imundinho, não } \\
\text { lavava sempre as mãos, antes de comer ou } \\
\text { após usar o banheiro. Mas eu procuro lavar } \\
\text { bem os alimentos antes de comer. Corto as } \\
\text { unhas quase sempre, mais quando minha } \\
\text { mãe e minha avó mandam. Gosto muito de } \\
\text { andar descalço e de tomar banho no açude e } \\
\text { pescar peixe. As vezes jogo o lixo em } \\
\text { qualquer lugar na rua, nem sempre tem } \\
\text { lixeira. O povo joga mesmo. Não me preocupo } \\
\text { muito com a higiene não. Para mim verme era } \\
\text { coisa de criança pequena. O professor tinha } \\
\text { dado aula sobre isso mais nem liguei muito só } \\
\text { ia estudar perto da prova, pensei que não era } \\
\text { muito importante. Nunca me preocupei com } \\
\text { os outros adolescentes só se preocupa com } \\
\text { ele mesmo. }\end{array}$ & $\begin{array}{l}\text { Agora sou consciente que a higiene é importante, que devo } \\
\text { sempre me manter limpinho, com as unhas cortadas, lavar } \\
\text { bem os alimentos e lavar as mãos sempre antes e após } \\
\text { comer e também quando for ao banheiro e ao sair também, } \\
\text { andar sempre calçado e essa história de tá tomando banho } \\
\text { de no açude que tá contaminado também não pode. Devo } \\
\text { jogar o lixo na lixeira se não achar logo guardar até achar } \\
\text { uma lixeira para jogar. Agora sei qualquer pessoa pode } \\
\text { pegar verme. Ajudou no meu conhecimento para eu } \\
\text { prevenir mesmo em casa, ter mais higiene e tal, me ajudou } \\
\text { bastante no pude ver que o professor falou sobre a higiene } \\
\text { na prevenção das doenças tanto dentro de casa e no } \\
\text { bairro. A importância de um saneamento básico e tal. Eu } \\
\text { vou procurar dizer a todos da importância da higiene. } \\
\text { Conscientizar as pessoas ao meu redor dizendo que é } \\
\text { melhor se prevenir do que ficar doente e gastar mais com } \\
\text { remédio. }\end{array}$ \\
\hline
\end{tabular}

Fonte: BERNARDINO AO, et al., 2020.

Sobre o conhecimento dos discentes sobre as parasitoses, três alunos relataram a parasitose como relacionada a barriga d'água. No transcurso deste, a visão foi sendo modificada e o senso de conscientização foi tomado pelo grupo. Quando indagados sobre como identificar as parasitoses, os discentes relataram conhecer apenas o "exame de fezes" e poucos deles tinham realizado quando criança.

O conhecimento dos discentes sobre as medidas de biossegurança para prevenir as parasitoses, eles relataram que antes não tinham o hábito constante de realizar a higiene e que com a conscientização das ações implementadas adotaram medidas que fortaleceram essas atitudes. Havendo um bom condicionamento das ações o que reflete no resultado atitudes positivas voltadas para a educação em saúde.

A intervenção de educação em saúde favoreceu uma maior aproximação dos profissionais de saúde (acadêmicos de Enfermagem) com a escola, bem como a avaliação de importantes indicadores que envolvem a saúde dos adolescentes como (crescimento e desenvolvimento obesidade, nutrição atividade física, saúde reprodutiva e sexualidade) que poderão subsidiar a implementação de ações previstas pelas políticas públicas de saúde.

\section{DISCUSSÃO}

De acordo com Faria CR (2015), baseando-se no conhecimento do território, dos problemas de saúde e da organização dos serviços, a Atenção Básica à Saúde (ABS), deve atuar através de um conjunto de ações, de caráter individual ou coletivo, situadas no primeiro nível de atenção dos sistemas de saúde, voltadas a promoção da saúde, a prevenção de agravos, o tratamento e a reabilitação.

No caso das enteroparasitoses, as condições sanitárias e de higiene das comunidades devem ser consideradas, visto que os principais veículos de transmissão se encontram na água e alimentos contaminados com ovos ou larvas. $E$ os casos que muitas vezes são assintomáticos, dificultam a determinação de sua prevalência e o controle de sua transmissão (FARIA CR, 2015).

\section{CONSIDERAÇÕES FINAIS}

Conclui-se neste estudo, que as enteroparasitoses representam uma problemática que abrange principalmente a classe mals desfavorecida, devido às condições habitacionais entre outros. 
Isto se deve a problemas básicos como os determinantes sociais de saúde que estão relacionados a saúde individual e coletiva de difícil resolução imediata.

É inquestionável que a educação em saúde no controle das parasitoses é uma ferramenta viável tendo um baixo custo de grande eficácia em sua aplicabilidade podendo atingir resultados significativos e duradouros ao longo do tempo, é indicada para populações com alto ou baixa endemicidade.

\section{REFERÊNCIAS}

1. BRAGAGNOLLO G, et al., Intervenção educativa lúdica sobre parasitoses intestinais com escolares. Revista Brasileira de Enfermagem, 2019; 72( 5): 1203-1210.

2. BRASIL EGM, et al., Promoção da saúde de adolescentes e Programa Saúde na Escola: complexidade na articulação saúde e educação. Revista da escola de enfermagem da USP. 2017; 51: e03276.

3. FARIA CR. Educação em saúde: uma ferramenta para a prevenção e controle de parasitoses intestinais na estratégia saúde da família. 2015. 21 f. Tese (Doutorado) - Curso de Curso de Especialização em Atenção Básica em Saúde da Família, Universidade Federal do Triângulo Mineiro, Triângulo Mineiro, 2015. 
RESUMO EXPANDIDO: Estudo Original

TÍTULO: NOVOS DERIVADOS HÍBRIDOS FTALIMIDO-TIAZOLINONAS: SÍNTESE E ATIVIDADE ANTI-T. CRUZI

Autor/coautores: Kaio Henrique de Freitas', Vanessa Gouveia de Melo Silva1, Valéria Pereira Hernandes Aline Caroline da Silva Santos ${ }^{1}$, Ana Cristina Lima Leite ${ }^{1}$.

Instituição: Universidade Federal de Pernambuco (UFPE), Recife-Pernambuco.

Palavras-chave: Doença de Chagas, Estruturas privilegiadas, Ftalimido-tiazolinonas.

\section{INTRODUÇÃO}

Doenças negligenciadas constituem um conjunto de doenças infecciosas centradas em regiões de países subdesenvolvidos, onde prevalece a falta de saneamento básico e acesso a serviços de saúde. Dentre esse grupo de patologia, destaca-se a Doença de Chagas, uma infecção parasitária causada pelo protozoário Trypanosoma cruzi que afeta aproximadamente 6 a 7 milhões de pessoas no mundo.

Nessa circunstância, o benznidazol é o único medicamento aprovado para tratamento dessa parasitose durante a fase aguda e fases crônicas assintomáticas. Entretanto, sua eficácia durante a fase crônica sintomática é controversa. Diante disso, as estruturas privilegiadas surgem como uma eficiente abordagem para a síntese e descoberta de novos fármacos anti-T. cruzi (GOMES PATM, et al., 2016).

Nesse contexto, a identificação e utilização de estruturas privilegiadas para obtenção de moléculas bioativas são recorrentes devido a essas estruturas possuírem amplo espectro de atividades farmacológicas (LEITE ACL, et al., 2019).

Compostos derivados das tiazolinonas e das ftalimidas apresentam amplos registros de bioatividade na literatura, vêm sendo utilizados como bloco de construção para o desenvolvimento de moléculas com potenciais atividades antiprotozoários (GOMES PATM, et al., 2016) (FILHO GBO, et al., 2015). Dessa forma, a necessidade da pesquisa e síntese de novos fármacos para doenças negligenciadas, se fazem necessários.

\section{OBJETIVO}

Identificar protótipos a fármacos com atividade anti-T. cruzi frente as formas evolutivas (amastigotas e tripomastigotas) do parasita, por meio de planejamento estrutural, síntese e avaliação biológica de novos derivados híbridos ftalimido-tiazolinonas.

\section{MÉTODO}

A síntese dos derivados ftalimido-tiazolinonas foi realizada em três etapas: primeira, condensação entre o anidrido ftálico e a tiossemicarbazida, seguida de ciclização em tiazolinona, e finalmente a reação com diferentes benzaldeídos substituídos para obtenção da série final. Assim, a estrutura química dos compostos foi confirmada por intermédio de espectroscopia de Ressonância Magnética Nuclear de Hidrogênio (RMN $\left.{ }^{1} \mathrm{H}\right)$ e de carbono ( $R M N{ }^{13} \mathrm{C}$ ).

Para a avaliação farmacológica, foram realizados testes de concentração citotóxica (CC50) frente a macrófagos da linhagem RAW 264.7 e concentração inibitória (IC50) frente às formas amastigota e tripomastigota de Trypanossoma cruzi. Os valores foram determinados por análise de regressão linear utilizando o software GraphPad Prism.

\section{RESULTADOS}

Os derivados ftalimido-tiazolinonas foram obtidos em forma de sólidos e ao final do processo, houve necessidade de purificação dos produtos através de recristalização em metil-etil-cetona a quente. Os rendimentos alcançados para cada produto na etapa final da síntese se mostraram na faixa de 19,2\%-92,1\%. A estrutura química das moléculas foi confirmada por dados espectroscópicos, de acordo com os espectros que mostra o processo de caracterização por $\mathrm{RMN}^{1} \mathrm{H}$ e $\mathrm{RMN}^{13} \mathrm{C}$. 
Dentre os compostos finais testados, três apresentaram concentração inibitória para $50 \%$ da população (IC50) na forma tripomastigota, com destaque para o composto $1 \mathrm{~A}\left(\mathrm{IC}_{50}=8,9 \mu \mathrm{M}\right)$, que se mostrou quase duas vezes mais potente que o fármaco de referência benznidazol $\left(I_{50}=14,6 \mu \mathrm{M}\right)$. Quando testado a concentração citotóxica $\left(C_{50}\right)$ para tripomastigotas $T$. cruzi, os melhores valores variaram entre $173,3 \mu \mathrm{M}$ e $244,4 \mu \mathrm{M}$, sendo o composto 1B $\left(\mathrm{CC}_{50}=244,4 \mu \mathrm{M}\right)$ duas vezes menos tóxico que o benznidazol $\left(\mathrm{CC}_{50}=123,7 \mu \mathrm{M}\right)$.

Quanto ao índice de seletividade, a relevância vai para o 1B (IS=17), demonstrando-se mais seletivo, quando comparado ao BZD (IS $=8,5)$.

Tabela 1 - Resultados obtidos para atividade antichagásica dos Ftalimido-tiazolinonas.<smiles>O=C1N/C(=N\N2C(=O)c3ccccc3C2=O)S/C1=C/c1ccccc1</smiles>

Estrutura geral dos derivados ftalimido-tiazolinonas

\begin{tabular}{|c|c|c|c|c|c|c|}
\hline Código & $\begin{array}{l}\text { Citotoxicida } \\
\text { de } \\
\left(\mathrm{CC}_{50}\right) \mu \mathrm{M}\end{array}$ & $\begin{array}{c}\mathrm{IC}_{50} \\
\text { Tripomastigota } \\
\text { suM (Cepa Y) }\end{array}$ & IS & $\begin{array}{c}\text { IC }_{50} \\
\text { Amastigota } \\
\mu \mathrm{M} \text { (Cepa } \\
\text { Tulahuen) }\end{array}$ & IS $_{\text {(amas) }}$ & $\mathbf{R}$ \\
\hline $1 A$ & 36,6 & 8,9 & 4,1 & 27,6 & 1,3 & $3-\mathrm{Cl}$ \\
\hline $1 B$ & 244,4 & 14,3 & 17,0 & 47,8 & 5,1 & 3,4-diCl \\
\hline $1 C$ & 28,8 & 76,7 & 0,4 & 37,2 & 0,8 & 3-MeO \\
\hline 1D & 40,0 & 9,5 & 4,2 & 22,5 & 1,8 & 4-MeO \\
\hline $1 E$ & 213,6 & 145,0 & 1,5 & 50,7 & 4,2 & $3-\mathrm{NO}_{2}$ \\
\hline $1 F$ & 120,4 & 139,0 & 0,9 & 50,7 & 2,4 & $4-\mathrm{NO}_{2}$ \\
\hline $1 G$ & 48,0 & 93,3 & 0,5 & 29,1 & 1,7 & 3-Me \\
\hline $1 \mathrm{H}$ & 67,1 & 66,5 & 1,0 & 12,6 & 5,3 & 4-Me \\
\hline 11 & 131,3 & 60,2 & 2,2 & 54,7 & 2,4 & $4-\mathrm{OH}$ \\
\hline $1 \mathrm{~J}$ & 61,1 & 67,1 & 0,9 & 49,3 & 1,2 & 4-t-butil \\
\hline $1 \mathrm{~K}$ & 173,3 & 122,9 & 1,4 & 47,9 & 3,6 & $\begin{array}{c}4- \\
\text { trifluorometil }\end{array}$ \\
\hline $1 \mathrm{~L}$ & 212,2 & 62,2 & 3,4 & 51,0 & 4,2 & 4-N,N-diMe \\
\hline BZD & 123,7 & 14,6 & 8,5 & 6,3 & 19,6 & \\
\hline
\end{tabular}

Legenda: $\mathbf{C C}_{50}=$ Concentração Citotóxica para $50 \%$ das Células; $\mathbf{I C}_{50}=$ Concentração Inibitória para $50 \%$ da População; IS(amas) = Índice de Seletividade Frente a Amastigotas; IS(tripo) = Índice de Seletividade Frente a Tripomastigotas; BZD = Benznidazol.

Fonte: FREITAS KH, et al., 2020. 


\section{DISCUSSÃO}

Os valores obtidos de Citotoxicidade ( $\left.\mathrm{CC}_{50}\right)$, Concentração Inibitória $\left(\mathrm{IC}_{50}\right)$ e Índice de Seletividade (IS) revelaram que os compostos $1 \mathrm{~A}$ e $1 \mathrm{~B}$ se mostraram mais promissores.

Nesse caso, pode-se inferir que a inserção do cloro, na posição 3 do benzaldeído, seja responsável pelo incremento da atividade biológica para o composto $1 \mathrm{~A}$, e que $\mathrm{o}$ valor mais promissor de IS e $\mathrm{CC}_{50}$ para 0 composto 1B pode estar relacionado à substituição 3,4-diCl no aldeído benzoico.

Assim, com base nos resultados encontrados por GOMES PATM, et al. (2016) e FILHO GBO, et al. (2015), realizar modificações estruturais com substituições no anel tiazolinona pode gerar uma nova série de moléculas bioativas contra o Trypanossoma cruzi.

\section{CONSIDERAÇÕES FINAIS}

As comprovações de dados estruturais através de análise de $\mathrm{RMN}^{1} \mathrm{H}$ e $\mathrm{RMN}^{13} \mathrm{C}$, mostram que os 12 novos derivados híbridos ftalimido-tiazolinonas propostos na síntese, foram efetivamente formados.

Além disso, todos os derivados foram testados quanto sua atividade anti-T. cruzi, frente as suas formas evolutivas assim como a citotoxicidade para macrófagos.

Portanto, os valores relevantes de $\mathrm{IC}_{50}$ e IS das moléculas $1 \mathrm{~A}$ e $1 \mathrm{~B}$, respectivamente, revelaram resultados promissores, quando comparados ao fármaco de referência BZD.

\section{REFERÊNCIAS}

1. GOMES PATM, et al. Phthalimido-thiazoles as building blocks and their effects on the growth and morphology of Trypanosoma cruzi. European Journal of Medicinal Chemistry, 2016; 111: 46-57.

2. FILHO GBO, et al. Structural design, synthesis and pharmacological evaluation of 4-thiazolidinones against Trypanosoma cruzi. Bioorganic \& Medicinal Chemistry, 2015; 23: 7478-7486.

3. LEITE ACL, et al. Privileged Structures in the Design of Potential Drug Candidates for Neglected Diseases. Current Medicinal Chemistry, 2019; 26: 4323. 
RESUMOS EXPANDIDOS: Estudo Original

TÍTULO: NOVAS DISPERSÕES SÓLIDAS POLIMÉRICAS COM ATIVIDADE ANTILEISHMANIA OBTIDAS DO SB-83: UM DERIVADO 2-AMINOTIOFENO

Autor/coautores: Bárbara Cristina Silva Holanda Queiroz'; Verônica da Silva Oliveira ${ }^{1}$; Marcelo de Sousa da Silva1'; Francisco Jaime Bezerra Mendonça Júnior²; Ádley Antonini Neves de Lima1.

Instituição: ${ }^{1}$ Universidade Federal do Rio Grande do Norte (UFRN), Natal-RN. ${ }^{2}$ Universidade Estadual da Paraíba (UEPB), Campina Grande - Paraíba.

Financiamento: Coordenação de Aperfeiçoamento de Pessoal de Nível Superior (CAPES).

Palavras-chave: Antileishmania, Aminotiofeno, Dispersões.

\section{INTRODUÇÃO}

Leishmanioses são zoonoses causadas por mais de 20 espécies diferentes de parasitas pertencentes ao gênero Leishmania.

O parasito Leishmania amazonensis é encontrado no Novo Mundo, principalmente na América Latina e está associado a diferentes formas clínicas de leishmaniose cutânea, comumente refratárias aos tratamentos disponíveis. A quimioterapia para leishmaniose é limitada e apresenta diversos efeitos colaterais, fato que impulsiona a busca por novas alternativas terapêuticas (STEVERDING D, 2017).

O composto sintético 2-[(5-bromo-1H-indol-3-ilmetileno)-amino]-4,5,6,7-tetrahidro-4H[b]tiofeno-3carbonitrila, o SB-83, é um derivado 2-aminotiofeno que, em estudos anteriores, apresentou alta seletividade para diferentes formas de $L$. amazonensis, bem como baixa citotoxicidade para as células do hospedeiro (RODRIGUES KAF, et al., 2018).

Todavia, o SB-83 apresenta baixa solubilidade aquosa, fato que prejudica sua biodisponibilidade por via oral. Para tal, uma solução viável seria a formação de Dispersões Sólidas (DS) com o SB-83, visto que, essa técnica tem como objetivo incorporar a droga em uma matriz polimérica hidrofílica, resultando em sua dissolução em água e melhoria de seus parâmetros físico-químicos (MOREIRA CDLFA, et al., 2018).

Por essa razão, há um aumento da biodisponibilidade do composto no organismo, o que tornaria a DS com SB-83 uma alternativa farmacológica promissora para o tratamento de leishmanioses.

\section{OBJETIVO}

Avaliar a atividade antileishmania in vitro de dispersões sólidas contendo SB-83 e os polímeros PVP (polivinilpirrolidona) e PEG 6.000 (polietilenoglicol), obtidas pelo método de rotaevaporação, sobre formas promastigotas de $L$. amazonensis.

\section{MÉTODO}

As DS foram obtidas pelo método de rotaevaporação (EV), onde à mistura física de SB-83 mais polímeros (PEG 6.000 e PVP), na razão de 1:1 (p/p), foram adicionados água e etanol (1:4). As soluções foram levadas ao rotaevaporador, secas em estufa a $50^{\circ} \mathrm{C}$ e, posteriormente, caracterizadas físico-quimicamente.

Para a atividade antileishmania in vitro, a quantidade de $1 \times 10^{6}$ promastigotas de $L$. amazonensis foram semeadas em placas de 96 poços contendo as dispersões sólidas SB-83/PEG e SB-83/PVP, com concentrações variando de 100 a $1,0 \mu \mathrm{g} / \mathrm{mL}$.

Posteriormente, as placas foram incubadas em estufa B.O.D. a $26^{\circ} \mathrm{C}$ por $24 \mathrm{~h}$. Por fim, a viabilidade celular foi avaliada pelo método colorimétrico da Resazurina® e as respectivas IC50 (concentração inibitória média) calculadas.

\section{RESULTADOS}

Através das técnicas de caracterização físico-química das dispersões sólidas de SB-83 com os polímeros PEG e PVP, tais como DRX (difração de raios X) e MEV (microscopia eletrônica de varredura), foi possível constatar a real formação de um novo sistema com essas moléculas, observando-se a redução dos picos 
cristalinos do SB-83 nas misturas e a mudança na forma característica de cada substância, especialmente no que diz respeito à cristalinidade dos isolados.

Os resultados dos ensaios in vitro demonstraram potencial de inibição de formas promastigotas de $L$. amazonensis em torno de 100\% para a dispersão SB-83/PVP e valor de aproximadamente $98 \%$ para a DS SB-83/PEG, nas concentrações de $100 \mu \mathrm{g} / \mathrm{mL}$ e $50 \mu \mathrm{g} / \mathrm{mL}$ (Figura 1) e, considerando a proporção entre SB83 e polímero utilizada no preparo das DS (1:1 - 50\% polímero $+50 \%$ SB-83), pode-se inferir que as DS apresentaram melhor atividade antileishmania que o composto isolado. Os valores de IC50 obtidos pelo GraphPad Prism 5.0 foram de 6,31 $\mu \mathrm{g} / \mathrm{mL}$ para o SB-83; 6,51 $\mu \mathrm{g} / \mathrm{mL}$ para SB-83/PVP e 8,20 $\mu \mathrm{g} / \mathrm{mL}$ para SB83/PEG.

Figura 1 - Atividade antileishmania in vitro de DS de SB-83 após 24h

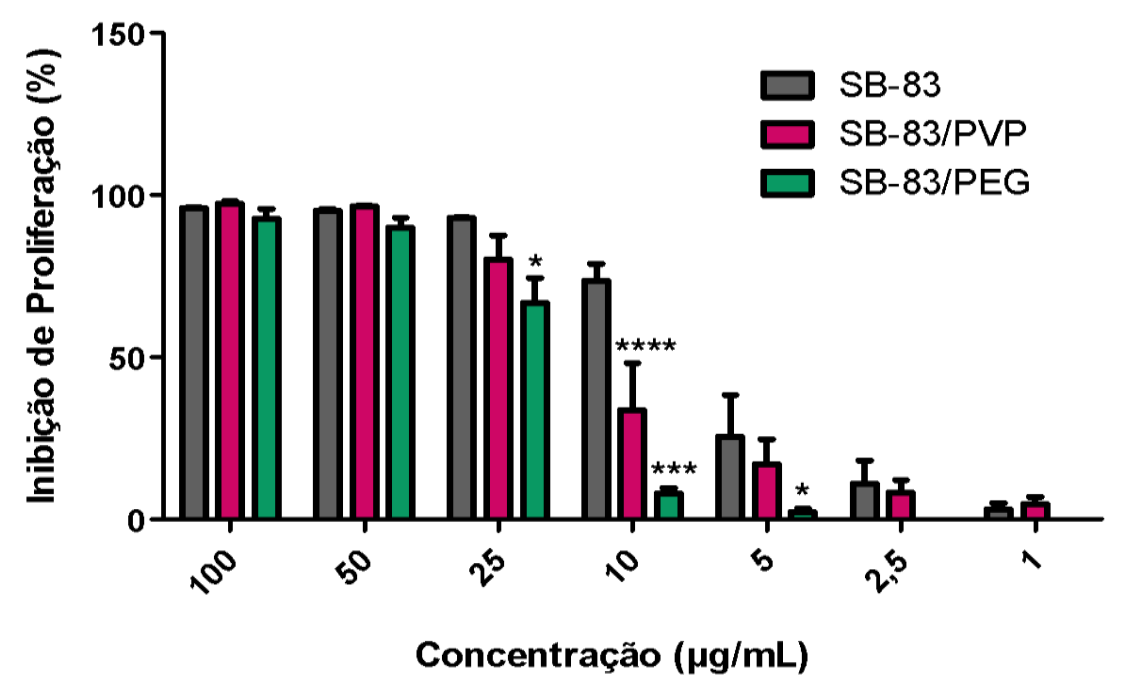

Fonte: QUEIROZ BCSH, et al., 2020.

\section{DISCUSSÃO}

As imagens de microscopia eletrônica de varredura (MEV) do SB-83 expressam o perfil cristalino do composto, mostrando cristais grossos com predominância da forma piramidal e agulhas. Já as imagens obtidas para os sistemas SB-83/PEG e SB-83/PVP exibiram partículas com formas irregulares, com superfícies rugosas e morfologia diferente do SB-83 e dos polímeros quando isolados, sugerindo a formação de um novo sistema - a dispersão sólida.

A redução da cristalinidade do composto pode acarretar aumento de sua hidrossolubilidade, que é um dos principais objetivos a ser atingido com a elaboração das DS.

Com a hidrossolubilidade aumentada, o SB-83 pode vir a ser mais biodisponível, em uma formulação por via oral para tratamento de leishmanioses, visto que, já foi comprovada sua atividade biológica em estudos anteriormente realizados por Rodrigues KAF, et al. (2018), e a inovação com a formulação de DS poliméricas vêm para viabilizar a utilização desse composto como futura alternativa terapêutica.

\section{CONSIDERAÇÕES FINAIS}

Pelos resultados obtidos com esta pesquisa, constatou-se a formação de dispersões sólidas entre o SB83 e os polímeros PVP e PEG, através do método de rotaevaporação, além do incremento de suas características físico-químicas.

Ademais, as dispersões sólidas poliméricas obtidas a partir do SB-83 apresentaram significativa atividade leishmanicida in vitro em diferentes concentrações, até mesmo superior ao composto isolado. 
Investigações futuras são necessárias, inclusive para avaliar a toxicidade dessas dispersões em células de hospedeiros, a fim de confirmar seu uso como alternativa terapêutica frente à leishmaniose.

\section{REFERÊNCIAS}

1. MOREIRA CDLFA, et al. Amorphous solid dispersions of hecogenin acetate using different polymers for enhancement of solubility and improvement of anti-hyperalgesic effect in neuropathic pain model in mice. Biomedicine and Pharmacotherapy, 2018; 97: 70-879.

2. RODRIGUES KAF, et al. SB-83, a 2-Amino-thiophene derivative orally bioavailable candidate for the leishmaniasis treatment. Biomedicine \& Pharmacotherapy, 2018; 108: 1670-1678.

3. STEVERDING D. The history of leishmaniasis. Parasites \& Vectors, 2017; 10: 82. 
RESUMO EXPANDIDO: Revisão Bibliográfica

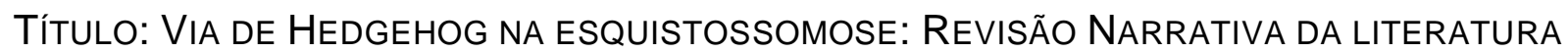

Autor/coautores: Débora Nascimento da Nóbrega ${ }^{1}$, Ana Luiza Trajano Mangueira de Melo² $^{2}$, Bruna Eduarda Freitas Monteiro², Gábata de Fátima Gomes da Silva1', Taciana Furtado de Mendonça Belmont ${ }^{3}$.

Instituição: Instituto Aggeu Magalhães (IAM-FIOCRUZ), Recife-Pernambuco'; Instituto de Ciências Biológicas (ICB-UPE), Recife-Pernambuco²; Faculdade de Ciências Médicas (FCM-UPE), Recife-Pernambuco3.

Palavras-chave: Esquistossomose, Proteínas Hedgehog, Fibrose.

\section{INTRODUÇÃO}

A esquistossomose é uma doença de veiculação hídrica, com ocorrência em 54 países, entre eles o Brasil, onde cerca de 1,5 milhões de pessoas vivem em áreas de risco. Esta doença é de grande importância para a saúde pública, apesar disso, ainda é considerada uma doença negligenciada, principalmente por se concentrar em populações de baixa renda (NOYA O, et al., 2015).

Devido à frequente exposição da população ao esquistossomo, as formas crônicas hepatointestinal e hepatoesplênica são frequentes nas regiões endêmicas. $O$ tratamento para esquistossomose com praziquantel é eficaz no controle da doença, mas não é capaz de recuperar o tecido fibrótico dos pacientes que evoluem nas formas crônicas. Não existindo um tratamento adequado a este quadro, muitos pacientes são indicados ao transplante (MCMANUS DP, et al., 2020).

Os genes hedgehogs são cruciais na embriogênese e organogênese, sendo responsáveis pela modulação de genes que promovem a formação e crescimento de tecidos/órgãos, entretanto, estes genes foram associados ao desenvolvimento e progressão de câncer e na formação de tecido fibrótico (KATOH M, 2019).

Entender como a via de hedgehog está relacionada na esquistossomose pode abrir novos caminhos com fins terapêuticos e na melhor assistência dos pacientes com esquistossomose, reduzindo o número de cirurgias necessárias, transplantes e óbitos.

\section{OBJETIVO}

Analisar o resultado de pesquisas envolvendo a sinalização pela via de hedgehog nos processos patológicos da esquistossomose.

\section{REVISÃO BIBLIOGRÁFICA}

Com a frequente oviposição das fêmeas de Schistosomas spp. nas veias mesentéricas hepáticas, antígenos do ovo estimulam uma resposta inflamatória granulomatosa (MCMANUS DP, et al., 2020).

Nos estágios iniciais da infecção, linfócitos e macrófagos produzem citocinas pró-inflamatórias e antifibrogênicas (INF- $\gamma$ e TNF- $\alpha$ ), entretanto com a evolução do quadro, na fase crônica, há uma mudança alternativa na caracterização dos macrófagos, aumentando o acúmulo e deposição de tecido fibrótico, ocasionando a fibrose periportal e hipertensão portal (MCMANUS DP, et al., 2020; LI H, et al., 2016).

Através de imunohistoquímica, foi averiguado que antígenos solúveis do ovo estimulam a produção de ligantes de hedgehog $(\mathrm{Hh})$ por macrófagos de pacientes com esquistossomose, cultivados. Ligantes de $\mathrm{Hh}$ quando interagem com seu receptor (Patched), inibe o co-receptor Smoothened (shh), restringindo-o a migrar para a base do cílio, onde ativa uma família de fatores de transcrição - glioma (Gli) (PEREIRA TA, et al., 2013 apud ELHENAWY AA, et al., 2017).

A ativação de Gli1, 2 e 3 induz a transcrição de genes alvos de $\mathrm{Hh}$, levando a uma ativação alternativa de macrófagos de fenótipo M2. Macrófagos M2 expressam marcadores como Arginase-1, CD206, CD163 e VEGF-A, que promovem a fibrogênese e regulação do remodelamento vascular, contribuindo com 0 crescimento anormal do endotélio e formação de miofibroblastos (PEREIRA TA, et al., 2013 apud ELHENAWY AA, et al., 2017). 
A pentoxifilina (PTX) e o GDC-0449 (Vismodegib) foram testados como inibidores da via hedgehog, indicando possíveis tratamentos anti-fibrogênicos. Os resultados mostraram que PTX reduziu a expressão in vitro de mRNA de shh e gli1, em macrófagos previamente estimulados por antígenos de S. japonica (LI H, et al., 2016). Enquanto GDC-0449 se liga ao shh e exerce efeitos antagônicos ao Hh, este por sua vez reduziu significativamente o diâmetro de granulomas em camundongos infectados com S. mansoni (ELHENAWY AA, et al., 2017).

\section{DISCUSSÃO}

Assim como a esquistossomose, a infecção pelo Vírus da Hepatite $\mathrm{C}(\mathrm{HCV})$ é uma das principais causas de fibrose hepática em países em desenvolvimento. Granato M. e colaboradores (2016) descobriram que Gli2 encontra-se ativada nos núcleos de fibroblastos expostos ao HCV por ensaio de imunofluorescência, e através de Western-Blot verificaram uma expressão aumentada de Gli-2 no lisado celular exposto a soros com HCV, comparado aos controles. No entanto, na presença de antivirais a expressão foi reduzida em soros contendo HCV.

Os autores sugeriram, portanto, que o vírus pode ter um efeito na ativação da sinalização $\mathrm{Hh}$, favorecendo o processo de fibrose, semelhante aos estudos desta revisão, encontrando uma correlação entre antígenos do ovo do esquistossomo e a ativação da via de Hh.

Portanto, a sinalização pela via de Hh pode ter um papel importante na regulação de genes durante processos infecciosos causados por patógenos (GRANATO M, et al., 2016).

\section{CONSIDERAÇÕES FINAIS}

A investigação das vias de hedgehog promoveu um avanço no conhecimento patológico e nas implicações imunogenéticas associadas à esquistossomose, em especial no que se refere ao seu envolvimento na regulação da fibrose hepática e na remodelação vascular.

Desta forma, tornou-se possível a abrangência de novas pesquisas em terapias farmacêuticas para o tratamento das formas crônicas, como a hepatoesplênica da doença.

Entretanto, ainda existe um número significativamente reduzido de pesquisas relatadas com a temática do presente estudo, sendo necessárias, portanto, maiores investigações.

\section{REFERÊNCIAS}

1. ELHENAWY AA, et al. Possible antifibrotic effect of GDC-0449 (Vismodegib), a hedgehog-pathway inhibitor, in mice model of Schistosoma-induced liver fibrosis. Parasitology international, 2017; 66 (5): 545-554.

2. GRANATO M, et al. HCV derived from sera of HCV-infected patients induces pro-fibrotic effects in human primary fibroblasts by activating GLI2. Scientific reports, 2016; 6 (1):1-11.

3. KATO M. Genomic testing, tumor microenvironment and targeted therapy of Hedgehog-related human cancers. Clinical Science, 2019; 133 (8): 953-970.

4. $\mathrm{LI} \mathrm{H}$, et al. Pentoxifylline inhibits liver fibrosis via hedgehog signaling pathway. Journal of Huazhong University of Science and Technology [Medical Sciences], 2016; 36 (3): 372-376.

5. MCMANUS DP, et al. Schistosomiasis-from immunopathology to vaccines. Seminars in Immunopathology. Springer Berlin Heidelberg, 2020; 1-17.

6. NOYA O, et al. Schistosomiais in America. Neglected tropical diseases-Latin America and the Caribbean, $2015 ; 11-43$. 
RESUMO EXPANDIDO: Revisão Bibliográfica

\section{TítUlo: ANÁlise COMPARATIVA dO PERFIL EPIDEMIOLÓGICO DA DENGUE EM MEIO A PANDEMIA} DO COVID-19

Autores/coautores: Júlia de Kássya Alcantara Santana, Cristiana Maria de Oliveira, Thaise Queiroz de Melo. Instituição: Universidade Salgado de Oliveira (UNIVERSO), Recife-Pernambuco.

Palavras chaves: Arbovirose, SARS-CoV-2, Saúde coletiva.

\section{INTRODUÇÃO}

A dengue é uma arbovirose causada pela picada mosquito Aedes aegypti contaminado com o vírus da mesma, sendo considerada uma doença febril aguda. Sabe-se que o aumento do nível pluviométrico (chuvas) e as falhas nas ações de controle do mosquito vetor (Aedes aegypti) contribuem para o crescimento de casos de dengue nesse período principalmente em países tropicais, como o Brasil, que lida com epidemias de dengue desde 1986, pois a sua propagação dar-se a partir do acúmulo de água parada, com maior proliferação em período mais chuvosos (de março a julho) (MASCARENHAS, et al., 2020).

Coincidentemente, nesse período epidemiológico de dengue de 2020 o Brasil se depara com a chegada da pandemia do COVID-19, que é uma doença causada pelo coronavírus SARS-CoV-2. Na qual apresenta características clínicas semelhantes à da dengue, como a lesão cutânea, dores de cabeça intensa e o quadro febril, podendo assim contribuir com a subnotificação de casos de dengue devido a semelhança nos diagnósticos, necessitando de uma atenção epidemiológica especial (LORENZ, et al., 2020).

\section{OBJETIVO}

Analisar o perfil epidemiológico da Dengue em meio à pandemia do COVID-19, e expressar comparações durante o mesmo período do ano anterior contribuindo para a vigilância epidemiológica e controle vetorial do Aedes aegypti.

\section{METODOLOGIA}

Foi realizada uma revisão de literatura integrativa, onde a pesquisa deu-se através da Biblioteca Virtual de Saúde, os descritores utilizados foram "dengue" e "COVID-19", onde permitiu o achado de 67 artigos inicialmente. As bases de dados incluídas foram a Medline, Scielo, Lilacs e Coleciona SUS tendo como assunto principal dengue. Após a leitura e análise restaram apenas 8 artigos e destes, foram incluídos 4 artigos.

Foram excluídos os artigos que constavam informações desatualizadas, que tratavam de uma localidade específica e que o foco era apenas em lesões. A temporalidade dos dados foi comparativa entre as semanas epidemiológicas até o mês de junho do ano de 2019 e 2020.

\section{REVISÃO BIBLIOGRÁFICA}

Tendo em vista que o vírus da dengue possui quatro sorotipos (DEN-1, DEN-2, DEN-3 e DEN-4), a infecção por um dos sorotipos resulta imunidade somente para aquele sorotipo específico, logo, os indivíduos podem ser infectados pelos quatro sorotipos. Em contrapartida, o novo coronavírus (SARS-CoV-2) é um vírus com mutação recente que ainda está sendo estudado, mas já apresenta casos de coinfecção, é necessário destacar que os vírus não estão relacionados antigenicamente, ou seja, pertencem a famílias virais distintas e distantes. (SAAVEDRA-VELASCO, et al., 2020).

Além do mais, no Brasil, as condições precárias de habitação e saneamento acarretam desfavoráveis indicadores socioeconômicos que refletem a qualidade de vida da maioria da população, ampliam os impactos e dificultam as estratégias de enfrentamento das doenças. Por essa razão, a vigilância epidemiológica deve ser contínua, ainda que em meio a pandemia, disponibilizando informações necessárias sobre os casos suspeitos e confirmados da dengue visando o controle vetorial (proliferação do mosquito), evidenciando a importância da educação em saúde (ORGANIZACIÓN PANAMERICANA DE LA SALUD, 2020). 
Em aspectos quantitativos, o ano de 2019 teve uma alta prevalência de casos de dengue no Brasil, quando comparado a 2018 houve um aumento de cerca de $264 \%$. Já em 2020 , estima-se um aumento no período de surto epidemiológico, pois até a semana epidemiológica (SE) 11, a curva epidêmica dos casos prováveis no ano corrente ultrapassa o número de casos do mesmo período para o ano de 2019 (Boletim epidemiológico, 2020). No entanto, a partir da SE 12, quando houve os primeiros casos de COVID-19 no Brasil ocorreu uma diminuição significativa dos casos prováveis em relação ao ano anterior. (MINISTÉRIO DA SAÚDE, 2020).

\section{DISCUSSÃO}

De acordo com as literaturas analisadas, pôde-se perceber que o impacto entre os dois surtos epidemiológicos em mesmo momento pode acarretar consequências significativas para a população brasileira (MASCARENHAS MDM,2020): propondo uma subnotificação dos casos ou atrasos dos mesmos, em razão da atenção prioritária a COVID-19 devido à alta transmissibilidade (MINISTERIO DA SAÚDE, 2020).

Esse estudo limita-se por ser da situação atual, passível de alteração e acréscimos dos dados epidemiológicos em análise. Novas pesquisas (SAAVEDRA-VELASCO M, 2020) podem ser realizadas em relação à coinfecção dos casos, formas de o sistema de saúde lidar com possíveis novos surtos que venham a se chocar, erradicação do vírus da dengue e vacinas assegurando assim a eliminação de possíveis dúvidas em relação à proteção e combate das epidemias (MASCARENHAS MDM, 2020).

\section{CONSIDERAÇÕES FINAIS}

Em virtude dos fatos mencionados, percebeu-se que o número de casos de dengue cresceu em relação ao ano anterior, mas a partir das notificações dos primeiros casos de COVID-19 o número decaiu significativamente.

O enfrentamento dessas doenças como no caso da dengue requer a implantação de estratégias eficazes de conscientização da população no sentido de eliminar criadouros de mosquitos; e nos casos do atual coronavírus lavagem das mãos, uso de máscaras e, principalmente, distanciamento social.

\section{REFERÊNCIAS}

1. BRASIL. Secretaria de Vigilância em Saúde, Boletim Epidemiológico. Ministério da saúde, 2020. Disponível em: https://www.saude.gov.br/images/pdf/2020/June/16/Boletim-epidemiologico-SVS-24final.pdf. Acessado em: 6 de julho de 2020.

2. LOREN C, et al. COVID-19 and dengue fever: A dangerous combination for the health system in Brazil. Travel Med Infect Dis, 2020; 35: 101659.

3. MASCARENHAS MDM, et al. Ocorrência simultânea de COVID-19 e dengue: o que os dados revelam?. Cad. Saúde Pública, 2020; 36(6): e00126520.

4. OPS. Prevención y control del dengue durante la pandemia de COVID-19, 2020. Disponível em: http://docs.bvsalud.org/biblioref/2020/05/1097252/dengue-prevencion-control-covid-19.pdf. Acessado em: 6 de julho de 2020.

5. SAAVEDRA-VELASCO M, et al. Coinfección entre dengue y COVID-19: Necesidad de abordaje en zonas endémicas. Rev Fac Cien Med Univ Nac Cordoba, 2020; 77(1): 52-54. 
RESUMO EXPANDIDO: Revisão Bibliográfica

TíTULO: ABORDAGEM HISTÓRICA E ARQUEOLÓGICA DA ENTAMOEBA HISTOLYTICA

Autor/coautores: José Pedro Martins Barbosa Filho; José Odimar de Caldas Brandão Filho.

Instituição: Universidade Federal de Pernambuco (UFPE), Recife-Pernambuco.

Palavras-chave: Entamoeba histolytica, Paleoparasitologia, História.

\section{INTRODUÇÃO}

O gênero Entamoeba engloba um grupo de organismos unicelulares, anaeróbicos, organismos parasitários encontrados em humanos, primatas não humanos, outras espécies de vertebrados e invertebrados em todo o mundo. A Entamoeba histolytica, única espécie definitivamente associada a danos patológicas, é um protozoário patogênico intestinal invasivo causadora da amebíase.

Esta parasitose apresenta ampla distribuição geográfica com alta prevalência em regiões tropicais, onde as condições de higiene e educação sanitária são consideradas deficientes. A crescente migração de pessoas de países em desenvolvimento para países desenvolvidos favoreceu a disseminação do parasito por todo o mundo. Estimativas da Organização Mundial de Saúde (OMS) indicam que aproximadamente 50 milhões de pessoas são afetadas pela $E$. histolytica, sendo responsável por cerca de cem mil mortes por ano, tornandoa uma das causas mais importantes de morbimortalidade no homem (XIMÉNEZ C, et al., 2015).

Muitas ocorrências antigas de parasitos foram registradas nos últimos dez milênios e é possível propor uma reconstrução da história deles, principalmente após a introdução da imunologia nas análises paleoparasitológicas na década de 1980 para testar a presença de protozoários de importância médica em amostras antigas (ARAÚJO A, et al., 2015).

\section{OBJETIVO}

Realizar na literatura um levantamento sobre as ocorrências arqueológicas e revisão histórica da Entamoeba histolytica. A busca literária foi realizada nas plataformas de pesquisa ScienceDirect, Pubmed e Scielo. Foram selecionados artigos com informações sobre os aspectos históricos e paleoaqueológicos da espécie.

\section{REVISÃO BIBLIOGRÁFICA}

A detecção de E. histolytica através de achados arqueológicos se baseiam na recuperação de marcadores parasitas de coprólitos (fezes antigas preservadas) ou amostras de sedimentos colhidas na região pélvica de esqueletos, fossas, latrinas e todos os contextos que contêm potencialmente matéria fecal humana. A microscopia foi utilizada com sucesso em casos muito raros, com excepcional boas condições de preservação, ao passo que a imunologia, particularmente os ensaios imunoabsorventes ligados a enzimas (ELISA), produziu resultados positivos para a detecção de antígenos específicos preservados do parasita (HAQUE R, et al., 2015).

Os primeiros relatos da presença de cistos de Entamoeba sp. observados em amostras arqueológicas (possivelmente E. coli de acordo com as hipóteses) remetem ao ano de 1964.

Somente no ano de 1961, confirmaram a presença da E. histolytica em amostras antigas. Estudos realizados revisaram ocorrências iniciais através de ELISA para testar materiais de sítios arqueológicos. Uma amostra suíça do sítio arqueológico na cidade de Concise, (lago Neufchatel), datado do período neolítico (3700 anos a.C.), foi positivo para antígenos específicos de E. histolytica, confirmando a presença do parasita na Suíça pré-histórica (LE BAILLY M e BOUCHET F, 2015). Com o auxílio de ELISA análises foram feitas em um conjunto de amostras de sedimentos do solo de uma latrina no Acre, em Israel, identificando a presença da E. histolytica. A latrina, datada do século XIII d.C., estava localizada em um hospital usado por cruzados europeus pertencentes à ordem militar de São João. Técnicas imunológicas utilizadas em amostras de dois cemitérios do período colonial no Caribe, em Guadalupe revelaram evidências de E. histolytica. 
Nesta análise, uma amostra datada do período pré-colonial também testou positivo para a ameba, confirmando a presença do parasita antes da chegada dos europeus durante o século XV (LE BAILLY M, et al., 2016).

\section{DISCUSSÃO}

A integração de ferramentas biológicas na paleoparasitologia tornou-se crucial para o desenvolvimento futuro desse campo de pesquisa. O uso de tais técnicas avançadas leva ao diagnóstico específico direto de parasitas antigos, o que nem sempre é possível usando microscopia baseada nos dados morfométricos atualmente disponíveis.

O surgimento da linhagem de E. histolytica nas Américas pré-colombianas e no Oriente Médio por volta do século XII dá origem a hipóteses de como as migrações humanas (rotas do Atlântico ou do Pacífico) contribuíram para a difusão desse patógeno, resultando em sua distribuição atual. Nos últimos 6000 anos, os dados coletados até agora relacionados a E. histolytica sugerem, como hipótese, uma origem europeia da atual cepa do parasito, com uma possível difusão para o leste e depois para as Américas por meio de migrações ou trocas humanas via rotas comerciais. (LE BAILLY M, et al., 2017).

\section{CONSIDERAÇÕES FINAIS}

Outras cepas da E. histolytica podem estar presentes no passado, mas ferramentas modernas especificamente adaptadas à cepa atual não podem detectá-las.

Embora a aplicação da imunologia e da biologia molecular deva ser cada vez mais desenvolvida, o uso da microscopia deve ser mantido e aprimorado, pois apenas abordagens combinadas podem levar a uma reconstrução exaustiva da biodiversidade e co-evolução dos parasitos.

Esses achados arqueológicos mostram o papel dos seres humanos na difusão de patógenos e na atual distribuição de patologias, e confirmam que os parasitas são uma valiosa informação para o estudo de rotas de migração antigas.

\section{REFERÊNCIAS}

1. ARAUJO A, et al. New World Paleoparasitology. In: Mitchell, P. (Ed.). Sanitation, Latrines and Intestinal Parasites in Past Populations. Ashgate edition, Surrey, 2015; 165-202.

2. HAQUE R, et al. Diagnosis of amebic liver abscess and intestinal infection with the TechLab Entamoeba histolytica II antigen detection and antibody tests. J. Clin. Microbiol, 2015; 38(9): 3235-3239.

3. LE BAILLY M, BOUCHET F. A first attempt to retrace the history of dysentery caused by Entamoeba histolytica. In: Mitchell, P. (Ed.), Sanitation, Latrines and Intestinal Parasites in Past Populations. Ashgate edition, Surrey, 2015; 219-228.

LE BAILLY M, et al. Archaeological occurrences and historical review of the human amoeba, Entamoeba histolytica, over the past 6000 years. Infection, Genetics and Evolution, 2017; 42(1): 34-40.

5. LE BAILLY M, et al. New evidence of Entamoeba histolytica infections in pre-Columbian and colonial cemeteries in the Caribbean. J. Parasitol, 2016; 100(1): 684-686.

6. XIMÉNEZ C, et al. Human amebiasis: breaking the paradigm?. International Journal of Environmental Research and Public Health, 2015; 7(3): 1105-1120. 
RESUMO EXPANDIDO: Revisão Bibliográfica

TíTULO: PERFIL CLÍNICO-EPIDEMIOLÓGICO DE PACIENTES COM ESQUISTOSSOMOSE NO NORDESTE BRASILEIRO - UMA REVISÃO BIBLIOGRÁFICA

Autor/Coautor: Artur Vinícius de Lima Montenegro Costa, Clarice Valentim de Melo, Heloisa de Barros Dantas e Francisca Janaina Soares Rocha.

Instituição: Universidade Federal de Pernambuco (UFPE), Recife-Pernambuco.

Palavras-chave: Esquistossomose, Perfil Clínico-Epidemiológico, Nordeste brasileiro.

\section{INTRODUÇÃO}

A Esquistossomose, popularmente conhecida no Brasil como "barriga d'água" ou "doença do caramujo", é uma doença parasitária causada, principalmente, pelo helminto trematódeo: Schistosoma mansoni. A Organização Mundial da Saúde (OMS) a considera como a segunda doença parasitária infecciosa de maior importância do mundo.

No Nordeste brasileiro, a esquistossomose é enquadrada como endêmica, pois a região fornece um clima propício e condições de saúde pública precárias. Nesse contexto, fatores biológicos, socioeconômicos, culturais, ambientais e sistemas de tratamento de água ineficazes contribuem para o aumento no risco de contaminação (MACEDO JAM e COSTA ABS, 2020).

Essas condições interferem diretamente na população de baixa renda com condições de higiene e saneamento básico inadequadas, refletindo no perfil clínico e epidemiológico dos pacientes acometidos pela enfermidade. Além disso, por ser uma doença tropical negligenciada, a esquistossomose apresenta uma redução nos investimentos em pesquisa, na elaboração de novos medicamentos e em ações de controle sanitário (SILVA MBA, et al., 2015).

\section{OBJETIVOS}

Caracterizar, por meio de levantamento bibliográfico, o perfil clínico-epidemiológico de pacientes acometidos por esquistossomose na região Nordeste do Brasil, bem como associar e comparar as características sociais da doença entre os seus diferentes Estados.

\section{MÉTODO}

Trata-se de uma revisão integrativa da literatura, utilizando acervos científicos como: Google Acadêmico, SCIELO, PubMed e Lilacs. Os critérios de inclusão foram baseados no tempo de publicação entre 2015-2020 e português como linguagem principal.

As publicações selecionadas devem abordar o perfil clínico e epidemiológico de pacientes com Esquistossomose e estar situadas em estados do Nordeste brasileiro. As palavras-chave utilizadas foram "esquistossomose", "perfil clínico epidemiológico " e "nordeste brasileiro".

\section{REVISÃO BIBLIOGRÁFICA}

A revisão bibliográfica abordou cidades de quatro estados: Pernambuco, Bahia, Alagoas e Rio Grande do Norte. Todos se baseiam em uma análise descritiva e quantitativa do perfil social, clínico e epidemiológico de pacientes com esquistossomose. Estudo realizado em um Hospital Universitário de Pernambuco revelou que, entre 2007 e 2013, surgiram 381 casos de esquistossomose no referido hospital, sendo 56,6\% homens acima de 60 anos. Isso reforça o fato de o estado ter 102 municípios considerados endêmicos para a doença, além da maior ocupação no campo ou na agricultura em contato com águas contaminadas ser, em sua maioria, por homens (SILVA MBA, et al., 2015).

Ademais, os resultados obtidos endossam o fato de os homens procurarem cada vez menos os serviços primários de saúde, desenvolvendo doenças crônicas ao longo do tempo. Ainda de acordo com o estudo, as 
principais complicações apresentadas entre os pacientes foram ascite, hipertensão portal e hemorragia digestiva alta.

Por outro lado, a pesquisa realizada nos municípios da Bahia entre 2001 e 2017 constatou 544 casos registrados, sendo $51,65 \%$ do sexo feminino, prevalecendo a faixa etária de 20 a 39 anos. Além disso, foi visto que as regiões urbanas $(76,10 \%)$ apresentaram maior índice em comparação com a zona rural (18,57\%), isso explica a crescente migração de trabalhadores rurais às cidades, podendo levar consigo a doença e 0 vetor, disseminando-a pela zona urbana (LEITE BHS, et. al, 2017).

Sabe-se que o perfil dos pacientes contaminados está diretamente ligado às características socioeconômicas dos indivíduos e noções básicas de educação em saúde. Assim, o estudo realizado na Bahia mostrou que $56 \%$ dos casos possuíam baixa escolaridade. Como complemento, a pesquisa feita no Rio Grande do Norte indica que o maior índice da escolaridade dos contaminados está entre a quinta e a oitava série.

\section{DISCUSSÃO}

Estudos mostram que a incidência da esquistossomose no Nordeste ainda é progressiva e preocupante, com base nos dados do Sistema de Informação de Agravos de Notificação (SINAN) em cada estado. Além disso, vê-se que a enfermidade está presente de forma equilibrada em ambos os sexos, mas com oscilações de faixa etária.

Ademais, os dados dos artigos analisados revelam uma ligação direta entre o perfil clínico epidemiológico do paciente com os fatores sociais, econômicos, culturais e demográficos que aumentam a dispersão da doença na região (LEITE BHS, et al., 2017).

Contudo, por se tratar de estudos observacionais de longo prazo, há certa variação entre os dados analisados, decorrente de subnotificações, erros ou até mesmo a falta de atualização dos casos no SINAN.

\section{CONSIDERAÇÕES FINAIS}

O Nordeste é uma das regiões que mais sofre com condições inadequadas de saneamento básico, ausência de ações educativas em saúde e alto índice de pobreza, fatores que contribuem para a contaminação pelo Schistosoma mansoni.

A esquistossomose é considerada um grave problema de saúde pública nacional, apresentando alta taxa de internação e mortalidade.

Assim, seu reconhecimento é importante para que haja adesão às políticas de controle sanitário e educação em saúde, alcançando o perfil socioepidemiológico da população mais suscetível à doença.

\section{REFERÊNCIAS}

1. CHILES GR, et al. Perfil epidemiológico da esquistossomose nos municípios da costa das baleias no período de 2001 a 2017. Brazilian Journal of Animal and Environmental Research. 2020; (3)2, 405-415.

2. LEITE BHS, et al. Incidência de Esquistossomose Mansônica em Pernambuco no Período Compreendido entre 2010 a 2016. Ciências Biológicas e de Saúde Unit - Facipe. 2017; (3)2, 57-66.

3. MACEDO JAM, COSTA ABS. Abordagem sobre a Schistosoma Mansoni e seu perfil epidemiológico nos municípios do Rio Grande do Norte/RN. Medicus. 2020; (2)1, 7-13.

4. SANTOS CMA, et al. Comparativo e perfil dos infectados em esquistossomose no estado de Alagoas entre 2016 e 2017. Revista eletrônica Pubvet. 2019; (13)8, 1-8, a386.

5. SILVA MBA, et al. Perfil epidemiológico de pacientes suspeitos de esquistossomose e patologias associadas em um hospital pernambucano. Revista Enfermagem Digital Cuidado e Promoção da Saúde. 2015; (1)1, 43-46. 
RESUMOS EXPANDIDO: Revisão Bibliográfica

TíTULO: ANÁLISE DO PRESSUPOSTO JURÍDICO DO DIREITO À SAÚDE DE PACIENTES COM TUBERCULOSE

Autor/coautores: Lucas Victtor de Carvalho Gomes1; Julyanne Victória dos Santos Ferreira2; Ana Paula Correia de Albuquerque da Costa3

Instituição: Universidade Federal da Paraíba (UFPB), Santa Rita- Paraíba1 ,3; Universidade Federal Rural de Pernambuco (UFRPE), Recife- Pernambuco2.

Palavras-chave: Doença, infectocontagiosa, Dignidade.

INTRODUÇÃO

O Direito à saúde é reconhecido enquanto essencialidade humana posta no rol de Direitos Sociais estabelecidos pela Constituição Federal. Nesse diapasão, observa-se que este direito é negligenciado quando se analisa a questão da tuberculose (TB) por diversos fatores infra elencados.

A TB é uma doença infectocontagiosa causada pela Mycobacterium tuberculosis, que segundo a Organização Mundial da Saúde (OMS), 10 milhões de novos casos são notificados a cada ano, colocando-a entre as dez maiores causas de mortes no mundo, afetando principalmente países em condições de subdesenvolvimento, em que as pessoas vivem em condições precárias, e tem seu direito à saúde negligenciado.

Destarte, existir se consigna modernamente, em viver com saúde e em gozo da Dignidade Humana, assim, não adianta a Constituição garantir Direitos Fundamentais, como a igualdade e a liberdade, se não priorizar a vida num desses direitos (SILVA JA, 2017). Nesse ínterim, verifica-se a importância do viver com dignidade e sua relação com a saúde.

\section{OBJETIVO}

Reunir informações acerca da tuberculose com um olhar crítico e jurídico da doença somados a problemática de saúde pública. Tendo como objetivos específicos analisar as bases do direito constitucional à saúde e os dados epidemiológicos em uma interligação com o Direito Público.

\section{REVISÃO BIBLIOGRÁFICA}

As marcas da história econômica latino-americana e as interferências globais produziram determinantes de desigualdades sociais de difícil reparo, sem intervenção do ente estatal como promotor do bem estar coletivo. Tais dificuldades sociais foram muito agravadas e gestadas na própria responsabilidade estatal em suas marcas fiscais e econômicas, de modo que em muitos países por formatações privadas no setor público as prestações de serviços sociais acabaram ficando a cargo precípuo e qualitativo do setor privado em detrimento do público, em específico nas questões de saúde.

Visando sanar tais dificuldades surgem esforços globais para que se atinjam as metas dos Objetivos de Desenvolvimento do Milênio (ODM). Sendo assim, a estratégia Stop TB, implantada no período de 1990 a 2015, teve progresso na luta contra a TB (BARREIRA D, 2018; MACHADO CV e LIMA DL, 2017).

No entanto, quando a questão é TB observa-se em todo o mundo um grande número de casos e de reincidência da doença, que levam milhares de mortes provocadas pela resistência bacteriana, sendo a principal causa de reincidência resistente a não conclusão do tratamento por parte dos pacientes, que muitas vezes negligenciam o tratamento, o abandonam e continuam transmitindo a doença para outros indivíduos. Todavia, (BARREIRA D, 2018) aponta em seu estudo, que após os 25 anos de vigência dos ODM, a tuberculose se tornou a doença infecciosa que mais mata em todo o mundo e a principal causa de morte entre pessoas vivendo com o Vírus da Imunodeficiência Humana (HIV), superando a aids como a mais letal doença 
infecciosa da atualidade. Em 2016, estima-se que 10,4 milhões de pessoas adoeceram e 1,7 milhão morreram devido à TB (incluindo 400 mil co-infectadas com TB/HIV).

\section{DISCUSSÃO}

A TB é uma doença infectocontagiosa que quando não dada a devida atenção, pode levar uma família a óbito, ou deixar graves sequelas incapacitantes, comprometendo a qualidade de vida dos indivíduos, a produtividade e a capacidade de garantir o sustento familiar. Assim, baseado no perfil epidemiológico da doença no Brasil, que se contrapõe à considerável possibilidade de cura, justifica-se conhecer estratégias agregadoras, recursos capazes de promover diagnósticos cada vez mais precoces, interrupção de cadeia de transmissão e alternativas de favorecimento à adesão ao tratamento (SILVA EA e SILVA GA, 2016).

Destarte, é necessário acompanhamento estatal, pois tais feitos estão ligados as noções de interesse social e coletivo. $O$ individualismo e o abstencionismo ou neutralismo do Estado liberal provocaram imensas injustiças (SILVA JA, 2017) de modo que a saúde pública deve ser pensada de forma ampla efetivando direitos a coletividade, assim as doenças quando negligenciadas constituem um agravo a dignidade do indivíduo.

\section{CONSIDERAÇÕES FINAIS}

Em suma, destacam-se neste estudo as condições sociais de pessoas com TB, sendo necessário o conhecimento do fenômeno das desigualdades sociais brasileiras como marcadores da manutenção da vida. É possível compreender a relação dessas representações sociais com as práticas adotadas no diagnóstico e tratamento, uma vez que a forma como esses indivíduos compreendem sua doença, elaborando seus significados, faz direta relação com a experiência do tratamento, orientando suas práticas sociais.

Nesse contexto, independente da condição social do sujeito ele não pode ficar desamparado pela falta de ações dos órgãos estatais, ou ainda pela ineficácia dessas ações.

\section{REFERÊNCIAS}

1. BARREIRA B. Os desafios para a eliminação da tuberculose no Brasil. Epidemiol. Serv. Saude, v.1, p.1-4, 2018.

2. MACHADO CV, LIMA DL. Políticas e sistemas de saúde na América Latina: identidade regional e singularidades nacionais. CSP, 2017.

3. SILVA JA. Curso de Direito Constitucional Positivo. 40. ed. São Paulo: Malheiros, 2017.

4.SILVA EA, SILVA GA. O sentido de vivenciar a tuberculose: um estudo sobre representações sociais das pessoas em tratamento. Physis: Revista de Saúde Coletiva. v .26, n. 4, 2016. 
RESUMO EXPANDIDO: Revisão Bibliográfica

Título: Associação entre LRV e a fisiopatologia da leishmaniose mucocutânea: uma revisão bibliográfica

Autor/coautores: Fernanda de Souza Parente, Raul Antonio Lopes Silva Campos, Rafael Reis do Espírito Santos, Sérgio Marcelo Rodríguez Málaga.

Instituição: Universidade Federal do Pará (UFPA), Belém-Pará.

Palavras-chave: Leishmaniose, LRV, Fisiopatologia.

\section{INTRODUÇÃO}

As leishmanioses representam um grupo de doenças infecciosas, de caráter zoonótico, causadas por protozoários do gênero Leishmania, os quais podem causar quadros tegumentares e patologias graves de caráter visceral, sendo transmitidos ao homem por meio da picada de fêmeas de flebotomíneos infectados (CARVALHO RVH, et al., 2019). Na América Latina, e principalmente no Brasil, a Leishmaniose Tegumentar (LTA) é endêmica, com manifestações clínicas que variam de pequenas lesões cutâneas (LC) a quadros mais graves, como leishmaniose cutânea difusa (LCD) e a leishmaniose mucocutânea (LMC) (CANTANHÊDE LM, et al., 2015).

Muitos fatores têm sido associados à variação da gravidade na LTA, como a espécie do parasita infectante, o vetor associado à transmissão, o sistema imunológico do hospedeiro e, recentemente, a presença de um vírus endossimbiótico de RNA dupla fita denominado Leishmania RNA virus (LRV), descrito primeiramente em cepas de Leishmania (Viannia) guyanensis, e que tem sido considerado um fator importante no agravamento das lesões em ensaios experimentais com animais (CANTANHÊDE LM, et al., 2015; CARVALHO RVH, et al., 2019).

\section{OBJETIVO}

Realizar uma revisão bibliográfica sobre a associação entre o Leishmania RNA Vírus e protozoários do gênero Leishmania, bem como a sua fisiopatologia e relação com o prognóstico da Leishmaniose Mucocutânea.

\section{MÉTODO}

Trata-se de uma revisão integrativa na qual as buscas foram realizadas nas bases de dados PubMed e Scielo, segundo os seguintes descritores: "leishmania rna virus" AND ("leishmaniasis" OR "leishmaniose" OR "resistance" OR "resistência" OR "genome" OR "genoma" OR "symbiosis" OR "simbiose"), buscando responder a pergunta condutora: "Há relação entre a presença do LRV e a exacerbação na leishmaniose?". Como critério de inclusão foram selecionados apenas os artigos na língua inglesa e portuguesa publicados entre 2015 e 2020. Foram excluídos artigos em outro idioma, estudos duplicados e correções de artigos. Em seguida, foi feita uma nova exclusão, a partir da leitura do resumo dos estudos, eliminando aqueles que não relacionavam o LRV com a Leishmaniose ou apresentavam divergências, resultando na seleção de 6 artigos para a revisão.

\section{REVISÃO BIBLIOGRÁFICA}

O LRV pode ser dividido em dois tipos: LRV1, localizado nas leishmanias do Novo Mundo e LRV2, presente em parasitas do Velho Mundo. Recentemente, estudos associaram o LRV1 ao aparecimento de casos de LMC (BARKATIS S, et al.2019), que podem ocorrer devido a um processo inflamatório exacerbado em função do reconhecimento do RNA viral pelos receptores Toll-Like 3 (TLR3), resultando na produção de interferons tipo I (CARVALHO RVH, et al., 2019). Esse processo leva à ativação reduzida do inflamassoma e, consequentemente, a uma eliminação ineficaz do parasita, além de favorecer a indução de diversas citocinas e quimiocinas, como TNF- $\alpha$, IL-12, IL-6 e IL-17, tornando o padrão de resposta Th2 mais predominante (BARKATI S, et al., 2019). A superexpressão dessas citocinas pró-inflamatórias leva a uma inflamação crônica 
na lesão primária, o que, por sua vez, facilita a formação de lesões metastáticas, ou seja, facilita a disseminação dos parasitas para um local secundário (mucosa nasal), manifestando-se como uma LMC (HARTLEY M, et al., 2018).

Em contrapartida, diferentemente do LRV1, o LRV2 não demonstrou influenciar na exacerbação da LMC. Porém, estudos com Leishmania (Leishmania) aethiopica LRV2+ demonstraram que os efeitos imunológicos causados pelo vírus eram similares aos observados em infecções por Leishmania LRV1+, indicando que o LRV2 poderia estar associado ao aumento da gravidade da leishmaniose no Velho Mundo (KLESCHENKO Y, et al., 2019).

\section{DISCUSSÃO}

A presença de LRV1 associada a manifestações graves foi demonstrada em linhagens das espécies $L$.(V.) guyanensis e $L$.(V.) braziliensis, entretanto, para outras espécies como $L$. (L.) amazonensis, L. (V.) lainsoni ou $L$. (L.) infantum, esse achado não foi demonstrado, evidenciando que a espécie infectada é determinante na manifestação da doença (CANTANHÊDE LM, et al., 2018). Por fim, várias evidências apontam a associação do LVR com o aparecimento da forma grave da doença. No entanto, a gravidade e a cronicidade da leishmaniose não estão associadas apenas à presença do LRV, uma vez que, cepas de Leishmania LRV-, também causam manifestações graves, com presença de metástases e recidivas (CANTANHÊDE LM, et al., 2015).

\section{CONSIDERAÇÕES FINAIS}

Pesquisas atuais apontam os mecanismos utilizados pelo LRV para causar infecções exacerbadas no hospedeiro vertebrado e os os efetores da defesa do ser humano que atuam no processo. Ademais, estudos indicaram que o LRV1, na LTA, pode intensificar a infecção causada por $L$. (V.) guyanensis e L. (V.) braziliensis, porém não foi comprovado que em casos de L. (L.) amazonensis, L. (V.) lainsoni ou L. (L.) infantum o vírus tenha influência na gravidade doença.

Pesquisas identificam ainda que o LRV2 pode estar associado ao aumento da gravidade da leishmaniose no Velho Mundo.

\section{REFERÊNCIAS}

1. BARKATI S, et al. Cutaneous leishmaniasis in the 21st century. Current Opinion in Infectious Diseases, 32(5), 419-425. 2019.

2. CANTANHÊDE LM, et al. Further Evidence of an Association between the Presence of Leishmania RNA Virus 1 and the Mucosal Manifestations in Tegumentary Leishmaniasis Patients. Public Library of Science; 2015.

3. CANTANHÊDE LM, et al. New insights into the genetic diversity of Leishmania RNA Virus 1 and its speciesspecific relationship with Leishmania parasites. PLoS One. 2018;13(6):e0198727.

4. CARVALHO RVH, et al. Leishmania RNA virus exacerbates Leishmaniasis by subverting innate immunity via TLR3-mediated NL RP3 inflammasome inhibition, Nature comunications, 2019.

5. HARTLEY M, et al. Leishmania guyanensis parasites block the activation of the inflammasome by inhibiting maturation of IL-1ß. Microb. Cell 5, 2018; 137:149.

6. KLESCHENKO Y, et al. Molecular Characterization of Leishmania RNA virus 2 in Leishmania major from Uzbekistan. Genes (Basel). 2019;10(10):830. 
RESUMOS EXPANDIDO: Revisão Bibliográfica

TítUlo: EstratÉGIAS TERAPÊUticAs PARA O TRATAMENTO DA HEPATITE C

Autor/coautores: Jéssica Maria Fragoso Cavalcante; Fernanda Miguel de Andrade

Instituição: Faculdade de Integração do Sertão-FIS. Serra Talhada Pernambuco.

Palavras-chave: Hepatite C, Tratamento farmacológico, Terapia farmacológica.

\section{INTRODUÇÃO}

A hepatite $C$ é uma doença infeciosa causada pelo vírus da hepatite $C(\mathrm{VHC})$, que pertence a familia Flaviviridae. Trata-se de um retrovírus cuja infecção é uma das principais causas de doença hepática crônica em âmbito mundial. Atualmente o VHC afeta mais de 170 milhões de pessoas no mundo, e cerca de 400 mil vão a óbito todo ano devido a complicações dessa doença, principalmente por cirrose e carcinoma hepatocelular (POHC, 2017; KOIZUMI Y, et al., 2017).

O tratamento instituído para indivíduos infectados pelo VHC é baseado nas características do paciente, nos subtipos virais diagnosticados, no histórico clínico e resposta a tratamentos prévios, no grau de fibrose hepática e na presença de cirrose, além da existência de coinfecções (POHC, 2017).

Por muitos anos, o tratamento farmacológico mais utilizado para a hepatite $C$ foi baseado na combinação de interferon (IFN) e ribavirina (RBV), porém a introdução de novas terapias livres de IFN tem crescido consideravelmente no tratamento da hepatite $C$. Esses medicamentos podem ser combinados, com ou sem o uso de RBV, e demonstram altos índices de eficácia, baixos índices de descontinuação do tratamento e menor quantidade de eventos adversos (HE S, et al., 2015).

\section{OBJETIVO}

Analisar as estratégias terapêuticas propostas para o tratamento da hepatite $\mathrm{C}$ em publicações de 2015 a 2020.

\section{MÉTODO}

Trata-se de uma revisão integrativa, realizada a partir de buscas nos seguintes bancos de dados: PubMed e SciELO. Onde foram levados em consideração os seguintes critérios de inclusão: publicações de 2015 a 2020, texto integral disponível no idioma inglês, e pesquisas experimentais; e os seguintes critérios de exclusão: revisões de literatura. Descritores utilizados: "Hepatite C", "Tratamento farmacológico", "Terapia farmacológica".

\section{REVISÃO BIBLIOGRÁFICA}

Encontraram-se no PubMed e SciELO, respectivamente, 38 e 3 artigos, totalizando 41 artigos. Após a leitura do título, resumo e texto na íntegra, foram excluídos 34 artigos que não se enquadravam nos critérios de inclusão.

A análise dos artigos selecionados mostrou que por muitos anos, o tratamento da hepatite $C$ crônica foi baseado no uso de interferon associado a ribavirina e/ou um dos primeiros antivirais de ação direta (DAA) (boceprevir ou telaprevir). A combinação tripla apresenta maior resposta virológica sustentada (RVS), porém provoca efeitos adversos (PERLIN C, et al., 2017).

Sobre a busca por novas terapias (Tabela 1), percebeu-se que nos últimos anos pesquisas apontaram uma segunda geração de DAAs como alternativa para a diminuição dos efeitos adversos causados pelo IFN. Esses antivirais têm como alvo um ou mais sitíos biológicos específicos do VHC. Essas opções terapêuticas apresentam facilidade posológica, menor período de tratamento e menos efeitos adversos (HE S, et al., 2015). 
De acordo com Koizumi et al. (2017), a combinação tripla de DAAs de segunda geração, quando comparada a combinação dupla de DAAs, apresenta atividade antiviral aprimorada e probabilidade menor de ocorrer resistência ao medicamento em concentrações relevantes.

Em uma análise comparativa com 15 medicamentos anti-VHC de diferentes classes, o sofosbuvir, análogo do nucleotídeo inibidor da polimerase NS5B, apresentou um dos maiores potenciais para inibir eventos de replicação viral (KOIZUMI Y, et al., 2017). Em contrapartida, Maiti et al. (2016) observaram que pró- fármacos contendo aminoácidos bifuncionais apresentam essa ação inibidora mais potente que o sofosbuvir.

O GP205 é um novo inibidor macrocíclico da NS3, pode ser usado em combinação com inibidores da NS5B ou NS5A (sofosbuvir e daclatasvir) apresentando eficácia sinérgica ( ZHAI P, et al., 2018).

Tabela 1 - Mecanismos de ação e efeitos adversos de terapias para o tratamento da HepatiteC

\begin{tabular}{|c|c|c|}
\hline Terapia & Mecanismos de ação & Efeitos adversos \\
\hline IFN+Ribavirina (Em uso) & Inibe a DNA polimerase & $\begin{array}{l}\text { Alopecia,anemia,neutropenia, } \\
\text { trombocitopenia,distúrbios } \\
\text { autoimunes, retinopatia, depressão. }\end{array}$ \\
\hline $\begin{array}{l}\text { IFN+Ribavirina+boceprevir } \\
\text { telaprevir (Em desuso) }\end{array}$ & Inibe a enzima NS3 e o seu cofator & $\begin{array}{l}\text { Fadiga, ressecamento da pele, } \\
\text { anemia, náuseas e alterações no } \\
\text { paladar }\end{array}$ \\
\hline Sofosbuvir (Em uso) & Inibe a DNA polimerase & $\begin{array}{l}\text { Mialgia, cefaleia, febre, náusea e/ou } \\
\text { vômito, artralgia, alterações de humor e } \\
\text { insônia }\end{array}$ \\
\hline $\begin{array}{cr}\text { Pró-fármacos } & \text { contendo } \\
\text { aminoácidos bifuncionais (Em estudo) }\end{array}$ & Inibe a DNA polimerase & Em investigação \\
\hline GP205 (Em estudo) & Inibe a NS3 & Em investigação \\
\hline GP205+Sofosbuvir (Em estudo) & Inibem NS3 e NS5B & Em investigação \\
\hline GP205+Daclatasvir (Em estudo) & Inibem NS3 e NS5A & Em investigação \\
\hline
\end{tabular}

Fonte: CAVALCANTE JMF e Andrade FM, 2020.

\section{DISCUSSÃO}

Embora o tratamento baseado na combinação de IFN com ribovirina e um DAA resulte em uma maior RVS, esse tratamento diminui a qualidade de vida do paciente devido à alta incidência de eventos adversos (PERLIN C, et al., 2017).

Apesar da eficácia e tolerância comprovadas, o tratamento baseado em terapias triplas de DAAs são de alto custo, além disso, existe a possibilidade de surgimento de resistência a medicamentos e de interações medicamentosas (HE S, et al., 2015).

Embora os resultados mostrem que pró-fármacos contendo aminoácidos bifuncionais, hidroxiantraquinonas e o GP205 apresentam ação anti-VHC, ainda são necessários estudos futuros para verificar a possibilidade de resistência a medicamentos, produção de efeitos adversos, bem como a exploração de terapias combinadas utilizando esses compostos.

\section{CONSIDERAÇÕES FINAIS}

De acordo com estudos analisados aconteceu uma busca por alternativas que diminuíssem os efeitos adversos pelo tratamento de infecções do VHC baseado na utilização de IFN. As alternativas encontradas além de diminuírem tais efeitos também apresentaram benefícios relacionados a especificidade, posologia e tempo de tratamento, mostrando que podem ser uma boa opção de tratamento. Porém, apesar dessas novas alternativas apresentarem características importantes para o tratamento da hepatite $\mathrm{C}$, existem fatores 
limitantes, como o alto custo, que fazem com que a busca por uma droga eficiente e acessível para toda a população, continue.

\section{REFERÊNCIAS}

1. HE S, et al. High-Throughput Screening, Discovery, and Optimization To Develop a Benzofuran Class of Hepatitis C Virus Inhibitors. ACS combinatorial science, 2015; 17(10): 641-652

2. KOIZUMI Y, et al. Quantifying antiviral activity optimizes drug combinations against hepatitis $C$ virus infection. Proceedings of the National Academy of Sciences of the United States of America, 2017; 114(8): $1922-1927$.

3. MAITI M, et al. Bifunctional aryloxyphosphoramidate prodrugs of 2'-C-Me-uridine: synthesis and anti- HCV activity. Organic \& biomolecular chemistry, 2016; 14(37): 8743-8757

4. PERLIN C , et al. Qualidade de vida em pacientes brasileiros com hepatite crônica C. tratada ou não tratada. Rev. Inst. Med. trop. São Paulo, São Paulo,2017; 59: e81.

5. POHC. Polaris Observatory HCV Collaborators. Global prevalence and genotype distribution of hepatitis C virus infection in 2015: a modelling study. Lancet Gastroenterol Hepatol, 2017; 2:161-176.

6. ZHAI P, et al. GP205, a new hepatitis C virus NS3/4A protease inhibitor, displays higher metabolic stability in vitro and drug exposure in vivo. Acta pharmacologica Sinica, 2018; 39: e11. 


\section{Título: Extratos de Plantas como Alternativa para o Tratamento da \\ ESQUISTOSSOMOSE MANSÔNICA: UMA REVISÃO SISTEMÁTICA}

Autor/coautores: Eduardo Henrique Matos Pires ${ }^{1}$, Amanda Lucena dos Santos ${ }^{1}$, João Lucas Arcanjo de Barros Ribeiro², Bárbara Cristine dos Santos Silva, Francinete ${ }^{1}$ Torres Barreiros da Fonsêca1.

Instituição: 1 Universidade Federal Rural de Pernambuco (UFRPE), Recife-Pernambuco; 2Universidade Federal de Pernambuco (UFPE), Recife-Pernambuco.

Palavras-chave: Extrato, Esquistossomose Mansônica, Fitoterapia.

\section{INTRODUÇÃO}

A esquistossomose é uma das doenças negligenciadas de maior ocorrência e distribuição pelo mundo, tendo maior incidência na África, Ásia e América Latina. Cerca de 779 milhões de pessoas se encontram em risco de infecção enquanto 250 milhões estão infectadas com alguma espécie do gênero Schistosoma (McMANUS DP, et al., 2018).

A espécie responsável pela maioria das manifestações hepatoesplênicas da doença é a $S$. mansoni que ao se instalar nas veias mesentéricas libera seus ovos, estes são levados pela circulação e alojam-se no fígado onde o processo inflamatório é estabelecido (McMANUS DP, et al., 2018).

O tratamento da esquistossomose mansônica baseia-se na quimioterapia, sendo o praziquantel a droga mais utilizada devido sua alta eficácia e segurança. Entretanto, após 40 anos como a droga preferida para tratamento dessa doença, evidências experimentais e em trabalhos de campo demonstram indícios de resistência do verme a essa droga (VALE N, et al., 2017).

Visto isso, novos tratamentos alternativos necessitam ser desenvolvidos. Uma das possibilidades para alcançar esse objetivo é o estudo de extratos de plantas que possuam algum efeito esquistossomicida e que sejam seguros para o paciente (ACHEAMPONG DO, et al., 2020; DE OLIVEIRA CNF, et al., 2017; JATSA HB, et al., 2015).

\section{OBJETIVO}

Revisar a literatura sobre trabalhos publicados nos últimos 5 anos que avaliaram a ação esquistossomicida em ensaios in vivo com extratos vegetais e caracterizar esses estudos quanto ao efeito dos extratos e outros parâmetros.

\section{MÉTODO}

Foi realizada uma revisão sistemática da literatura em junho de 2020 nas bases Scopus, ScienceDirect, WebOfScience e PubMed, utilizando os seguintes descritores: (plant) AND (extract) AND (Schistosoma mansoniOR schistosomiasis). A seleção dos descritores foi efetuada mediante consulta ao DeCS (Descritores em Ciências da Saúde).

Os critérios de inclusão foram artigos de pesquisa original, publicados entre 2015-2020, que tenham avaliado a atividade anti-esquistossomose mansônica in vivo utilizando extratos de plantas. Artigos que avaliaram um composto específico isolado da planta foram excluídos. As famílias botânicas, caso não constasse no artigo, foram classificadas de acordo com o site Tropicos (https://www.tropicos.org/home).

\section{REVISÃO BIBLIOGRÁFICA}

De acordo com a metodologia adotada, foram encontrados 264 artigos potencialmente elegíveis. Após análise dos títulos e resumos, 35 artigos foram selecionados e lidos na íntegra por dois pesquisadores. Ao final, foram selecionados 20 artigos que atenderam todos os critérios. 
Dos 20 artigos selecionados, 18 eram da África, principalmente do Egito (50\%) e Camarões (25\%). 0 tratamento se mostrou positivo em $95 \%$ dos estudos, sendo relatada redução na carga parasitária, na quantidade de ovos nas fezes, fígado e intestino, além de melhora na função hepática e redução na formação e tamanho de granulomas (Tabela 1).

Tabela 1. Algumas espécies avaliadas e efeito do tratamento em parâmetros biológicos.

\begin{tabular}{|c|c|c|c|c|c|c|c|c|}
\hline Espécie & $\begin{array}{l}\text { Parte da } \\
\text { planta }\end{array}$ & $A$ & B & C & $D$ & $\mathrm{E}$ & $\mathrm{F}$ & $\mathrm{G}$ \\
\hline $\begin{array}{l}\text { Sida } \\
\text { pilosa }\end{array}$ & $\begin{array}{l}\text { Partes } \\
\text { aéreas }\end{array}$ & $(+)$ & $(+)$ & $(+)$ & n.a. & $(+)$ & n.a. & $(+)$ \\
\hline $\begin{array}{l}\text { Solanum } \\
\text { tuberosu } \\
m\end{array}$ & Folha & 0 & n.a. & n.a. & n.a. & n.a. & n.a. & n.a. \\
\hline $\begin{array}{l}\text { Cleroden } \\
\text { drum } \\
\text { umbellat } \\
\text { um }\end{array}$ & Folhas & $(+)$ & $(+)$ & $(+)$ & $(+)$ & $(+)$ & n.a. & n.a. \\
\hline $\begin{array}{l}\text { Ziziphus } \\
\text { spina- } \\
\text { christi }\end{array}$ & Folhas & n.a. & $(+)$ & $(+)$ & n.a. & $(+)$ & $(+)$ & $(+)$ \\
\hline $\begin{array}{l}\text { Cynara } \\
\text { scolymus }\end{array}$ & Folhas & n.a. & 0 & 0 & n.a. & $(+)$ & 0 & $(+)$ \\
\hline $\begin{array}{l}\text { Ceratoni } \\
\text { a siliqua }\end{array}$ & Vagens & n.a. & $(+)$ & $(+)$ & n.a. & $(+)$ & $(+)$ & $(+)$ \\
\hline $\begin{array}{l}\text { Commip } \\
\text { hora } \\
\text { myrrha }\end{array}$ & $\begin{array}{l}\text { Planta } \\
\text { inteira }\end{array}$ & n.a. & n.a. & $(+)$ & n.a. & n.a. & n.a. & n.a. \\
\hline $\begin{array}{l}\text { Ozoroa } \\
\text { pulcherri } \\
\text { ma }\end{array}$ & Raíz & $(+)$ & $(+)$ & $(+)$ & $(+)$ & $(+)$ & $(+)$ & n.a. \\
\hline $\begin{array}{l}\text { Artemisia } \\
\text { annua } L \text {. }\end{array}$ & $\begin{array}{l}\text { Folhas e } \\
\text { galhos }\end{array}$ & $(+)$ & n.a. & n.a. & n.a. & n.a. & n.a. & n.a. \\
\hline $\begin{array}{l}\text { Ozoroa } \\
\text { pulcherri } \\
\text { ma }\end{array}$ & Raíz & $(+)$ & $(+)$ & $(+)$ & $(+)$ & $(+)$ & n.a. & n.a. \\
\hline
\end{tabular}

Legenda: n.a.= não avaliado; $(+)=$ efeito positivo no tratamento; $(0)=$ efeito não significativo; $A=$ ovos nas fezes; $B=$ ovos no fígado/intestino; $C=$ vermes adultos; $D=$ hepatoesplenomegalia; $E=$ enzimas fígado; $F=$ granulomas; $\mathrm{G}=$ fibrose. Fonte: PIRES EHM, et al., 2020.

No total, 23 espécies de plantas foram avaliadas quanto a atividade esquistossomicida, predominando estudos de plantas das famílias Asteraceae (21\%), Malvaceae (8\%), Fabaceae (8\%) e Anacardiaceae (8\%). Foi observado que diferentes partes da planta são investigadas, sendo utilizado principalmente as folhas (39\%), raízes (13\%) e partes aéreas (13\%). 
Dos artigos analisados, 9 (45\%) fizeram a caracterização do perfil fitoquímico do extrato, sendo observado uma quantidade de compostos fenólicos variando de $24 \mathrm{mg} / \mathrm{g}$ a $87 \mathrm{mg} / \mathrm{g}$ de extrato seco, dentre eles flavonóides, taninos e alcalóides.

A posologia só foi investigada em 8 artigos, a avaliação de toxicidade em 3 e o período ideal para medicação somente em 2. Entre os artigos que avaliaram a dose ideal e em qual momento medicar está o trabalho conduzido por De Oliveira CNF, et al. (2017).

\section{DISCUSSÃO}

Os estudos realizados tiveram a maioria das respostas positivas para o tratamento da esquistossomose mansônica, o que pode ser indicado pela possível presença de compostos fenólicos na composição fitoquímica dos extratos, como alcalóides e taninos, reconhecidos anti-helmínticos (JATSA HB, et al., 2015). A maioria dos artigos foram desenvolvidos no continente Africano, provavelmente, por ser endêmico para a maioria das espécies do gênero Schistosoma (McMANUS DP, et al., 2018). Apesar do praziquantel só mostrar atividade contra a forma adulta do Schistosoma spp. (DE OLIVEIRA CNF, et al., 2017), somente 2 artigos investigaram o efeito do extrato em fases menos avançadas da doença, demonstrando a carência de pesquisas nesse sentido.

\section{CONSIDERAÇÕES FINAIS}

Apesar de ser uma doença conhecida há anos, a esquistossomose mansônica ainda afeta milhões de pessoas, fazendo-se necessário a investigação de tratamentos efetivos. Os estudos selecionados demonstraram o potencial de vários extratos de plantas como candidatos para o desenvolvimento de novos agentes esquistossomicidas. Apontamos a necessidade de estudos mais aprofundados para validar a segurança dos extratos, bem como a dose recomendada adequada do extrato para a erradicação do verme e preservar a função hepática.

\section{REFERÊNCIAS}

1. ACHEAMPONG DO, et al. Ethnopharmacological evaluation of schistosomicidal and cercaricidal activities of some selected medicinal plants from Ghana. Tropical Medicine and Health, 2020; 48(19).

2. DE OLIVEIRA CNF, et al. Schistosomamansoni: In vivo evaluation of Phyllanthusamarushexanic and ethanolic extracts. Experimental Parasitology, 2017; 183.

3. JATSA HB, et al. Schistosomicidal, hepatoprotective and antioxidant activities of the methanolic fraction from ClerodendrumumbellatumPoir leaves aqueous extract in Schistosomamansoni infection in mice. BMC Complementary and Alternative Medicine, 2015; 15(248).

4. McMANUS DP, et al. Schistosomiasis. Primer, 2018; 13(4).

5. VALE N, et al. Praziquantel for schistosomiasis, single drug revisited metabolism, mode of action and resistance. Antimicrobial Agents and Resistance, 2017; 61(5). 
TíTULO: FATORES DE VIRULÊNCIA DO NOVO VÍRUS DA INFLUENZA A (H1N2) E SEU POTENCIAL DE EVOLUÇÃO PARA UMA PANDEMIA

Autor/coautores: Hiolanda Nayara da silva1, Maria Fernanda da Silva1, Daryckson Gessé Pereira de Araujo1, Roberta Luciana do Nascimento Godone1,2

Instituição: 1Faculdade Uninassau - Campus Caruaru; 2Secretaria de Educação de Pernambuco, Recife Pernambuco.

Palavras-chave: Novo Influenza, Pandemia, Viroses.

\section{INTRODUÇÃO:}

O vírus da Influenza A (IAV) é classificado como um patógeno da família dos ortomixovírus, responsável pelo desenvolvimento das principais gripes, epidemiologicamente representa um problema de saúde pública, na bibliografia técnico ciêntifica já foram identificados vários subtipos da IAV, como H1N1 responsável pela pandemia de 2009 (BEIRIGOAPT, et al., 2017) onde seespalhou-se rapidamente pelo mundo, afetando principalmente pessoas com idade $<65$ anos (SILVAPCR, 2015), essa família de vírus apresentam um grande poder de contágio pois sua transmissão ocorre através da inalação de partículas virais, apresentando possibilidade de desenvolvimento de epidemias e pandemias ocasionais.

A primeira identificação da sublinhagem H1N2 foi realizada entre os anos de 1988 e 1989 na china, porém somente em 2002 foi confirmada os primeiros casos da infecção, em outros países pela Organização Mundial da Saúde (OMS). O H1N2 apresenta em seu traço genético um rearranjo onde uni semelhanças das cepas encontradas em suínos norte-americanos, aves europeias e asiáticas (BEIRIGOAPT, et al., 2017); as cepas do H1N1 vem apresentando um aumento em sua diversidade genética desde o ano de 2013, desenvolvendo assim uma grande gama de subtipos do vírus (SUN H, et al., 2020).

\section{OBJETIVO:}

Revisar na literatura científica a importância da vigilância e monitoramento deste novo vírus H1N2 para que não haja possíveis aumentos em relação a sua contaminação.

\section{REVISÃO BIBLIOGRAFICA:}

De acordo com trabalhos publicados nos últimos anos foram encontrados dados que confirmam que 0 H1N2 ou G4, é geneticamente descendente da gripe suína H1N1, causadora da pandemia em 2009 (SUN H, et al., 2020), o G4 vem demonstrando características essenciais de um possível vírus pandêmico, sendo necessários melhores estudos e metodologias de controle desse patógeno; levando em consideração as taxas de contágio por ingestão de produto contaminado ou contato com animais infectados, apresentam um risco a saúde pública, uma vez que essas novas variantes tornam esse vírus com capacidade de adaptação animal/humana bem robusta (PULIT-PENALOZAJA, et al., 2018).

O primeiro isolamento do H1N2 foi feito no japão no ano de 1978, contaminando grande parte da população suína do país, entre os anos de 2011 e 2012 o vírus foi isolado na china e coréia do sul e foi observado que o mesmo já havia traços de outros subtipos virais (LEEJH, et al., 2015), alguns estudos e testes adicionais demostraram que o $\mathrm{H} 1 \mathrm{~N} 2$ pode infectar humanos ligando-se às células e se replicando rapidamente dentro das células das vias aéreas, o vírus tem como sua principail característica a facilidade de contágio podendo ocorrer de forma direta ou indireta, a direta ocorre de pessoa para pessoa, enquanto a indireta ocorre com a contaminação de superfícies contaminadas com o vírus. O vírus está demonstrando uma crescente reprodução entre as populações de porcos em vários locais do mundo podendo representar uma séria ameaça à saúde humana se não monitoradocuidadosamente, embora o G4 possua genes H1N1 (SILVAPCR, 2015), pessoas que receberam vacinas contra a gripe sazonal não apresentam imunidade para a H1N2, pelo 
fato de que suas novas características e rearranjos gênicos conseguem interagir com as células normalmente, sem o efeito do sistema imunológico.

\section{DISCUSSÃO:}

A transmissão bidirecional da H1N2 entre suínos e pessoas tornou-se a ação evolutiva do novo vírus influenza.

O sequenciamento de seu genoma foi realizado e uma comparação de sua cepa com outros vírus influenza disponíveis no banco de dados de genes (GenBank), embora o novo isolado de H1N2 tenha o seu replicamento bem sucedido em camundongos, ele se mostra menos virulento (PENG X, et al, 2016), esses resultados fornecem evidências adicionais de que os suínos servem como hospedeiros intermediários para os rearranjos gênicos de novos subtipos do vírus influenza.

Portanto, deve-se enfatizar a importância da vigilância dos suinos, como um sistema de alerta precoce para surtos de influenza nas populações suínas e humanas (PENG X, etal, 2016).

\section{CONSIDERAÇÕES FINAIS:}

Levando em consideração os resultados das pesquisas, observa-se que os suínos são uma das principais espécies de reservatórios para os vírus influenza $A$ e desempenham um papel fundamental na transmissão de IAVs. O vírus G4 adquiriu maior infectividade humana, causando preocupação para uma possível geração de vírus pandêmicos. Portanto, é necessária uma integração entre a saúde humana, a saúde animal, o ambiente e a adoção de políticas públicas efetivas para prevenção e controle de enfermidades, para que não ocorra a proliferação ainda maior do vírus, tanto entre os suínos, como também nas pessoas que trabalham com os animais.

\section{REFERÊNCIAS:}

1. BEIRIGO APT, et al. Influenza A (H1N1): Revisão bibliográfica. Revista de Saúde e Biologia, 2017; v.12, n.2, p.53-67.

2. LEE JH, et al, Evaluation of the zoonotic potential of a novel reassortant $\mathrm{H} 1 \mathrm{~N} 2$ swine influenza virus with gene constellation derived from multiple viral sources, Infection, Genetics and Evolution, 2015; 378-393.

3. PENG X, et al, Molecular characterization of a novel reassortant H1N2 influenza virus containing genes from the 2009 pandemic human H1N1 virus in swine from eastern China, RevistaEletrônica Springer Science, 2016; Jun;52(3):405-10.

4. PULIT-PENALOZA JA, et al, Comparative In Vitro and In Vivo Analysis of H1N1 and H1N2 Variant Influenza Viruses Isolated from Humans between 2011 and 2016. Journal of Virology. 2018; 92(22):e01444-18.

5. SILVA PCR, Dinâmica molecular dos vírus Influenza $A$ (H1N1) pandêmico em cinco anos de circulação no Brasil, Tese (Doutorado em Medicina Tropical) - Fundação Oswaldo Cruz, 2015.176f.

6. SUN H, et al, Prevalent Eurasian avian-like H1N1 swine influenza virus with 2009 pandemic viral genes facilitating human infection, RevistaEletrônica PNAS, 2020; 117 (29) 17204-17210. 
TíTULO: ABORDAGENS NO DESENVOLVIMENTO DE VACINAS MULTIVALENTES CONTRA FILARIOSE LINFÁTICA

Autor/coautores: Emerson de Oliveira Silva1, Nídia Cristina Coelho Vieira de Melo2, Aprígio Tavares Pessôa Filho2, Pedro José Rolim Neto1

Instituição: Laboratório de Tecnologia dos Medicamentos (LTM) - Universidade Federal de Pernambuco (UFPE), Recife-Pernambuco1; Faculdade Santíssima Trindade (FAST), Nazaré da Mata-Pernambuco2.

Palavras-chave: Filariose, Profilaxia, Vacina.

\section{INTRODUÇÃO}

A filariose linfática $(F L)$ é uma doença tropical negligenciada que ameaça cerca de 893 milhões de pessoas em 49 países em todo o mundo. Conhecida como elefantíase, a FL é causada por vermes parasitas do gênero Wuchereria bancrofti e Brugia malayi, e tem sua transmissão vetorizada por mosquitos portadores de larvas infectantes desenvolvidas, que ao serem inseridas no hospedeiro através da picada do mosquito, migram para o sistema linfático onde se desenvolvem em vermes adultos e geram quadros graves e incapacitantes nos indivíduos infectados (DAVIS EM, et al., 2019; WHO, 2020).

As estratégias atuais para o controle da FL consiste na administração em massa de medicamentos e por ações de saneamento básico para o controle vetorial. Mesmo assim, dezenas de países ainda não conseguiram eliminar a FL, inclusive o Brasil. O desenvolvimento de uma abordagem profilática mais efetiva e duradoura na forma de vacina, até então inexistente para a FL, pode ser uma valiosa arma para o controle da disseminação da FL em regiões consideradas endêmicas (KALYANASUNDARAM R, et al., 2020; KHATRI V, et al., 2018; WHO, 2020).

\section{OBJETIVO}

Abordar a importância da pesquisa e desenvolvimento de vacinas multivalentes para a otimização da proflilaxia da filariose linfática.

\section{REVISÃO BIBLIOGRÁFICA}

A filariose linfática (FL) é uma doença imunossupressora. As microfilárias, forma laval do parasita, dificulta a resposta imunológica do infectado para conseguir sobreviver e se desenvolver no desfavorável ambiente da circulação linfática. A aquisição de uma imunidade mais efetiva contra o parasita da FL ocorre de forma lenta. Entretanto, alguns indivíduos acometidos pela FL desenvolvem uma maior resistência ao parasita por apresentarem uma inerente alta carga de imunoglobulina $\mathrm{G}$ circulante atuando contra o parasita filarial. Essa informação valida a possibilidade do estímulo da capacidade imunológica do hospedeiro infectado com o parasita filarial mediante vacina (KWARTENG A e AHUNO ST, 2017).

Os avanços em biotecnologia possibilitou uma melhor análise do genoma e proteoma das formas de vida do parasita da filariose para a identificação de candidatos potenciais a serem utilizados como antígenos em protótipos de vacinas contra a LF. É necessário que o canditato a antígeno selecionado tenha similaridade funcional para ambas as principais espécies representativas para a FL (Wuchereria bancrofti e Brugia malayi) (KALYANASUNDARAM R, et al., 2020).

Estudos usando parasitas filariais de roedores e bovinos, forneceu informações sobre possíveis canditatos antigênicos e o entendimento da resposta imune do hospedeiro. Para as espécies infectantes em humanos, os principais promissores antígenos relatados são a transcrição larval-2 (ALT-2), a proteínas de choque térmico (HSP 12,6) e tetraspanina de grande loop extracelular (TSP-LEL). No progresso atual, as vacinas mais promissoras com melhores resultados em modelos experimentais são as abordagens que combinam vários antígenos, denominadas de vacinas multivalentes. 
A formulação contendo três proteínas antigênicas (HSP12.6, ALT-2 e TSP-LEL) resultou em 57\% de proteção contra infecções em modelos de macacos, sendo a mais promissora abordagem dentre todos os exemplos de vacinas multivalentes pesquisadas contra FL (KALYANASUNDARAM R, et al., 2020; KHATRI V, et al., 2018).

\section{DISCUSSÃO}

A capacidade do parasita filarial em manipular o sistema imunológico do infectado, auxilia na sua persistência no organismo dificultando resposta imune mesmo mediante vacinação. Sendo um organismo multicelular, o parasita filarial possui diversos mecanismos de escape do sistema imune do hospedeiro. Isso explica o maior sucesso nos resultados pré-clínicos em modelos de animais de abordagens em vacinas contendo vários antígenos em uma única formulação profilática (KALYANASUNDARAM R, et al., 2020). Adicionalmente, vacinas multivalentes podem ganhar o reforço imunoadjuvante de fármacos já usados no tratamento e quimioprofilaxia da FL, como a dietilcarbamazina, que possui efeito imunoestimulatório da resposta celular e humoral (JAWAHARLAL JPP, et al., 2015).

É necessário o aprofundamento dos estudos na busca de melhores antígenos e seus impactos na imunoestimulação para o desenvolvimento de vacinas contra a filariose que sejam eficazes em humanos. Principalmente porque o tratamento disponível é precário e pode haver o ressurgimento da infecção póstratamento.

\section{CONSIDERAÇÕES FINAIS}

Mesmo com boas perspectivas quanto ao desenvolvimento de vacinas contra filariose linfática, os atuais estudos revelam um progresso lento, limitação de estudos clínicos e dificuldades em achar modelos animais experimetais para melhor entendimento da imunoestimulação contra filariose.

O uso de imunoadjuvantes em vacinas multivalentes pode ser crucial para que o organismo infectado adquira uma imunidade protetora mais efetiva contra o parasita. Esforços no desenvolvimento de vacinas contra a filariose pode induzir uma imunidade coletiva. De fato, o sinergismo entre a profilaxia mediante vacinação e o tratamento farmacológico em massa pode representar a erradicação da filariose linfática do planeta.

\section{REFERÊNCIAS}

1. DAVIS EM, et al. Evaluating the Evidence for Lymphatic Filariasis Elimination. Trends in Parasitology, 2019; 11: e860869.

2. JAWAHARLAL JPP, et al. Immunoadjuvant effect of diethylcarbamazine in experimental filariasis. International Immunopharmacology, 2015; 2: e458462.

3. KALYANASUNDARAM R, et al. Advances in Vaccine Development for Human Lymphatic Filariasis. Trends in Parasitology, 2020; 2: e195205.

4. KHATRI V, et al. Prospects of developing a prophylactic vaccine against human lymphatic filariasis evaluation of protection in non-human primates. International Journal of Parasitology, 2018; 48(9-10): e773783.

5. KWARTENG A, AHUNO ST. Immunity in Filarial Infections: Lessons from Animal Models and Human Studies. Scandinavian Journal of Immunology, 2017; 85: e251257.

6. WORLD HEALTH ORGANIZATION - WHO. Lymphatic filariasis. 2020. Disponível em:

7. https://www.who.int/news-room/fact-sheets/detail/lymphatic-filariasis. Acessado em: 02 de março de 2020. 
TítULO: ABORDAGENS DA NANOTECNOLOGIA NO APRIMORAMENTO DO TRATAMENTO DA HANSENÍASE

Autor/coautores: João Lima Tavares, lago Dillion Lima Cavalcanti, Mariane Cajubá de Britto Lira Nogueira.

Instituição: Universidade Federal de Pernambuco (UFPE), Recife-Pernambuco.

Palavras-chave: Nanossistemas, Mycobacterium leprae, Hanseníase.

\section{INTRODUÇÃO}

A hanseníase, anteriormente conhecida como lepra, é uma doença crônica contagiosa causada pela bactéria Mycobacterium leprae. Essa doença tem assolado a humanidade durante séculos e, apesar da existência de tratamento, continua sendo um problema para cerca de 200.000 pessoas no mundo, principalmente no Brasil que é o segundo país com o maior número de casos anuais de hanseníase nos últimos anos (QUARESMA MSM, et al., 2019). Há algumas décadas, a Organização Mundial de Saúde (OMS) definiu a combinação de clofazimina, dapsona e rifampicina como padrão mundial de tratamento da infecção. Apesar da eficácia comprovada desse método chamado de terapia multidroga, o potencial terapêutico da clofazimina e dapsona é limitado devido à baixa solubilidade em água que causa baixa biodisponibilidade e, consequentemente, a necessidade por maiores doses e tempo de uso dos medicamentos mais longos (CRUZ RCS, et al., 2017).

A nanotecnologia mostra-se como uma possível alternativa para superação dos obstáculos presentes no tratamento da hanseníase, visto que, permite a modificação das propriedades e características físicoquímicas dos fármacos após encapsulação em nanossistemas, como lipossomas, nanopartículas, nanoemulsões, dentre outros (ISLAN AG, et al., 2017; CHENTHAMARA D, et al., 2019).

\section{OBJETIVOS}

Relatar e divulgar as diferentes abordagens da nanotecnologia para o aprimoramento dos métodos atualmente utilizados no tratamento da infecção causada pela bactéria Mycobacterium leprae, a partir dos dados presentes na literatura.

\section{METODOLOGIA}

Trata-se de um estudo quantitativo bibliográfico, tipo revisão integrativa da literatura. A pesquisa utilizou bancos dados: ScienceDirect, Scifinder e SciELO, utilizando os seguintes descritores: "hanseníase", "Mycobacterium leprae", "nanopartículas", "lipossomas" e "nanotecnologia farmacêutica" também em sua versão em inglês. Foram utilizados artigos publicados até março de 2020.

Foram incluídos artigos completos que versavam sobre o tratamento da hanseníase e artigos de nanoencapsulação de fármacos utilizados na terapia da doença. Excluíram-se os artigos incompletos, que abordavam sobre a encapsulação de fármacos em nanossistemas, mas que não estavam relacionados ao tratamento da hanseníase.

\section{REVISÃO BIBLIOGRÁFICA}

Após pesquisa e aplicação dos critérios de inclusão e exclusão, foram utilizados 12 artigos para a revisão. A hanseníase é uma doença crônica antiga, transmitida através das secreções orais e nasais humanas, afetando principalmente a pele, os olhos e os nervos periféricos. Clinicamente, a hanseníase é classificada de acordo com a quantidade de bacilos: paucibacilar (poucos bacilos) e multibacilar (muitos bacilos) (QUARESMA MSM, et al., 2019).

Apesar de curável, ainda é considerada um problema para as autoridades de saúde mundiais como pode ser observado pelos 208.613 casos novos apenas no ano de 2018. No Brasil, é uma doença endêmica em muitas regiões, apresentando um total de 28.660 casos novos em 2018 no país, segundo os dados da Organização Mundial de Saúde, número apenas menor que na Índia. Há cerca de 3 décadas, a OMS 
estabeleceu um tratamento padrão para a hanseníase e o mesmo continua sendo utilizado atualmente, consiste na utilização de clofazimina, dapsona e rifampicina associados (CRUZ RCS, et al., 2017; QUARESMA MSM, et al., 2019).

Apesar da eficácia da terapia multidroga, a alta insolubilidade em água da dapsona e da clofazimina causa baixa biodisponibilidade, e a necessidade de maiores doses que, ao longo do tempo, causam diversos efeitos colaterais nos pacientes como dor abdominal, metemoglobinemia e cardiotoxicidade (CHAVES LL, et al., 2018).

Com o objetivo de superar essas dificuldades, os pesquisadores vêm explorando o uso de nanossistemas para encapsulação de fármacos.

Na Figura 1 podem ser observados exemplos de nanosistemas, ao qual apresentam diversas alternativas que possibilitam o aprimoramento da terapia multidroga.

Figura 1 - Nanopartículas poliméricas pH sensível carreado com dapsona (A), lipossomas contendo clofazimina (B) e nanoemulsão com dapsona (C) utilizados para o tratamento da hanseníase.
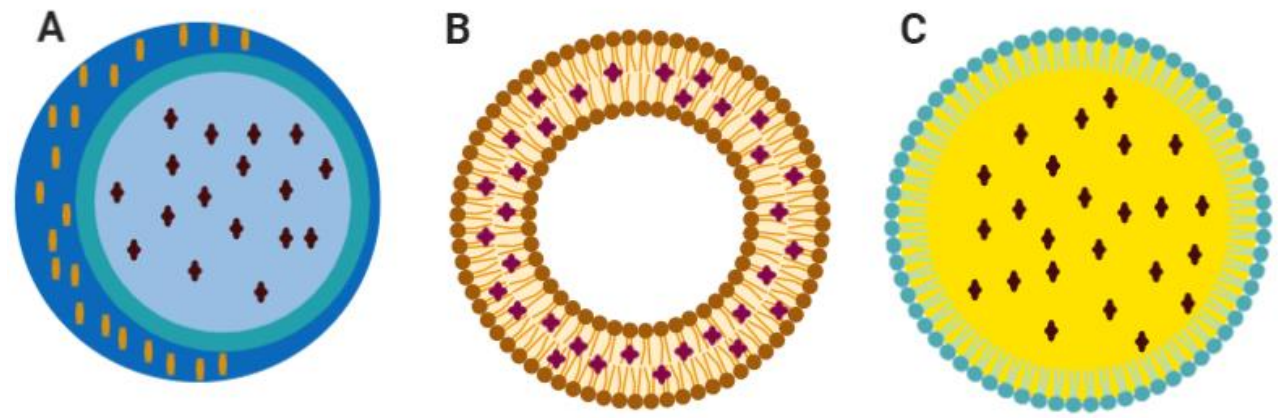

Fonte: TAVARES JL, et al., 2020.

\section{DISCUSSÃO}

Segundo a literatura, nanopartículas poliméricas ou lipossomas de clofazimina (Figura 1B) permitem um efeito de redução da citotoxicidade do fármaco a partir da diminuição do tamanho de partícula, aumento da absorção e biodisponibilidade do fármaco (CHAVES LL, et al., 2018).

Efeito semelhante é observado nas nanopartículas de dapsona revestidas com Eudradit L100, polímero sensível ao pH (Figura 1A), que permite a proteção à acidez do estômago e liberação do fármaco no intestino delgado (CHAVES LL, et al., 2017).

Outra alternativa, é a utilização de nanopartículas lipídicas sólidas na encapsulação da clofazimina para administração oral (CHAVES LL, et al., 2018).

Além desses nanossistemas, a utilização de nanoemulsões contendo dapsona (Figura 1C) é descrita como uma alternativa para administração deste fármaco pela via tópica para o tratamento da hanseníase.

\section{CONSIDERAÇÕES FINAIS}

A partir desta pesquisa, pode-se concluir que a inserção da nanotecnologia farmacêutica na tentativa de aprimoramento do tratamento da hanseníase é promissora e desejável, visto que os resultados apresentados superaram os problemas atualmente encontrados no tratamento, como a baixa biodisponibilidade e a toxicidade. Neste sentido, é de fundamental importância a elaboração de novas pesquisas que visem o desenvolvimento de produtos nanotecnológicos para a diminuição tanto dos casos como das mortes causadas por essa doença negligenciada. 


\section{REFERÊNCIAS}

1. CHAVES LL, et al. Overcoming clofazimine intrinsic toxicity: statistical modelling and characterization of solid lipid nanoparticles. Journal of the Royal Society Interface, 2018; 15(139): 20170932.

2. CHAVES LL, et al. pH-sensitive Nanoparticles for Improved Oral Delivery of Dapsone: Risk Assessment, Design, Optimization and Characterization. Nanomedicine (Lond), 2017; 12(16): 1975-1990.

3. CHENTHAMARA D, et al. Therapeutic efficacy of nanoparticles and routes of administration. Biomaterials Research, 2019; 23(20): 1-29.

4. CRUZ RCS, et al. Leprosy: current situation, clinical and laboratory aspects, treatment history and perspective of the uniform multidrug therapy for all patients. Anais Brasileiros de Dermatologia, 2017; 92(6): 761-773.

5. ISLAN AG, et al. Nanopharmaceuticals as a solution to neglected diseases: Is it possible?. Acta Tropica, 2017; 170: 16-42.

6. QUARESMA MSM, et al. Perfil clínico e epidemiológico dos pacientes portadores de hanseníase em uma unidade de referência no estado do Pará. Revista Eletrônica Acervo Saúde, 2018; Sul.18(18): e269. 
RESUMO EXPANDIDO: Revisão Bibliográfica

TÍTULO: SISTEMAS DE LIBERAÇÃO DE BENZNIDAZOL: UMA REVISÃO INTEGRATIVA DOS RECENTES ESFORÇOS PARA SUPERAR AS LIMITAÇÕES FÍSICO-QUÍMICAS DO PRINCIPAL AGENTE ANTICHAGÁSICO

Autor/coautores: Alane Rafaela de Carvalho Amaral ${ }^{1}$, Kaio Henrique de Freitas ${ }^{1}$, Larissa Gabriele Sales Santos ${ }^{1}$, Rodrigo Vinícius Brito Lira¹, Lucas José de Alencar Danda'1.

Instituição: Universidade Federal de Pernambuco'1 (UFPE), Recife-Pernambuco.

Palavras-chave: Benznidazol, Sistemas de liberação in vitro, Doença de Chagas.

\section{INTRODUÇÃO}

A doença de Chagas é a infecção parasitária mais importante da América Latina e acomete aproximadamente 6 a 7 milhões de pessoas no mundo (FIGUEIRÊDO CBM, et al., 2018). As opções terapêuticas disponíveis para tratá-la ainda são bem limitadas, com apenas duas drogas, o benznidazol (BNZ) e o nifurtimox, sendo BNZ o tratamento de primeira linha adotado para a doença. Apesar da eficácia comprovada na fase aguda, o BNZ possui eficácia reduzida na fase crônica, levando ao abandono do tratamento devido aos elevados níveis de toxicidade. Além disto, a molécula de BNZ apresenta baixa solubilidade aquosa, o que compromete ainda mais sua biodisponibilidade oral.

Para endereçar as limitações físico-químicas ou reduzir a toxicidade de BNZ pela via oral, diversos sistemas de liberação de fármacos (SLF) contendo BNZ vêm sendo desenvolvidos desde 2011. SLFs baseados em ciclodextrinas, dispersões poliméricas, nanopartículas poliméricas, entre outros, contendo BNZ, foram propostos na tentativa de aprimorar a eficácia terapêutica de BNZ para tratamento da doença de Chagas.

\section{OBJETIVO}

Realizar revisão dos trabalhos científicos publicados nos últimos 5 anos de sistemas de liberação de BNZ, com foco na composição dos sistemas e performances in vitro e in vivo, quando relatados.

\section{MÉTODO}

Realizou-se uma revisão integrativa de literatura através das bases de dados Scopus e Web of Knowledge, utilizando a busca avançada com as seguintes sintaxis: "benznidazole AND dissolution", "benznidazole AND release", "benznidazol AND dissolução" e "benznidazol AND liberação".

Como critérios de inclusão, foram selecionados artigos originais entre 2016-2020, cujos temas envolvessem SLF contendo benznidazol.

Foram excluídos trabalhos que não realizaram ensaios de liberação in vitro ou estudos de farmacocinética in vivo, assim como publicações de SLF iguais do mesmo grupo de pesquisa. No último caso, foi selecionada a publicação mais recente para discussão.

\section{REVISÃO BIBLIOGRÁFICA}

Ao aplicar os termos de busca, foram apresentadas 39 publicações, das quais 9 foram selecionadas após a leitura dos resumos e aplicação dos critérios de inclusão. Após aplicar os critérios de exclusão, 6 publicações foram selecionadas para o estudo (Tabela 1). SLFs de composições diversas foram identificados, com breve descrição a seguir. 
Tabela 1 - Publicações consideradas para estudo após busca bibliográfica e aplicação dos critérios de inclusão e exclusão.

\begin{tabular}{llll}
\hline Ano & Autores & Origem & Sistema \\
\hline 2017 & DE MELO PN, et al. & Brasil & Ciclodextrina \\
2017 & DOS SANTOS-SILVA AM, et al. & Brasil & Nanopartícula polimérica \\
2017 & FIGUEIRÊDO CBM, et al. & Brasil/Canadá & Dispersão sólida \\
2018 & FIGUEIRÊDO CBM, et al. & Brasil/Canadá & Mistura eutética \\
2018 & NHAVENE EPF, et al. & Brasil & Nanopartículas de sílica \\
2018 & GARCÍA MC, et al. & Argentina & Complexos interpolieletrolíticos
\end{tabular}

Fonte: AMARAL ARC, et al., 2020.

Complexos de inclusão de BNZ com hidroxipropil- $\beta$-ciclodextrina foram obtidos em misturas ternárias com os co-solventes trietanolamina ou 1-metil-pirrolidona (DE MELO PN, et al., 2017). Nanopartículas catiônicas carregadas com BNZ foram preparadas por emulsificação seguida de evaporação de solventes, a partir de polímeros de polimetilmetacrilato (DOS SANTOS-SILVA AM, et al., 2017).

Dispersões sólidas contendo BNZ com posaconazol (PCZ), um antifúngico recentemente investigado para tratamento de doença de Chagas, foram preparadas com polivinilpirrolidona (PVP-K30) ou polivinilpirrolidonaco-vinilacetetato (PVP/VA64) por evaporação de solventes (FIGUEIRÊDO CBM, et al., 2017). Uma mistura eutética dos mesmos fármacos foi desenvolvida pelo mesmo grupo de pesquisa e preparada por evaporação de solventes, utilizando quantidades relativas de cada fármaco com base nas doses terapêuticas (FIGUEIRÊDO CBM, et al., 2018).

Nanopartículas de sílica mesoporosa de tamanho ordenado foram preparadas com quitosana ligada à superfície para ancorar moléculas de BNZ (NHAVENE EPF, et al., 2018). Complexos interpolieletrolíticos para liberação prolongada de BNZ foram preparados com base em polímeros polimetacrilatos ou polissacarídeos (GARCÍA MC, et al., 2018).

\section{DISCUSSÃO}

De maneira geral, todos os estudos de SLFs contendo BNZ influenciaram no desempenho in vitro do fármaco, alterando sua taxa de dissolução e, possivelmente, sua eficácia. Destacam-se o melhoramento da citotoxicidade em células renais normais pelas nanopartículas catiônicas de BNZ (DOS SANTOS-SILVA AM, et al., 2017), além de sua biodisponibilidade in vivo quando liberado de complexo interpolieletrolítico preparado com polímeros de polimetacrilato (GARCÍA MC, et al., 2018).

Dispersões sólidas amorfas e mistura eutética de BNZ com PCZ foi capaz de sustentar soluções supersaturadas de ambos os fármacos por mais tempo quando comparadas ao material cristalino (FIGUEIRÊDO CBM, et al., 2017, 2018).

\section{CONSIDERAÇÕES FINAIS}

Apesar dos avanços, ressalta-se que poucos trabalhos apresentaram testes in vivo ou modelos in vitro alternativos nos seus desenhos experimentais para endereçar o tratamento da doença. Na maioria dos casos, os estudos limitaram-se a testes de dissolução em meios não-biorrelevantes.

Ainda, há falta de consenso sobre o que pode impactar positivamente no tratamento da doença, com objetivos variando entre o aumento e a diminuição da taxa de dissolução do fármaco.

Apesar das limitações, os estudos apresentam avanços científicos que podem vir a melhorar o tratamento da doença de Chagas, uma doença que afeta majoritariamente a população economicamente vulnerável. 


\section{REFERÊNCIAS}

1. DE MELO PN, et al. Interaction pathways of specific co-solvents with hydroxypropyl-beta-cyclodextrin inclusion complexes with benznidazole in liquid and solid phase. Journal of Molecular Liquids, 2016; 223, 350-359.

2. DOS SANTOS-SILVA AM, et al. Designing structural features of novel benznidazole-loaded cationic nanoparticles for inducing slow drug release and improvement of biological efficacy. Materials Science \& Engineering C-materials for Biological Applications, 2017; 78, 978-987.

3. FIGUEIRÊDO CBME, et al. Enhanced delivery of fixed-dose combination of synergistic antichagasic agents posaconazole-benznidazole based on amorphous solid dispersions. European Journal of Pharmaceutical Sciences, 2018; 119, 208-218.

4. FIGUEIRÊDO CBME, et al. Enhancement of dissolution rate through eutectic mixture and solid solution of posaconazole and benznidazole. International Journal of Pharmaceutical, 2017; 525, 32-42.

5. GARCIA MC, et al. Polysaccharides-based multiparticulated interpolyelectrolyte complexes for controlled benznidazole release. International Journal of Pharmaceutical, 2018; 545,366-377.

6. NHAVENE EPF, et al. Chitosan grafted into mesoporous silica nanoparticles as benznidazol carrier for Chagas diseases treatment. Journal Microporous and Mesoporous Materials, 2018; 272, 265-275. 
RESUMOS EXPANDIDO: Relato de Experiência

Título: Relato de ExperiÊncia: Gestão de Resíduos de Serviços de Saúde Frente AO NOVO CORONAVÍRUS (COVID-19).

Autor/coautores: Paulyne Souza Silva Guimarães, Isabelle Cristina de Oliveira Vieira, Silvana Maria Barros de Oliveira, Risonilda Costa Silva, Gisele de Souza Vicente.

Instituição: Universidade Federal de Alagoas (UFAL), Maceió-Alagoas

Palavras-chave: Resíduos de Serviços de Saúde, Coronavírus, Saúde do Trabalhador.

\section{INTRODUÇÃO}

Os Resíduos de Serviços de Saúde (RSS) conhecido popularmente como lixo hospitalar proveniente da assistência à saúde, são gerados nas instituições de saúde, clínicas, laboratórios, serviço de unidade móvel, funerárias, entre outros semelhantes. Estes, dentro de uma perspectiva maior constituem um desafio com suas interfaces, já que além da questão ambiental, apresentam riscos para a saúde pública e do trabalhador (AMARANTE JAS, et al., 2017).

No contexto da pandemia causada pela infecção do novo coronavírus (CoVID-19) os RSS merecem destaque, devido a velocidade de disseminação do vírus, ampliação da rede de serviços de saúde, uso em demasia de materiais descartáveis, incluindo nesse rol os Equipamentos de Proteção Individual (EPIs) dos profissionais que prestam assistência direta ou indireta aos casos suspeitos ou confirmados da doença e, por consequência o aumento qualiquantitativo dos resíduos infectantes (BRASIL, 2020)

A gestão adequada e segura dos RSS de acordo com o regulamento técnico da Agência Nacional de Vigilância Sanitária (ANVISA), constitui-se como um processo contínuo que depende de embasamento científico-técnico, monitoramento da ações, sobretudo, qualificação dos recursos humanos (BRASIL, 2018).

\section{OBJETIVO}

Relatar o processo de construção de um material educativo para comunidade acadêmica, geradores de resíduos, profissionais de saúde e apoio que atuam na gestão e no manuseio dos resíduos de serviços de saúde.

\section{RELATO DE EXPERIÊNCIA}

Trata-se de um estudo descritivo, do tipo relato de experiência, que descreve momentos vivenciados entre uma cirurgiã-dentista e a equipe do laboratório de habilidades de enfermagem de uma universidade pública de uma capital do Nordeste na idealização e construção de um guia prático sobre gestão dos RSS em tempos de pandemia.

Para construção inicialmente buscou-se nos documentos oficiais do Ministério da Saúde Portaria no 2349/2017, Conselho Nacional de Meio Ambiente (CONAMA) Resolução nํ358/05, RDC no 222/2018 da ANVISA e Nota Técnica GVIMS/GGTES/no 04/2020, bem como Nota Técnica DVS/COVISA/no 01/2020 da Vigilância Sanitária do município sobre gestão dos RSS em tempos de pandemia. A segunda etapa constituiuse em definir o layout, imagens e cores (Figura 1).

A terceira etapa foi esclarecer que os resíduos provenientes de indivíduos suspeitos ou confirmados da infecção pelo novo coronavírus são classificados no grupo $A$, subgrupo $A 1$, por estarem enquadrados como agente biológico, classe de risco 3 , sendo sua transmissão de alto risco individual e moderado risco para a comunidade e meio ambiente. A quarta etapa foi alertar que nos ambientes para atendimento de pessoas suspeitas ou confirmadas de COVID-19 deve-se manter apenas lixeira de resíduos infectantes; o acondicionamento deve ser em saco vermelho com símbolo de substância infectante, com rótulos de fundo branco, desenho e contornos pretos e, caso o serviço de saúde não possua os referidos sacos para atender a demanda, poderá utilizar saco branco leitoso; os sacos devem estar acondicionados em lixeira de material lavável, provida de sistema de abertura sem contato manual. 
A equipe assistencial e de limpeza deve ser orientada que os sacos devem ser substituídos quando atingirem $2 / 3$ de sua capacidade ou pelo menos uma vez a cada 48 horas, independentemente do volume.Os RSS devem receber tratamento antes da disposição final ambientalmente correta. A quinta etapa foi a publicização do guia prático.

Figura 1 - Guia Prático

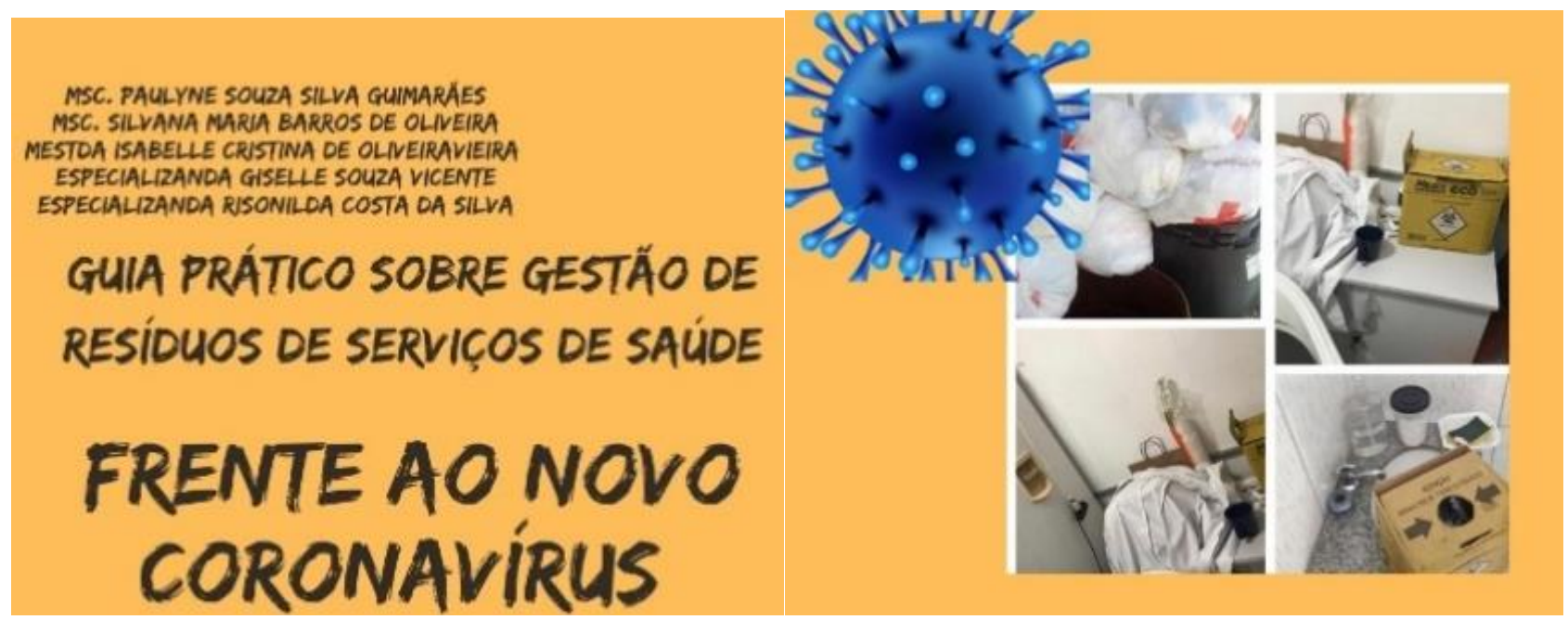

Fonte: GUIMARÃES PSS, et al., 2020. [Imagem criada a partir da Nota Técnica GVIMS/GGTES/ANVISA № 04/2020]

\section{DISCUSSÃO}

Construir materiais educativos para serem usados no atual contexto das ações de saúde é uma atividade complexa, pois eles servem como reomendação para adoção das normas de biossegurança diante da pandemia (KAMPF G, et al., 2020). O guia prático foi desenvolvido de maneira a gerar detalhamento sobre a gestão e o manuseio dos RSS, composto por uma estrutura teórica embasada por principios científicos e técnicos. As pesquisas sobre RSS evidenciam a necessidade de conscientização, dado o contexto em que profissionais apresentam desconhecimento sobre a classe dos RSS e desvalorização do seu correto manuseio em suas práticas (ZHU N, et al., 2020). As limitações desse material didático foram consideradas, tendo em vista a carência de publicações que aborde o tema no contexto pandêmico, incluindo recomendações para os resíduos domiciliares, uma vez que existem pessoas em tratamento da CoVID-19 em regime domiciliar. Espera-se que este guia possa contribuir com pesquisas futuras.

\section{CONSIDERAÇÕES FINAIS}

A pandemia trouxe um grande impacto negativo para a saúde pública nacional e mundial e para a economia, imprimindo a necessidade preeminente de subsidiar as ações institucionais acerca dos RSS. O material educativo tem por propósito apresentar e orientar a comunidade acadêmica, geradores de resíduos, profissionais de saúde e apoio quanto a gestão e o manuseio adequado dos RSS no contexto pandêmico, visando resguardar a saúde pública, do trabalhador e a preservação do meio ambiente, portanto é uma questão de biossegurança que deve ser considerada nas tomadas de decisão no enfrentamento da CoVID19

\section{REFERÊNCIAS}

1. AMARANTE JAS, et al., Avaliação do gerenciamento dos resíduos de medicamentos e demais resíduos de serviços de saúde na Região Serrana de Santa Catarina. Eng. Sanit. Ambient., 2017; 22(2), 317326.

2. BRASIL. Agência Nacional de Vigilância Sanitária. Nota Técnica № 04/2020 GVIMS/GGTES/ANVISA de 08 de maio de 2020. Orientações para serviços de saúde: medidas de prevenção e controle que 
devem ser adotadas durante a assistência aos casos suspeitos ou confirmados de infecção pelo novo coronavírus (SARS-CoV-2), 2020.2 Disponível em: http://portal.anvisa.gov.br/documents/33852/271858/Nota+T\%C3\%A9cnica+n+04-2020+GVIMSGGTES-ANVISA/ab598660-3de4-4f14-8e6f-b9341c196b28. Acessado em: 26 de julho de 2020.

3. BRASIL, Agência Nacional de Vigilância Sanitária. Resolução RDC ํㅡ 222, de 28 de março de 2018. Regulamenta as boas práticas de gerenciamento dos resíduos de serviços de saúde. Brasília: Diário Oficial da República Federativa do Brasil, 2018. Disponível em: http://portal.anvisa.gov.br/documents/10181/3427425/RDC_222_2018_.pdf/c5d3081d-b331-46268448-c9aa426ec410. Acessado em: 26 de julho de 2020.

4. KAMPF G, et al. Persistence of coronaviruses on inanimate surfaces and their inactivation with biocidal agentes: Journal of Hospital Infection, 2020; 104 (3), 246-251.

5. TEIXEIRA MV, et al. Avaliação da Gestão dos Resíduos em Unidades Básicas de Saúde de um Município Sul-Brasileiro. Revista Fund Care Online. 2018; 10(3):824-831.

6. ZHU N, et al. A novel coronavirus from patients with pneumonia in China, 2019. New England Journal of Medicine, 2020. 


\section{RESUMO EXPANDIDO}

TítUlo: ReVISÃo SistemÁtica dos PARÂMETROS FARMACOCINÉTICOS DA DAPSONA Autor/coautores: João Rodrigues de Lima, Marcela Paula Mainardi, João Pedro Costa dos Santos Guerra, Fernanda da Costa Ferreira Guerra, Michel Leandro Campos.

Instituição: Universidade Federal de Mato Grosso, Campus Universitário de Sinop, Instituto de Ciências da Saúde (UFMT), Sinop-Mato Grosso.

Palavras-chave: Farmacocinética, Hanseníase, Dapsona.

\section{INTRODUÇÃO}

A hanseníase é uma doença infecciosa crônica causada pelo Mycobacterium leprae ou Mycobacterium lepromatosis (BELACHEW, 2019) que acomete mucosas, pele e o sistema nervoso periférico. A Organização Mundial da Saúde (OMS) preconiza a poliquimioterapia (PQT), composta pela rifampicina, dapsona e clofazimina em dose específica por um período de 6 ou 12 meses (BELACHEW AW e NAAFS B, 2019). Apesar dos esforços para implementar um esquema terapêutico padronizado, os números de novos casos de hanseníase no país cresceram entre os anos de 2016-2018.

É possível que diferenças individuais entre pacientes alterem a exposição total ao fármaco e contribuam para a falha terapêutica.

Nesse contexto, torna-se relevante encontrar e analisar as informações de farmacocinética dos fármacos envolvidos no tratamento de diferentes estudos, de maneira a evidenciar diferenças disposicionais que mereçam mais atenção. Os parâmetros obtidos nesses trabalhos podem ser usados para elaboração de um modelo farmacocinético da dapsona que possa ser usado nas reavaliações clínicas e que determine a relação entre dose e resposta terapêutica nesses pacientes.

\section{OBJETIVO}

Revisar sistematicamente os parâmetros farmacocinéticos da dapsona disponíveis na literatura para evidenciar influências por outros tratamentos, condições patológicas e características gerais de população, construindo uma base de dados desses parâmetros.

\section{MÉTODO}

O estudo consiste em uma Rveisão Sistemática de parâmetros farmacocinéticos. A busca dos artigos foi realizada nos buscadores PubMed, Scopus e Web of Science em 20 de agosto de 2019, independentemente do período de publicação. Para realizar a busca, foram utilizados descritores para o fármaco (dapsone, diaminodiphenylsulfone, DADPS, diaphenylsulfone e NSC6091) e para os parâmetros farmacocinéticos (pharmacokinetic, bioequivalence, plasma concentration, plasma level, half-life, peak concentration, bioavailability, area under curve, Tmax, Cmax, Cmin, clearance, volume of distribution), juntamente com os operadores Booleanos AND e OR.

Para inclusão, os estudos deveriam conter qualquer parâmetro farmacocinético da dapsona. Os critérios de exclusão foram: estudos exclusivamente em animais ou in vitro e com concentrações plasmáticas em desacordo com o método analítico apresentado.

\section{REVISÃO BIBLIOGRÁFICA}

Revisões de parâmetros farmacocinéticos se fundamentam na aplicabilidade dos parâmetros avaliados em situações clínicas e simulações de novas situações. Uma revisão de Benznidazol (WIENS, et al., 2016) forneceu estimativas aprimoradas dos parâmetros farmacocinéticos sob condições de jejum, de uma dose única de $100 \mathrm{mg}$ em adultos. Assim, os parâmetros compilados e avaliados pela revisão podem ser usados 
por médicos e formuladores de políticas para um melhor manejo das doenças. No presente estudo, foram encontrados 751 artigos na busca inicial. Após a remoção das duplicatas, resultaram 431 artigos para análise dos resumos.

Destes, 113 obedeciam aos critérios mencionados e foram selecionados para a leitura na íntegra e, após essa leitura, apenas 48 foram efetivamente utilizados na revisão sistemática. Os artigos foram organizados, utilizando o Microsoft Office Excel. Para as análises apresentadas na figura, foram considerados apenas os estudos em adultos.

Figura 1. Distribuição dos valores de área sob a curva de zero ao último tempo em função da dose administrada e de características do estudo.

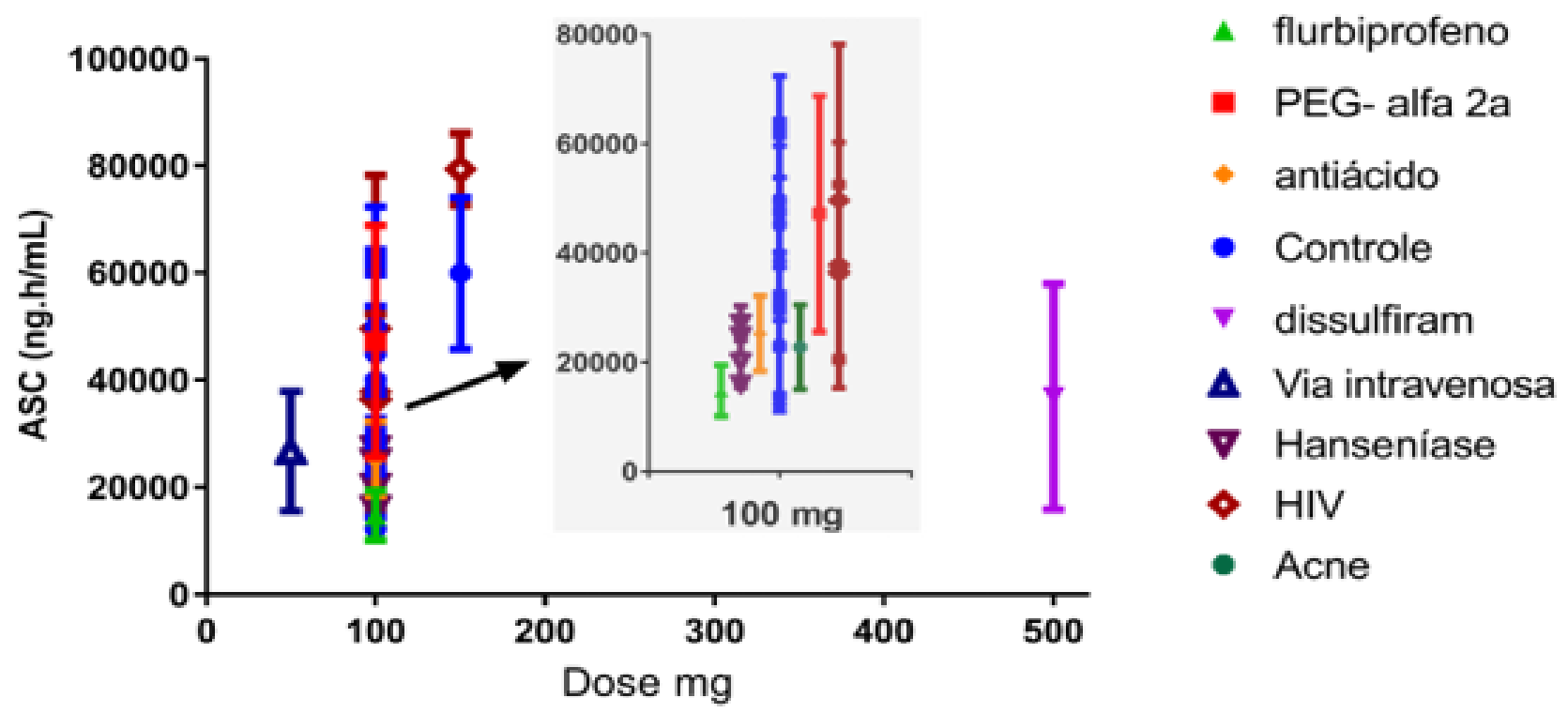

Fonte: LIMA, JR, et al., 2020

Foram extraídos 54 valores de área sob a curva (ASC) de 0-t e 22 ASC 0 -inf. Na figura 1 pode ser observada a distribuição de alguns valores de área sob a curva. Foram obtidos 58 valores de concentração máxima $\left(\mathrm{C}_{\text {máx }}\right)$ e 42 valores de tempo para concentração máxima $\left(\mathrm{T}_{\text {máx }}\right)$. A constante de eliminação $\left(K_{\text {el }}\right)$ teve 15 resultados enquanto 79 valores de meia-vida foram extraídos.

Os parâmetros clearence $(\mathrm{Cl})$ e volume de distribuição $(\mathrm{Vd})$ tiveram 36 e 31 resultados presentes, respectivamente. Quanto aos valores extraídos, as médias do parâmetro meia-vida de eliminação variaram de 10 a 48 h, o clearance ficou entre 0,18 e 3,7 L/h e o volume de distribuição entre 13,5 e 135,3 L.

\section{DISCUSSÃO}

Em análise ao desenvolvimento de revisões sistemáticas, percebemos que elas podem promovem a avaliação da qualidade dos estudos primários para oferecer um guia para estudos futuros acerca do mesmo tema (DELGADO-RODRÍGUEZ e SILLERO-ARENAS, 2018). Ademais, o fornecimento dos parâmetros farmacocinéticos compilados pode proporcionar dados apropriados a meta-análises subsequentes com grande impacto no conhecimento terapêutico, como presente em (WIENS, et al., 2016) que viabilizou maior domínio da farmacocinética do Benzonidazol.

Como mostrado na figura 1, a exposição ao fármaco quando 500 mg são administrado em concomitancia com a administração de dissulfiram não aumentou proporcionalmente quando comparada os valores de ASC da dose de $100 \mathrm{mg}$. A administração do flurbiprofeno também apresentou valores de ASC que margeiam os limites inferiores do grupo controle. 


\section{CONSIDERAÇÕES FINAIS}

A revisão sistemática acerca da farmacocinética da dapsona concluiu a importância da reavaliação dos parâmetros desse medicamento, visto existir variação de alguns resultados entre os artigos publicados até o presente momento.

Um exemplo está na discrepância dos valores de parâmetros como a ASC, o que reafirma a importância do estudo, visto que mostrou que tal parâmetro pode variar por condições individuais entre os pacientes.

Assim, mediante a importância da farmacocinética para melhor terapêutica clínica, a revisão mostrou êxito, uma vez que elucidou aspectos importantes da farmacocinética da dapsona.

\section{REFERÊNCIAS}

1. BELACHEW WI, NAAFS B. Position statement: LEPROSY: Diagnosis, treatment and follow-up Journal of the European Academy of Dermatology and Venereology, 2019; 33(7), 1205-1213.

2. ORGANIZAÇÃO MUNDIAL DA SAÚDE. Leprosy (Hansen's disease), em Health Topics, OMS, 2019. Disponível em: https://www.who.int/health-topics/leprosy\#tab=tab_1. Acessado em: 26 de julho de 2020.

3. WIENS MO, et al. Systematic Review and Meta-analysis of the Pharmacokinetics of Benznidazole in the Treatment of Chagas Disease. Antimicrob Agents Chemother. 2016;60(12):7035-7042.

4. DELGADO-RODRÍGUEZ M, SILLERO-ARENAS M. Systematic Review and Meta-analysis. Medicina Intensiva, 2018; 42(7):444-453. 
RESUMO EXPANDIDO: Revisão Bibliográfica

TÍTULO: FATORES DE VIRULÊNCIA DO NOVO VÍRUS DA INFLUENZA A (H1N2) E SEU POTENCIAL DE EVOLUÇÃO PARA UMA PANDEMIA

Autor/coautores: Hiolanda Nayara da silva1, Maria Fernanda da Silva1, Daryckson Gessé Pereira de Araujo1, Roberta Luciana do Nascimento Godone1,2

Instituição: ${ }^{1}$ Faculdade Uninassau - Campus Caruaru; ${ }^{2}$ Secretaria de Educação de Pernambuco, Recife Pernambuco.

Palavras-chave: Novo Influenza, Pandemia, Viroses.

\section{INTRODUÇÃO}

O vírus da Influenza A (IAV) é classificado como um patógeno da família dos ortomixovírus, responsável pelo desenvolvimento das principais gripes, epidemiologicamente representa um problema de saúde pública, na bibliografia técnico ciêntifica já foram identificados vários subtipos da IAV, como H1N1 responsável pela pandemia de 2009 (BEIRIGOAPT, et al., 2017) onde seespalhou-se rapidamente pelo mundo, afetando principalmente pessoas com idade $<65$ anos (SILVAPCR, 2015), essa família de vírus apresentam um grande poder de contágio pois sua transmissão ocorre através da inalação de partículas virais, apresentando possibilidade de desenvolvimento de epidemias e pandemias ocasionais.

A primeira identificação da sublinhagem H1N2 foi realizada entre os anos de 1988 e 1989 na china, porém somente em 2002 foi confirmada os primeiros casos da infecção, em outros países pela Organização Mundial da Saúde (OMS). O H1N2 apresenta em seu traço genético um rearranjo onde uni semelhanças das cepas encontradas em suínos norte-americanos, aves europeias e asiáticas (BEIRIGOAPT, et al., 2017); as cepas do H1N1 vem apresentando um aumento em sua diversidade genética desde o ano de 2013, desenvolvendo assim uma grande gama de subtipos do vírus (SUN H, et al., 2020).

\section{OBJETIVO}

Revisar na literatura científica a importância da vigilância e monitoramento deste novo vírus H1N2 para que não haja possíveis aumentos em relação a sua contaminação.

\section{REVISÃO BIBLIOGRAFICA}

De acordo com trabalhos publicados nos últimos anos foram encontrados dados que confirmam que 0 H1N2 ou G4, é geneticamente descendente da gripe suína H1N1, causadora da pandemia em 2009 (SUN H, et al., 2020), o G4 vem demonstrando características essenciais de um possível vírus pandêmico, sendo necessários melhores estudos e metodologias de controle desse patógeno; levando em consideração as taxas de contágio por ingestão de produto contaminado ou contato com animais infectados, apresentam um risco a saúde pública, uma vez que essas novas variantes tornam esse vírus com capacidade de adaptação animal/humana bem robusta (PULIT-PENALOZAJA, et al., 2018).

O primeiro isolamento do H1N2 foi feito no japão no ano de 1978, contaminando grande parte da população suína do país, entre os anos de 2011 e 2012 o vírus foi isolado na china e coréia do sul e foi observado que o mesmo já havia traços de outros subtipos virais (LEEJH, et al., 2015), alguns estudos e testes adicionais demostraram que o $\mathrm{H} 1 \mathrm{~N} 2$ pode infectar humanos ligando-se às células e se replicando rapidamente dentro das células das vias aéreas, o vírus tem como sua principail característica a facilidade de contágio podendo ocorrer de forma direta ou indireta, a direta ocorre de pessoa para pessoa, enquanto a indireta ocorre com a contaminação de superfícies contaminadas com o vírus.

O vírus está demonstrando uma crescente reprodução entre as populações de porcos em vários locais do mundo podendo representar uma séria ameaça à saúde humana se não monitoradocuidadosamente, embora o G4 possua genes H1N1 (SILVAPCR, 2015), pessoas que receberam vacinas contra a gripe sazonal não 
apresentam imunidade para a H1N2, pelo fato de que suas novas características e rearranjos gênicos conseguem interagir com as células normalmente, sem o efeito do sistema imunológico.

\section{DISCUSSÃO}

A transmissão bidirecional da H1N2 entre suínos e pessoas tornou-se a ação evolutiva do novo vírus influenza. O sequenciamento de seu genoma foi realizado e uma comparação de sua cepa com outros vírus influenza disponíveis no banco de dados de genes (GenBank), embora o novo isolado de H1N2 tenha o seu replicamento bem sucedido em camundongos, ele se mostra menos virulento (PENG X, et al, 2016), esses resultados fornecem evidências adicionais de que os suínos servem como hospedeiros intermediários para os rearranjos gênicos de novos subtipos do vírus influenza. Portanto, deve-se enfatizar a importância da vigilância dos suinos, como um sistema de alerta precoce para surtos de influenza nas populações suínas e humanas (PENG X, etal, 2016).

\section{CONSIDERAÇÕES FINAIS}

Levando em consideração os resultados das pesquisas, observa-se que os suínos são uma das principais espécies de reservatórios para os vírus influenza $A$ e desempenham um papel fundamental na transmissão de IAVs. O vírus G4 adquiriu maior infectividade humana, causando preocupação para uma possível geração de vírus pandêmicos.

Portanto, é necessária uma integração entre a saúde humana, a saúde animal, o ambiente e a adoção de políticas públicas efetivas para prevenção e controle de enfermidades, para que não ocorra a proliferação ainda maior do vírus, tanto entre os suínos, como também nas pessoas que trabalham com os animais.

\section{REFERÊNCIAS:}

1. BEIRIGO APT, et al. Influenza A (H1N1): Revisão bibliográfica. Revista de Saúde e Biologia, 2017; v.12, n.2, p.53-67.

2. LEE JH, et al, Evaluation of the zoonotic potential of a novel reassortant $\mathrm{H} 1 \mathrm{~N} 2$ swine influenza virus with gene constellation derived from multiple viral sources, Infection, Genetics and Evolution, 2015; 378-393.

3. PENG X, et al, Molecular characterization of a novel reassortant H1N2 influenza virus containing genes from the 2009 pandemic human H1N1 virus in swine from eastern China, RevistaEletrônica Springer Science, 2016; Jun;52(3):405-10.

4. PULIT-PENALOZA JA, et al, Comparative In Vitro and In Vivo Analysis of H1N1 and H1N2 Variant Influenza Viruses Isolated from Humans between 2011 and 2016. Journal of Virology. 2018; 92(22):e01444-18.

5. SILVA PCR, Dinâmica molecular dos vírus Influenza A (H1N1) pandêmico em cinco anos de circulação no Brasil, Tese (Doutorado em Medicina Tropical) - Fundação Oswaldo Cruz, 2015.176f.

6. SUN H, et al, Prevalent Eurasian avian-like H1N1 swine influenza virus with 2009 pandemic viral genes facilitating human infection, Revista Eletrônica PNAS, 2020; 117 (29) 17204-17210. 
RESUMO EXPANDIDO: Revisão bibliográfica

TÍTULO: TERAPIA COMBINADA ENTRE LECTINAS E ANTIBIÓTICOS COMO UMA ESTRATÉGIA PROMISSORA PARA SUPERAR A RESISTÊNCIA BACTERIANA: UMA REVISÃO DA LITERATURA Autor/coautores: João Victor de Oliveira Santos1, Sérgio Dias da Costa Jr1, Ylanna Larissa Alves Ferreira1, Luís André de Almeida Campos1, Isabella Macário Ferro Cavalcanti1,2

Instituição: Laboratório de Imunopatologia Keizo Asami (LIKA), Universidade Federal de Pernambuco (UFPE), Recife-PE1; Laboratório de Microbiologia e Imunologia, Centro Acadêmico de Vitória (CAV), Universidade Federal de Pernambuco (UFPE), Vitória de Santo Antão-Pernambuco².

Palavras-chave: Infecção, Sinergismo, Antimicrobianos.

\section{INTRODUÇÃO}

A resistência antimicrobiana (RAM) representa um dos principais desafios em saúde pública, impactando negativamente no processo de assistência de saúde, conduzindo a piores desfechos clínicos e contribuindo para o aumento das taxas de morbimortalidade e dos custos com a assistência clínica (FERREIRA GRS, et al., 2018).

Simultaneamente ao aumento do número de relatos de RAM, houve uma diminuição convergente na descoberta de novos antimicrobianos, o que promoveu o direcionamento de pesquisas voltadas a busca por terapias alternativas à base de produtos naturais (JANDÚ JJB, et al., 2017).

As lectinas são uma classe de proteínas ou glicoproteínas de origem não imune, que se ligam de forma reversível e específica a polissacarídeos.

O estudo da interação carboidrato-lectina, permitiu descobertas quanto as suas propriedades, incluindo sua atividade imunomoduladora, anti-inflamatória, antitumoral, antifúngica e antibacteriana (PROCÓPIO TF, et al., 2019). Apesar do aumento expressivo no número de publicações referente a aplicações antimicrobianas de compostos naturais nos últimos anos, o número de antimicrobianos em pesquisa e em desenvolvimento não é suficiente para eliminar a RAM (BAKAL SN, et al., 2017).

Assim, uma alternativa terapêutica promissora é a terapia antimicrobiana combinada entre antibióticos e lectinas para potencializar a atividade antibacteriana (FERREIRA GRS, et al., 2018).

\section{OBJETIVO}

Realizar uma revisão integrativa sobre a aplicação experimental de lectinas em terapias baseadas em combinações sinérgicas com antibióticos, como uma alternativa para o tratamento de infecções causadas por bactérias resistentes.

\section{MÉTODO}

Trata-se de uma revisão integrativa utilizando as plataformas PubMed e ScienceDirect. Os critérios de inclusão foram artigos científicos publicados em inglês nos últimos 10 anos, utilizando os descritores "Lectinas", "Sinergismo" e "Terapia combinada". O critério de exclusão foi estudos que não eram artigos científicos, como resumos, dissertações, teses, dentre outros.

\section{REVISÃO BIBLIOGRÁFICA}

Uma vez que o tema dessa revisão é relativamente novo, poucos estudos relatam a interação de lectinas e antibióticos, porém os resultados dos estudos encontrados são promissores. O estudo mais recente, verificou o efeito sinérgico da lectina extraída da sarcotesta de Punica granatum (PgTeL) com ceftazidima frente a quatro isolados de Escherichia coli produtor de beta-lactamase de espectro estendido (ESBL) e um isolado Escherichia coli produtor de metalo-beta-lactamase (MBL). Também foi detectado sinergismo dessa lectina com ampicilina frente a um isolado de ESBL, com carbenicilina frente a um isolado de ESBL e com cefuroxima frente a três isolados de ESBL. A combinação permitiu uma redução de 4 a 128 vezes nos valores 
da concentração inibitória mínima (CIM) da ceftazidima, 33 vezes da ampicilina, 16 vezes da carbenicilina e 256 a 1000 vezes da cefuroxima (DA SILVA PM, et al., 2019).

Outro estudo avaliou os efeitos da lectina extraída das folhas de Calliandra surinamensis pinnulae (CasuL), e comprovaram o efeito sinérgico das combinações de CasuL-tetraciclina e CasuL-ampicilina frente a isolados de Staphylococcus aureus isolados de mastites de bovinos e caprina (PROCÓPIO TF, et al., 2019). Foi demonstrado também o efeito sinérgico da lectina extraída da inflorescência da Alpinia purpurata (ApuL) com oxacilina frente a duas cepas de Staphylococcus aureus resistente à oxacilina (MRSA), e ApuL-ceftazidima frente a Pseudomonas aeruginosa multidrogarresistente (MDR) (FERREIRA GRS, et al., 2018). Em outro estudo foi possível verificar que a combinação de uma lectina obtida a partir da cepa de Acinetobacter baumannii com ceftazidima frente a $S$. aureus e $E$. coli apresentou aumento significativo da atividade antibacteriana em comparação a monoterapia, com uma redução do valor da CIM de 8x frente a ambos os microrganismos (MUSLIM SN, 2015).

\section{DISCUSSÃO}

A terapia combinada consiste na utilização de uma ou mais moléculas/compostos visando a potencialização da atividade biológica. Essa terapia apresenta vantagens como a expansão do espectro antimicrobiano, minimização do desenvolvimento da resistência, menor toxicidade devido a utilização de menores concentrações, custos menores por serem renováveis por natureza e possibilita a aplicação do antimicrobiano, quando este de forma isolada poderia não ser eficaz frente determinado microrganismo (FERREIRA GRS, et al., 2018).

Embora haja muitos estudos avaliando a potencialização de fármacos associados a moléculas extraída de plantas, as pesquisas que verificam o sinergismo entre lectinas e os fármacos comerciais são escassas. Em todos os estudos encontrados, foi observado que as lectinas intensificaram o efeito terapêutico dos antimicrobianos convencionais, promovendo a redução da CIM.

\section{CONSIDERAÇÕES FINAIS}

A RAM é um problema de saúde pública que causa altos índices de morbimortalidade mundialmente. $O$ tratamento através da monoterapia com os antimicrobianos comerciais tem se tornado ineficaz, sendo necessário novas abordagens terapêuticas como a terapia combinada. Essa terapia apresenta muitas vantagens, destacando-se a diminuição da toxicidade dos antibióticos, pois eles serão utilizados em baixas concentrações, e a possibilidade de ultrapassar a resistência bacteriana. Nesse sentido, as lectinas são moléculas promissoras para terapia antimicrobiana combinada, pois são de fácil obtenção, são extraídas com baixo custo e apresentam potencial antibacteriano, podendo atuar como agentes coadjuvantes em associação com os antibióticos e configurar um futuro promissor para terapêutica.

\section{REFERÊNCIAS}

1. BAKAL SN, et al. Finding novel antibiotic substances from medicinal plants-antimicrobial properties of Nigella sativa directed against multidrug resistant bacteria. European Journal of Microbiology and Immunology, 2017; 7(1): 92-98.

2. DA SILVA PM, et al. Punica granatum sarcotesta lectin (PgTeL) has antibacterial activity and synergistic effects with antibiotics against $\beta$-lactamase-producing Escherichia coli. International Journal of Biological Macromolecules, 2019; 135: 931-939.

3. FERREIRA GRS, et al. Antimicrobial potential of Alpinia purpurata lectin (ApuL): Growth inhibitory action, synergistic effects in combination with antibiotics, and antibiofilm activity. Microbial Pathogenesis, 2018; 124: $152-162$.

4. JANDÚ JJB, et al. Targeting the immune system with plant lectins to combat microbial infections. Frontiers in Pharmacology, 2017; 8: 671.

5. MUSLIM SN. Improving of antibacterial activity for antibiotics by purified and characterized lectin from Acinetobacter baumanni. Iraqi Journal of Biotechnology, 2015; 14(1): 9-22.

6. PROCÓPIO TF, et al. Looking for alternative treatments for bovine and caprine mastitis: Evaluation of the potential of Calliandra surinamensis leaf pinnulae lectin (CasuL), both alone and in combination with antibiotics. MicrobiologyOpen, 2019; 8(11): 1-11. 
RESUMO EXPANDIDO: Revisão Bibliográfica

TÍTULO: RELEVÂNCIA DA INTERVENÇÃO NUTRICIONAL COMO ESTRATÉGIA PARA INTERVIR NO PROGNÓSTICO DE PORTADORES DE DCNT INFECTADOS POR COVID-19: UMA BREVE REVISÃO Autor/coautores: Gabrielle Guimarães Araújo, Elias Tibúrcio Júnior, Sandra Maria Souza da Silva, Danielle Guimarães Araújo.

Instituição: Universidade Federal de Pernambuco (UFPE), Recife-Pernambuco.

Palavras-chave: DCNT, COVID-19, Nutrição

\section{INTRODUÇÃO}

Desde sua origem em dezembro de 2019, o COVID-19 continua a causar morbidade em grande escala e com mortalidade global. De acordo com o relatório da Organização Mundial da Saúde (OMS), desde o início do surto até o mês de maio, mais de 4 milhões de casos foram confirmados, mais de 300000 foram fatais (BASU, 2020; RYCHTER et al., 2020).

Embora haja um grande empenho por diversas entidades em atuar no controle da doença transmissível causada por este vírus, intervir nas doenças crônicas não transmissíveis (DCNT) também é de importância vital, uma vez que a pandemia terá também um impacto substancial nestas. Além disso, segundo estimativas globais, um alto risco de mortalidade nos casos Covid-19 é atribuído a uma ou mais comorbidades e fatores de risco para DCNT podem aumentar a suscetibilidade ao vírus (PALMER et al., 2020).

Nesse contexto, o estado nutricional pode ter um impacto significativo na saúde geral do indivíduo. Uma alimentação adequada é capaz de reduzir o risco de desenvolviemnto de DCNT e pode influenciar nas funções imunológicas, minimizando a vulnerabilidade à infecções. Somado a isso, a nutrição consiste em uma ferramenta promissora devido à sua segurança e facilidade de aplicação (ZABETAKIS et al., 2020).

\section{OBJETIVO}

Realizar uma revisão integrativa de literatura com o intuito de descrever a relevância da intervenção nutricional como estratégia para intervir no prognóstico de pacientes portadores de DCNT infectados por COVID-19.

\section{MÉTODO}

O estudo trata-se de uma Revisão Integrativa da Literatura. A recopilação do material ocorreu em julho de 2020. Foram selecionados artigos publicados entre 2015-2020, no idioma inglês. O material foi extraído das seguintes bases de dados: PubMed e Scielo, utilizando-se os descritores "DCNT", "COVID-19" e "Nutrição".

Os artigos selecionados preenchiam os critérios de inclusão, através da leitura de títulos e resumos. Incluíram-se artigos disponíveis envolvendo as DCNT e o COVID-19. Foram excluídos artigos de revisão que não abordassem o tema em sua integralidade.

\section{REVISÃO BIBLIOGRÁFICA}

A atual situação de pandemia do COVID-19 impõe cautela no que diz respeito aos pacientes portadores de doenças crõnicas não-trasmissíveis. A inflamação crônica, presente em infecções virais, está implicada no aparecimento, progressão ou desenvolvimento de DCNT. Em contrapartida, acredita-se que a inflamação sistêmica subjacente possa exacerbar a infecção por COVID-19 (ZABETAKIS et al., 2020).

A presença de comorbidades em pacientes com COVID-19 é atualmente uma preocupação significativa. Por exemplo, pacientes com diabetes e pressão alta, apresentam danos aos vasos sanguíneos, culminando em complicações trombóticas aumentadas no COVID-19 associadas aos casos graves. Do mesmo modo, pacientes com obesidade e comorbidades que comprometam a função cardíaca ou pulmonar, carregam fatores de risco para complicações decorrentes da infecção por COVID-19. Por outro lado, a desnutrição pode causar impactos no sistema imunológico, tornando o indivíduo imunocomprometido (RYCHTER et al., 2020). 
Uma estratégia eficaz para reduzir o risco de desenvolver DCNT é controlar as atividades dos mediadores inflamatórios por meio de fatores de risco modificáveis, como dieta e exercício físico. Evidencia-se a existência de várias dietas e nutrientes que potencialmente conferem propriedades anti-inflamatórias e imunomoduladoras a doenças, incluindo DCNT, sem o risco de imunossupressão (ZABETAKIS et al., 2020).

As alterações no estado emocional provocadas pela pandemia estão também levando a mudanças na desordem alimentar em diversas populações. A ansiedade, a depressão e o estresse têm sido associados a um incremento nos índices de compulsão ou transtornos alimentares, o que evidencia que o apoio psicológico é uma abordagem essencial para o gerenciamento desses agravos ocasionados pela atual situação (ASHBY, 2020).

Tabela 1 - Compilação de informações dos estudos selecionados.

\begin{tabular}{|c|c|c|c|}
\hline Título do artigo & Autores & Revista/Ano & Resultados \\
\hline $\begin{array}{l}\text { COVID-19: The } \\
\text { Inflammation Link and } \\
\text { the Role of Nutrition in } \\
\text { Potential Mitigation. }\end{array}$ & $\begin{array}{l}\text { ZABETAKIS } \\
\text { I, et al. }\end{array}$ & $\begin{array}{l}\text { Nutrients, } \\
2020 .\end{array}$ & $\begin{array}{l}\text { Uma dieta saudável e equilibrada pode } \\
\text { oferecer os macro e micronutrientes } \\
\text { necessários para restaurar e manter a } \\
\text { função das células imunes, aumentando } \\
\text { assim a proteção contra as DCNT. }\end{array}$ \\
\hline $\begin{array}{l}\text { Non-communicable } \\
\text { disease management in } \\
\text { vulnerable patients } \\
\text { during Covid-19. }\end{array}$ & BASU S. & $\begin{array}{l}\text { Indian } \\
\text { Journal of } \\
\text { Medical } \\
\text { Ethics. }\end{array}$ & $\begin{array}{l}\text { O desafio de manter a continuidade do } \\
\text { atendimento em pacientes com DCNT na } \\
\text { época da pandemia de Covid-19 adquire } \\
\text { enorme importância no contexto dos } \\
\text { resultados de saúde. }\end{array}$ \\
\hline $\begin{array}{l}\text { The potential long-term } \\
\text { impact of the COVID-19 } \\
\text { outbreak on patients with } \\
\text { non-communicable } \\
\text { diseases in Europe: } \\
\text { consequences for } \\
\text { healthy ageing. }\end{array}$ & $\begin{array}{l}\text { PALMER K, } \\
\text { et al. }\end{array}$ & $\begin{array}{l}\text { Aging } \\
\text { Clinical and } \\
\text { Experimental } \\
\text { Researche, } \\
2020 .\end{array}$ & $\begin{array}{l}\text { É fundamental atender urgentemente às } \\
\text { necessidades básicas dos pacientes com } \\
\text { DCNT, identificando ações prioritárias para } \\
\text { apoiá-los no gerenciamento de suas } \\
\text { condições crônicas, tanto durante a } \\
\text { emergência existente como a médio / longo } \\
\text { prazo. }\end{array}$ \\
\hline $\begin{array}{l}\text { The Impact of the } \\
\text { COVID-19 Pandemic on } \\
\text { Unhealthy Eating in } \\
\text { Populations with } \\
\text { Obesity. }\end{array}$ & $\begin{array}{l}\text { ASHBY } \\
\text { NJS. }\end{array}$ & $\begin{array}{l}\text { Obesity: The } \\
\text { Journal of } \\
\text { The Obesity } \\
\text { Society, } \\
2020 .\end{array}$ & $\begin{array}{l}\text { A pandemia do COVID-19 produziu } \\
\text { emoções negativas como ansiedade e } \\
\text { pânico na população. Diante disso, prevê- } \\
\text { se que ela leve a um consumo diferenciado } \\
\text { de alimentos não saudáveis, gerando } \\
\text { maiores taxas de obesidade. }\end{array}$ \\
\hline $\begin{array}{l}\text { Should patients with } \\
\text { obesity be more afraid of } \\
\text { COVID-19? }\end{array}$ & $\begin{array}{l}\text { RYCHTER } \\
\text { AM, et al. }\end{array}$ & $\begin{array}{l}\text { Obesity } \\
\text { Reviews, } \\
2020 .\end{array}$ & $\begin{array}{l}\text { A obesidade deteriora o curso da infecção } \\
\text { e está associada com um aumento da } \\
\text { mortalidade entre os pacientes com } \\
\text { COVID-19. }\end{array}$ \\
\hline
\end{tabular}

Fonte: ARAÚJO GG, et al., 2020.

\section{DISCUSSÃO}

O presente estudo foca na necessidade de considerar os impactos indiretos que a pandemia terá sobre os pacientes portadores de DCNT e na importância de se adotar mudanças nos comportamentos alimentares. Os artigos analisados evidenciam que o aumento nas taxas de DCNT, bem como o descontrole dos casos existentes, poderia comprometer ainda mais a sustentabilidade de sistemas de saúde, agravando a condição dos pacientes portadores (ASHBY, 2020; PALMER et al., 2020; ZABETAKIS et al., 2020). 
Uma limitação do presente estudo é a incapacidade de os dados atuais estimarem as variáveis que potencialmente afetam a ingestão de alimentos não saudáveis durante a pandemia e a escassez de dados estatísticos, uma vez que se trata de um quadro epidemiológico ainda muito novo.

\section{CONSIDERAÇÕES FINAIS}

As DCNT representam atualmente um ônus significativo para os sistemas globais de saúde. Para evitar seu desenvolvimento ou progressão, uma atenção especial deve ser dada à adoção de hábitos saudáveis. No cenário atual de pandemia, o grande foco da gestão da saúde tem sido o controle do emergente Covid19, o que pode levar a relativa negligência em relação a outras condições, afetando criticamente as necessidades de saúde dos pacientes com DCNT mais vulneráveis, representando um grave problema de saúde pública, passível de intervenção.

\section{REFERÊNCIAS}

1. ASHBY NJS. The Impact of the COVID-19 Pandemic on Unhealthy Eating in Populations with Obesity. Obesity: The Journal of The Obesity Society. 2020.

2. BASU S. Non-communicable disease management in vulnerable patients during Covid-19. Indian Journal of Medical Ethics. 2020; (2):103-105.

3. RYCHTER AM, et al. Should patients with obesity be more afraid of COVID-19? Obesity Reviews. 2020.

4. PALMER K, et al. The potential long-term impact of the COVID-19 outbreak on patients with noncommunicable diseases in Europe: consequences for healthy ageing. Aging Clinical and Experimental Researche. 2020.

5. ZABETAKIS I, et al. COVID-19: The Inflammation Link and the Role of Nutrition in Potential Mitigation. Nutrients. 2020;12(5):1466.

6. WHO. Coronavirus disease (COVID-19). 2020. Disponível em: https://www.whi.int/emergencies/diseases/novel-coronavirus-2019. Acessado em: 08 de junho de 2020. 
RESUMO EXPANDIDO: Revisão Bibliográfica

TíTULO: POTENCIAL ANTILEISHMANIAL DE NANOPARTíCULAS DE PRATA: UMA REVISÃO

Autor/coautores: Azael Francisco Silva Neto1; Tâmara Thaiane Almeida Siqueira1; Luís André de Almeida Campos1; Rafaela de Siqueira Ferraz Carvalho1; Mariane Cajubá de Britto Lira Nogueira1,2.

Instituição: Universidade Federal de Pernambuco (UFPE), Recife- $\mathrm{PE}^{1}$; Universidade Federal de Pernambuco (UFPE), Vitória de Santo Antão-PE².

Palavras-chave: Leishmaniose, Nanopartículas de Prata, Atividade Leishmanicida.

\section{INTRODUÇÃO}

A leishmaniose é uma doença negligenciada causada por espécies do gênero Leishmania e pode ser classificada como visceral, cutânea, mucosa e calazar. Na última década, dentre as infecções tropicais, ela foi a segunda causa mais comum de morte, e estima-se que essa parasitose acomete 12 milhões de pessoas em todo o mundo, com cerca de 1 a 2 milhões de novos casos anualmente. Ela está presente em 98 países nos continentes Africano, Americano e Asiático, sendo considerada um problema de saúde pública (DE ALMEIDA L, et al., 2017; SANGENITO LS, et al., 2019).

$\mathrm{Na}$ terapêutica atual, os antiparasitários de escolha são os antimoniais pentavalentes, seguido de anfotericina B e pentamidina. Entretanto, o tratamento é longo e provoca efeitos adversos que dificultam a adesão do paciente a terapia (SANGENITO LS, et al., 2019). Com o objetivo de superar essas limitações, as nanopartículas de prata (NPs-Ag) apresentam-se como uma alternativa viável, visto que estudos já demonstraram sua atividade antimicrobiana, anti-inflamatória e antioxidante (EL-KHADRAGY M, et al., 2018).

\section{OBJETIVO}

Realizar uma revisão integrativa visando investigar os efeitos antileishmaniais das NPs-Ag, levando em consideração o potencial antiparasitário, os mecanismos de ação e a síntese dessas nanopartículas como uma alternativa aos medicamentos antileishmaniais convencionais.

\section{MÉTODO}

Trata-se de uma revisão integrativa da literatura e como estratégia de identificação e seleção dos artigos foi realizado um levantamento bibliográfico nas plataformas PubMed, SciELO, ScienceDirect e Google Acadêmico. Utilizou-se os descritores "neglected diseases", "leishmaniasis", "Leishmania spp.", "silver nanoparticles". Os critérios de inclusão foram estudos completos publicados em inglês entre os anos de 2016 a 2020, com testes in vitro e/ou in vivo que abordassem atividade antiparasitária frente às espécies causadoras da leishmaniose cutânea e visceral. Os critérios de exclusão foram estudos duplicados, teses, dissertações e publicações de anais de eventos. Foram encontrados 247 artigos, após a leitura do título, resumo e palavras-chave foram selecionados 18 artigos para leitura e com uma análise criteriosa 4 foram escolhidos por atenderem a todos os critérios de elegibilidade.

\section{REVISÃO BIBLIOGRÁFICA}

Estudos recentes analisaram a atividade antileishmanial das NPs-Ag. Ahmad et al. (2016) avaliaram a eficácia das NPs-Ag biogênicas ligadas a anfotericina B (NPs-Ag-AnB) in vitro frente à Leishmania tropica, causadora de leishmaniose cutânea. Após 48h, na ausência de luz, as NPs-Ag apresentaram inibição de $73 \%$, enquanto as NPs-Ag-AnB apresentaram inibição de $85 \%$. Com a incidência de radiação UV, os valores de inibição obtidos para as NPs-Ag e as NPs-Ag-AnB, foram $83 \%$ e $96 \%$, respectivamente.

Meaad et al. (2017) compararam a atividade leishmanicida in vitro das NPs-Ag e do pentosan frente Leishmania tropica, causadora da leishmaniose cutânea. A IC 50 das NPs-Ag para as formas amastigotas foi de $1,1 \mu \mathrm{g} / \mathrm{mL}$ e para as formas promastigotas de $1,7 \mu \mathrm{g} / \mathrm{ml}$. Para o pentosan, não foi encontrada a $\mathrm{IC}_{50}$, uma vez que não houve morte de pelo menos $50 \%$ nas concentrações testadas $(0,3-2,1 \mu \mathrm{g} / \mathrm{ml})$ para amastigotas e promastigotas. 
Ullah et al. (2018) realizaram testes in vitro para analisar o potencial antiparasitário das NPs-Ag biogênicas e sintetizadas quimicamente frente às formas promastigotas de Leishmanias infantum, causadora da leishmaniose visceral. A IC50 das NPs-Ag foi de $51,23 \mu \mathrm{g} / \mathrm{ml}$ e das NPs-Ag biogênicas variou de 19,42 a 30,71 $\mu \mathrm{g} / \mathrm{ml}$, indicando que as NPs-Ag biogênicas apresentam maior eficácia de inibição.

El-Khadragy et al. (2018) analisaram o potencial antileishmanial in vivo das NPs-Ag biossintetizadas através da Moringa oleífera e do pentosan frente a Leishmania major, causadora de leishmaniose cutânea. Os camundongos infectados que não receberam nenhum tratamento apresentaram lesões progressivas no local da inoculação durante as quatro semanas. As lesões da pele tratadas com as NPs-Ag desapareceram em 21 dias, enquanto com o pentosan continuaram após 28 dias. Assim, conforme discutido nos artigos, o tratamento com as NPs-Ag mostrou-se mais eficaz no tratamento da leishmaniose cutânea e visceral.

\section{DISCUSSÃO}

Conforme discutido nos artigos selecionados, as NPs-Ag tornaram-se um agente leishmanicida promissor, pois são capazes de produzir espécies reativas de oxigênio e óxido nítrico, causando danos oxidativos aos protozoários e eliminando as espécies de Leishmania (ULLAH I, et al., 2018). As NPs-Ag podem alterar vias bioquímicas e fisiológicas, a composição química, a morfologia e a estrutura geral do parasita, induzindo a perda da capacidade infectante dos promastigotas e a sobrevivência dos amastigotas nas células hospedeiras. As NPs-Ag alteram a função metabólica e reprodutiva do parasita, induzindo o processo de apoptose diminuindo a carga parasitária em camundongos infectados (MEAAD A, et al., 2017; ELKHADRAGY M, et al., 2018).

\section{CONSIDERAÇÕES FINAIS}

Dessa maneira, conclui-se que as NPs-Ag são ferramentas promissoras no tratamento da Leishmaniose, especialmente as NPs-Ag biogênicas, que desenvolvem sua atividade antileishmanial em concentrações menores quando comparadas àquelas sintetizadas quimicamente. Entretanto, ainda são necessários mais estudos in vivo e que mimetizem as condições ambientais para comprovar a segurança dessas NPs. Assim, esta revisão evidencia o potencial leishmanicida, os mecanismos de ação, e a influência na atividade antiparasitária dependente da via de síntese das NPs-Ag.

\section{REFERÊNCIAS}

1. AHMAD A, et al. Isatis tinctoria mediated synthesis of amphotericin B-bound silver nanoparticles with enhanced photoinduced antileishmanial activity: a novel green approach. Journal of Photochemistry and Photobiology B: Biology, 2016, 161: 17-24

2. DE ALMEIDA L, et al. Nanotechnological strategies for treatment of leishmaniasis-a review. Journal of Biomedical Nanotechnology, 2017; 13(2): 117-133.

3. EL-KHADRAGY M, et al. Clinical efficacy associated with enhanced antioxidant enzyme activities of silver nanoparticles biosynthesized using Moringa oleifera leaf extract, against cutaneous leishmaniasis in a murine model of Leishmania major. International Journal of Environmental Research and Public Health, 2018, 15(5): e1037.

4. MEAAD, A. Gharby; AL-QADHI, Ban N.; JAAFAR, Sadeq M. Evaluation of silver nanoparticles (Ag NPs) activity against the viability of Leishmania tropica promastigotes and amastigotes in vitro. Iraqi Journal of Science, v. 58, n. 1A, p. 13-21, 2017

5. SANGENITO LS, et al. Leishmaniasis and Chagas disease-neglected tropical diseases: Treatment updates. Current Topics in Medicinal Chemistry, 2019; 19(3): p. 1-5.

6. ULLAH I, et al. Comparative study on the antileishmanial activities of chemically and biologically synthesized silver nanoparticles (AgNPs). 3 Biotech, 2018; 8(2): e98. 
RESUMO EXPANDIDO: Revisão Bibliográfica

TítUlo: Perspectivas farmacoterapêuticas PARA A COVID-19

Autor/coautores: Michelle Melgarejo da Rosa, Mateus Augusto Barbosa de Negreiros Costa Lima.

Instituição: Universidade Federal de Pernambuco (UFPE), Recife-PE.

Palavras-chave: Infecções por Coronavírus, Tratamento Farmacológico, Perspectivas terapêuticas.

\section{INTRODUÇÃO}

A pandemia causada pelo SARS-CoV-2, um novo coronavírus, pertencente a familía Coronaviridae, tornou-se atualmente o tema mais abordado dentro da comunidade científica, devido a sua alta mortalidade e morbidade, assim como ao pouco conhecimento difndido acerca desse novo típo de coronavírus (CONNORS JM; LEVY JH, 2020).

A fisiopatologia da infecção e os respectivos tratamentos destinados ao combate da COVID-19, tem se atualizado constantemente, cada vez mais com novas informações e mudanças cruciais no que diz respeito as terapêuticas definidas, seja por meio do uso de medicamentos ou medidas de suporte não farmacológicas.

O redirecionamento de fármacos está sendo adotado mundialmente para que consigamos descobrir terpias medicamentosas à COVID-19. Farmácos já utilizados para outras patologias passam a ser investigados, na pandemia em questão. Mais de 1300 medicamentos estão em diferentes fases de pesquisas, entretanto apenas 3 com estudos concluidos. Mais de 6 meses de COVID-19 e, infelizmente, ainda não suprimos as espectativas terapêuticas a doença.

\section{OBJETIVO}

Discutir terapias farmacológicas em estudo para a COVID-19, assim como elucidar a implicância das mesmas na fisiopatologia da doença, e por meio disso criar bases para os profissionais de saúde tomarem decisões farmacoterapêuticas baseadas em evidências.

\section{REVISÃO BIBLIOGRÁFICA}

A definição da farmacoterapêutica para a COVID-19 é um desafio constante, devido a isso, alguns estudos sobre medicamentos relacionados com o tratamento desta virose têm embasado condutas medicamentosas no combate a infecção pelo coronavírus. As classes farmacológicas mais estudadas são os antiinflamatórios, anticoagulantes e trombolíticos e anti-parasitários.

De acordo com Zhang W, et al. (2020), o uso de glicocorticóides tem se mostrado efetivo em pacientes com apresentação de complicações respiratórias e hipertermia. Os dados apresentados no estudo mostram que os corticóides auxiliam no controle e manejo da febre, bem como, mostraram-se eficazes na otimização da oxigenação dos pacientes.

Dentre entres medicamentos, a dexametasona é a mais representada em pesquisas. Em um relatório preliminar publicado por Horby PW, et al. (2020), o uso deste fármaco (6 mg/dia por 10 dias, por via oral ou intravenosa) reduziu significativamente a mortalidade da virose, assim como o tempo de suporte ventilatório dos pacientes que receberam o medicamento, devido a melhora na oxigenação e complicações pulmonares.

Os anticoagulantes e trombolíticos (Heparina e derivados), tem sido usado como profilaxia ou intervenção, devido a trombogenia da infecção. A aplicação desses fármacos preventivamente, mostrou-se eficaz contra o desenvolvimento de trombose microvascular em pacientes com infecção severa, principalmente por prevenir a síndrome de angústia respiratória do adulto (SARS), já a aplicação intervensionista desses medicamentos se dá como tratamento de suporte para SARS e pacientes já portadores de coagulopatias (CONNOR JM; LEVY JH, 2020).

Embora a Ivermectina, um agente anti-parasitário, tenha até o presente momento apresentado resultados in vitro, seu uso foi aprovado pelo Food and Drug Administration (FDA) para o tratamento da COVID-19, em 
pacientes com quadros de severidade variados. Mesmo os resultados sendo apenas in vitro, este fármaco mostrou-se capaz de reduzir $93 \%$ a replicação viral e $99,8 \%$ da carga viral celular em 24 horas (CALY L, et al., 2020).

Figura 1 - Medicamentos e seus respectivos usos no tratamento da COVID-19

\begin{tabular}{|l|l|}
\hline Medicamentos & Uso \\
\hline $\begin{array}{l}\text { Glicocorticóides, principalmente } \\
\text { Dexametasona. }\end{array}$ & $\begin{array}{l}\text { Combate complicações respiratórias e febre, reduz mortalidade tempo } \\
\text { de suporte ventilatório. }\end{array}$ \\
\hline $\begin{array}{l}\text { Anticoagulantes e trombolíticos } \\
\text { (Heparina e derivados). }\end{array}$ & $\begin{array}{l}\text { Previne e trata a trombose microvascular e SARS, como também } \\
\text { auxilia no tratamento de pacientes coagulopatas. }\end{array}$ \\
\hline Ivermectina & Redução da replicação e carga viral. \\
\hline
\end{tabular}

Fonte: (LIMA MABNC e ROSA MM, 2020).

\section{DISCUSSÃO}

Até o presente momento, as definições das condutas terapêuticas estão em constante modificação (CALY $\mathrm{L}$, et al., 2020). Os fármacos supracitados, embora tenham mostrado algum auxílio no tratamento da COVID19, ainda precisam melhores resultados frente a patogenia da infecção. Há necessidade de estudos multicentricos e randomizados para termos uma terapêutica cientificamente validada (NGUYEN AA, et al., 2020).

Contudo, mesmo com um número limitado de evidências, os estudos sobre fármacos em uso, ou potenciais fármacos contra o SARS-CoV-2, tem direcionado cada vez mais a terapêutica. Há necessidade de uso farmacológico assertivo e com impactos positivos aos prognósticos dos pacientes, reduzindo agravamentos por condutas farmacológicas errôneas e infundadas (ZHANG W, et al., 2020).

\section{CONSIDERAÇÕES FINAIS}

Sabe-se da crescente necessidade de terapias assertivas a COVID-19. Visando isso, múltiplos pesquisadores investem na pesquisa clínica e são motivados a encontrar resultados confiáveis e reprodutíveis, que possam sanar perguntas sobre possibilidades terapêuticas à COVID-19, evitando, também, o uso desnecessário de medicamentos. Mesmo em um forca-tarefa mundial, ainda não há uma substância com tal representatividade. Entretanto seguimos confiando que os dados científicos mostrarão o melhor caminho terapêutico e imunológico para ser inserido ao contexto COVID-19.

\section{REFERÊNCIAS}

1. CALY L, et al. The FDA-approved drug ivermectin inhibits the replication of SARS-CoV-2 in vitro. Antiviral Research, 2020; 178, 104787.

2. CONNORS JM, LEVY JH. COVID-19 and its implications for thrombosis and anticoagulation. American Society of Hematology, 2020; 135(23).

3. HORBY PW, et al. Dexamethasone in Patients with Covid -19 - Preliminary Report. Recovery. The New England Journal of Medicine, 2020.

4. NGUYEN AA, et al. Immunoglobulins in the treatment of COVID-19 infection: Proceed with caution!. Clinical Immunology, 2020; 216, 108459.

5. ZHANG W, et al. The use of anti-inflammatory drugs in the treatment of people with severe coronavirus disease 2019 (COVID-19): The Perspectives of clinical immunologists from China. Clinical Immunology, 2020; 214, 108393. 
RESUMO EXPANDIDO: Revisão Bibliográfica

TítUlo: PERFIL EPIDEMIOLÓGICO E ESTRATÉGIAS DE CONTROLE DE ARBOVIROSES (DENGUE, ZIKA E CHIKUNGUNYA) NO BRASIL - UMA REVISÃO BIBLIOGRÁFICA.

Autor/Coautor: Heloisa de Barros Dantas, Artur Vinícius de Lima Montenegro Costa, Clarice Valentim de Melo, Kaio Henrique de Freitas e Francisca Janaina Soares Rocha.

Instituição: Universidade Federal de Pernambuco (UFPE), Recife-PE.

Palavras-chave: Arboviroses, Perfil Epidemiológico, Estratégias de Controle.

\section{INTRODUÇÃO}

São arbovírus mais comuns no cenário epidemiológico brasileiro os dos vírus da Dengue (DENV), Chikungunya (CHIKV) e Zika (ZIKV) (DONALISIO MR, et al., 2017). Com isso, nos últimos anos a Saúde Pública tem se deparado com a problemática de tentar controlar o vetor Aedes aegypti que é o principal transmitente dos quatro sorotipos do vírus da dengue, além de propagar chikungunya e zika, recémemergidos no Brasil (TERRA MR, et al., 2017).

Vale ressaltar ainda que as modificações no meio ambiente por ações antrópicas, como, por exemplo, poluição das águas, solos e outras decorrentes de atividades econômicas, além de processos de globalização e as mudanças climáticas, condicionam insetos vetores a se tornarem sinantrópicos, favorecendo a transmissão de doenças ao homem (CAMARA TNL, 2016).

Portanto, sendo as arboviroses recorrentes no Brasil e visto os fatores, os quais, ajudam na propagação de hospedeiros, se torna imprescindível entender o perfil epidemiológico e as possíveis estratégias de controle que podem ser adotadas, para tentar diminuir o contágio por estas patologias.

\section{OBJETIVO}

Revisar, por intermédio de levantamento bibliográfico, estudos relacionados ao perfil epidemiológico de arboviroses (dengue, zika e chikungunya) transmitidas no Brasil, assim como, destacar estratégias de controle para diminuir a propagação destas.

\section{MÉTODO}

Para realizar esta revisão integrativa da literatura, utilizou-se como fonte as bases de dados: Google Acadêmico, SCIELO, PubMed, Lilacs e bibliotecas acadêmicas. Em relação aos critérios de seleção, foram incluídos artigos publicados no período de 2015-2020, sendo o idioma português ou inglês. As publicações selecionadas abrangem o perfil epidemiológico das arboviroses (dengue, zika e chikungunya) no Brasil e estratégias de controle. As palavras-chave empregadas foram "arboviroses", "perfil epidemiológico" e "estratégias de controle".

\section{REVISÃO BIBLIOGRÁFICA}

As arboviroses emergiram no Brasil com o decorrer do tempo e ao analisar as referências bibliográficas, se faz possível entender em qual período cada uma destas surgiu. Em 1845, no estado do Rio de Janeiro ocorreu a primeira epidemia de dengue, séculos depois apareceu a chikungunya em setembro de 2014 na cidade do Amapá e a zika em 2015 nos estados da Bahia e Rio Grande do Norte (TERRA MR, et al., 2017).

Acerca do perfil epidemiológico, a dengue apontou 11.137.664 notificações de casos prováveis no período de 2003 a maio de 2019, se destacando nas regiões Centro-Oeste e Sudeste. Além disso, a zika entre 2016 e 2019 apresentou 239,634 indivíduos possivelmente contaminados com maior prevalência no ano de 2016 nos estados de Mato Grosso, Rio de Janeiro e Bahia. Se tratando da chikungunya, 2014 e 2019, contabilizou 589,076 episódios possíveis, sendo o ano de 2016 e 2017 os de maiores coeficientes de incidência, 114,0 e 89,4 casos por 100 mil habitantes, respectivamente.Todos os dados de perfil epidemiológico das arboviroses foram obtidos através do Sistema de Informação de Agravos de Notificação (SINAN). 
A incidência no número de casos está relacionada ao desafio de se controlar o Aedes aegypti, especialmente porque o Brasil ainda é um país em desenvolvimento. Os principais aspectos relacionados a frear esta problemática são a falta de saneamento básico, de infraestrutura nas cidades, como, por exemplo, coleta de lixo feita de maneira inadequada e intervalos no abastecimento de água o que afeta diretamente nas medidas tradicionais de controle do vetor (ZARA ALSA, et al., 2016).

\section{DISCUSSÃO}

Através da análise do perfil epidemiológico das arboviroses no Brasil e com base nos dados do SINAN, é possível identificar a desuniformidade na distribuição de casos por ano ou estado, o que pode ser explicado pelas divergências nas condições socioeconômicas dos espaços. Somado a isso, o crescimento desordenado das cidades, poluição dos rios e formação de valas, fornece um local propício a sítios de oviposição artificias para a proliferação e disseminação do Aedes aegypti (TERRA MR, et al., 2017). Dessa forma, é notória a necessidade de ser adotada estratégias de controle para erradicação de vetores e consequentemente da doença com avaliação continuada, para comprovar a sua efetividade (ZARA ALSA, et al., 2016).

\section{CONSIDERAÇÕES FINAIS}

Sendo o Brasil um país em desenvolvimento econômico, se faz necessário, estratégias de implementação de políticas públicas efetivas em relação ao saneamento básico, manejo de resíduos sólidos, fornecimento de água adequado e educação em saúde, para evitar a proliferação de vetores. Além disso, é imprescindível adotar políticas públicas que tornem ainda mais efetivo o trabalho da vigilância sanitária e do SINAN, principalmente nos períodos de baixa transmissibilidade, para assim detectar de forma precoce as alterações no padrão da doença e poder intervir de forma rápida no controle dessas arboviroses.

\section{REFERÊNCIAS}

1. DONALISIO MR, et al. Arboviroses emergentes no Brasil: desafios para a clínica e implicações para a saúde pública. Rev Saude Publica. 2017; 51: 30.

2. CAMARA TNL. Emerging arboviruses and public health challenges in Brazil. Rev. Saúde Pública. 2016, v. 50 [citado 2020-07-05], 36.

3. BRASIL. Manual do Ministério da Saúde. 2020 [2019]. Disponível em: http://www.saude.gov.br/ boletinsepidemiologicos. Acessado em: 26 de junho de 2020.

4. TERRA MR, et al. Aedes aegypti E AS ARBOVIROSES EMERGENTES NO BRASIL. REVISTA UNINGÁ REVIEW, [S.I.], v. 30, n. 3, jun. 2017.

5. ZARA ALSA, et al. Estratégias de controle do Aedes aegypti: uma revisão. Epidemiol. Serv. Saúde. 2016, vol.25, n. 2, pp.391-404. 
RESUMOS EXPANDIDO: Revisão Bibliográfica

TítULO: A IMPORTÂNCIA DO ACOMPANHAMENTO FARMACÊUTICO NO USO DE PSICOFÁRMACOS EM PACIENTES COM HANSENÍASE

Autor/coautores: Maria Milânia de Amorim Francelino Silva, Marcos Antônio da Silva Araújo, Caio José Anselmo de Lima, Marconi Rego Barros Júnior, Maria Luiza Carneiro Moura Gonçalves Rego Barros.

Instituição: Centro Universitário Brasileiro (UNIBRA), Recife-PE. Universidade Federal de Pernambuco (UFPE) Recife-PE.

Palavras-chave: Acompanhamento farmacêutico, Psicofármacos, Hanseníese.

\section{INTRODUÇÃO}

A hanseníase é uma patologia milenar infectocontagiosa, provocada pelo Mycobacterium leprae com tropismo por células tegumentares e nervos periféricos. É Caracterizada por levar consigo registros de preconceito e discriminação, em consequência das deformações na pele ligadas ao paciente não tratado. Além das limitações sociais e fisiológicas. Dessa forma, a qualidade de vida desses pacientes acometidos por essa patologia é atingida diretamente, devido ao desenvolvimento de distúbios psiquiátricos como insônia, ansiedade e depressão (TORRES DC, et al., 2017).

Nesse sentido, os pacientes que possuem essa doença fazem uso de algumas classes de psicofármacos, principalmente, ansiolíticos e antidepressivos. No entanto, esses fármacos estão associados muitas vezes, a várias reações adversas, que podem ser de caráter mais leve como: boca seca, visão turva e naúseas, ou podem ter quadros mais graves como: disfunções hepáticas, parkinsonismo e Síndrome de Stevens-Johnson e até fatais (BAES CVW e JURUENA MF, 2017).

Assim, é fundamental o acompanhamento farmacoterapêutico no uso de psicofármacos em pacientes com hanseníase. Visando amenizar os problemas relacionados a medicamentos, que podem comprometer ainda mais o quadro clínico desses pacientes. Bem como, garantir o sucesso na adesão do tratamento (SERRA AJM, 2018).

\section{OBJETIVO}

Expor a importância da acompanhamento farmacêutico na utilização psicofármacos por pacientes com hanseníase, bem como, a realização de intervenções farmacêuticas para a melhora na qualidade de vida do paciente atráves da redução de reaçôes adversas.

\section{MÉTODO}

Consiste em uma revisão bibliográfica integrativa com abordagem qualitativa. Através de pesquisas realizadas nas bibliotecas eletrônicas: LILACS, Scopus, Scielo e Pubmed. Os descritores abordados foram: "hanseníase", "acompanhamento farmacêutico", "qualidade de vida", "psicofármacos". Os critérios de inclusão foram estudos clínicos, teses e artigos disponíveis por completo nas bases eletrônicas. Os critérios de exclusão foram artigos incompletos e artigos que não estivessem em português. Foram utilizados artigos científicos relacionados entre o período de 2017-2020.

\section{REVISÃO BIBLIOGRÁFICA}

A hanseníase acomete ambos os sexos independente da idade. É transmitida por meio do contato prolongado e proximo do enfermo, por pessoas que já são suscetíveis a doença, através das secreções das vias respiratórias e gotículas de saliva. A influência genética de cada indivíduo define a suscetibilidade ao Mycobacterium leprae, avalia-se que a maior parte das pessoas possuam resistência a essa bactéria (MINISTÉRIO DA SAÚDE, 2017).

Sendo a principal e mais comum característica da doença o comprometimento dos nervos periféricos provocando, em sua maioria, má-formações capazes de provocar problemas psicológicos, limitações sociais 
e incapacidade para o trabalho. O período de incubação pode ser maior que 20 anos devido ao padrão lento que o bacilo apresenta de multiplicação, mas normalmente se da de 2 a 5 anos até o surgimento dos primeiros sintomas, como alterações sensitivas na pele (SECRETARIA MUNICIPAL DE SAÚDE, 2019).

É importante salientar, que $23,3 \%$ dos pacientes com hanseniase possuem grau de incapacidade nível I e II. Dessa forma, quando se tem o diagnóstico, muitos já possuem sequelas incapacitantes. Assim, a qualidade de vida desse paciente tem uma diminuição direta, além de limitações na sua vida social, influênciando no desenvolvimento de distúrbios psicológicos como depressão e ansiedade, devido, principalmente, ao preconceito da sociedade por desconhecer a doença (TORRES DC, et al., 2017).

Consequentemente, sabendo que os psicofármacos são muito utilizados no controle de transtornos psicológicos e que alguns fatores podem influenciar diretamente na terapia, inclusive as reações adversas que podem implicar ainda mais com o quadro psicológico desse paciente. É necessário um acompanhamento profissional para possíveis intervenções (BAES CVW e JURUENA MF, 2017).

Tabela 1- Principais Reações Adversas dos psicofármacos de acordo com a classe farmacológica.

\begin{tabular}{ll} 
Classe farmacológica & Reações Adversas \\
\hline Antidepressivos & $\begin{array}{l}\text { Boca seca, constipação intestinal, retenção urinária, visão turva, hipotensão } \\
\text { ortostática, sedação, ganho de peso, sudorese, distúrbios de memória, insônia, } \\
\text { tremores, ansiedade e inquietude. }\end{array}$ \\
\hline Antipsicóticos & $\begin{array}{l}\text { Acatisia, parkinsonismo, distonias, discinesias tardias, hiperprolactinemia, } \\
\text { galactorréia, amenorreia, ginecomastia e diminuição da libido. }\end{array}$ \\
\hline Ansiolíticos & $\begin{array}{l}\text { Sedação, sonolência, fadiga, perda de memória, incoordenação motora, redução da } \\
\text { atenção e concentração, piora da apneia do sono, disinibição e descontrole. }\end{array}$ \\
\hline Estabilizadores & $\begin{array}{l}\text { Ganho de peso, náusea, vômitos, diarréia, pirose, toxicidade hepática, sonolência, } \\
\text { de humor }\end{array}$
\end{tabular}

Fonte: (BAES CVW e JURUENA MF, 2017)

\section{DISCUSSÃO}

Percebe-se que os pacientes hansenícos em sua maioria apresentam algum tipo de comprometimento da sua qualidade de vida na maioria dos estudos (SANTOS RS, et al., 2020; TORRES DC, et al., 2017; SERRA AJM, 2018). Afetando principalmente o aspecto psicossocial devido às incapacidades físicas, lesões cutâneas e marginalização das pessoas acometidas pela doença (SANTOS RS, et al., 2020). No qual os psicofármacos como antidepressivo são utilizados para tratar indivíduos possuintes de depressão e ansiedade e também para reações hansênicas tipo 1 (MINISTÉRIO DA SAÚDE, 2017). Assim, o farmacêutico se torna indispensável na promoção do uso racional desses medicamentos através da atenção farmacêutica buscando orientar os pacientes sobre as possíveis reações adversas, interações medicamentosas, principalmente com os corticoides, pois são muito utilizados no tratamento, e fármaco-alimento, além de ajustar ou retirar medicações. Afim de promover um menor impacto sobre as condições fisiológicas e sociais do paciente. (SERRA AJM, 2018).

\section{CONSIDERAÇÕES FINAIS}

A maioria dos pacientes com hanseníase, apresenta redução na sua qualidade de vida e transtornos mentais. Portanto, é imprescindível a atuação do profissional farmacêutico, junto a uma equipe multidisciplinar para elaboração de estratégias farmacológicas e não farmacológicas para melhorar a qualidade de vida desses pacientes. Bem como, a prestação de acompanhamento farmacêutico, para avaliar se o tratamento interfere no seu bem-estar, e se o mesmo necessita ser reduzido ou interrompido. 


\section{REFERÊNCIAS}

1. BAES CVW, JURUENA MF. Pharmacotherapy for general practitioners. Revista da Faculdade de Medicina de Ribeirão Preto e do Hospital das Clínicas da FMRP (Online), 2017; 50(Supl.1):22-36.

2. BELO HORIZONTE. Secretaria Municipal de Saúde. Guia de atuação do farmacêutico na hanseníase, 2019. Disponível em: https://prefeitura.pbh.gov.br/sites/default/files/estrutura-de-governo/saude/guiaatuacao\%20-farmaceutico-hanseniase.pdf. Acessado em: 23 de julho de 2020.

3. BRASIL. Ministério da Saúde. Secretaria de Vigilância em Saúde. Departamento de Vigilância das Doenças Transmissíveis. Guia prático sobre a hanseníase [recurso eletrônico]. Departamento de Vigilância das Doenças Transmissíveis. - Brasília: Ministério da Saúde, 2017. Disponível em: https://portalarquivos2.saude.gov.br/images/pdf/2017/novembro/22/Guia-Pratico-de-Hanseniase-

WEB.pdf. Acessado em: 23 de julho de 2020.

4. SANTOS RS, et al. Life quality, anxiety and depression evaluation of leprosy patients. Brazilian Journal of health Review, 2020; 3(2): 2932-2943.

5. SERRA AJM. A importância do seguimento farmacoterapêutico voltado ao paciente com hanseníase. 2018. 41 folhas. Trabalho de Conclusão de Curso (Graduação em Farmácia) - Faculdade Pitágoras, São Luís, 2018.

6. TORRES DC, et al. COMPARISON OF THE QUALITY OF LIFE OF INDIVIDUALS WITH AND WITHOUT LEPROSY. Revista Ceuma Perspectivas. Edição Especial, 2017; 30(2): 64-77. 
RESUMOS EXPANDIDO: Revisão Bibliográfica

Título: Os Desafios do Tratamento Da Tuberculose Em Pacientes Coinfectados

Pelo Vírus da Imunodeficiência Humana (Hiv): Uma Revisão Integrativa.

Autor/Coautores: Joricene Soares De Macedo Junior'1, Rafael Menezes Lopes ${ }^{1}$, Artur Diogenes Pinheiro Paiva², Diego Amaral De Miranda Castro1, Pablo Ramon Gualberto Cardoso'.

Instituição: Centro Universitário Maurício de Nassau (Uninassau), Recife-PE ${ }^{1}$; Universidade Federal de Roraima (UFRR), Boa Vista-RR ${ }^{2}$

Palavras-chave: Tuberculose, AIDS, Tratamento.

\section{INTRODUÇÃO}

Apesar da tuberculose (TB) ser uma doença curável, o seu tratamento em pacientes com Vírus da Imunodeficiência Humana (HIV) não possui resultados satisfatórios. É comum a ocorrência de lesão hepática advinda do uso de drogas para TB, o que intensifica a interrupção do tratamento dessa doença negligenciada (RUIZ, et al., 2018). Consequentemente, é frequente um intenso avanço do HIV nesses indivíduos (RESENDE, et al., 2019).

Cerca de um terço da população mundial que convive HIV está infectado pela bactéria Mycobacterium tuberculosis. Esses indivíduos possuem maior propensão em desenvolver TB ativa. A TB, quando associada ao HIV, pode trazer piores prognósticos ao indivíduo. Dentre as dificuldades enfrentadas para se conseguir êxito no combate à TB conjuntamente ao HIV, destaca-se o desenvolvimento de resistência farmacológica, falta de informação da sociedade, bem como a ineficaz assistência da família do paciente e recorrência de efeitos adversos à medicação atrelada à interação farmacológica (MAGNABOSCO, et al., 2019). Nesse contexto, é funcional uma abordagem multiprofissional ao paciente objetivando-se prevenir, identificar e resolver possíveis problemas de interação medicamentosa (RESENDE, et al., 2019).

\section{OBJETIVO}

Estudar a interferência da infecção do HIV no tratamento da tuberculose, compreendendo os determinantes dos prognósticos nos indivíduos acometidos, bem como as atuais dificuldades enfrentadas no complexo tratamento dessa doença negligenciada.

\section{MÉTODO}

Realizou-se um levantamento bibliográfico nas bases de dados Scielo e Pubmed, do tipo revisão integrativa em julho de 2020 utilizando os descritores Tuberculosis, Acquired Immunodeficiency Syndrome, Treatment, associados pelo operador booleano "AND". Para a realização da busca foram aplicados os seguintes critérios de inclusão: texto completo disponível, publicações entre os anos de 2017 a 2020 com os idiomas português e inglês, sendo incluídas 171 publicações. Posteriormente, foram efetuados os seguintes critérios de exclusão: artigos repetidos nas bases de dados, estudos de relato de caso, capítulos de livros, publicações sem fundamentos pertinentes ao escopo do estudo e títulos que não correspondem aos descritores selecionados. Assim, 30 publicações foram selecionadas.

\section{REVISÃO BIBLIOGRÁFICA}

A princípio, para o manejo de coinfecção TB-HIV/AIDS é recomendado que no tratamento para HIV seja utilizado TARV (Terapia antirretroviral) para evitar a multiplicação viral. Já no caso da TB, é administrado uma combinação de dois fármacos (rifampicina e isoniazida). No intuito de evitar interações medicamentosas e diminuir a toxicidade, pode-se substituir a rifampicina pela rifabutina. No entanto, essa mudança ocasiona o aumento no custo do tratamento, acarretando uma distribuição limitada à população, dificultando ainda mais o acesso e a adesão (ROSSETTO, et al., 2019).

Outrossim, notou-se que $43,33 \%$ dos artigos selecionados relataram diversas dificuldades na manutenção do tratamento, seja por ausência de assistência ou de vínculos com as unidades de saúde, bem como as 
diferentes interações medicamentosas, potencialmente desencadeadoras de toxicidade ao paciente. Verificase também que fatores como grau de escolaridade, assim como uso de drogas lícitas e ilícitas podem estar associados ao abandono ou até mesmo ao não início do tratamento. Ademais, é perceptível a relação do sexo, da situação de emprego ativo e da presença de comorbidades com os desfechos associados ao abandono (MAGNABOSCO, et al., 2019).

Além disso, evidenciou-se que $33,33 \%$ dos artigos selecionados descrevem a ocorrência de resistência à medicação tradicional, o que acaba sendo um dos fatores da interrupção do tratamento convencional e da adesão de tratamentos alternativos muitas vezes não tão eficientes. Assim, prorroga o tempo de tratamento, dificulta a manutenção do paciente na rede de cuidados necessários à cura definitiva e ocasiona, em casos extremos, o desfecho clínico de óbito no indivíduo (RUIZ, et al., 2018).

\section{DISCUSSÃO}

A coinfecção da TB com o HIV possui alta prevalência em razão da TB ser uma doença oportunista devido à imunodepressão. Assim, o seu tratamento, concomitante ao do HIV tornam-se necessários. Entretanto, as medidas terapêuticas para a TB em pacientes soropositivos ainda apresentam diversos desafios, visto que, segundo os estudos analisados, a insatisfação com os resultados para o tratamento é evidente (TANUE, et al., 2019). Isso existe devido aos critérios que dificultam a adesão, como abandono ou não início do tratamento, além do estabelecimento da resistência e interação medicamentosa (RUIZ, et al., 2018). Ademais, a desordem do sistema imunológico desencadeada pela infecção ao HIV estimula um intenso agravamento do quadro patológico de TB (RESENDE, et al., 2019). Para novas pesquisas, indica-se o aumento do período da procura, as escolhas dos artigos ocorram por meio de uma seleção aleatória e critérios mais rigorosos de inclusão e exclusão.

\section{CONSIDERAÇÕES FINAIS}

Portanto, é relevante associar os cuidados familiares às recomendações médicas para elevar a adesão e manutenção ao complexo e extenso tratamento da tuberculose em pacientes coinfectados. Nesse cenário, destaca-se a importância do Tratamento Diretamente Observado, que necessita de uma assistência e maior vínculo com a unidade de saúde frequentada pelo indivíduo. Ademais, é funcional a elaboração de políticas de saúde nas populações de baixa renda para que a tuberculose deixe o status de doença negligenciada.

\section{REFERÊNCIAS}

1. MAGNABOSCO GT, et al. Desfecho dos casos de tuberculose em pessoas com HIV: subsídios para intervenção. Acta Paulista de Enfermagem, 2019; 32(5): 554-563.

2. RESENDE NH, et al. Drug therapy problems for patients with tuberculosis and HIV/AIDS at a reference hospital. Instituto Israelita de Ensino e Pesquisa Albert Einstein, 2019; 17(4): eAO4696.

3. ROSSETTO M, et al. Epidemiological profile of tuberculosis cases with HIV coinfection in Porto Alegre city, Brazil. Revista Brasileira de Enfermagem, 2019; 72(5): 1211-1218.

4. RUIZ L, et al. Current characteristics of tuberculosis and human immunodeficiency virus co-infection in a cohort of hospitalized patients in Medellín, Colombia. Biomédica: revista del Instituto Nacional de Salud, 2018; 38(2): 59-67.

5. TANUE EA, et al. Tuberculosis treatment outcome and its associated factors among people living with HIV and AIDS in Fako Division of Cameroon. PloS one, 2019; 14(7): e0218800. 
RESUMO EXPANDIDO: Revisão Bibliográfica

TÍTULO: NANOSSISTEMAS NO CARREAMENTO DE FÁRMACOS PARA O TRATAMENTO TÓPICO DE LESÕES PROVOCADAS PELA LEISHMANIOSE CUTÂNEA

Autor/coautores: Vinícius da Silva Maciel, lago Dillion Lima Cavalcanti, Mariane Cajubá de Britto Lira Nogueira.

Instituição: Universidade Federal de Pernambuco (UFPE), Recife-PE.

Palavras-chave: Nanotecnologia Farmacêutica, Leishmaniose Cutânea, Tratamento Tópico.

\section{INTRODUÇÃO}

Inseridas no grupo de doenças negligenciadas, a leishmaniose é uma doença infecciosa causada por protozoários intracelulares pertencentes ao gênero leishmania. Existem três formas de leishmaniose, a visceral que atinge os órgãos internos, a mucocutânea que atinge pele e mucosas e a mais comum, a cutânea que ataca a pele. É estimado a cada ano 1,5 milhões de novos casos de leishmaniose no mundo (MORENO E, et al., 2015).

Dando ênfase na leishmaniose cutânea, foco deste estudo, ela caracteriza-se por causar lesões ulceradas na pele. O tratamento tópico consiste em injeções no local da infecção e está atrelada ao uso de fármacos de baixa tolerância e alta toxicidade. Além disso, o tratamento é oneroso e por um período longo, sendo estes os principais fatores que levam os pacientes a abandonarem o tratamento (ESFANDIARI F, et al., 2019).

A nanotecnologia farmacêutica é descrita como uma aliada ao tratamento da leishmaniose cutânea, pois a partir da utilização de nanopartículas, lipossomas e outros nanossistemas, permite-se a entrega de fármacos aos sítios-alvo, potencializando seu efeito terapêutico, bem como aumentando sua biodisponibilidade e reduzindo a toxicidade (MORENO E, et al., 2015; NAFARI K, et al., 2020).

\section{OBJETIVO}

Realizar um levantamento bibliográfico sobre o uso de nanossistemas contendo fármacos utilizados no tratamento tópico de lesões causadas pela leishmaniose cutânea. Destacam-se os benefícios da encapsulação destes fármacos na terapêutica da leishmaniose cutânea.

\section{MÉTODO}

Trata-se de uma revisão integrativa da literatura, para a qual foi realizado um levantamento bibliográfico, compreendendo o período de 1993 a 2020. Foram utilizadas as palavras-chave "Leishmaniose cutânea", "Nanotecnologia farmacêutica" e "Tratamento Tópico" também em suas versões em inglês, utilizando os bancos de dados PUBMED, Scifinder, Scielo e Sciencedirect. Os critérios de inclusão adotados foram artigos completos que abordavam sobre o uso da nanotecnologia no tratamento de lesões da pele causadas pela leishmaniose. Foram excluídos artigos incompletos que embora abordassem sobre a aplicação de nanossistemas, não estavam relacionados a lesões provocadas pela leishmaniose. Após aplicação dos critérios de inclusão, foram selecionados inicialmente 13, dos quais 5 artigos foram incluídos após leitura completa.

\section{REVISÃO BIBLIOGRÁFICA}

A Leishmaniose tegumentar pode se apresentar clinicamente sob a forma cutânea. Nela os pacientes apresentam lesões ulceradas na pele que podem curar-se espontaneamente ou evoluir para um quadro de infecção mais agravado, necessitando de tratamentos específicos e prolongados (COMANDOLLIWYREPKOWSKI CD, et al., 2020).

Dentre os tratamentos utilizados de primeira linha, são comumente empregadas injeções diárias de antimoniais pentavalentes, como o estibogluconato de sódio e o antimoniato de $\mathrm{N}$-metilglucamina. Em casos de baixa eficiência, são utilizados fármacos como miltefosina, isotionato de pentamidina e anfotericina $\mathrm{B}$. $\mathrm{O}$ 
tratamento de modo geral apresenta limitações, sendo os fármacos de primeira linha invasivos, onerosos e tendem a induzir resistência, enquanto os de segunda linha apresentam alta toxicidade, baixa biodisponibilidade e potencial teratogênico (COMANDOLLI-WYREPKOWSKI CD, et al., 2020).

Como alternativa, estudos de nanotecnologia farmacêutica buscam diminuir limitações do tratamento e proporcionar maior eficiência. MORENO e colaboradores (2015) verificaram que a $\beta$-lapachona manteve sua atividade antileishmania após a encapsulação em nanopartículas de quitosana-lecitina (Figura 1A). Além de obter um acúmulo do fármaco na derme de camundongos BALB/c, permeação através da pele, levando a não progressão da lesão. ESFANDIARI e colaboradores (2019) utilizaram nanopartículas de quitosana revestidas com manose para encapsulação da paromomicina. Os autores evidenciaram o direcionamento do fármaco aos macrófagos infectados e o combate do parasita intracelular, apresentando uma maior eficácia. KARAM e colaboradores (2020) desenvolveram nanocápsulas de quitosana contendo óleo essencial de Matricaria chamomilla L. (Figura 1C), mostrando-se um sistema promissor para o tratamento da leishmaniose cutânea. CASA e colaboradores (2018) por sua vez, utilizaram nanopartículas de albumina sérica bovina contendo anfotericina B (Figura 1B), observando uma manutenção da eficácia do fármaco com redução significativa da toxicidade nas condições estudadas.

Figura 1 - Nanopartículas de quitosana-lecitina com $\beta$-lapachona $(A)$, nanopartículas de albumina sérica bovina com anfotericina $B(B)$ e nanocápsula de quitosana de Matricaria chamomilla L. (C)
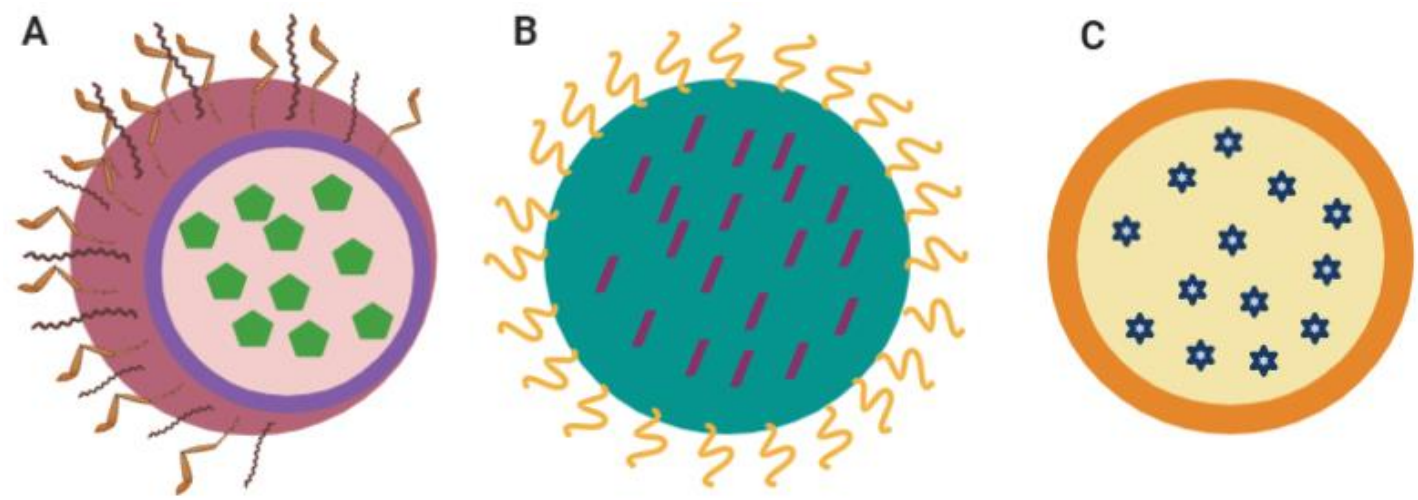

Fonte: MACIEL VS, et al., 2020.

\section{DISCUSSÃO}

Nanossistemas, como nanopartículas poliméricas e lipossomas, apresentam como vantagem a liberação dos fármacos encapsulados de maneira controlada e específica (NAFARI K, et al., 2020). A adição de ligantes nas superfícies das nanopartículas permite maior especificidade pelas células infectadas, diminuindo toxicidade e o tempo de tratamento. Um exemplo é a utilização da quitosana devido sua baixa toxicidade e biodegradabilidade. Outra vantagem é a encapsulação da $\beta$-lapachona na tentativa de atenuar suas limitações e direcionar para a sua atividade antileishmania (MORENO E, et al., 2015). A encapsulação dos fármacos permitiu superar limitações relacionadas a biodisponibilidade e redução da toxicidade nas condições estudadas.

\section{CONSIDERAÇÕES FINAIS}

A partir da revisão bibliográfica foi observado que os nanossistemas descritos nos artigos permitiram seletividade, redução da toxicidade e potencialização dos efeitos terapêuticos no tratamento de lesões de pele provocadas pela leishmaniose cutânea. Os nanossistemas permitiram a encapsulação de fármacos como a anfotericina B, $\beta$-lapachona, a paromomicina e o óleo essencial de Matricaria chamomilla L. mostrando atividade antileishmanicida. Estes estudos demonstram que a nanotecnologia pode ser uma aliada para driblar as limitações encontradas na terapia da leishmaniose cutânea. 


\section{REFERÊNCIAS}

1. CASA DM, et al. Bovine serum albumin nanoparticles containing amphotericin $B$ were effective in treating murine cutaneous leishmaniasis and reduced the drug toxicity. Experimental Parasitology, 2018; 192: 12-18.

2. COMANDOLLI-WYREPKOWSKI CD, et al. Aspectos farmacológicos da terapia medicamentosa utilizada para a leishmaniose cutânea: uma revisão de literatura. Revista Eletrônica Acervo Saúde, 2020; 12(8): e3352.

3. ESFANDIARI F, et al. Paromomycin-loaded mannosylated chitosan nanoparticles: Synthesis, characterization and targeted drug delivery against leishmaniasis. Acta Tropica, 2019; 197: 105045.

4. KARAM KT, et al. Development of chitosan nanocapsules containing essential oil of Matricaria chamomilla L. for the treatment of cutaneous leishmaniasis. International Journal of Biological Macromolecules, 2020; 162: 199-208.

5. MORENO E, et al. Assessment of $\beta$-lapachone loaded in lecithin-chitosan nanoparticles for the topical treatment of cutaneous leishmaniasis in L. major infected BALB/C mice. Nanomedicine: Nanotechnology, Biology, and Medicine, 2015; 11(8): 2003-2012.

6. NAFARI K, et al. Nanoparticles: New agents toward treatment of leishmaniasis. Parasite Epidemiology and Control, 2020; 10: e00156. 
RESUMO EXPANDIDO: Revisão Bibliográfica

TíTULO: AVALIAÇÃo dOS MÉTOdOS DE DIAGNÓSTICO PARA COVID-19

Autor/coautores: Heloísa Isabela Leão, Maria Eduarda de Oliveira Gonçalves, Louise Fernandes Caetano, Milena Ferreira de Lima, Maira Galdino da Rocha Pitta.

Instituição: Universidade Federal de Pernambuco (UFPE), Recife-PE.

Palavras-chave: COVID-19, Diagnóstico, RT-qPCR.

\section{INTRODUÇÃo}

Identificou-se o coronavírus da síndrome respiratória aguda grave 2 (SARS-CoV-2) em dezembro de 2019 após sequenciar amostras clínicas de um grupo de pacientes com pneumonia em Wuhan, China. A doença causada pelo SARS-CoV-2 é denominada doença do coronavírus - 2019 (COVID-19) (ZHU N, et al., 2020). É um tipo de coronavírus humano altamente patogênico ( $\mathrm{HCoV}$ ) que causa doenças zoonóticas e representa uma grande ameaça para saúde pública (ZHOU P, et al., 2020). A COVID-19 foi declarada uma pandemia pela Organização Mundial da Saúde (OMS) em 11 de março de 2020 e continuou a se espalhar agressivamente pelo mundo (OMS, 2020). Dentre as manifestações clínicas características de pacientes com COVID-19 estão: febre, tosse improdutiva, dispnéia, fadiga, leucopenia e evidência radiográfica de pneumonia (HUANG C, et al., 2020).

Além disto, de acordo com a OMS, o diagnóstico laboratorial considerado padrão ouro para a identificação do novo coronavírus, é a reação em cadeia da polimerase quantitativa com transcrição reversa em tempo real (RT-qPCR) (CORMAN VM, et al., 2020). Portanto, considerando a necessidade de ter dados confiáveis sobre os diferentes métodos que estão sendo utilizados para diagnosticar a COVID-19, esta revisão busca conhecer a precisão e utilidade clínica destes métodos.

\section{OBJETIVO}

Revisar e avaliar os diferentes tipos de diagnóstico para COVID-19, considerando critérios como sensibilidade e especificidade, comparando os métodos clínicos e laboratoriais, buscando assim, testes eficazes para o diagnóstico da doença em estudo.

\section{MÉTODO}

Esta revisão sistemática bibliográfica apresenta uma busca de artigos realizada nas bases de dados Pubmed, Science Direct, Scielo e Google Scholar, utilizando descritores como "COVID-19", "SARS-Cov-2", "diagnostic", "sensitivity" e "RT-qPCR". Foram considerados artigos de 2020, por ser uma doença emergente. Sendo os critérios de inclusão: estudos que correlacionam testes de diagnóstico com COVID-19 e que continham dados disponíveis para avaliar estes testes. As principais razões para a exclusão foram: estudos deficientes nos dados necessários para a análise e que não estavam dentro da área da revisão. Foram examinadas todas as listas de referência de estudos relevantes.

\section{REVISÃO BIBLIOGRÁFICA}

Testar a infecção por SARS-CoV-2 é fundamental nas medidas de saúde pública adotadas para controlar a pandemia de COVID-19 (BEN-AMI R, et al., 2020). Corman VM e colaboradores relataram que a aplicação de teste do gene RdRp do coronavírus com tecnologia bicolor pode discriminar 2019-nCOV (ambas sondas positivas) do RNA de SARS-CoV, se o último for usado como controle positivo. A preparação do vírion foi quantificada por RT-qPCR. Os ensaios foram altamente sensíveis, com melhores resultados obtidos para os do gene $\mathrm{E}$ e RdRp (5.2 e 3.8 cópias por reação, com 95\% de probabilidade de detecção, respectivamente). Contudo, em outro estudo, Hernigou J, et al. (2020) descreveram 28 pacientes com resultados iniciais negativos de RT-qPCR com o intervalo médio de tempo entre o resultado inicial negativo para o positivo de 6.2 dias, enquanto achados tomográficos confirmavam este diagnóstico. 
Li Z, et al. (2020) realizaram estudos com testes rápidos de Imunoglobulina M (IgM) e IgG combinados. Testaram-se oito hospitais e laboratórios chineses, com um total de 397 amostras de sangue de pacientes positivos e 128 de pacientes negativos. Apresentou-se uma sensibilidade de $88,66 \%$ e especificidade de $90,63 \%$. Entretanto, ainda havia falso-resultados.

A tomografia computadorizada de tórax (TC) tem significância nos estágios iniciais da infecção, (XIE X, et al., 2020), porém, sendo a RT-PCR a referência para o diagnóstico, a TC demonstrou alta sensibilidade (97\%), mas baixa especificidade (25\%) (Al T, et al., 2020).
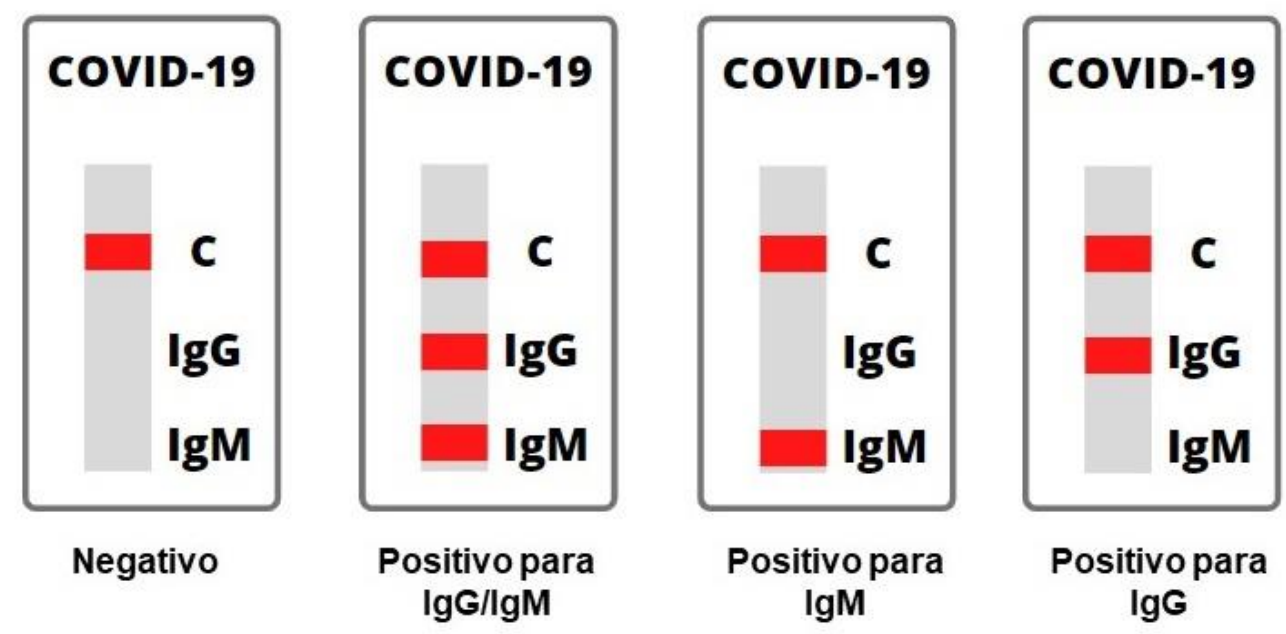

Figura 1 - Esquema de possíveis resultados para o teste rápido de SARS-Cov-2.

Fonte: LEÃO HI, et al., 2020.

\section{DISCUSSÃO}

RT-qPCR é amplamente utilizado no diagnóstico na virologia. No caso de uma emergência de saúde pública, laboratórios especializados podem obter essa tecnologia (CORMAN VM, et al., 2020). Testes baseados na amplificação de ácidos nucléicos permitem alta sensibilidade, Yip CC e colaboradores relatam ao analisar a sensibilidade de um novo ensaio de RT-qPCR, específico para genes do SARS-CoV-2. Resultados obtidos no estudo de Hernigou $\mathrm{J}$ e colaboradores sugerem baixa sensibilidade do RT-PCR no período inicial da COVID-19, entretanto, o trabalho descreve algumas limitações, como: inclusão de um pequeno número de pacientes, e que a detecção do RT-qPCR pode ser afetada por muitos fatores (reagentes de laboratório, método do teste usado e operacionalidade). Sobre testes rápidos, a Agência Nacional de Vigilância Sanitária (ANVISA) não os considera como diagnóstico para COVID-19, são utilizados para o mapeamento da população "imunizada". Estudos mostram que TC deve ser utilizada com outro diagnóstico adicional, aumentando sua especificidade.

\section{CONSIDERAÇÕES FINAIS}

Desta forma, o diagnóstico para COVID-19, uma doença emergente, ainda está em processo de validação. Apesar disto, já há estudos significativos para alguns testes, como o RT-qPCR, que é considerado, atualmente, padrão ouro de diagnóstico para COVID-19. Portanto, o conjunto de diagnósticos clínicos e laboratoriais é essencial para um bom acompanhamento do paciente, com todos estes parâmetros, podem ser correlacionados com a gravidade da doença. Entretanto, estudos adicionais precisam ser realizados.

\section{REFERÊNCIAS}

1. BEN-AMI R, et al. Large-scale implementation of pooled RNA extraction and RT-PCR for SARS-CoV-2 detection. Clinical Microbiology and Infection, 2020, 1:e6. 
2. CORMAN VM, et al. Detection of 2019 novel coronavirus (2019-nCoV) by real-time RTPCR. Eurosurveillance, 2020; 3: e2000045.

3. HERNIGOU J, et al. Thoracic computerised tomography scans in one hundred eighteen orthopaedic patients during the COVID-19 pandemic: identification of chest lesions; added values; help in managing patients; burden on the computerised tomography scan department. International Orthopaedics, 2020; 1 : e10.

4. LI Z, et al. Development and clinical application of a rapid IgM-lgG combined antibody test for SARS-CoV2 infection diagnosis. Journal of medical virology, 2020; 382: e733.

5. ZHU N, et al. A novel coronavirus from patients with pneumonia in China, 2019. New England Journal of Medicine, 2020; 372: e727. 
RESUMOS EXPANDIDO: Revisão Bibliográfica

TÍTULO: BENZNIDAZOL PARA O TRATAMENTO DA DOENÇA DE CHAGAS: EFEITOS E NOVAS ALTERNATIVAS FARMACOLÓGICAS

Autor/coautores: Karoline Mirella Soares de Souza, Ariadne Tennyle Vieira de Souza, Mateus de Melo Lima Waterloo, Raquel Pedrosa Bezerra, Ana Lúcia Figueiredo Porto.

Instituição: Universidade Federal de Pernambuco (UFPE), Recife-PE. Universidade Federal Rural de Pernambuco (UFRPE), Recife-PE.

Palavras-chave: Fármaco, Intervenção, Infecção.

\section{INTRODUÇÃO}

As doenças negligenciadas (DN) representam grande problema de saúde pública, pois os tratamentos são inconstantes e, em geral, relacionados a fatores ambientais, sociais e econômicos. Apesar do elevado número de infectados com diferentes $\mathrm{DN}$, não despertam interesse das indústrias farmacêuticas, por atingir principalmente a população de baixa renda, associado assim, ao baixo retorno financeiro (SANTOS SS, et al., 2020).

A doença de Chagas foi descrita no século XX pelo investigador Carlos Chagas, e uma das DN mais importantes, representando um desafio global. É uma doença infecciosa causada pelo protozoário Trypanosoma cruzi. Apresenta uma fase aguda que pode ser assintomática, e crônica, que se manifesta em formas indeterminadas, cardíaca e/ou digestiva (MINISTÉRIO DA SAÚDE, 2020).

Essa doença é centrada em áreas endêmicas da América latina, transmitida principalmente pelo contato com fezes / urina de triatomíneos infectados. Estima-se que 7 milhões de pessoas no mundo estejam infectadas com T. cruzi, e devido ao número de pessoas não diagnosticadas e/ou tratadas, colocam cerca de 70 milhões de pessoas em risco de infecção (WHO, 2020).

Atualmente, o tratamento está restrito a duas drogas: nifurtimox e benznidazol, descobertas e introduzidas nos anos 60-70. Demonstrando a necessidade de novos fármacos e/ou métodos de administração efetivos.

\section{OBJETIVO}

Revisar os efeitos da droga Benznidazol e atuais alternativas farmacológicas aplicadas a doença de Chagas mediante o método de administração e associação a compostos químicos em auxílio a sua eficácia

\section{REVISÃO BIBLIOGRÁFICA}

A doença de Chagas apresenta diferentes formas de contagio, comumente ocorre através das fezes contendo os protozoários $T$. cruzi quando em contato com a pele da vítima ou picada de triatomíneos infectados. Essa doença também pode ocorrer por transmissão vertical durante a gravidez, da mãe infectada para o filho, por transfusão de sangue ou pela ingestão de alimentos contaminados com vetores ou seus dejetos (MINISTÉRIO DA SAÚDE, 2020).

De acordo com a WHO, os infectados pelo T. cruzi devem ser tratados com benznidazol, devido a sua disponibilidade e efetividade comprovada, principalmente na fase aguda que é mais leve e ocorre nos primeiros meses após a infecção, causando sintomas moderados ou assintomático. Os principais sintomas são: febre prolongada (mais de 7 dias), dor de cabeça, fraqueza intensa, inchaço no rosto e pernas. Após a fase aguda, os infectados podem não apresentar sintomas por um longo periodo, geralmente a suspeita e diagnóstico é baseado nos achados clínicos e na história epidemiológica. Contudo, alguns casos são caracterizados pelo aparecimento de graves distúrbios degenerativos nos órgãos vitais ocasionando problemas digestivos como megacolon e megaesôfago, disfagia e cardiomegalia, que pode induzir diferentes problemas cardíacos, como insuficiência cardíaca (MINISTÉRIO DA SAÚDE, 2020). 
Testes recentes realizados durante o tratamento da doença de Chagas utilizando a droga benznidazol, demonstraram ser eficazes independentemente da situação clínica ou fase da doença, incluindo casos agudos e crônicos (CARDOSO CS, et al., 2018), além da prevenção da transmissão congênita. Entretanto, o tratamento por 60 dias apresenta efeitos colaterais (WHO, 2020), como distúrbios gastrointestinais, erupções cutâneas, febre e problemas neuromusculares.

\section{DISCUSSÃO}

Apesar dos efeitos colaterais, o benznidazol atua modificando covalentemente as macromoléculas, evitando a proliferação do parasita (SANTOS SS, et al., 2020), apresentando elevada qualidade. Alguns estudos realizaram a adição do benznidazol e/ou modificação dos métodos de consumo, mediante um tratamento mais eficaz e com menores efeitos colaterais. Perin et al. (2020) constataram que os efeitos colaterais do tratamento estão relacionados à dosagem e/ou duração da administração. Associaram diferentes concentrações de benznidazol e obtiveram resultados promissores utilizando ( $40 \mathrm{mg} / \mathrm{kg} / \mathrm{dia}) \mathrm{com}$ 2 semanas de tratamento no estágio agudo e crônico, sem apresentar efeitos colaterais com eficácia avaliada através da ausência do DNA do parasita no sangue. Corrêa et al. (2016) avaliaram a síntese dos complexos mistos e mononucleares de rutênio (II) no tratamento da doença de Chagas, demonstraram que complexos de Ru (II) apresentaram atividade antiparasitária contra T. cruzi, agindo de forma sinérgica com o benznidazol melhorando sua eficácia.

\section{CONSIDERAÇÕES FINAIS}

Constatou-se que apesar dos possíveis efeitos colaterais, a droga benznidazol caracteriza-se como principal e melhor agente em auxílio frente a doença de Chagas, podendo ser utilizado em ambas as fases, aguda ou crônica, potencializado seus efeitos mediante menor concentração da droga em tempo reduzido de uso, assim como associado a outro tipo de composto, neste caso complexos de Ru (II), exercendo melhor efetividade com menores e/ou sem apresentar efeitos colaterais nocivos ao organismo.

\section{REFERÊNCIAS}

1. BRASIL. Ministério da Saúde. Saúde de A a Z. Doença de Chagas: o que é, causas, sintomas, tratamento e prevenção. Disponível em: https://saude.gov.br/saude-de-a-z/doenca-de-chagas. Acessado em: 07 de julho de 2020.

2. CARDOSO CS, et al. Beneficial effects of benznidazole in Chagas disease: NIH SaMi-Trop cohort study. PLoS Neglected Tropical Diseases, 2018; 12(11): e0006814.

3. CORRÊA RS, et al. Ruthenium (II) complexes of 1, 3-thiazolidine-2-thione: Cytotoxicity against tumor cells and anti-Trypanosoma cruzi activity enhanced upon combination with benznidazole. Journal of Inorganic Biochemistry, 2016; 156: 153-163.

4. WHO. World Health Organization. Chagas disease (American trypanosomiasis). Disponível em: https://www.who.int/health-topics/chagas-disease\#tab=tab_1. Acessado em: 08 de julho de 2020.

5. PERIN L, et al. Low-dose of benznidazole promotes therapeutic cure in experimental chronic Chagas disease with absence of parasitism in blood, heart and colon. Experimental Parasitology, 2020; 210: 107834 .

6. SANTOS SS, et al. Searching for drugs for Chagas disease, leishmaniasis and schistosomiasis: a review. International Journal of Antimicrobial Agents, 2020; 55(4): 105906. 
RESUMO EXPANDIDO: Revisão Bibliográfica

TítUlo: AssistênCIA DE ENFERMAGEM NO TRATAMENTO dA TUBERCULOSE: UMA REVISÃO INTEGRATIVA DA LITERATURA

Autor/coautores: Letícia Amélia Santos de Santana1, Kylma Kettly Gomes da Silva2, Sheila Janaina da Silva Lima3, Amanda de Oliveira Bernardino4

Instituição: Centro Universitário Brasileiro (UNIBRA) ${ }^{1,2}$, Centro Universitário Tiradentes (UNIT) ${ }^{3}$, Universidade Federal de Pernambuco (UFPE). Recife-PE4 .

Palavras-chave: Tuberculose, Enfermeiro, Atenção Primária a Saúde.

\section{INTRODUÇÃO}

A tuberculose (TB) é um problema de saúde mundial e existe há milhares de anos. Foi conceituada em 1993, como uma situação de fatalidade sanitária, com 2,9 milhões de óbito, por um único agente infeccioso, transmitida pelo $M$. Tuberculosis através das vias aéreas. Levando em consideração um diagnóstico preciso e tratamento bem-feito, a prevalência de cura é grande. No Brasil, seu início pode ter sido trazido pela colonização portuguesa, jesuíta e colonos contaminados que chegava no Brasil (CANO, 2017).

Em 1839 surgiu o termo TUBERCULOSE, em 1882 o médico cientista Robert Koch descobriu e isolou o agente causador bacilo, após muitos estudos onde foi criado em um sanatório o repouso ao ar livre onde conservavam os doentes infectados em quartos ventilados e isolados longe da sociedade, assim realizando tratamento contínuo (MASSABNI AC e BONINI EH, 2019).

Atualmente a Tuberculose (TB) atinge a todos os grupos etários, com maior predomínio nos indivíduos amplamente ativos (15-54 anos) e do sexo masculino, doença infecciosa atinge principalmente pulmão e depois pode migrar para outros órgãos chamando de Tuberculose extrapulmonar, tem como sintomas febre vespertina, sudorese noturna, inapetência, emagrecimento, dores torácica, tosse persistente com presença de sangue (MASSABNI AC e BONINI EH, 2019).

\section{OBJETIVO}

Analisar através da literatura cientifica a assistência de enfermagem no tratamento da tuberculose, descrevendo o papel do enfermeiro na prevenção de complicações da tuberculose através da consulta de enfermagem e do tratamento supervisionado na atenção primária a saúde.

\section{METODOLOGIA}

Trata-se de uma revisão integrativa da literatura, para isso é necessário construí-la através de etapas: A primeira etapa consiste na formulação da questão de pesquisa que é "Qual a assistência de enfermagem no tratamento da tuberculose?". Na segunda foram definidos como descritores que poderiam surgir em estudos que responderiam à questão de pesquisa, os seguintes: "Tuberculose", "Enfermeiro", "Atenção Primária na Saúde" como operador lógico boleado "AND". Foram analisados 12 artigos.

\section{REVISÃO BIBLIOGRÁFICA}

Após a leitura dos títulos e dos resumos foram selecionados 354 artigos que consideravam o objetivo e questão de pesquisa propostas. Após leitura dos títulos, resumos e artigos na íntegra, chegou-se ao total de 12 artigos, sendo: 07 da BDENF, 03 da LILACS e 02 da MEDLINE. Os resultados apontaram os principais cuidados de enfermagem para o tratamento da tuberculose, evidenciando a importância da atenção básica e do enfermeiro para a cura e a prevenção de complicações.

Os estudos mostraram que o acolhimento ao paciente que recebeu o diagnóstico de tuberculose é uma ferramenta essencial para a formação do vínculo. Quando se tem formação de vínculo e acolhimento por parte dos profissionais os usuarios se sentem mais seguros ao longo do tratamento (TEMOTEO, 2019). 
A consulta de enfermagem deve ser específica para cada paciente de maneira holística e individual, pois cada paciente apresentará necessidades psicossociais, assim como sinais e sintomas diferentes. Uma das necessidades psicossociais comuns dos pacientes no decorrer do tratamento é querer se isolar, nesse caso é necessário que o enfermeiro explique ao paciente e seus familiares, que a tuberculose é uma doença igual a qualquer outra e que no início do tratamento com a medicação via oral, o paciente não transmite mais a doença (OLIVEIRA, 2016).

Um desafio para o tratamento da tuberculose é o preconceito e estigma que a doença tem, os pacientes entram em negação ao reconhecer os sintomas e só procuram ajuda quando estão debilitadas, por isso, a estratégia saúde da família tem o objetivo de desmitificar o preconceito e a resistência da comunidade à aderi o comprometimento com sua saúde (CECILIO, 2015).

\section{DISCUSSÃO}

Os estudos mostraram que a tuberculose por ser uma doença crônica, com um tratamento demorado, no terceiro mês de tratamento diminui consideravelmente seus sintomas e sinais, os pacientes tendem a abandonar o tratamento com a falsa sensação de melhora. É papel do enfermeiro orientar a importância de tomar todas as medicações na quantidade e horário correto e alertar as complicações caso essa medicação seja abandonada (JUNG, 2016). Um desafio a ser enfrentado no âmbito da saúde são as pessoas portadoras da tuberculose na forma assintomática, por não apresentar sintomas, se torna invisível ao tratamento precoce, trazendo complicações para o paciente. Sendo assim, o enfermeiro deve ser capaz de acolher esses pacientes para evitar complicações e orientar sobre a adoção de um estilo de vida saudável (JUNG, 2016).

\section{CONCLUSÃO}

A assistência de enfermagem no tratamento da tuberculose consiste em motivar o paciente para evitar o abandono do tratamento criando um vínculo ainda no acolhimento desse paciente, ajudar iniciar o plano terapêutico, examinar o paciente no mínimo uma vez ao mês para avaliar a evolução da doença, assim prevenindo complicações, identificar a necessidade psicossocial, sensibilizar o paciente para a importância do tratamento diretamente observado e acolher o paciente de baixa renda. É responsabilidade do enfermeiro em educar o paciente, a família e a comunidade sobre a tuberculose para desmitificar a doença e aumentar a adesão do paciente ao tratamento.

\section{REFERÊNCIAS}

1. CANO APG, et al. TUBERCULOSE EM PACIENTES PEDIÁTRICOS: COMO TEM SIDO FEITO O DIAGNÓSTICO? Rev. paul. Pediatr, 2017; 35(2): 165-170.

2. CECÍLIO HPM, et al. Opinião dos profissionais de saúde sobre os serviços de controle da tuberculose; Acta Paul Enferm, 2015; 28(11):19-25.

3. JUNG BC, et al. A invisibilidade da tuberculose na vida de pessoas: Experiências de busca por serviços de saúde. J Nurs Health, 2016;6(3):423-35

4. MASSABNI AC, BONINI EH. Tuberculose: história e evolução dos tratamentos da doença. Revista Brasileira Multidisciplinar, 2019; (22): 2.

5. OLIVEIRA DRC, et al. Avaliação da consulta de enfermagem aos pacientes com tuberculose na atenção primária à saúde. Rev. Eletr. Enf. 2016;180.

6. TEMOTEO RCA, et al. Enfermagem na adesão ao tratamento da tuberculose e tecnologias em saúde no contexto da atenção primária. Esc. Anna Nery. 2019; 23(3): e20180321. 
RESUMO EXPANDIDO: Revisão Bibliográfica

TÍTULO: IVERMECTINA: NOVOS HORIZONTES NA FARMACOTERAPIA

Autor/coautores: Lucas Oliveira da Silva ${ }^{1}$, Arthur van Lauter Albuquerque Pereira ${ }^{1}$, Suzana Gabrielly Rocha de Melo', Mônica Camelo Pessôa de Azevedo Albuquerque'1.

Instituição: Universidade Federal de Pernambuco' (UFPE), Recife-PE.

Palavras-chave: Ivermectina, Antiparasitário, COVID-19.

\section{INTRODUÇÃO}

As Doenças Negligenciadas (DNs) constituem um grupo de enfermidades que afetam países em desenvolvimento de climas tropical e subtropical, apresentando endemicidade alta, principalmente nas regiões rurais e urbanas com déficit em saneamento e higiene básica. Mais de um bilhão de indivíduos são acometidos anualmente em 149 países, sendo uma temática de interesse para a Saúde Pública, recorrendo a necessidade de aplicar ferramentas de intervenção e controle dessas doenças (WHO, 2017).

Desde o início do século XXI, poucos medicamentos foram produzidos e comercializados para combater as DNs, sendo necessária a busca de novas drogas. Dentre os fármacos utilizados para as doenças parasitárias, as quais constituem a maioria das DNs, a Ivermectina (IVM) ganha visibilidade, pois é responsável por combater diversos parasitos e vetores, além de apresentar atividade biológica in vitro sobre arbovírus (PEREZ-GARCIA LA, et al., 2020). Devido ao seu efeito endectocida, a IVM é uma droga de escolha para programas mundiais de controle de onconcercose e filariose linfática, demonstrando também atividade para outros parasitos. Recentemente, com o surgimento da COVID-19, a IVM ganhou destaque por apresentar eficácia in vitro sobre o SARS-CoV-2, sendo cotada como uma possível alternativa terapêutica (JEAN SS e HSUEH PR, 2020).

\section{OBJETIVO}

Revisar o potencial terapêutico da Ivermectina como medicamento antiparasitário e antiviral, abordando seu histórico e mecanismo de ação frente a vetores, vírus e parasitos; além da sua atividade in vitro para a doença emergente causada pelo SARS-CoV-2.

\section{REVISÃO BIBLIOGRÁFICA}

A Ivermectina, pertencente à classe das avermectinas, foi sintetizada por William Campbell através do processo de fermentação da Streptomyces avermitilis, sendo comercializada para uso veterinário em 1981, principalmente no combate à escabiose - a sarna sarcóptica, prevalente em animais domésticos. Atualmente, a IVM é um fármaco de escolha para várias doenças parasitárias, cujo mecanismo de ação eleva o influxo de cloreto nos canais glutamato-dependentes nos invertebrados, promovendo paralisia muscular e consequente morte dos parasitos. Com os avanços científicos, além das atividades anti-helmínticas e no combate dos artrópodes, a IVM demonstrou atividades antivirais (SHARUN K, et al., 2020), sendo um artifício benéfico para controle de muitas DNs.

Uma de suas relevâncias na terapêutica foi de conduzir o aumento de imunidade humana, intensificando a produção de citocinas e demonstrando resposta linfocitária positiva. Além disso, o antiparasitário mostrouse eficaz na inibição da replicação de arbovírus (dengue, zika, febre amarela, vírus da encefalite equina, vírus da influenza A) (PEREZ-GARCIA LA, et al., 2020). Devido à ação antiviral, apresentou-se como candidato para o HIV, pois foi responsável por inibir a interação da proteína integrase e o heterodímero Importina- $\alpha / \beta 1$, impedindo a replicação viral. Embora a maioria das atividades seja in vitro, há possibilidade de ser uma droga promissora para muitas enfermidades virais.

Desde o final de 2019 até os dias atuais, o mundo tem sido desafiado pelo SARS-CoV-2, um coronavírus agente etiológico da COVID-19, uma síndrome responsável por desencadear insuficiência respiratória aguda associada a sintomas como febre, perda de alguns sentidos do organismo, tosse, dispnéia e outros. Unidades 
de Terapia Intensiva (UTIs) foram ocupadas de forma brusca para tratamento dessa infecção e, infelizmente, números exorbitantes de óbitos foram surgindo. Embora ainda esteja indefinida a terapia medicamentosa efetiva contra essa doença pandêmica, a IVM demonstrou atividade in vitro sobre o vírus (JEAN SS e HSUEH PR, 2020).

Figura 1 - Estrutura molecular da Ivermectina. Mistura de homólogos B1a (5O-dimetil-22,23-di-hidroavermectina $\left.A_{1 a}\right)$ e B1b (5-O-dimetil-25-(1metilpropil)-22,23-di-hidro-25-(1-metil-etil) avermectina $\left.A_{1 a}\right)$

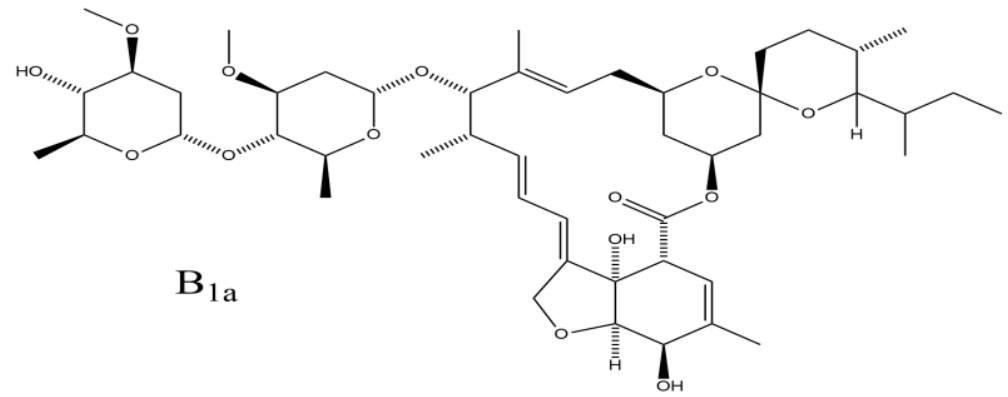

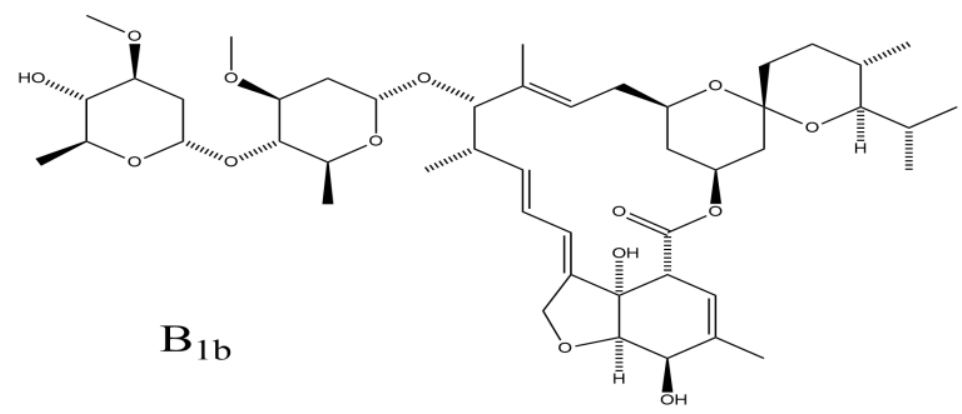

Fonte: DA SILVA LO, et al., 2020.

\section{DISCUSSÃO}

Apesar de a Ivermectina ser a droga de primeira escolha para helmintos e artrópodes, seu histórico de estudos também apresenta atividade laboratorial para Dengue, HIV e Zika. O fármaco foi candidato ao estudo in vitro para a COVID-19, dado o contexto de pandemia mundial vigente. $\mathrm{O}$ antiparasitário demonstrou atividade para o SARS-CoV-2, com a possibilidade de impedir que as proteínas virais penetrem no núcleo celular através da ligação ao heterodímero Imp $\alpha / \beta 1$ (SHARUN K, et al., 2020).

A droga reduziu $93 \%$ da replicação viral em $24 \mathrm{~h}$ e, após 2 dias, diminuiu cinco mil vezes mais, em meio de cultura celular. Mesmo se tratando de um estudo in vitro, não foi indicado toxicidade nas concentrações utilizadas. Considerando sua eficácia nos testes laboratoriais, a IVM pode ser cogitada como medicamento alternativo contra o vírus supracitado (CALY L, et al., 2020). Contudo, há necessidade de ensaios subsequentes para comprovar sua utilização no âmbito clínico-hospitalar.

\section{CONSIDERAÇÕES FINAIS}

Diante do exposto, evidencia-se a importância da Ivermectina na farmacoterapia para Doenças Negligenciadas e Emergentes. Em virtude da pandemia vigente, os estudos sobre o amplo espectro da IVM ganharam destaque e interesse no combate ao vírus da COVID-19, explorando seu potencial antiviral. Mesmo demonstrando eficácia para o coronavírus apenas em ensaios in vitro, esse medicamento possui potencial terapêutico. Vale salientar também que é necessário que, principalmente países mais afetados adotem medidas sanitárias eficazes para o combate de DNs, a fim de promover a profilaxia e educação em saúde. 


\section{REFERENCIAS}

1. CALY L, et al. The FDA-approved drug ivermectin inhibits the replication of SARS-CoV-2 in vitro. Antiviral Research. 2020.

2. JEAN SS, HSUEH PR. Old and re-purposed drugs for treatment of COVID-19. Expert Review of Antiinfective Therapy. 2020.

3. PEREZ-GARCIA LA, et al. Ivermectin: repurposing a multipurpose drug of Venezuela's humanitarian crisis. International Journal of Antimicrobial Agents. 2020.

4. SHARUN K, et al. Ivermectin, a new candidate therapeutic against SARS-CoV-2/COVID-19. Annals of Clinical Microbiology and Antimicrobials. 2020.

5. World Health Organization. Integrating neglected tropical diseases in global health and development: fourth WHO report on neglected tropical diseases, 2017. Disponível em: https://www.who.int/neglected_diseases/resources/9789241565448/en/. Acessado em: 26 de junho de 2020. 
RESUMOS EXPANDIDOS: Revisão Bibliográfica

TÍTULO: NANOSISTEMAS CONTENDO BENZNIDAZOL: UM AVANÇO TECNOLÓGICO NA TERAPÊUTICA DA DOENÇA DE CHAGAS

Autor/coautores: Samilly Gabrielly dos Santos Sales, Sandrelli Meridiana de Fátima Ramos dos Santos Medeiros, Jaqueline Siqueira Nunes, Rafaela de Siqueira Ferraz Carvalho, Mariane Cajubá de Britto Lira Nogueira.

Instituição: Laboratório de Imunopatologia Keizo Asami (LIKA), Universidade Federal de Pernambuco (UFPE), Recife - Pernambuco.

Palavras-chave: Doenças Negligenciadas, Doença de Chagas, Nanocarreadores.

\section{INTRODUÇÃO}

A Doença de Chagas (DC) é uma infecção parasitária negligenciada causada pelo protozoário Trypanosoma cruzi (T. cruzı) (QUEZADA CQ, et al., 2019). É considerada um dos grandes problemas de saúde pública na América Latina, devido aos altos níveis de morbidade e mortalidade, causando aproximadamente 12.000 mortes anualmente (ARRÚA E, et al., 2019).

Até o momento, existem apenas dois medicamentos aprovados para o tratamento da DC, sendo eles o Benznidazol (BNZ) e Nifurtimox (NFX), ambos descobertos há mais de 45 anos (ARRÚA EC, et al., 2019) o que reflete a necessidade de novas abordagens terapêuticas. Esses medicamentos apresentam baixa biodisponibilidade, elevada toxicidade, efeitos adversos graves, além de, em alguns casos, apresentarem uma resistência do T. cruzi (ARRÚA EC, et al., 2019). Neste contexto, percebe-se a urgência de alternativas sejam elas farmacológicas sejam a partir do uso de novas formas farmacêuticas, no combate a DC. É de amplo conhecimento que a utilização de sistemas de liberação controlada de fármacos permite uma otimização das propriedades físico-químicas dos fármacos encapsulados, sendo considerada como uma opção promissora para a veiculação dos fármacos utilizados no tratamento da DC (QUEZADA CQ, et al., 2019).

\section{OBJETIVO}

Realizar uma revisão da literatura a fim de examinar os avanços e a utilização de nanossistemas como plataformas promissoras na abordagem de novas terapêuticas no combate da Doença de Chagas.

\section{MÉTODO}

Trata-se de uma revisão integrativa da literatura, com o intuito de encontrar as pesquisas mais relevantes e atuais sobre as contribuições da nanotecnologia frente a Doença de Chagas.

Inicialmente, foi realizada uma busca a partir de artigos indexados nas seguintes bases de dados: Scientific Electronic Library Online (SCIELO), PubMed, ScienceDirect e Google Acadêmico, combinando os descritores "nanotecnologia", "nanocarreadores" e "doença de chagas". A partir dessa busca foram encontrados 282 resultados. Os critérios de inclusão foram estudos completos, publicados independente da língua e entre os anos de 2015 a 2020. Os critérios de exclusão, por sua vez, foram estudos repetidos, incompletos, duplicados, monografias, publicações de anais de eventos, e teses. Desta forma, resultando em 25 artigos e, dentre eles, foram selecionados 4 artigos que melhor abordaram o assunto de interesse.

\section{REVISÃO BIBLIOGRÁFICA}

As informações relevantes para o assunto discutido foram extraídas dos artigos e abordadas neste resumo.

A nanotecnologia é uma abordagem eficaz para melhorar a solubilidade aquosa e a biodisponibilidade de fármacos hidrofóbicos como o BNZ (QUEZADA CQ, et al., 2019). Neste sentido, Scalise et al. (2016) desenvolveram uma formulação de nanopartículas de benznidazol (BNZ-NPs), a fim de avaliar sua eficácia 
nas formas de tripomastigotas e na infecção intracelular em células de mamíferos e células primárias de miócitos cardíacos. A partir deste estudo, pela primeira vez foi demonstrado que as BNZ-NPs exibem um efeito notável na inibição do crescimento das amastigotas, além de aumentar a solubilidade do BNZ.

Seremeta et al. (2019), a fim de formular nanopartículas, como uma abordagem para aumentar a taxa de dissolução do BNZ, pela primeira vez demonstrou que a nanoprecipitação/liofilização são métodos eficazes para obter nanopartículas de BNZ com um alto rendimento. Nhavene et al. (2018) desenvolveram uma formulação de nanopartículas de sílica mesoporosa (MSNs) com succinato de quitosana, para atuar como âncora do BNZ, os resultados mostraram que o nanossistema proposto é uma potencial plataforma para a entrega do BNZ.

Também foi realizado um trabalho envolvendo lipossomas (LPs) por Vinuesa et al. (2017), os resultados encontrados mostraram uma toxicidade acentuada dos LPs em baixas concentrações e os valores de potencial zeta inferiores a $30 \mathrm{mV}$ indicaram que essas formulações sedimentariam com o tempo, dessa forma os LPs se mostraram inadequados para transportar e administrar BNZ; a composição dos LPs está especificada na Tabela 1. Não foi encontrado nenhum estudo recente abordando o NFX.

Tabela 1 - Estudos utilizando Nanossistemas para veiculação do Benznidazol (BNZ).

\begin{tabular}{|c|c|c|c|}
\hline Nanossistemas & Composição & Resultados & Referências \\
\hline Nanopartículas & $\begin{array}{l}\text { Etanol, água, poloxamer } \\
188 \text { como estabilizador. }\end{array}$ & $\begin{array}{l}\text { Efeito na inibição do crescimento de } T \text {. cruzi, } \\
\text { reduzindo os parasitas em } 40 \%\end{array}$ & $\begin{array}{l}\text { SCALISE ML, et } \\
\text { al., } 2016\end{array}$ \\
\hline Lipossomas & $\begin{array}{l}\text { Três diferentes misturas } \\
\text { de colesterol e } \\
\text { dipalmitoilfosfatidilcolina }\end{array}$ & $\begin{array}{l}\text { Concentrações de BNZ nos LPs }(<12 \mathrm{mM}) \\
\text { tornam o efeito antiparasitário desprezível; } \\
\text { portanto, a determinação do } \mathrm{IC}_{50} \text { não foi viável. }\end{array}$ & $\begin{array}{l}\text { VINUESA T, et } \\
\text { al., } 2017\end{array}$ \\
\hline Nanopartículas & $\begin{array}{l}\text { zSuccinato de quitosana } \\
\text { e sílica mesoporosa }\end{array}$ & $\begin{array}{l}\text { Os MSNs funcionalizados mostraram eficiência } \\
\text { no fornecimento de BZ, indicando a adequação } \\
\text { dessa amostra ao tratamento de infecções na } \\
\text { fase crônica. }\end{array}$ & $\begin{array}{l}\text { NHAVENE EP, et } \\
\text { al., } 2018\end{array}$ \\
\hline Nanopartículas & $\begin{array}{l}\text { Eudragit }^{\circledR} \text { RS PO e } \\
\text { Eudragit }^{\circledR} \text { RL PO. }\end{array}$ & $\begin{array}{l}\text { As nanopartículas obtidas tiveram rendimento } \\
\text { de } 86 \% \text { e possibilidade de flexibilidade de dose }\end{array}$ & $\begin{array}{l}\text { SEREMETA KP, } \\
\text { et al., } 2019\end{array}$ \\
\hline
\end{tabular}

\section{DISCUSSÃO}

É possível concluir que o uso da nanotecnologia é uma plataforma promissora para a DC, oferecendo terapêuticas melhoradas, bem como reduzindo as limitações biofarmacêuticas, como baixa solubilidade aquosa, limitação da permeabilidade e dos efeitos adversos dos medicamentos já aprovados e utilizados contra a DC, como o BNZ (ARRÚA EC, et al., 2019). Além disso, as propriedades particulares das nanoestruturas utilizadas permitem sua aplicação em diferentes dosagens administradas por via oral, reduzindo sua toxicidade e atendendo aos requisitos de dosagem em diferentes faixas etárias (SEREMETA KP, et al., 2019). Todavia, ainda se fazem necessários mais estudos a fim de desenvolver formulações seguras e estáveis (VINUESA T, et al., 2017)

\section{CONSIDERAÇÕES FINAIS}

De acordo com a literatura, nenhum trabalho recente foi desenvolvido abordando a nanoencapsulação do NFX. No entanto, pesquisas vêm sendo realizadas desenvolvendo novos sistemas de entrega de BNZ por meio de diferentes nanocarreadores como nanopartículas e lipossomas, por exemplo. Essas pesquisas apresentam resultados promissores indicando abordagens atraentes para melhorar as propriedades do BNZ, levando a uma potencial redução das doses e novos esquemas de tratamento para a Doença de Chagas. 


\section{REFERÊNCIAS}

1. ARRÚA EC, et al. Nanocarriers for effective delivery of benznidazole and nifurtimox in the treatment of chagas disease: A review. Acta tropica, 2019; 198(1): e105080.

2. NHAVENE EP, et al. Chitosan grafted into mesoporous silica nanoparticles as benznidazol carrier for Chagas diseases treatment. Microporous and Mesoporous Materials, 2018; 272(1): e265-275.

3. QUEZADA CQ, et al. Advances in nanocarriers as drug delivery systems in Chagas disease. International Journal of Nanomedicine, 2019; 14(1): e6407.

4. SCALISE ML, et al. Promising efficacy of benznidazole nanoparticles in acute Trypanosoma cruzi murine model: in-vitro and in-vivo studies. The American Journal of Tropical Medicine and Hygiene, 2016; 95(2); e388-393.

5. SEREMETA KP, et al. Development and characterization of benznidazole nano-and microparticles: A new tool for pediatric treatment of Chagas disease?. Colloids and Surfaces B: Biointerfaces, 2019; 177(1): e169177.

6. VINUESA T, et al. Benznidazole nanoformulates: a chance to improve therapeutics for Chagas disease. The American Journal of Tropical Medicine and Hygiene, 2017; 97(5): e1469-1476. 
RESUMO EXPANDIDO: Revisão Bibliográfica

TÍTULO:MÉTODOS DE DIAGNÓSTICO DA ESPOROTRICOSE FELINA - UMA ZOONOSE NEGLIGENCIADA

Autor/coautores: Mateus de Melo Lima Waterloo, Saulo Romero Felix Gonçalves, Ariadne Tennyle Vieira de Souza, Karoline Mirella Soares de Souza, Andrea Alice da Fonseca Oliveira.

Instituição: Universidade Federal Rural de Pernambuco (UFRPE), Recife-PE.

Palavras-chave: Gatos, Micose, Saúde Pública.

\section{INTRODUÇÃO}

A esporotricose é uma doença negligenciada com curso clínico variável de subagudo a crônico causada pelo agente etiológico Sporothrix schenckii, fungo monoespecífico e dimórfico (ALMEIDA LGF e ALMEIDA VGF, 2015). Essa micose apresenta distribuição cosmopolita e é uma zoonose que pode acometer felinos e humanos (MACÊDO-SALES PA, et al., 2018).

Os felinos domésticos desempenham participação fundamental na disseminação do agente (ALMEIDA LGF e ALMEIDA VGF, 2015). Nessa perspectiva, a esporotricose pode ser transmitida aos felinos por meio da terra e plantas que contém o fungo e consequentemente, através de arranhaduras e mordeduras,pode continuar o ciclo de transmissão, sendo esse um fator de risco para profissionais como veterinários e auxiliares (RODRIGUES AM, et al., 2016). Além disso, a ocorrência de tal doença está frequentemente relacionada a ocupação profissional, sendo mais relatada em profissionais que trabalham com a terra, por meio da implantação traumática do fungo na pele (GREMIÃO IDF, et al., 2017).

Atualmente, a esporotricose tem apresentado uma dinâmica de casos crescentes em vários estados brasileiros, denotando uma problemática de saúde pública (GREMIÃO IDF, et al., 2017). O correto diagnóstico associado a medidas de prevenção e controle com o intuito de designar o correto prognóstico e tratamento são essenciais.

\section{OBJETIVO}

Revisar os principais métodos laboratoriais para o diagnóstico de esporotricose felina utilizados na Medicina Veterinária, os quais consistem no isolamento fúngico em meio de cultura, o exame citopatológico e a Reação em Cadeia da Polimerase (PCR).

\section{REVISÃO BIBLIOGRÁFICA}

Dentre os principais métodos laboratoriais utilizados para o diagnótico de esporotricose felina destaca-se o isolamento fúngico do complexo Sporothrix schenckii em meio de cultura, considerado o golden test, sendo um dos principais o Ágar Brain Heart Infusion (BHI) suplementado com cloranfenicol, incubado a temperatura entre $25^{\circ}$ e $37^{\circ} \mathrm{C}$. Consiste na identificação macro e micromorfológica, utilizando o corante azul de metileno, com posterior realização do teste de termoconversão in vitro (BAZZI T, et al., 2016).

Tal metodologia apresenta limitações como o elevado custo, tempo maior referente a liberação do resultado, além de não poder ser processado de forma prática em ambientes ambulatoriais de clínicos médicos veterinários (MACÊDO-SALES PA, et al., 2018).

Outro método utilizado no diagnóstico da esporotricose felina consiste no exame citopatológico, de caráter presuntivo, é uma ferramenta rápida, de baixo custo e fácil execução, sendo rotineiramente empregada na rotina clínica médica veterinária (MACÊDO-SALES PA, et al., 2018).

Esse exame consiste em obter amostra por imprint ou esfoliação das lesões em gatos, utilizando lâmina de vidro e posterior de coloração por panótico rápido. Outros corantes, apesar de menos utilizados, também podem viabilizar o diagnóstico, como Giemsa, ácido periódico-Schiff (PAS) e metamina de prata de Grocott- 
Gomori (GMS). Microscopicamentemente, é possível observar estruturas leveduriformes estarinternalizadas ou não nos fagócitos (MACÊDO-SALES PA, et al., 2018).

Outro método, simples e com um elevado rendimento, sensibilidade e especificidade para o diagnóstico de esporotricose, é o diagnóstico molecular baseado na PCR, específica para espécie, permite a detectação e identificação do DNA de Sporothrix schenckii; uma vez que recorre-se a "primers" oligonucleotídeos baseados no gene quitina-sintetase 1 (CHS1) do agente. Tal metologia demonstrou a limitação de 10 a 100 fragmentos de DNA por rodada de PCR (RODRIGUES AM, et al., 2015), o que pode inviabilizar o diagnóstico do ponto de vista rápido e prático.

\section{DISCUSSÃO}

Corroborando com tais achados previamente publicados, em um estudo de casos com enfoque no uso de técnicas laboratoriais frente ao diagnóstico de esporotricose felina, utilizando amostras coletadas no estado do Rio de Janeiro, demonstrou que a sensibilidade no uso da cultura micológica foi maior do que a detectada na técnica de citopatologia por imprint (MACÊDO-SALES PA, et al., 2018). Conforme esperado, uma vez que apenas a técnica de cultura micológica permite o isolamento do agente causador da doença, sendo, assim, considerado o golden test (BAZZI T, et al., 2016).

Contudo, essa sensibilidade apresentada pela citopatologia, foi considerada uma técnica válida como recurso seguro, rápido e de baixo custo para o diagnóstico presuntivo da esporotricose em gatos domésticos, sendo a confecção da lâmina durante 0 atendimento clínico e sua análise laboratorial, fatores determinantes para o sucesso prático da técnica (MACÊDO-SALES PA, et al., 2018).

\section{CONSIDERAÇÕES FINAIS}

Nessa perspectiva, torna-se imprescindível o rápido e correto diagnóstico desses casos para que haja um prognóstico correto, evolução favorável do quadro e tratamento eficaz. Por fim, é essencial, com base no correto diagnóstico, o uso efetivo de medidas preventivas e de controle frente a esporotricose zoonótica, como limpeza e desinfecção do ambiente com água sanitária ou cloro e a limitação do acesso do animal à rua, evitando, assim, que o animal contraia a doença, evitando a transmissão entre felinos sadios e doentes e desses para seus tutores.

\section{REFERÊNCIAS}

1. ALMEIDA LGF, ALMEIDA VGF. Uma revisão interdisciplinar da esporotricose. Revista Eletrônica Estácio Saúde, 2015; 4(2): 171-179.

2. BAZZI T, et al. Características clínico-epidemiológicas, histomorfológicas e histoquímicas da esporotricose felina. Pesquisa Veterinária Brasileira, 2016; 36(4): 303-311.

3. GREMIÃO IDF, et al. Zoonotic epidemic of sporotrichosis: cat to human transmission. PLOS Pathogens, 2017;13(1):e1006077.

4. MACÊDO-SALES PA, et al. Diagnóstico laboratorial da esporotricose felina em amostras coletadas no estado do Rio de Janeiro, Brasil: limitações da citopatologia por imprint. Revista Pan-Amazônica de Saúde, 2018; 9(2):13-19.

5. RODRIGUES AM, et al. Molecular diagnosis of Pathogenic Sporothrix species. PLOS Neglected Tropical Diseases. 2015; 9(12):e0004190.

6. RODRIGUES AM, et al. Sporothrix species causing outbreaks in animals and humans driven by animalanimal transmission. PLOS Pathogens, 2016;12(7):e1005638. 


\section{RESUMO EXPANDIDO Revisão Bibliográfica}

TíTULO: DENGUE UMA DOENÇA NEGLIGENCIADA TROPICAL: PANORAMA, POPULAÇÕES AFETADAS, FATORES SOCIAIS E POLÍTICAS DE SAÚDE PÚBLICA PARA SUA PREVENÇÃO E TRATAMENTO

Autor/coautores: Ariadne Tennyle Vieira de Souza, Karoline Mirella Soares de Souza, Mateus de Melo Lima Waterloo, Ana Lúcia Figueiredo Porto, Raquel Pedrosa Bezerra.

Instituição: Universidade Federal de Pernambuco (UFPE), Recife-Pernambuco. Universidade Federal Rural de Pernambuco (UFRPE), Recife-PE.

Palavras-chave:Dengue, Determinantes sociais, Epidemiologia.

\section{INTRODUÇÃO}

Doenças tropicais negligenciadas (DTN) acometem um bilhão de pessoas mundialmente e sinalizam riscos à vida de outros milhões. Frequentemente associadas à pobreza e condições precárias de saúde como escassez de saneamento básico e água tratada, provocando prejuízos no rendimento escolar, desenvolvimento de crianças e impossibilitando adultos de suas atividades fomentando prejuízos econômicos (ALMEIDA TSO, et al, 2017).

A Organização Mundial da Saúde (OMS) aconselha cinco estratégias de saúde pública para a precaução e controle das DTN: medicação preventiva; otimizar a gestão dos casos; controlar vetores; fornecer água limpa, tratamento de esgoto e higiene; e saúde pública animal (OMS, 2018).

Dentre as DTNs tem-se a dengue, doença infecciosa emergente mais relevante do mundo. Esta arbovirose transmitida pelo Aedes aegypti possui quatro sorotipos, causando infecções assintomáticas e uma série de sintomas clínicos variando entre leves e graves (CORTES F, et al, 2018). Estima-se que haja 390 milhões de pessoas infectadas ao ano, 96 milhões de casos sintomáticos, levando a 500.000 casos graves e 12.500 mortes. O controle dessa e outras DTN somente será possível com apoio da indústria farmacêutica e ações que promovam acesso de medicamentos e subsídios de cura ou tratamento para milhões de pessoas pobres (LUNA EJA, et al, 2020).

\section{OBJETIVO}

Revisar na literatura o panorama da dengue, visualizar as populações mais atingidas, os determinantes da doença, programas de saúde pública e possíveis estratégias na prevenção e tratamento.

\section{REVISÃO BIBLIOGRÁFICA}

O Brasil notificou 1,6 milhão de casos em 2015, a maior epidemia já registrada no país, aproximadamente $12 \%$ dos casos registrados no continente americano, gerando custos que somam centenas de milhões de dólares aos cofres públicos (SOUZA MLA, et al, 2018). Alguns estudos indicam que a introdução do vírus Zika e / ou outras doenças transmitidas por vetores urbanos como o chikungunya pode distorcer a notificação da dengue. A área de prevalência da doença são as regiões tropical e subtropical, principalmente zonas urbanas e semi-urbanas, devido a presença do mosquito transmissor da doença, cobrindo uma localidade de aproximadamente 150 países. (CORTES F, et al, 2018).

A maioria das pesquisas sobre vetores concentram-se nas características biológicas do inseto, o combate ao vetor é uma das principais estratégias em saúde pública para prevenção da doença. Entretanto outros fatores devem ser levados em consideração como o sistema imunológico da população, perfil dos sorotipos circulantes, aumento na produção e utilização de descartáveis, crescimento populacional atrelado a falta de planejamento urbano, ausência de infraestruturas adequadas à saúde pública, condições e mudanças climáticas, armazenamento inadequado de água e migração (SOUZA MLA, et al, 2018). 
Não há tratamento específico para dengue, antipiréticos e analgésicos são usados para amenizar os sintomas. Anti-flamatórios não esteroidais devem ser evitados para não ocasionar sintomas mais graves da doença, nesses casos faz-se necessário atendimento médico especializado (OMS, 2018). Dentre as orientações para prevenção e controle da dengue estão diagnosticar e gerenciar os casos buscando erradicar os surtos evitando o contágio do vetor, bem como combatê-lo, capacitação dos profissionais em saúde, investimentos em pesquisas e implementação de vacinas (OMS, 2018).

\section{DISCUSSÃO}

Atualmente são necessárias novas intervenções de controle, como vacinas ou novas tecnologias de controle de vetores. Uma vacina contra a dengue foi testada e licenciada recentemente em seis países (Ásia e América Latina), mas ainda não recomendada pela OMS (CORTES F, et al, 2018). CYD-TDV é uma vacina viva tetravalente desenvolvida pela Sanofi Pasteur administrada em três doses, sua eficácia foi alta em participantes soropositivos, porém para participantes soronegativos a eficiência foi baixa havendo ainda um aumento em casos de dengue grave e hospitalizada nesses indivíduos a partir de 30 meses após a vacinação. (OMS, 2018). Sendo assim, pesquisas em vacinas contra a dengue ainda se fazem necessária.

\section{CONSIDERAÇÕES FINAIS}

Hiatos significativos sobre a epidemiologia e controle de muitas doenças negligenciadas tropicais e emergentes como a dengue existem no Brasil, as causas dessas lacunas estão associadas a eficiência de transmissão do vetor, sua alta adaptação as mudanças climáticas além das variações do vírus dificultando ainda mais o desenvolvimento de tecnologias eficazes em vacina. Investimentos e financiamentos em pesquisas e vacinas contra dengue são fundamentais para mitigar danos desssa e outras doenças negligenciadas na saúde humana.

\section{REFERÊNCIAS}

1. ALMEIDA TSO, et al. DELINEAMENTO DAS DOENÇAS TROPICAIS NEGLIGENCIADAS NO BRASIL E O SEU IMPACTO SOCIAL. Interscientia, 2017, 5(1): 69-91.

2. CORTES F, et al. Time series analysis of dengue surveillance data in two Brazilian cities. Acta Tropica, 2018, 182: 190-197.

3. LUNA EJA, et al. A cohort study to assess the incidence of dengue, Brazil, 2014-2018. Acta tropica, 2020, 204: 1-7.

4. World Health Organization. Dengue and severe dengue. Disponível em: https://www.who.int/en/newsroom/fact-sheets/detail/dengue-and-severe-dengue. Acessado em: 05 de julho de 2020. 5. SOUZA MLA, et al. Bayesian estimates for the mapping of dengue hotspots and estimation of the risk of disease epidemic in Northeast Brazil. Urban climate, 2018, 26:198-211. 


\section{RESUMOS SimpLES}

RESUMOS SIMPLES: Estudo Original

TítUlo: PERFIL EPIDEMIOLÓgICO dOS CASOS DE SíFILIS CONGÊNITA NO DISTRITO SANITÁRIO III DO RECIFE ENTRE 2015 A 2018

Autor/coautores: Maria Isabel Ferreira da Silva; Gustavo Ferreira Nascimento; Jose Anibal Matamoros; Eliane Campos Coimbra.

Instituição: Universidade de Pernambuco (UPE), Recife - Pernambuco.

Palavras-chave: Sífilis Congênita, Infecção Sexualmente Transmissível, Fator de risco.

\section{INTRODUÇÃO}

Sífilis é uma doença causada pela bactéria Treponema pallidum. As formas de transmissão mais comuns são por meio da via sexual, podendo ocasionar a sífilis adquirida, ou via transplacentária, onde o risco de taxa de transmissão pode chegar a 80\%, causando a sífilis congênita (SC) (CASANOVA AP, et al., 2016). A sífilis pode estar associada a alguns fatores que favorecem a exposição do indivíduo à doença, por isso, estudar essas associações são necessárias para criar estratégias de reorganização das ações de saúde, priorizando as características identificadas na população, promovendo a redução dos casos de transmissão vertical e adquirida (MACÊDO VC, et al., 2017).

\section{OBJETIVO}

Analisar o perfil epidemiológico dos casos de Sífilis congênita notificados no Distrito Sanitário III entre os anos de 2015 a 2018 e avaliar as características sociodemograficas e de saúde como fator de risco para aumento dos casos.

\section{MÉTODO}

Os dados foram obtidos através das fichas de Notificação/Investigação de Sífilis congênita notificados no Sistema de Informação de Agravos de Notificação (SINAN) no período de 2015 a 2018 no Distrito Sanitário III. Os mesmos foram tabulados no programa Excel e analisados estatisticamente através do programa STATA - Statistics/Data Analysis 15.0. O estudo teve aprovação do Comitê de Ética em Pesquisa (CEP) da Universidade de Pernambuco - CAAE: 06871119.0.0000.

\section{RESULTADOS}

No período avaliado foram notificados 77 casos de SC, em uma série histórica ascendente, passando de 16 para 24 casos de 2015 a 2018. A faixa etária materna mais frequente foi de 18 a 30 anos, quanto à escolaridade materna a maior parte possuía da $5^{\underline{a}}$ a $8^{\underline{a}}$ série incompleta $(35,06 \%)$ e em relação à raça/cor das mães das crianças com SC, a maioria delas se declararam como pardas $(61,04 \%)$. No que concerne ao acesso ao pré-natal, durante esse período $71,43 \%$ das mães de crianças com SC realizaram o mesmo. Em relação ao momento do diagnóstico $44,16 \%$ foram diagnosticadas durante o pré natal, assim como no momento do parto/curetagem.

\section{CONSIDERAÇÕES FINAIS}

O aumento de casos de SC aponta para a necessidade de redefinir as estratégias de promoção e prevenção da doença, fortalecendo os serviços de saúde e as políticas intersetoriais, entretanto, o aumento também pode estar relacionado à melhoria da notificação dos casos atribuída a avanços vistos no cenário brasileiro. Além disso, os achados mostram que a SC está associada a uma maior vulnerabilidade social e falhas na assistência pré-natal. 


\section{REFERÊNCIAS}

1. CASANOVA AP, et al. Vigilância epidemiológica de la sífilis en la ciudad de Valencia. Impacto y evolución del período 2003-2014. Enfermedades Infecciosas y Microbiología Clínica, 2016; 34: 3.

2. MACÊDO VC, et al. Risk factors for syphilis in women: case-control study. Revista de SaúdePública, $2017 ; 51: 78$. 
RESUMOS SIMPLES: Estudo Original

Título: Hepatites Virais em Governador Valadares, Minas Gerais: estudo DESCRITIVO

Autor/coautores: Larissa Rocha Manhães Alves; Bernardo Mendes Hott; Gislaine Cristina Moraes de Oliveira; Karen Duarte Moreira; Waneska Alexandra Alves.

Instituição: Universidade Federal de Juíz de Fora - Campus Avançado Governador Valadares (UFJF-GV), Governador Valadares - Minas Gerais.

Palavras-chave: Doenças Transmissíveis, Hepatite Viral Humana, Epidemiologia Descritiva.

\section{INTRODUÇÃO}

Hepatites virais são responsáveis por alta morbimortalidade mundial, refletindo em cerca de 1,34 milhões de óbitos e 325 milhões de infectados cronicamente com o vírus da hepatite B ou C em 2015 (LANINI, et al., 2019; OMS, 2017). No país, de 1999 a 2016, 561.058 casos confirmados foram notificados pelo Sistema de Informação de Agravos de Notificação (SINAN), sendo 37,8\% de hepatite B e 32,5\% de hepatite C. Quanto à mortalidade, de 2000 a 2015, foram registrados pelo Sistema de Informação de Mortalidade (SIM), 61.297 óbitos por hepatites A, B, C e D, sendo 97,2\% relacionados à hepatite B e C (MINISTÉRIO DA SAÚDE, 2017).

\section{OBJETIVO}

Descrever os casos notificados e confirmados de hepatites virais, considerando os tipos A, B, C, D e E, na população do município de Governador Valadares, Minas Gerais durante o período de 2008 a 2015.

\section{MÉTODO}

Foram estudados os registros de casos confirmados de hepatites virais de pessoas residentes no município de Governador Valadares (GV), Minas Gerais, no período de 2008 a 2015 notificados no SINAN. As variáveis estudadas foram datar de notificação, faixa etária, sexo, raça/cor, escolaridade, forma clínica, etiologia e fonte de infecção. Excluíram-se do estudo os casos não residentes em GV e os suspeitos, não confirmados e não notificados. Foi utilizada estatística descritiva por meio do software Epilnfo 7.1.2.

\section{RESULTADOS}

Observou-se 175 casos confirmados de Hepatites Virais, durante o período estudado. Variáveis com maior número de notificações foram: sexo masculino, raça branca, de 20-39 anos e indivíduos de $5^{\mathrm{a}}-8^{\mathrm{a}}$ série e ensino médio completo. Os casos de Hepatite B são os mais prevalentes, seguido da Hepatite $C$, e a forma crônica se sobressai à aguda, sendo as principais vias de transmissão notificadas: sexual, domiciliar e transfusional. Foram encontradas diferentes prevalências entre os dados de GV, de Minas Gerais e do Brasil, variando com fatores ambientais e socioeconômicos de cada localidade. Nas fichas de notificação, cerca de $21,1 \%$ dos casos foram ignorados/brancos. A partir de 2012, houve diminuição dos casos.

\section{CONSIDERAÇÕES FINAIS}

Por se tratar de um estudo descritivo, não é possivel determinar se o decréscimo dos casos confirmados, a partir de 2012, significa maior eficiência das medidas de controle da doença ou aumento da subnotificação. As análises realizadas permitiram maior compreensão e discussão acerca do contexto em que essas doenças estão inseridas na cidade de GV e em que as ações em saúde podem ser efetivadas.

\section{REFERÊNCIAS}

1. LANINI S, et al. Viral Hepatitis: Etiology, Epidemiology, Transmission, Diagnostics, Treatment, and Prevention. Infect Dis Clin North Am, 2019; 33(4): e1045-1062.

2. MINISTÉRIO DA SAÚDE (BR). Secretaria de Vigilância em Saúde. Boletim Epidemiológico de Hepatites Virais - 2017. Brasília: Ministério da Saúde. 2017; 48(1): e65.

3. WHO. Global Hepatitis Report, 2017. e:83. 
RESUMOS SIMPLES: Estudo Original

TítUlo: PERFIL EPIDEMIOLÓGICO, CLíNICO, LABORATORIAL E TERAPÊUTICO DE PORTADORES DE TUBERCULOSE ATENDIDOS NA REDE SUS EM PERNAMBUCO.

Autor/coautores: Kessia Kelly Batista da Silva, Haiana Charifker Schindler, Aline dos Santos Peixoto, Lilian Maria Lapa Montenegro Pimentel, Rodrigo Cezar Abreu de Aquino.

Instituição: Centro Universitário Estácio do Recife (FIR), Instituto Aggeu Magalhães (IAM), Recife Pernambuco.

Financiamento: Conselho Nacional de pesquisa (CNPq), Fundação de Amparo a Ciencia e Tecnologia do Estado de Pernambuco (FACEPE).

Palavras-chave: Tuberculose, Epidemiologia, Diagnóstico.

\section{INTRODUÇÃO}

A tuberculose (TB) é um problema de saúde mundial, trata-se da doença infecciosa com agente etiológico único mais mortal do planeta (BRASIL, 2018). No Brasil a incidência é de 35 casos/100 mil habitantes com mortalidade de 2,2 casos/100 mil habitantes. Pernambuco está entre os estados com 31-50 casos/100 mil habitantes e ocupa a segunda posição com maiores números de mortes (4 casos por 100 mil habitantes). Recife é a quinta capital com maiores índices da doença (80,6 casos por 100 mil habitantes) e a capital com maior número de óbitos (6,3 óbitos por 100 mil habitantes) (BRASIL, 2020).

\section{OBJETIVO}

Analisar o perfil epidemiológico e clínico, assim como, descrever os aspectos laboratoriais e terapêuticos de portadores de tuberculose pulmonar (TBP) e extrapulmonar (TBE) atendidos em hospitais que fazem parte da rede SUS em Pernambuco.

\section{MÉTODO}

Esse trabalho faz parte de um projeto maior submetido e aprovado pelo comitê de ética em pesquisa (CAAE: 45739715.7.0000.5190 - № do parecer: 1.489.477), com amostras de 37 portadores de tuberculose, de idades variadas, de hospitais que compõem a Rede SUS em Pernambuco, submetidos a uma entrevista estruturada com dados epidemiológicos, clínicos, laboratoriais e terapêuticos, acompanhados durante o período de 30 dias após a adesão ao tratamento para observação da melhora clínica.

\section{RESULTADOS}

Os 37 participantes são: homens (59,5\%) e mulheres (40,5\%), a maioria com $30-39$ anos (27\%), em enfermaria hospitalar $(83,8 \%)$, apresentando fatores de risco/comorbidades $(81,1 \%)$, cerca de metade dos participantes possuem cicatriz da BCG $(48,6 \%)$ e $35,1 \%$ realizaram tratamento anti-TB anteriormente. As sintomatologias mais frequentes foram febre $(89,2 \%)$, tosse $(83,8 \%)$ e perda de peso $(81,1 \%)$. Os exames mais realizados pelos diagnosticados com TBP foram: $R X(96,2 \%)$, Xpert $(80,8 \%)$ e cultura $(96,2 \%)$; e pelos com TBE foram: RX (70\%), TC (70\%), biópsia para histopatologia $(70 \%)$ e cultura $(100 \%)$. A maioria dos indivíduos teve diagnóstico pelo médico hospitalar após 1-3 meses sintomáticos $(67,6 \%)$ apresentando melhora clínica 30 dias após tratamento (2RHZE/4RH) (94,6\%).

\section{CONSIDERAÇÕES FINAIS}

Com os dados apresentados observa-se a importância da associação clínico-epidemiológica e laboratorial no diagnóstico, visto que os exames laboratoriais possuem limitações que dificultam este diagnóstico, especialmente na forma extrapulmonar da doença, logo, o aperfeiçoamento das técnicas existentes e inovação de novas técnicas pode favorecer um diagnóstico precoce auxiliando na redução da morbimortalidade da TB em Pernambuco. 


\section{REFERENCIAS}

1. BRASIL Ministério da Saúde. Secretaria de vigilância em saúde. Departamento de Vigilância das Doenças Transmissíveis. Boletim epidemiológico Especial. № especial, Brasília: Ministério da Saúde, 2020. Disponível em: http://www.saude.gov.br/images/pdf/2020/marco/24/Boletim-tuberculose-2020-marcas--1.pdf Acessado em: 5 de julho de 2020.

2. BRASIL. Ministério da Saúde. Secretaria de vigilância em saúde. Departamento de Vigilância das Doenças Transmissíveis. Boletim epidemiológico. V. 49, № 11, Brasília: Ministério da Saúde, 2018. Disponível em: https://www.saude.gov.br/images/pdf/2018/novembro/19/2018-032.pdf. Acessado em: 5 de julho de 2020. 
RESUMOS SIMPLES: Estudo Original

TÍTULO: AVALIAÇÃO DO POTENCIAL ANTIFÚNGICO DE NANOPARTÍCULAS DE QUITOSANA ASSOCIADAS À PEÇONHA DA SERPENTE CROTALUS DURISSUS CASCAVELLA

Autor/coautores: Fiamma Gláucia-Silva, Luanda Bárbara Ferreira Canário, Guilherme Maranhão Chaves, Arnóbio Antônio da Silva Júnior, Matheus de Freitas Fernandes Pedrosa.

Instituição: Universidade Ferderal do Rio Grande do Norte (UFRN), Natal - RN.

Palavras-chave: Nanobiotecnologia, Crotalus durissus cascavella, Antifúngico.

\section{INTRODUÇÃO}

O aumento considerável de casos de infecções causadas por microrganismos super-resistentes aos fármacos convencionais, levou a resistência microbiana um alarmante problema global, que evidencia a necessidade de novas alternativas terapêuticas (CAMPANINI-SALINAS, et al., 2018). Componentes com elevado potencial terapêuticos têm sido identificados nas peçonhas de serpentes, com comprovada atividade antimicrobiana. A cascavel sul-americana contém em sua peçonha várias proteínas biologicamente ativas com importante ação terapêutica, podendo ser ferramentas farmacológicas na pesquisa de novas drogas (FARIAS, et al., 2017). Nanossistemas vêm sendo investigados como sistemas de liberação para macromoléculas terapêuticas. A quitosana tem sido extensivamente investigada na formulação de nanocarreadores, particularmente de genes e proteínas (AUWAL, et al., 2017).

\section{OBJETIVO}

O objetivo desse estudo foi produzir nanopartículas de quitosana associadas à peçonha da serpente Crotalus durissus cascavella pelos métodos de adsorção e incorporação nas concentrações de 0,5 e 1,0\%, além de avaliar o potencial antifúngico pela determinação da concentração inibitória mínima.

\section{MÉTODO}

As nanopartículas de quitosana (NPQ) foram obtidas pelo método de gelificação iônica. A associação da peçonha da serpente $C$. $d$. cascavella (CDC) às nanopartículas foi realizada pelos métodos de adsorção e incorporação (NPQ-CDC-ADS e NPQ-CDC-INC) nas concentrações de 0,5 e 1,0\%. Os nanossistemas foram caracterizados físico-químicamente. O potencial antifúngico foi avaliado através método de microdiluição em caldo para determinação da concentração inibitória mínima (CIM) frente as leveduras do gênero Candida.

\section{RESULTADOS}

Os resultados demonstram que as NPQ apresentam propriedade antifúngica, exibindo CIM de $100 \%$ de $11,1,22,3,178,5$ e $178,5 \mu \mathrm{g} / \mathrm{mL}$ para $C$. tropicalis, C. parapsilosi, C. krusei e C. rugosa, respectivamente. As NPQ-CDC-ADS e NPQ-CDC-INC revelaram um maior efeito inibitório sobre estas mesmas cepas apresentando CIM entre 5,5 e 22,3 $\mu \mathrm{g} / \mathrm{mL}$, quando comparadas ao grupo NPQ. Para as cepas $C$. albicans e C. dubliniensis apenas a NPQ-CDC-ADS $1,0 \%$ apresentou atividade com CIM de $89,2 \mu \mathrm{g} / \mathrm{mL}$. E para $C$. glabrata as NPQ-CDC-ADS 0,5 e 1,0\% tiveram CIM de $178,5 \mu \mathrm{g} / \mathrm{mL}$. A peçonha bruta foi usada como controle, sendo observado a CIM maior que $178,5 \mu \mathrm{g} / \mathrm{mL}$.

\section{CONSIDERAÇÕES FINAIS}

Os dados apresentados revelaram que o uso das nanopartículas de quitosana associadas à peçonha de C. d. cascavella foi capaz de reduzir a CIM contra cepas de diferentes espécies do gênero Candida, demonstrando a importância do uso de nanopartículas como um promissor carreador de proteínas ou peptídeos de peçonhas como uma alternativa para potencializar o efeito terapêutico dessas moléculas, podendo eventualmente ser aplicada no futuro como um possível agente antifúngico. 


\section{REFERÊNCIAS}

1. AL-ASMARI AK et al. Assessment of the Antimicrobial Activity of Few Saudi Arabian Snake Venoms. The open microbiology journal, 2015; 9: e18.

2. AUWAL $S$ et al. Improved in vivo efficacy of anti-hypertensive biopeptides encapsulated in chitosan nanoparticles fabricated by ionotropic gelation on spontaneously hypertensive rats. Nanomaterials, 2017; 7: e11.

3. FARIAS LHS, et al. Crotoxin stimulates an M1 activation profile in murine macrophages during Leishmania amazonensis infection. Parasitology, 2017; 144: e1458. 
RESUMOS SIMPLES: Estudo Original

TíTULO: AVALIAÇÃO DA EXPRESSÃO DE GRUPOS DE GENES CODIFICANTES DE PROTEÍNAS PARÁLOGAS GP63 AO LONGO DO CICLO DE VIDA DE LEISHMANIA BRAZILIENSIS

Autor/coautores: Allana Kelly Oliveira Dutra1,2; Adriana Neuman Albuquerque Lins Moura de Brito1,2; Artur Leonel de Castro Neto2; Wagner José Tenório dos Santos2; Osvaldo Pompilio de Melo Neto2.

Instituição: Universidade Federal de Pernambuco (UFPE), Recife-PE'; Fundação Oswaldo Cruz- Instituto Aggeu Magalhâes (FIOCRUZ-IAM), Recife-PE².

Financiamento: Conselho Nacional de Desenvolvimento Científico e Tecnológico (CNPq).

Palavras-chave: Leishmania braziliensis, GP63, RNAseq.

\section{INTRODUÇÃO}

Protozoários do gênero Leishmania são responsáveis pelas diferentes Leishmanioses, doenças negligenciadas de importância mundial (TORRES-GUERRERO E, 2017). Dentre os fatores de virulência desses parasitas, se destaca a proteína GP63, codificada por múltiplos genes distintos (MEDINA LS, 2016). Estudos indicam que diferenças na sequência proteíca dessa proteína levam a diferenças no seu momento de expressão durante o ciclo de vida desses parasitas (NETO ALC, et al., 2019). A L. braziliensis é a espécie patogênica com o maior número de genes de GP63 e que, no entanto, codificam proteínas sem equivalentes em outras espécies. Uma análise de expressão destes genes é necessária para se entender suas funções na patogênese deste parasita.

\section{OBJETIVO}

Este estudo objetiva avaliar a expressão de grupos definidos de genes codificantes de GP63 em $L$. braziliensis e $L$. infantum ao longo de curvas de crescimento das suas formas promastigotas.

\section{MÉTODO}

Primeiramente, foram feitas análises de RNAseq de formas promastigotas em fase logarítmica e estacionária de L. braziliensis. Em seguida, para avaliar a expressão diferencial de proteínas, foram utilizados quatro soros anti-GP63 diferentes, produzidos contra peptídeos específicos de proteínas classificadas em diferentes grupos. Estes soros foram utilizados em ensaios de Western blotting com extratos celulares brutos provenientes de curvas de crescimento de L. braziliensis e $L$. infantum.

\section{RESULTADOS}

Nas análises de RNAseq, um transcrito (LbrM. 10.0590), foi identificado como o mais abundante em todas as fases de crescimento de promastigotas. Outros dois transcritos (LbrM. 10.0530 e 10.1610) também se destacaram, porém, ambos em menor quantidade. Os demais transcritos foram classificados como muito raros. Ainda com relação a estes três transcritos, todos apresentaram maior abundância na fase estácionaria de crescimento. Já no que concerne a expressão das diferentes proteínas, dois dos soros utilizados reconheceram proteínas expressas de maneira constitutiva em fase logarítimica e estácionária, embora com pesos moleculares diferentes tanto em $L$. braziliensis quando em $L$. infantum.

\section{CONSIDERAÇÕES FINAIS}

Os resultados indicam que um conjunto menor de genes GP63 pode ser expresso simultaneamente, codificando proteínas que podem ser funcionalmente distintas devido a diferenças no processamento póstraducional. Essa expressão preferencial de genes selecionados sugere que esses genes estão envolvidos em atividades no vetor invertebrado, além do hospedeiro mamífero. 


\section{REFERÊNCIAS}

1. MEDINA LS, et al. The gp63 gene cluster is highly polymorphic in natural Leishmania (Viannia) braziliensis populations, but functional sites are conserved. PLoS ONE, 2016; 11(9): 1-13.

2. NETO ALC, et al. In silico characterization of multiple genes encoding the GP63 virulence protein from Leishmania braziliensis: identification of sources of variation and putative roles in immune evasion. BMC Genomics, 2019; 20(118): 1-17.

3. TORRES-GUERRERO E, et al. Leishmaniasis: a review. F1000Research, 2017; 6:750. 
RESUMOS SIMPLES: Estudo Original

TíTULO: CENÁRIO DA TUBERCULOSE INFANTO-JUVENIL INDÍGENA: VISÃO DIAGNÓSTICA

Autor/coautores: Gisele Aparecida Soares Cunha de Souza/ Amanda Silveira Marino / Nathalia Halax Orfão.

Instituição: Fundação Universidade Federal de Rondônia (UNIR), Porto Velho-RO.

Palavras-chave: Tuberculose, Indígenas, Diagnóstico.

\section{INTRODUÇÃO}

O risco para adoecimento de tuberculose (TB) na população indígena é três vezes maior do que na população em geral. Em crianças, os sintomas são inespecíficos e podem ser confundidos com outras patologias que dificultam o diagnóstico precoce. $O$ acesso ao diagnóstico precoce da TB contribui para o manejo clínico da doença nas crianças e adolescentes e um desfecho favorável (VIANA PVS, et al., 2019). Entretanto, a literatura aponta que os indígenas, em Rondônia, tiveram dificuldade no acesso à exames diagnósticos relacionados à dimensão geográfica, problemas ecônomicos e funcionais, sendo que expressiva quantidade de pacientes conseguiu atendimento 30 dias após o início dos primeiros sintomas (MALACARNE J, et al., 2019).

\section{OBJETIVO}

Caracterizar o perfil dos exames diagnósticos dos casos de TB em crianças e adolescentes indígenas, no estado de Rondônia, no período entre 2008 a 2018.

\section{MÉTODO}

Estudo descritivo, do tipo transversal e abordagem quantitativa realizado a partir dos registros das variáveis (idade, raça/cor, sexo e exames diagnósticos) no Sistema de Informação de Agravos de Notificação (SINAN). Foram considerados como critérios de inclusão, os casos de 0 a 19 anos, residentes em Rondônia. Posteriormente, os dados foram analisados por meio de estatística descritiva, após atender os preceitos éticos, conforme parecer 3.939.122 CEP/UNIR.

\section{RESULTADOS}

Dos 7.804 casos que foram notificados em Rondônia, 322 (4,1\%) eram indígenas, destes $55(17,1 \%)$ eram crianças e 44 (13,7\%) eram adolescentes. A maioria realizou radiografia de tórax (91,9\%), destes $82,88 \%$ eram suspeitos de TB; A baciloscopia não foi realizada por (49,5\%) dos casos e apresentou-se positiva em $(22,2 \%)$; a cultura de escarro não foi realizada por $(76,8 \%)$ e apresentou-se positiva $(15,1 \%)$; a histopatologia não foi realizada por $(93,9 \%)$ e apresentou-se positiva $(4,0 \%)$; e, por fim o teste molecular rápido não foi realizado por (87\%) e detectável para a rifampicina em $(4,3 \%)$ das amostras.

\section{CONSIDERAÇÕES FINAIS}

Esses dados refletem sobre os exames diagnósticos realizados, principalmente a radiografia de tórax que possui baixo custo e facilidade de realização auxiliando na detecção de alterações características da TB infantil. Mesmo que a coleta de amostra de escarro seja difícil nessa população, a solicitação de baciloscopia e cultura é imprescindível, não eximindo a avaliação clínica e a ampliação das ações de saúde para rastreamento e detecção precoce dos casos.

\section{REFERÊNCIAS}

1. MALACARNE J, et al. Acesso aos serviços de saúde para o diagnóstico e tratamento da tuberculose entre povos indígenas do estado de Rondônia, Amazônia Brasileira, entre 2009 e 2011: um estudo transversal. Revista Eletrônica Epidemiologia e Serviços de Saúde, 2019; 28(3): e2018231.

2. VIANA PVS, et al. Tuberculose entre crianças e adolescentes indígenas no Brasil: fatores associados ao óbito e ao abandono do tratamento. Cadernos de Saúde Pública, 2019; 3: e00074218. 
RESUMOS SIMPLES: Estudo Original

Título: Leptospirose Humana em PeRnambuco: Estudo Epidemiológico dos Dados DO SINAN DE 2018 E 2019

Autor/coautores: Bruna Kristyer, Gabriella Aguiar, Carlos Mendes.

Instituição: Centro Universitário Joaquim Nabuco (UNINABUCO), Paulista-PE.

Palavras-chave: Leptospirose Humana, Pernambuco, SINAN.

\section{INTRODUÇÃO}

A leptospirose, doença provocada por bactérias do gênero Leptospira, é uma zoonose que ocorre em vários países do mundo, mediante contato com solo ou água contaminado (BARBOSA LN, et al., 2019). O clima tropical brasileiro, as condições sanitárias e a fragilidade socioeconômica do país, favorecem o surgimento de doenças como a leptospirose (QUEMEL GK, 2019). O presente estudo se trata de uma análise dos novos casos da doença em Pernambuco, através de dados disponibilizados em uma plataforma online, com o intuito de sistematizar dados e subsidiar futuras pesquisas e discussões a respeito de políticas públicas na área de saúde.

\section{OBJETIVO}

Analisar e organizar a incidência de casos de Leptospirose no estado de Pernambuco durante os anos de 2018 e 2019 observando as características que se destacam no perfil epidemiológico da doença.

\section{MÉTODO}

Realizou-se uma pesquisa na literatura recente e em bases de dados eletrônicos (Google Acadêmico e SciELO). A coleta dos dados foi realizada no Sistema de Informações de Agravos de Notificações (SINAN), do departamento de informática do SUS, utilizando os dados de infectados por leptospirose nos anos de 2018 e 2019, com as variáveis de pesquisa: Sexo, Faixa etária e Município de residência. Os dados foram então organizados e esquematizados.

\section{RESULTADOS}

Durante o período analisado, foram registrados o total de 436 casos confirmados, sendo $81,19 \%$ destes do gênero masculino e $18,81 \%$ para o feminino. A faixa etária mais acometida foi de 20 a 39 anos correspondendo a $38,30 \%$, em seguida, a de 40 a 59 anos com $28,21 \%$. Observou-se também um aumento no número de ocorrências, de 213 em 2018, para 223 em 2019. Os dados demonstraram que a maior incidência de notificações por município de residência, aconteceu na região metropolitana, que representou $82,79 \%$. Recife permaneceu em 1. lugar em ambos os anos, totalizando 198 casos. Outros municípios que também receberam destaque foram: Olinda com 43 e Jaboatão dos Guararapes com 35 casos.

\section{CONSIDERAÇÕES FINAIS}

Essa pesquisa expõe e sistematiza a incidência de novos casos de leptospirose em Pernambuco, revelando que ela continua sendo endêmica na Região Metropolitana do Recife. Assim sendo, salienta-se a relevância do estudo para subsidiar o desenvolvimento de ações e políticas públicas para promoção e prevenção de saúde além da extensão de pesquisas que possam identificar o perfil de vítimas mais acometidas e dessa maneira, futuras contaminações serem evitadas.

\section{REFERÊNCIAS}

1. BARBOSA L, et al. A Microbiologia básica de leptospira spp.: uma ferramenta para melhorar estudos sobre leptospirose. Revista de Educação Continuada em Medicina Veterinária e Zootecnia do CRMV-SP 2019; 8: e37930.

2. QUEMEL G, et al. Metodologias Ativas de Aprendizagem: construção de diagnósticos de enfermagem sobre um estudo de caso. Revista Eletrônica Acervo Saúde, 2019; 25: e826. 
RESUMO SIMPLES: Estudo Original

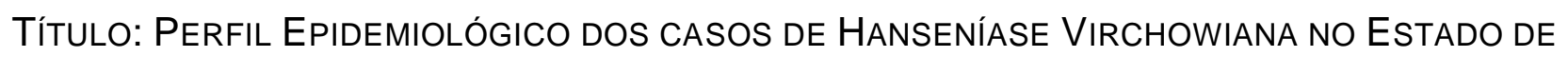
PERnAMBuco No PERÍOdO DE 2013 A 2017: UMA ABORDAGEM QUANTITATIVA

Autor/coautores: Thales Willys do Nascimento Gomes1, Valkiria Pereira da Silva1, ${ }^{2}$ Ariel do Amaral Vital, Cléber José da Silva2, Rosana Maria da Conceição Silva2.

Instituição: Centro Universitário Maurício de Nassau (Uninassau), Recife-PE¹. Universidade Federal de Pernambuco (UFPE), Recife-PE².

Palavras-chave: Hanseníase Virchowiana, Epidemiologia, Mycobacterium leprae.

\section{INTRODUÇÃO}

A hanseníase caracteriza-se como uma doença infecciosa de evolução crônica ocasionada pelo agente etiológico Mycobacterium leprae e acomete principalmente pele e nervos. O estado imunológico do paciente é o principal determinante da apresentação clínica da doença, que pode manifestar-se sob as seguintes formas: Indeterminada, Tuberculóide, Virchowiana e Dimorfa (SANTOS KCB, et al., 2019). A hanseníase Virchowiana destaca-se por apresentar características infiltrativas na pele, na mucosa das vias aéreas superiores e nos pavilhões auriculares. Convém pontuar ainda, que essa forma da doença pode evoluir para quadros mais graves, como neurite, irite, artrite e causar incapacidade física ao paciente (PINHEIRO MGC, et al., 2017).

\section{OBJETIVO}

Analisar a incidência da forma clínica da hanseníase Virchowiana no estado de Pernambuco entre os anos de 2013 e 2017 com base no Sistema de Informação de Agravos de Notificação (SINAN).

\section{MÉTODO}

Trata-se de um estudo transversal, descritivo, quantitativo com dados secundários provenientes do banco de dados do Sistema de Informação de Agravos de Notificação (SINAN) do Departamento de Informática do SUS (DATASUS). As variáveis analisadas foram: ano da notificação (2013-2017), sexo, novos casos da hanseníase Virchowiana no estado de Pernambuco. As notificações cujos dados estavam em branco ou ignorado foram descartados.

\section{RESULTADOS}

Durante o período de 2013-2017 foram notificados, no estado de Pernambuco 1.418 casos da forma Virchowiana da hanseníase, sendo: $(n=1.03272,8 \%)$ do sexo masculino e $(n=386 ; 27,2 \%)$ do sexo feminino. Foi detectado um aumento de 59,7\% dos casos notificados entre os anos de 2013 ( $n=236)$ e 2014 ( $n=377)$, que pode estar relacionado a programas de rastreio para doenças negligenciadas. Contudo, no período entre 2015 e 2016 houve uma diminuição de 32,3\%, dos casos registrados. Por fim, ao comparar o ano com maior número de casos notificados da forma Virchowiana da Hanseníase (2014), em relação ao ano de 2017 $(n=250)$, constatou-se uma diminuição de $33,7 \%$ dos casos notificados em Pernambuco.

\section{CONSIDERAÇÕES FINAIS}

Os casos notificados da forma clínica Virchowiana revela que o estado de Pernambuco ainda é uma região endêmica para a forma multibacilar da doença. A persistência de casos de hanseníase, apesar das estratégias de detecção precoce e tratamento disponibilizados na rede pública, exige a intensificação de orientações e ações de vigilância em saúde, tendo em vista a alta infectividade e o potencial incapacitante associado a essa doença. 


\section{REFERÊNCIAS}

1. PINHEIRO MGC, et al. Compreendendo a "alta em hanseníase": uma análise de conceito. Revista Gaúcha de Enfermagem, 2017; 38(4): e63290.

2. RIBEIRO MDA, et al. Estudo epidemiológico da hanseníase no Brasil: reflexão sobre as metas de eliminação. Revista panamericana de salud publica, 2018; 42: e42.

3. SANTOS KCB, et al. Estratégias de controle e vigilância de contatos de hanseníase: revisão integrativa. Saúde em Debate [online], 2019; 43, (121): 576-591. 
RESUMOS SIMPLES: Estudo Original

TíTULO: DESAFIO DO TRATAMENTO DA TUBERCULOSE NOS CASOS DE COINFECÇÃO TB/HIV EM UM MUNICÍPIO PRIORITÁRIO DA AMAZÔNIA OCIDENTAL

Autor/coautores: Amanda Silveira Mariano1, Gisele Aparecida Soares Cunha de Souza1, Lucas Macedo Martins2, Valeria Moreira da Silva1, Nathalia Halax Orfão1

Instituição: ${ }^{1}$ Fundação Universidade Federal de Rondônia (UNIR), Porto Velho, Rondônia; ${ }^{2}$ Universidade Estadual do Mato Grosso (UNEMAT), Cáceres, Mato Grosso.

Financiamento: Conselho Nacional de Desenvolvimento Científico e Tecnológico (CNPq)/ Programa Institucional de Bolsas de Iniciação Científica (PIBIC)/UNIR.

Palavras-chave: Tuberculose, HIV, Resultado do Tratamento.

\section{INTRODUÇÃO}

A Tuberculose (TB) é um desafio para a saúde pública, com elevado risco de acometimento e óbito em indivíduos infectados pelo vírus da imunodeficiência humana (HIV). O Brasil se encontra entre os países com maior incidência de TB e coinfecção TB/HIV no mundo (WHO, 2019), e a Região Norte detem 12,8\% dos casos de TB (BRASIL, 2020), evidenciando a necessidade de intervenções para prevenção e controle da doença, principalmente acerca da adesão ao tratamento em pessoas vivendo com HIV/aids (PVHA), que tem maior chance de insucesso no tratamento da TB (TOLA A, 2019). Assim, o Sistema de Informação de Agravos de Notificação (SINAN) constitui importante ferramente da vigilância.

\section{OBJETIVO}

Analisar os desfechos do tratamento da TB, de acordo com o tempo, nos casos de coinfecção TB/HIV em um município prioritário da Amazônia Ocidental, no período de 2014 a 2018.

\section{MÉTODO}

Estudo descritivo, transversal e quantitativo, a partir das variáveis tempo de tratamento e situação de encerramento dos casos coinfectados TB/HIV notificados no SINAN, entre 2014 e 2018, na Amazônia Ocidental, cuja atenção para estes casos é centralizada no Serviço de Assistência Especializada (SAE). Foram incluidos indivíduos maiores de idade, e excluidos aqueles cujas variáveis analisadas estivessem "em branco". Realizou-se análise descritiva, atendendo aos preceitos éticos conforme parecer 2.399.327 CEP/UNIR.

\section{RESULTADOS}

Dos 755 casos de coinfecção TB/HIV no estado, 279 casos residiam no referido município, sendo que um foi excluído devido à idade e dois por apresentarem a variável "situação de encerramento" em branco; totalizando 276 casos para este estudo. O tempo médio de tratamento da TB foi 147,2 dias ( $d p= \pm 88,15$ ), sendo o máximo 385 dias, onde verificou-se baixo percentual de cura $(42 \%)$ ocorrido prioritariamente acima de 180 dias (88,8\%), além de elevado percentual de abandono (34,4\%), principalmente entre 91 a 180 dias $(45,3 \%)$, quando também ocorreu outros desfechos, como o óbito por TB $(100 \%)$, óbitos por outras causas $(35,3 \%)$, mudança de diagnóstico $(66,7 \%)$, TB-DR (100\%) e falência (100\%).

\section{CONSIDERAÇÕES FINAIS}

O estudo aponta para importantes fragilidades na adesão ao tratamento e vínculo entre os usuários e serviços de saúde, constituindo grande desafio, pois contribui para o baixo percentual de cura, elevado para abandono e ocorrência de outros desfechos desfavoráveis. Destaca-se também a qualidade dos dados apresentados, evidenciando necessidade de aprimoramento das equipes de saúde quanto ao preenchimento adequado da ficha de notificação e retroalimentação dos dados no sistema. 


\section{REFERÊNCIAS}

1. BRASIL. Ministério da Saúde. Secretaria de Vigilância em Saúde. Boletim Epidemiológico. Tuberculose. Brasília: Ministério da Saúde: 2020.

2. TOLA A, et al. Treatment outcome of Tuberculosis and associated factors among TB/HIV co-infected patients at public hospitals of Harar Town, Eastern Ethiopia. A five-year retrospective study. BMC Public Health, 2019; 19: e1658

3. World Health Organization. Global Tuberculosis Report 2019. Geneva: WHO; 2019. 
RESUMOS SIMPLES: Estudo Original

TÍTULO: HIDRAZONAS DERIVADAS DO LAPACHOL COM POTENCIAL ANTILEISHMANIA: DETERMINAÇÃO IN SILICO E ANÁLISE DE ADME/T

Autor/coautores: Cristiane Costa Lima, Matheus Vieira Castro, Sidney Silva Simplício, Arlan de Assis Gonsalves, Cleônia Roberta Melo Araújo.

Instituição: Universidade Federal do Vale do São Francisco (UNIVASF), Petrolina-PE.Financiamento: Fundação de Amparo à Ciências e Tecnologia do Estado de Pernambuco (FACEPE).

Palavras-chave: Lapachol, Leishmania, ADME/T.

\section{INTRODUÇÃO}

A leishmaniose é uma parasitose causada por protozoários do gênero Leishmania, é uma doença zoonótica que tem o cão como principal reservatório. É uma enfermidade endêmica comum principalmente em países subdesenvolvidos. Até o presente momento o arsenal farmacológico disponível não é eficaz, pois promovem reações adversas consideráveis e são de alto custo (SOUZA D, et al., 2020). O lapachol apresentou atividade antileishmania, desde então seus análogos destacaram-se na busca de melhoras da atividade biológica e redução dos efeitos tóxicos (COSTA E, et al., 2017). Sendo assim, os parâmetros farmacocinéticos e toxicidade são essenciais, logo, os ensaios in silico surgem auxiliando no planejamento de compostos com propriedades e atividades desejadas.

\section{OBJETIVO}

Analisar a toxicidade e as propriedades farmacocinéticas de absorção, distribuição, metabolismo e excreção de cinco hidrazonas derivadas do lapachol (LHDZ1 a LHDZ5) com potencial antileishmania com base nos resultados dos testes in silico obtidos do programa online gratuito PreADMET.

\section{MÉTODO}

Para a coleta dos dados utilizou-se o software PreADMET. As hidrazonas foram desenhadas nos módulos de predição de ADME e de Toxicidade. Os descritores escolhidos foram: absorção em células Caco-2, absorção intestinal humana $(\mathrm{AlH})$; ligação às proteínas plasmáticas (LPP), permeabilidade na Barreira Hematoencefálica (BHE); interação com enzimas do complexo CYP; excreção renal através da permeabilidade em células MDCK; mutagenicidade; carcinogenicidade em ratos e cardiotoxicidade por inibição do gene hERG.

\section{RESULTADOS}

As hidrazonas derivadas do lapachol apresentaram baixa excreção renal, ótima $\mathrm{AlH}$, negativo para o teste de carcinogenicidade, não atuaram na CYP2D6, foram substrato para CYP3A4. Hidrazonas com grupos retiradores de elétrons (LHDZ4 e LHDZ5) apresentaram-se mutagênicos, baixa permeabilidade na BHE, não atuaram na CYP2, forte LPP e média permeabilidade em células Caco-2 para LHDZ5, baixa permeabilidade em células Caco-2 e fraca interação LPP para (LHDZ4). Hidrazonas contendo grupos doadores de elétrons (LHDZ2 e LHDZ3) e sem substituinte (LHDZ1) no anel apresentaram alta permeabilidade BHE, média absorção em células Caco-2, inibe as CYP2C, não são mutagênicos, a LHDZ3 apresentou alto risco de cardiotoxicidade e a LHDZ2 médio risco de cardiotoxicidade.

\section{CONSIDERAÇÕES FINAIS}

As hidrazonas LHDZ1 e LHDZ2 mostraram resultados satisfatórios e promissores para compostos bioativos. A LHDZ3 apresentou grande potencial de causar arritmias e outras cardiopatias devido ao alto nível de inibição do gene hERG. Os compostos LHDZ4 e LHDZ5 mostraram-se pouco promissores devido a capacidade de causar mutação celular. 


\section{REFERÊNCIAS}

1. COSTA E, et al. Antileishmanial Activity of Handroanthus serratifolius (Vahl) S. Grose (Bignoniaceae). Evidence-Based Complementary and Alternative Medicine, 2017; 2017: e6.

2. SOUZA D, et al. Síntese, atividade antileshmania e citotóxica de hidrazonas derivadas de aldeídos naturais. Quim. Nova, 2020; 43: e50-57. 
RESUMOS SIMPLES: Estudo Original

Título: Prevalência da Doença de Chagas Aguda na Região Norte do Brasil no PERÍODO DE 2015 A 2018

Autor/coautores: Salomão Mendes Amaral, Lucas Daniel Lima dos Santos, Rodrigo Arruda Valente Soares da Fonseca, Mylena Andréa Oliveira Torres.

Instituição: Centro Universitário do Maranhão (CEUMA), São Luís - Maranhão.

Palavras-chave: Doença de Chagas, Brasil, Epidemiologia.

\section{INTRODUÇÃO}

A Doença de Chagas (DC) é uma patologia de característica parasitária causada pelo Tripanosoma cruzi e tem como vetores de trasmissão os triatomíneos hematófogos. Ela pode ser transmitida de diversas formas para o ser humano, seja oral, vertical, acidental, vetorial, por transfusão sanguínea ou, até mesmo, por transplante de órgãos. Essa patologia ainda pode ser sub-dividida nas fases aguda e crônica (SILVA GC, et al., 2020). Dentre as doenças infecto-parasitárias, a DC é considerada a quarta, como grande causadora de impacto social na América Latina. $O$ tratamento dessa patologia consiste na eliminação do parasita e atenuação dos sintomas clínicos (MENDES LL, et al., 2017).

\section{OBJETIVO}

Analisar a prevalência da Doença de Chagas aguda na região Norte do Brasil no período de 2015 a 2018 , avaliando-se os meses de janeiro a dezembro do intervalo estudado para a pesquisa epidemiológica.

\section{MÉTODO}

O trabalho em questão trata-se de um estudo epidemiológico de análise retrospectiva e abordagem quantitativa. Os dados foram obtidos a partir do Sistema de Informação de Agravos de Notificação (SINAN) do Departamento de Informática do Sistema Único de Saúde (DATASUS) entre os anos de 2015 a 2018, tendo como parâmetros de análise: ano, estado, faixa etária e sexo.

\section{RESULTADOS}

Nos anos pesquisados, foram notificados 1282 casos da DC na região Norte no Brasil, sendo 20,98\% ( $n=269)$ em 2015; 27,22\% ( $n=349$ ) em 2016; 25,90\% ( $n=332)$ em 2017 e 25,90\% ( $n=332)$ em 2018. Dentre os estados com mais indivíduos acometidos pelo protozoário, observou-se Amazonas com 3,12\% ( $n=40)$, Amapá com 4,52\% ( $n=58)$ e Pará com $88,06 \%(n=1129)$. Na variável faixa etária, identificou-se que os doentes foram mais prevalentes nos intervalos de 20 a 39 anos com $34,56 \%(n=443)$ e de 40 a 59 anos com $23,40 \%$ ( $n=300)$. Em relação ao sexo, observou-se: masculino com $54,21 \%$ ( $n=695)$ e feminino com $45,78 \%$ $(\mathrm{n}=587)$.

\section{CONSIDERAÇÕES FINAIS}

Pode-se inferir que nos anos de 2017 e 2018 houve uma diminuição das pessoas acometidas pela Doença de Chagas. Além disso, essa enfermidade é mais prevalente nas faixas etárias de pessoas economicamente ativas e no sexo masculino. Cumpre observar que essa patologia se concentra majoritariamente no estado do Pará, o que o torna endêmico.

\section{REFERÊNCIAS}

1. MENDES LL, et al. Tratamento da fase crônica da Doença de Chagas: revisão sistemática. Brazilian Journal of Clinical Analyses, 2017; 49(4): e333-8.

2. SILVA GG, et al. Perfil epidemiológico da Doença de Chagas aguda no Pará entre 2010 e 2017. Pará Research Medical Journal, 2020; 4: e29. 
RESUMOS SIMPLES: Estudo Original

TíTULO: PeRFIL EPIDEMIOLÓGICO DE PACIENTES ACOMETIDOS POR TUBERCULOSE NO ESTAdO DE MAto Grosso entre 2009 E 2019

Autor/coautores: Vilian Veloso de Moura Fé, Maria Clara Martins de Araújo, Júlio César Marques de Aquino, Vitória Paglione Balestero de Lima.

Instituição: Universidade Federal de Mato Grosso (UFMT), Sinop-MT.

Palavras-chave: Tuberculose, Epidemiologia, Mato Grosso.

\section{INTRODUÇÃO}

A tuberculose é uma doença infectocontagiosa negligenciada de fácil transmissão e associada a baixos níveis socioeconômicos, sendo necessários diagnóstico e tratamento precoces para evitar rápida disseminação (OLIVA HNP, et al., 2019). Apesar da diminuição de sua prevalência nos últimos anos, articulação de estratégias para tomada de medidas de controle mais rígidas são necessárias para erradicação desta doença (DA SILVA KOG, et al., 2020). Assim, diante de elevadas taxas de abandono do tratamento (SILVA PHS, et al., 2020), este estudo regional é essencial para um entendimento completo da melhor abordagem a ser realizada com o público local.

\section{OBJETIVO}

Caracterizar o perfil epidemiológico dos portadores de tuberculose no Estado do Mato Grosso (MT) entre os anos de 2009 e 2019, a fim de fomentar aprimoramento de ações de controle dessa patologia.

\section{MÉTODO}

Estudo transversal descritivo, no qual foram coletados dados de todos os pacientes acometidos com tuberculose em Mato Grosso por meio de consulta ao Sistema de Informação de Agravos de Notificação (SINAN), abrangendo de janeiro de 2009 a dezembro de 2019. As características clínicas e epidemiológicas incluídas foram: sexo, cor, exame de imagem e laboratorial, tipo de tuberculose e prognóstico. Também foi realizado uma revisão bibliográfica do tema.

\section{RESULTADOS}

Durante o período, notificou-se 16.511 casos de tuberculose no MT. 2013 foi o ano com mais diagnósticos, 1.861 casos. $66,88 \%$ eram do sexo masculino e $53,93 \%$ ocorreram em pardos, seguidos de brancos $(22,47 \%)$. Dos 12.329 pacientes que realizaram raio-x de tórax, 11.417 (92,6\%) tiveram resultado suspeito e $723(5,8 \%)$ normais. 2.635 pacientes realizaram teste tuberculínico e $71,08 \%$ eram reativos, fracos (349) ou fortes (1542). $54(0,3 \%)$ pacientes tiverem tuberculose multirresistente. $87,35 \%$ apresentaram tuberculose do tipo pulmonar. $83,5 \%$ não realizaram a cultura de escarro e apenas 850 foram positivos. $28 \%$ dos pacientes tiveram a baciloscopia de cura comprovada. 413 (2,5\%) pacientes foram à óbito e 58,57\% tiveram alta por cura.

\section{CONSIDERAÇÕES FINAIS}

Verificou-se nesse estudo que o perfil principal de pacientes acometidos com tuberculose foi de indivíduos do sexo masculino, pardos e com o tipo pulmonar da doença. Além disso, 92\% dos exames de raio-x tiveram resultados suspeitos, demonstrando a importância desse exame. Por meio dos dados coletados, é possível especificar o público-alvo a fim de aprimorar medidas de controle.

\section{REFERÊNCIAS}

1. DA SILVA KOG, et al. Análise das metas de controle da tuberculose no Brasil: uma revisão narrativa. Revista Eletrônica Acervo Saúde, 2020; 12(5): e3063.

2. OLIVA HNP, et al. Estudo epidemiológico da tuberculose no estado de Minas Gerais. Revista Eletrônica Acervo Saúde, 2019; 18: e78.

3. SILVA PHS, et al. Aspectos sociodemográficos e clínicoepidemiológicos da tuberculose em um município do nordeste brasileiro. Revista Eletrônica Acervo Saúde, 2020; 12(5): e1916. 
RESUMOS SIMPLES: Estudo Original

TítUlo: PERFIL EPIDEMIOLÓGICO DE PACIENTES ACOMETIDOS POR LEISHMANIOSE

Tegumentar no estado de Mato Grosso entre 2009 e 2019

Autor/coautores: Maria Clara Martins de Araújo, Julio Cesar Marques de Aquino, Vilian Veloso de Moura Fé, Vitória Paglione Balestero de Lima.

Instituição: Universidade Federal de Mato Grosso (UFMT). Sinop - Mato Grosso.

Palavras-chave: Leishmaniose, Epidemiologia, Mato Grosso.

\section{INTRODUÇÃO}

A Leishmaniose tegumentar é uma doença tropical negligenciada, não contagiosa, transmitida pela picada do flebotomíneo fêmea (VASCONCELOS JR, et al., 2018). A expansão da fronteira agrícola, com início nos tempos coloniais e que acontece com maior força atualmente na Amazônia legal, potencializa a exposição ao vetor transmissor e leva ao surgimento de novos focos da doença (DE SOUSA OLIVEIRA R, et al., 2019). No Brasil, esta patologia - com potencial de causar deformidades físicas e danos psicossociais - está presente em todas as regiões (SILVA MAA, et al., 2019). Assim, são necessárias ações que levem à prevenção e ao diagnóstico precoce desta doença.

\section{OBJETIVO}

Analisar as características clínicas, epidemiológicas e demográficas dos pacientes notificados com leishmaniose tegumentar entre janeiro de 2009 e dezembro de 2019 no estado de Mato Grosso, buscando maior assertividade nas políticas públicas de combate a essa patologia.

\section{MÉTODO}

Estudo transversal descritivo, no qual foram coletados dados dos pacientes acometidos com leishmaniose em Mato Grosso por meio de consulta ao Sistema de Informação de Agravos de Notificação, de 2009 a 2019. As características clínicas e epidemiológicas incluidas foram: ano de notificação, sexo, faixa etária, cor/raça, escolaridade, presença de lesões cutâneas e/ou mucosas, exame parasitológico e desfecho. Os dados foram tabulados e foi realizada uma revisão bibliográfica sobre o tema.

\section{RESULTADOS}

Entre 2009 e 2019, foram notificados 25.899 casos de leishmaniose tegumentar no Mato Grosso. O ano com mais diagnósticos foi 2009 , com 3.660 acometidos. $79,31 \%$ dos indivíduos eram do sexo masculino. A faixa etária com maior número de casos foi entre 20 e 39 anos, representando 40,76\%. Os indivíduos de cor parda foram os mais acometidos (46,19\%). 53,41\% dos pacientes diagnosticados não cursaram o ensino médio. No tocante às características clínicas, 93,96\% dos indivíduos apresentaram lesão cutânea ao diagnóstico e 7,32\% possuíam lesão mucosa. O resultado do exame parasitológico foi positivo em $76,79 \%$ dos casos. $81,79 \%$ dos pacientes tiveram alta por cura e 16 enfermos faleceram em decorrência da doença.

\section{CONSIDERAÇÕES FINAIS}

Nesta casuística, observa-se que o perfil de pacientes se destacou pela grande presença de indivíduos do sexo masculino, entre 20 e 30 anos, de cor parda, de baixa escolaridade e com lesão cutânea ao diagnóstico. Além disso, nota-se que houve diminuição dos casos ao longo dos anos estudados. Diante desses dados, medidas de controle mais específicas podem ser tomadas por órgãos públicos.

\section{REFERÊNCIAS}

1- DE SOUSA OLIVEIRA R, et al. Ocorrência da coinfecção leishmaniose tegumentar americana/HIV no Estado do Maranhão. Revista Eletrônica Acervo Saúde, 2019; 11(11): e487. 
2- VASCONCELOS JM, et al. Leishmaniose tegumentar americana: perfil epidemiológico, diagnóstico e tratamento. RBAC, 2018; 50(3): 221-7.

3- SILVA MAA, et al. Leishmaniose Tegumentar Americana: uma análise histopatológica e molecular em lesões de dermatites no estado de Pernambuco, Brasil. RBAC, 2019; 51(4): 315-21. 
RESUMOS SIMPLES: Estudo Original

TÍTULO: ANÁLISE IN SILICO DO PERFIL FARMACOCINÉTICO DE HIDRAZONAS COM POTENCIAL LEISHMANICIDA UTILIZANDO O PREADMET

Autor/coautores: Matheus Vieira Castro/Cristiane Costa/Arlan de Assis Gonsalves e Cleônia Roberta Melo Araújo.

Instituição: Universidade Federal do Vale do São Francisco (UNIVASF), Petrolina - Pernambuco.

Financiamento: Conselho Nacional de Desenvolvimento Científico e Tecnológico (CNPq).

Palavras-chave: Leishmanicida, Hidrazona, in silico.

\section{INTRODUÇÃO}

A terapêutica atual para tratar leishmanioses limita-se a fármacos antimoniais pentavalentes, anfotericina $\mathrm{B}$ e pentamidina, estes apresentam problemas farmacocinéticos e toxicológicos que possibilitam efeitos adversos bastante danosos aos usuários. Em química medicinal, na busca por novos leishmanicidas, de melhor desempenho e menor toxicidade, os compostos da classe hidrazona demonstram destaque (SOUZA $\mathrm{DM}, 2020)$. Dentre as técnicas modernas usadas para triagem de novas moléculas, os métodos in silico apresentam-se como sendo baratos, rápidos e práticos na predição de propriedades farmacocinéticas e toxicológicas de novos compostos, sendo utilizados cada vez mais no planejamento de novos fármacos com farmacocinética melhorada e toxicidade reduzida (SANTOS RC, 2018).

\section{OBJETIVO}

Analisar in silico por meio do software PreADMET, o perfil farmacocinético de novas hidrazonas nomedas de HDZ-1 a HDZ-8, e originadas da hibridação de aldeídos com as estruturas privilegiadas: isonicotinoilhidrazona e ftalazinilhidrazona, com potencial leishmanicida e antiparasitário

\section{MÉTODO}

As hidrazonas planejadas foram analisadas utilizando software online PreADMET, disponível em http://preadmet.bmdrc.org/. As estruturas das hidrazonas (HDZ-1-HDZ-8) foram desenhadas nos módulos de predição: absorção em células Caco-2 e intestinal humana (AlH); ligação às proteínas plasmáticas (LPP); permeabilidade na barreira hematoencefálica (BHE); metabolismo e interação com enzimas do complexo CYP; excreção renal via permeabilidade em células MDCK. E toxicidade: mutagenicidade, carcinogenicidade em ratos e cardiotoxicidade por inibição do gene $h E R G$.

\section{RESULTADOS}

AlH: HDZ-1 a HDZ-8 >90\%, média 93,1\%. Caco-2: HDZ-1 a HDZ-8 4-70nm.s ${ }^{-1}$, média 23nm.s ${ }^{-1}$. LPP: HDZ- $6>90,87 \%$, todas as outras hidrazonas $<90 \%$, média $72,70 \%$, com exceção da HDZ-2 que apresentou $31.86 \%$. BHE: HDZ-6 e HDZ-8 0,25 e 0,41 respectivamente, as demais hidrazonas apresentaram média 0,05, HDZ-5 apresentou 0,02. CYP: HDZ-3 e HDZ-7 inibem CYP2C19 e CYP2C9, nenhuma hidrazona inibiu ou foi substrato para CYP2D6, as HDZ-2, HDZ-3 e HDZ-5 inibiram CYP3A4, e HDZ-1 a HDZ-8 foram substratos fracos para CYP3A4. MDCK: HDZ-1 a HDZ-8 $<25 \mathrm{~nm} . \mathrm{s}^{-1}$, com média $10.41 \mathrm{~nm} . \mathrm{s}^{-1}$, HDZ-7 apresentou 0.2nm.s 1. Toxicidade: HDZ-1 a HDZ-8 foram mutagênicos, também carcinogênicos em ratos, apresentaram médio risco de inibição do gene $h E R G$.

\section{CONSIDERAÇÕES FINAIS}

Resultados obtidos na análise in silico apontam predições das propriedades farmacocinéticas das novas hidrazonas, demonstrando valores interessantes quanto absorção, ligação a proteínas plasmáticas e metabolismo. Além de resultados moderados quanto a cardiotoxicidade. $O$ que tornam esses compostos interessantes para análise in vitro frente ao parasita leishmania, podendo ser feita análise detalhada em 
cultura de células sobre o potencial carcinogênico e seletividade dos compostos frente célula infectada com parasita.

\section{REFERÊNCIAS}

1. SANTOS RC, et al. Modificação molecular incremental: análise de parâmetros físicoquímicos, farmacocinéticos e toxicológicos in silico de fármacos inibidores seletivos da recaptação de serotonina (ISRSs). Boletim Informativo Geum, 2018; 9(2): 31-38.

2. SOUZA DM, et al. Síntese, atividade antileishmania e citotóxica de hidrazonas derivadas de aldeídos naturais. Química Nova, 2020; 43(1): 50-57. 
RESUMOS SIMPLES: Estudo Original

TÍTULO: DESAFIOS E ENFRENTAMENTOS NA DISPENSAÇÃO DE MEDICAMENTOS PARA PACIENTES PORTADORES DE TUBERCULOSE EM UMA FARMÁCIA DA FAMÍLIA, EM TEMPOS DE PANDEMIA

Autor/coautores: Mônica Maria Henrique dos Santos1, Renata Aczza Alves Cândido1, Lucas Mendes de Lima1, Maria Julha Felix Pereira1 e Igor Artur de Farias2.

Instituição: Faculdade Pernambucana de Saúde (FPS), Recife-PE'; Policlínica Salomão Kelner (PSK) Recife$\mathrm{PE}^{2}$.

Palavras-chave: Tuberculose, Covid-19, Assistência Farmacêutica.

\section{INTRODUÇÃO}

A tuberculose - TB, uma das doenças infecciosas que mais mata no mundo, ainda é considerada como uma doença negligenciada. Um estudo chinês realizado em 2020, no Hospital Shenyang Chest, com 36 participantes, sugere que a infecção latente ou ativa por tuberculose pode aumentar a suscetibilidade à coinfecção entre TB e COVID-19, a rapidez da evolução dos sintomas e a gravidade do quadro (CHEN Y, et al., 2020). O Farmacêutico, na Farmácia da Família, possui posição estratégica na prevenção e tratamento da TB, tendo na dispensação sua principal ferramenta, garantindo, ao mesmo tempo, o acesso a medicamentos e o distanciamento social a esta população (MACIEL ELN, et al., 2020).

\section{OBJETIVO}

Descrever as estratégias de enfrentamento na dispensação de medicamentos para pacientes portadores de tuberculose em tempos de pandemia, em uma Farmácia da Família na Cidade do Recife.

\section{MÉTODO}

Estudo descritivo através de um relato de experiência da gestão de uma Farmácia da Família da cidade do Recife, que a partir de reuniões de colegiados municipais, resultaram como principais estratégias para garantir o acesso de medicamentos para pacientes portadores de tuberculose, mudanças na programação de aquisição e reestruturação da dispensação de medicamentos para um período de 90 dias, garantindo, desta forma, o distanciamento social, para esses pacientes.

\section{RESULTADOS}

Mesmo diante de todos os esforços na implementação de estratégias que além de garantir o acesso de medicamentos aos pacientes portadores de tuberculose, também garantissem o distanciamento social, durante a pandemia, pudemos observar no relato do farmacêutico e nos relatórios do Sistema de Hórus, que não houve estoque suficiente dos medicamentos para efetivação deste planejamento, expondo os pacientes a terem de se dirigir às unidades de saúde, mensalmente, para recebimento de seu medicamento. Sendo assim, foi necessário um esforço da equipe de saúde nas práticas de orientação para os cuidados e prevenção da COVID-19 junto aos pacientes, conforme recomendações do Manual de Diretrizes para Diagnóstico e Tratamento da COVID-19.

\section{CONSIDERAÇÕES FINAIS}

Em tempos de pandemia, tanto o distanciamento social como o medicamento, devem ser assegurados aos pacientes portadores de TB. Medidas estas que requerem do gestor e equipe de saúde habilidades e atitudes que garantam essas atividades. Promover o distanciamento social de forma mais clara para as pessoas infectadas pelo TB, ressaltando a importância da Farmácia da Família na orientação aos pacientes durante a dispensação, contribuem com estas ações. 


\section{REFERÊNCIAS}

1. CHEN Y, et al. Active or latent tuberculosis increases susceptibility to COVID-19 and disease severity. MedrxivmedRxi. Mar. 2020

2. MACIEL ELN, et al. Tuberculose e coronavirus: o que sabemos? Epidemiologia e Serviços de Saúde, 2020; 29: e 2020128.

3. BRASIL. Manual do Ministério da Saúde. Diretrizes para o diagnóstico e tratamento da Covid-19. Brasília. 2020. Disponível em: https://sbim.org.br/images/files/notas-tecnicas/ddt-covid-19-200407.pdf. Acessado em: 02 de julho de 2020. 
RESUMOS SIMPLES: Relato de Experiência

TÍTULO: BUSCANDO ESTRATÉGIAS DE ENFRENTAMENTO DA COVID-19 POR MEIO DE EXPERIÊNCIA PREGRESSA EM SURTO DA CHIKUNGUNYA EM 2017: AÇÕES REALIZADAS EM UM MUNICÍPIO do LESTE dE MinAs GeRAIS.

Autor/coautores: Julia Fernandes Parenti de Almeida, Débora de Souza Pazini; Gislaine Cristina Moraes de Oliveira, Karen Duarte Moreira, Sílvio José Santana.

Instituição: Universidade Federal de Juiz de Fora - Campus Avançado Governador Valadares (UFJF-GV), Governador Valadares - Minas Gerais.

Palavras-chave: Controle de doenças transmissíveis, Monitoramento epidemiológico, Saúde Pública.

\section{INTRODUÇÃO}

Declarada pela Organização Mundial da Saúde (OMS) como Emergência de Saúde Pública de Interesse Internacional (PHEIC), a Corona Virus Disease 2019 (COVID-19) exige uma resposta coordenada, destacando-se, no Brasil, a articulação entre Vigilância Epidemiológica e Atenção Primária à Saúde (APS) (CRODA J, et al., 2020). Nesse sentido, capacitações e protocolos são essenciais em tais situações (WILLAN $\mathrm{J}$, et al., 2020). Historicamente, a população brasileira vivencia continuamente ciclos de epidemias de arboviroses, que apesar de suas distinções, preparam o Sistema Único de Saúde (SUS) para o enfrentamento de doenças futuras, podendo, por exemplo, orientar as medidas frente à pandemia atual (SILVA VA e RAMOS JF, 2017; CRODA J, et al., 2020).

\section{OBJETIVO}

Relatar a experiência sobre o enfrentamento do surto de Chikungunya em 2017, em um município na região Leste de Minas Gerais e, a partir das atitudes tomadas, buscar estatégias de controle da pandemia atual.

\section{RELATO DE EXPERIÊNCIA}

No período de janeiro a maio de 2017, o surto de casos suspeitos de Chikungunya deixou muitos profissionais da área da saúde com dúvidas no manejo da arbovirose em questão. Nesse contexto, foi realizada a capacitação dos médicos residentes em Medicina de Família e Comunidade por especialistas da área, tornando-os aptos para enfrentar tal doença e difundir as informações sobre o seu correto manejo para outros profissionais, resultando, assim, em benefício primordial para a população assistida.

Além das capacitações interprofissionais, foram disponibilizados documentos pela Secretaria Municipal de Saúde e criados Centros de Referência. Em paralelo, vê-se que essa última medida tem sido reaplicada na situação de pandemia atual com a criação dos Centros de Atendimento para o Enfrentamento da COVID19, no âmbito da APS.

Dessa forma, uma estrutura semelhante pode ser adotada no enfrentamento à COVID-19. Por exemplo, no caso da Chikungunya, a capacitação foi realizada inicialmente por um reumatologista. Assim, pensando na mesma estratégia, no caso da COVID-19, ela poderia ser feita pelos médicos infectologistas, os quais são especialistas no controle de infecções e no enfrentamento de pandemias.

\section{CONSIDERAÇÕES FINAIS}

O fortalecimento da atenção básica se mostra fundamental por ela desempenhar a coordenação do cuidado, evitando, assim, o colapso do sistema de saúde e a sobrecarga de leitos hospitalares. O desenvolvimento de ferramentas de contenção à pandemia é dependente, também, de investimentos em pesquisa, que devem ser realizados como forma de obtenção de um referencial teórico confiável para o planejamento de ações e tomada de decisões em saúde pública. 


\section{REFERÊNCIAS}

1. AVELINO-SILVA VI, RAMOS JF. Arboviroses e Políticas Públicas no Brasil. Revista Ciências em Saúde, 2017; 7(3).

2. CRODA J, et al. COVID-19 in Brazil: advantages of a socialized unified health system and preparation to contain cases. Revista da Sociedade Brasileira de Medicina Tropical, 2020; 53: e20200167.

3. WILLAN J, et al. Challenges for NHS hospitals during covid-19 epidemic. British Medical Journal, 2020; 368. 
RESUMO SIMPLES: Revisão Bibliográfica

TÍTULO: ESTRATÉGIAS DE SAÚDE UTILIZADAS PARA GESTANTES PORTADORAS DE HIV/AIDS NA REDUÇÃO DA TRANSMISSÃO VERTICAL

Autor/coautores: Fernanda Eliza Ferreira Ramalho Sales1, Damiana Maria Minhaqui da Conceição1, Joyce Santana do Nascimento1, Flávia Delane Nobrega Ramalho Sales2.

Instituição: Centro Universitário São Miguel (UNISÃOMIGUEL) ${ }^{1}$, Recife-PE; Faculdade de Ciências Humanas de Olinda (FACHO), Olinda-PE².

Palavras-chave: Gestantes, HIV, Transmissão Vertical de Doenças Infecciosas.

\section{INTRODUÇÃO}

A Síndrome da Imunodeficiência Adquirida (AIDS) representa um problema de saúde pública a nível mundial, sendo uma doença crônica causada pelo Vírus da Imunodeficiência Humana (HIV) que ocasiona perda progressiva da imunidade celular e aparecimento de infecções oportunistas. (GOULART CS, et al. 2018). O Ministério da Saúde realizou a implementação de medidas concretas de saúde pública através da atuação do enfermeiro nas Unidades de Saúde da Família (USF), como a realização de exames para o diagnóstico de infecção pelo HIV, denominado teste anti-HIV, durante a gestação, acompanhada de aconselhamento e adoção universal da terapia antirretroviral para gestantes e crianças expostas ao HIV (MINISTÉRIO DA SAÚDE, 2019).

\section{OBJETIVO}

Identificar as estratégias de saúde utilizadas para gestantes portadoras de HIV/AIDS como forma de reduzir a transmissão vertical com ênfase na importância do enfermeiro durante o processo na sua prática assistencial.

\section{MÉTODO}

Trata-se de uma revisão integrativa realizada com base nas informações do Ministério da Saúde, Revista Saúde.com e SCIELO em jul/2020. Considerou-se artigos publicados nos últimos cinco anos, em português, com relevância a temática proposta, encontrando-se os descritores: Gestantes, HIV, Transmissão Vertical de Doenças Infecciosas. Foram encontrados 12 artigos e desconsiderados os que não se enquadraram aos critérios.

\section{REVISÃO BIBLIOGRÁFICA}

O papel do enfermeiro é o da orientação, com foco na escuta sobre as preocupações e as dúvidas das gestantes, respeitando suas especificidades biológicas, psicossociais e culturais, reduzindo a transmissão vertical. Um pré-natal bem acompanhado e eficaz, realizado pelo enfermeiro da unidade básica de saúde, possibilita o nascimento de um bebê saudável e não infectado, minimizando a transmissão vertical.

É no pré-natal que a mulher deverá ser orientada sobre sua condição de saúde para que possa vivenciar a gestação, o parto e a maternidade de forma menos angustiante, pois ao visualizarem a possibilidade de o filho tornar-se soropositivo, preocupam-se com o fato da criança sofrer discriminação e preconceito, além do sofrimento agregado à condição da própria doença. Para as que planejam a gestação, acredita-se que com o acompanhamento do pré-natal e o tratamento médico adequado, consigam gerar um bebê saudável e não infectado.

\section{CONSIDERAÇÕES FINAIS}

É necessária a humanização do atendimento, do aconselhamento e da assistência no pré-natal e no pósparto as gestantes, assim como a capacitação dos profissionais de saúde durante sua formação acadêmica para a aplicação das estratégias de saúde, mitigando os casos de transmissão vertical e obtendo-se um maior alcance populacional através das práticas de educação em saúde. 


\section{REFERÊNCIAS}

1. BRASIL. Manual do Ministério da Saude. Protocolo clínico e diretrizes terapêuticas para prevenção da transmissão vertical de HIV, sífilis e hepatites virais. 2019; e1.

2.CAIRES MASS, et al. Prevenção da transmissão vertical do vírus da imunodeficiência humana (HIV). Revista Saúde.com, 2017; 13: e3.

3.GOULART CS, et al. Percepção do enfermeiro da atenção básica acerca do atendimento à gestante soropositiva. J. Health Biol Sci, 2018; 6: e3. 
RESUMO SIMPLES: Revisão Bibliográfica

TíTULO: DESAFIOS DO ENFRENTAMENTO DA INFLUENZA NO BRASIL DURANTE A PANDEMIA DA COVID-19

Autor/coautores: Joyce Santana do Nascimento'; Damiana Maria Minhaqui da Conceição'; Larissa Santos Carneiro Gomes²; Juliana Mendes Correia1.

Instituição: Centro Universitário São Miguel (UNISÃOMIGUEL), Recife-PE¹; Centro Universitário Maurício de Nassau (UNINASSAU), Recife-PE².

Palavras-chave: Covid-19, Influenza, Pandemia.

\section{INTRODUÇÃO}

A campanha de vacinação contra a Influenza, realizada anualmente em abril, foi antecipada para o mês de março em virtude do surgimento do novo Coronavírus (COVID-19) visando evitar a sobrecarga do sistema público de saúde, pois ambas viroses possuem sintomas semelhantes, tais como: tosse, febre, dor de cabeça e podem evoluir para Síndrome Respiratória Aguda Grave (SRAG) (MINISTÉRIO DA SAÚDE, 2020). Todavia, a cobertura vacinal contra Influenza diminuiu 2,65\% no Brasil em 2020, comparado ao ano anterior, sendo mais acentuada na região Norte (16,73\%), além de metas não atingidas nos grupos prioritários em algumas localidades do país.

\section{OBJETIVO}

Determinar os fatores que contribuíram para a redução da cobertura vacinal por Influenza em 2020, associados ao medo vivenciado pela população em decorrência do isolamento social com a COVID-19.

\section{MÉTODO}

Trata-se de uma revisão integrativa realizada com base nas informações do Ministério da Saúde, SciELO e Revista Eletrônica Acervo Saúde. Levou-se em consideração publicações dos últimos cinco anos, em português, com adequação e relevância da temática proposta, obtendo-se os descritores: COVID-19; Influenza; Pandemia. Artigos sem essas características foram excluídos da pesquisa.

\section{REVISÃO BIBLIOGRÁFICA}

O isolamento social ocasionado pela COVID-19, provocou o medo do contágio pelo vírus, fazendo com que houvesse o receio da população em sair de casa para a vacinação contra a Influenza. No estado do Amazonas, em especial, o precário acesso à internet também interferiu no acompanhamento das informações sobre vacinação, assim como dificuldades na aquisição dos imunobiológicos para cada fase da campanha (DIAS JL e NASCIMENTO MIN, 2020). Em contrapartida, notícias falsas disseminadas através da internet fizeram com que algumas pessoas acreditassem que o consumo de chás pudesse ser indicado no tratamento da Influenza e da COVID-19 ao invés do antiviral oseltamivir (LANA RM, et al., 2020). O menor quantitativo de profissionais de saúde atuantes como consequência da COVID-19, apresentou-se como uma das complicações durante as estratégias da campanha contra a Influenza no Brasil. Ademais, como reflexo do temor ao novo Coronavírus, a meta de $90 \%$ da cobertura vacinal não foi atingida pelos grupos considerados vulneráveis, como crianças, gestantes, puérperas e adultos entre 55 e 59 anos.

\section{CONSIDERAÇÕES FINAIS}

Conclui-se que protocolos emergências devem ser planejados visando a garantia da segurança no trabalho dos profissionais de saúde, bem como a manutenção da cobertura vacinal contra Influenza nos casos de situações críticas, como durante a COVID-19 no Brasil.

\section{REFERÊNCIAS}

1. DIAS JL, NASCIMENTO MIN. A campanha da Influenza 2020 em meio a pandemia do Coronavírus no estado do Amazonas: um relato de experiência. Revista Eletrônica Acervo Saúde, 2020; Esp; n.46; e4053. 
2. LANA RM, et al. Emergência do novo Coronavírus (SARS-CoV-2) e o papel de uma vigilância nacional em saúde oportuna e efetiva. Cad. Saúde Pública [online], 2020; 36, 3.

3. BRASIL. Informe Técnico da 22ª Campanha Nacional de Vacinação contra a Influenza. 2020. Disponível em: $\quad$ https://sbim.org.br/images/files/notas-tecnicas/informe-tecnico-ms-campanha-influenza-2020final.pdf. Acessado em: 10 de julho de 2020. 
RESUMOS SIMPLES: Revisão Bibliográfica

TÍTULO: AVALIAÇÃO DA CROMATOGRAFIA DE TROCA IÔNICA COMO ETAPA DE PURIFICAÇÃO NA PRODUÇÃO DE SORO ANTIOFÍDICO

Autor/coautores: Robson Silva Júnior, Jonathan Silva Balsamão.

Instituição: Fundação Ezequiel Dias (FUNED), Belo Horizonte - Minas Gerais.

Palavras-chave: Troca iônica, Soro hiperimune, Acidente ofídico.

\section{INTRODUÇÃO}

O ofidismo foi incluído na lista de Doenças Tropicais Negligenciadas em 2009 pela Organização Mundial de Saúde (OMS), este agravo se destaca devido a sua alta frequência, morbimortalidade e impacto socioeconômico (BERNARDE, et al., 2015). Segundo LIMA (2015), os antivenenos ofídicos, no Brasil, são produzidos por laboratórios oficiais e apresentam eficácia satisfatória, porém reações adversas são descritas após o uso clínico desses medicamentos. Grande parte destas reações ocorrem devido à origem biológica do produto, composto por frações proteicas de imunoglobulinas $\mathrm{G}$ (IgGs) heterólogas equinas. Estas frações denominadas $F(a b ') 2$, se ligam às proteínas do veneno promovendo a sua neutralização, impedindo que tais proteínas possam exercer seu efeito tóxico sobre o organismo.

\section{OBJETIVO}

Revisar na literatura a utilização da técnica de cromatografia de troca iônica e avaliar a viabilidade da sua aplicação como etapa de purificação de proteínas no processo de produção de soros antiofídicos.

\section{REVISÃO BIBLIOGRÁFICA}

A purificação da fração $F(a b$ ')2, por cromatografia de troca iônica é um procedimento bem estabelecido por muitos produtores de soro antiofídico ao redor do mundo. Estudos descrevem etapas de precipitação ácida, onde os ácidos orgânicos tricloroacético e caprílico (ácido n-octanóico) são descritos como os mais utilizados, ou precipitação salina por sulfato de amônio (LEÓN, 2018). A etapa de precipitação é empregada como técnica preparativa antes da realização da cromatografia de troca iônica, removendo boa parte das proteínas indesejadas presentes no plasma equino, evitando assim a saturação da resina de troca iônica. $O$ isolamento e purificação da fração $F\left(a b^{\prime}\right) 2$ de IgG equina, por cromatografia de troca iônica em resina SPSepharose é descrito como um processo eficaz para a remoção dos contaminantes proteicos residuais, principalmente pequenos peptídeos, pepsina e resquícios de reagentes concentrados na fase sobrenadante da etapa de precipitação. Esse processo combinado à precipitação ácida apresenta uma elevada taxa de recuperação e pureza da fração de interesse, quando comparado ao resultado alcançado pelas metodologias tradicionalmente empregadas pela maioria dos produtores nacionais (LIMA, 2015).

\section{CONSIDERAÇÕES FINAIS}

Constata-se a viabilidade da cromatografia de troca iônica na produção de soros antiofídicos, uma vez que os estudos evidenciam pureza e taxa de recuperação satisfatória da fração $F(a b$ ')2 obtida por meio dessa técnica, observa-se também a necessidade de revisão do processo de precipitação de hemocomponentes contaminantes, uma vez que o uso do ácido caprílico demonstra melhores resultados comparados à precipitação salina.

\section{REFERÊNCIAS}

1. BERNARDE, et al. Ofidismo no Estado do Acre - Brasil. Journal of Amazon Health Science 2015; 1: 44-63.

2. LEÓN, G. et al. Current technology for the industrial manufacture of snake antivenoms. Toxicon 2018; vol. 151, p. 63-73.

3. LIMA MV. Obtenção de soros antivenenos ofídicos de elevada pureza e atividade específica pela Fundação Ezequiel Dias. 2015. 89 f. Dissertação (Mestrado em Gestão, Pesquisa e Desenvolvimento na Indústria Farmacêutica). Instituto de Tecnologia em Fármacos, Fundação Oswaldo Cruz, Rio de Janeiro. 2015. 
RESUMOS SIMPLES: Revisão Bibliográfica

Título: Aspectos Clínicos da Tripanossomíase Humana Africana ou DoEnÇa do SONO

Autor/coautores: João Lucas Arcanjo de Barros Ribeiro, Eduardo Henrique Matos Pires, Bárbara Cristine dos Santos Silva, Amanda Lucena dos Santos, Francinete Torres Barreiro da Fonsêca.

Instituição: Universidade Federal de Pernambuco (UFPE) e Universidade Federal Rural de Pernambuco (UFRPE). Recife-PE

Palavras-chave: T. brucei, doença do sono, tripanossomíase humana africana

\section{INTRODUÇÃO}

A doença do sono ou Tripanossomíase Humana Africana (THA) é uma doença parasitária causada por subespécies do Trypanosoma brucei, um protozoário pertencente à família Trypanosomatidae. A THA é transmitida pela mosca Tsé-Tsé do gênero Glossina comum na África Subsaariana, o vetor infecta o hospedeiro durante o repasto sanguíneo e desenvolve seu ciclo adjunto à fisiopatologia da doença (CNOPS, et al., 2015). Classificada pela Organização Mundial da Saúde (OMS) como doença tropical negligenciada, a THA afeta populações com poucos recursos financeiros e por isso não desperta amplo interesse de pesquisas para controle e terapia da doença (OMS, 2019).

\section{OBJETIVO}

Revisar a literatura disponível a respeito de trabalhos publicados em bancos de dados nos últimos 5 anos que avaliaram aspectos e características importantes na clínica da tripanossomíase humana africana ou doença do sono.

\section{REVISÃO BIBLIOGRÁFICA}

A subespécie T. brucei gambiense é responsável por desenvolver a forma crônica da doença e por isso sua progressão pode durar anos, já a subespécie T. brucei rhodesiense causa a forma aguda. A THA pode ser dividida em um primeiro estágio sistêmico, sem sintomas clínicos específicos, podendo apresentar fadiga, febre, dor articular e dor de cabeça, com possibilidade de evoluir à medida que a infecção atingir o sistema linfático gerando linfadenopatias (CNOPS, et al., 2015). Já o segundo estágio ocorre após o cruzamento da barreira hematoencefálica gerando sintomas como: alteração do sono com sonolência diurna e insônia noturna, distúrbios sensoriais, motores e psiquiátricos (KENNEDYPG e RODGERS J, 2019). Foi estimado pela OMS que 70 milhões de pessoas estão sob o risco de contrair a THA na África, e além disso, o manejo da doença é difícil por seu tratamento não contemplar todos os estágios da doença e apresentar uma elevada toxicidade (OMS, 2019).

\section{CONSIDERAÇÕES FINAIS}

Por consequência, novas pesquisas a respeito de terapias inovadoras e mais eficazes para o tratamento da tripanossomíase humana africana são vitais e devem ser estimuladas, juntamente a estratégias de controle e diagnóstico adaptados as condições socioeconômicas das regiões endêmicas para doença.

\section{REFERÊNCIAS:}

1. CNOPS, et al. Escape mechanisms of African trypanosomes: why trypanosomosis is keeping us awake. Parasitology, 2015; 142(3), 417.

2. KENNEDY PG, RODGERS J.Clinical and neuropathogenetic aspects of human African trypanosomiasis. Frontiers in immunology. 2019; 10, 39.

3. OMS. Human African trypanosomiasis (Sleeping sickness), 2020. Disponível em: https://www.who.int/health-topics/human-african-trypanosomiasis\#tab=tab_1. Acessado em: 09 de julho de 2020. 
TíTULO: ANÁLISE DAS INTERNAÇÕES POR BRUCELOSE NOS ESTADOS BRASILEIROS

Autor/coautores: Rafisah Sekeff Simão Alencar'; Larissa Bispo Alves Roncen'; José Lima Assunção Junior2 Instituição: ${ }^{1}$ Pontifícia Universidade Católica de Minas Gerais (PUCMG), Poços de Caldas- Minas Gerais; 2Instituto Federal do Maranhão (IFMA), São Luís- Maranhão.

Palavras-chave: Epidemiologia, Doenças Emergentes, Brucelose

\section{INTRODUÇÃO}

A brucelose humana é a zoonose causada por bactérias do gênero Brucella e é transmitida às pessoas por contato direto ou indireto com animais infectados ou seus subprodutos. Ademais, é considerada pela OMS uma doença emergente, sendo necessária atenção especial dos órgãos competentes (SCHMITT Cl, et al., 2017). Manifesta-se por um quadro febril, dores musculares e ósseas e é subdiagnosticada, podendo acarretar supurações de órgãos, conferindo gravidade ao estado do paciente (SOARES CPOC, et al., 2015). Esse estudo visa analisar o aumento do número de casos de internações por brucelose no âmbito brasileiro para alertar a necessidade de possíveis intervenções.

\section{OBJETIVO}

Analisar o panorama das internações por brucelose nos últimos 5 anos pelo sistema de saúde público brasileiro e, dessa forma, constatar a necessidade de planos de intervenção no cenário nacional.

\section{MÉTODO}

As informações analisadas foram pesquisadas no banco de dados do Departamento de Informática do Sistema Único de Saúde, considerando as seguintes variáveis: brucelose; internações; sexo; e período de 2015 a 2019. Ademais, foi realizada uma revisão de literatura na BVS e Scielo, cujos descritores foram "brucelose and epidemiologia". Incluíram-se estudos publicados a partir de 2015, em português e inglês.

\section{REVISÃO BIBLIOGRÁFICA}

De 113 internações nacionais por brucelose, 11 foram em 2015, 26 em 2016, 23 em 2017, 26 em 2018 e 27 em 2019. Na região Sul, encontra-se o estado com o maior número de internações do país: Paraná, com 16 casos. Na região Sudeste, São Paulo (14); na região Norte, Rondônia (11); no Nordeste, Rio Grande do Norte e Maranhão (9); e no Centro-Oeste, Goiás (7). Tais dados revelam aumento do número de internações por brucelose ao longo dos anos, resultado divergente de outros estudos que demonstram uma queda relevante de tais internações no contexto internacional (BALDO MJ, et al., 2017). Nesse sentido, os principais desafios nacionais são o subdiagnóstico da doença, as consequências de uma forma atípica e altas taxas de subnotificação tanto da presença em animais, como seres humanos (BALDO MJ, et al., 2017), aliado aos poucos investimentos nos serviços de saúde pública (SOARES CPOC, et al., 2015).

\section{CONSIDERAÇÕES FINAIS}

A brucelose é uma condição evitável e, diante do aumento anual das internações, é necessária maior atenção para esta. Deve-se, então, capacitar sobretudo os criadores animais sobre ela, incluindo medidas preventivas. Ademais, diante de uma literatura escassa, estudos na comunidade, além da promoção de medidas intervencionistas, são cruciais para o melhor entendimento e controle dessa zoonose.

\section{REFERÊNCIAS:}

1. BALDO MJ, et al. Estudo de 12 Anos de Internamentos num Hospital Distrital. Medicina Interna, 2017; 24 (3).

2. SCHMITT Cl, et al. Brucelose: uma questão de saúde pública. Revista Electrónica de Veterinaria, 2017; 18 (9).

3. SOARES CPOC, et al. Prevalência da Brucella spp em humanos. Ver. Latino-Am. Enfermagem, 2015; 23 (5). 
RESUMOS SIMPLES: Revisão Bibliográfica

TíTULO: ANÁLISE DA SITUAÇÃO EPIDEMIOLÓGICA DA SÍFILIS GESTACIONAL NO BRASIL: UMA REVISÃO

Autor/coautores: Rafaella Cavalcanti Silva da Costa1; Amanda Gomes Lima Bezerra1; Helen da Silva Sousa1; Ingride de Sousa Araújo Macêdo1; Ricardo Oliveira de Andrade1,2.

Instituição: Centro Universitário Maurício de Nassau (UNINASSAU), Recife-PE1; Centro Universitário Tabosa de Almeida (ASCES-UNITA), Caruaru-PE2.

Palavras-chave: Epidemiologia, Sífilis Congênita, Treponema pallidum.

\section{INTRODUÇÃO}

São doenças negligenciadas aquelas que têm como causa agentes infecciosos e parasitas, baixo incentivo e notoriedade, especialmente nas populações de menor prestígio socioeconômico. A sífilis, enfermidade causada pela bactéria Treponema pallidum, é uma doença ainda negligenciada no Brasil, ademais, a contaminação pode ocorrer durante a gestação, parto ou amamentação, sendo as fases primária e secundaria da doença as que ocorrem maior taxa de transmissão, uma vez que há mais espiroquetas na circulação. Além disso, a transmissão para o feto pode levar ao abortamento ou morte neonatal.(ARAUJO AGR, et al., 2019).

\section{OBJETIVO}

Revisar o perfil epidemiológico das gestantes acometidas por sífilis congênita em alguns estados do Brasil por meio de uma busca na literatura realizada através de artigos disponibilizados nas bases de dados Scielo e Acervo Mais nos últimos dois anos.

\section{REVISÃO BIBLIOGRÁFICA}

Estudo realizado em Rio Grande - RS identificou que a prevalência de não realização do exame variou conforme o número de consultas pré-natais, 1 a 3 consultas: prevalência de 15,7\%; 4 a 12 consultas: prevalência de $0,6 \%$. Mulheres de pele preta, renda familiar inferior a um salário mínimo, escolaridade inferior a 8 anos e não suplementação com sulfato ferroso também são fatores determinantes na não realização do teste sorológico para sífilis (CESAR JÁ, et al., 2020). Outra pesquisa evidenciou que a maioria das mulheres que apresentavam sífilis durante o período gestacional tinham entre 20 e 30 anos. Um dos problemas foi o diagnóstico tardio uma vez que $44,3 \%$ das gestantes confirmaram a doença apenas no terceiro trimestre de gestação (ARAUJO AGR, et al., 2019). Dentre as problemáticas da sífilis congênita está a não realização do tratamento adequado por parte da mãe, que justifica o fato de apenas 3,78\% de um total 2445 mulheres realizaram o tratamento adequado (LEAL TLSL, et al., 2020).

\section{CONSIDERAÇÕES FINAIS}

Infere-se que investir em vigilância epidemiológica, educação para a saúde e para o autocuidado, diagnóstico precoce e fortalecimento de vínculo entre comunidade e profissionais da saúde, são medidas que podem ter um impacto positivo para a condução adequada do pré-natal, bem como da assistência à saúde da gestante durante este período, uma vez que, a identificação precoce desta garante o tratamento adequado e a redução de complicações ao feto pós-parto.

\section{REFERÊNCIAS}

1. ARAUJO AGR, et al. Estudo epidemiológico dos casos de sífilis em gestantes em uma cidade do norte de Minas Gerais. Revista Eletrônica Acervo Saúde, 2019; 3: e143.

2. CESAR JÁ, et al. Não realização de teste sorológico para sífilis durante o pré-natal: prevalência e fatores associados. Revista Brasileira de Epidemiologia [online], 2020; 23: e200012.

3. LEAL TLSL, et al. Perfil epidemiológico dos casos de sífilis congênita no Maranhão. Revista Eletrônica Acervo Científico,2020;8:e2936. 
RESUMOS SIMPLES: Revisão Bibliográfica

TÍTULO: ASSISTÊNCIA FARMACÊUTICA VOLTADA A PORTADORES DE DOENÇAS CRÔNICAS ASSOCIADAS À HANSENÍASE

Autor/coautores: Thays Vitória da Silva Rodrigues1, Maria Eduarda da Silva1, Ninive Bezerra Florêncio2, Gleyka Daísa de Melo Santos2.

Instituição: 1Faculdade Santíssima Trindade (FAST), Nazaré da Mata- Pernambuco. 2Universidade Federal de Pernambuco (UFPE), Recife-Pernambuco.

Palavras-chave: Assistência Farmacêutica, Doenças Crônicas, Hanseníase.

\section{INTRODUÇÃO}

A hanseníase é uma doença negligenciada representando um grave problema de saúde pública no Brasil, sendo endêmica em vários estados, com cerca de 47.000 novos casos por ano (FERREIRA AF, et al., 2019). Dentre estes, existem os portadores de doenças crônicas como Hipertensão Arterial (HAS), Diabetes Mellitus (DM), entre outras, que se classificam como portadores de multimorbidades. Estes pacientes normalmente necessitam fazer uso contínuo de medicamentos, caracterizando-se muitas vezes como polifarmácia, juntamente com a terapia multidrogas (MDT) tratamento utilizado para hanseníase, resultando frequentemente no agravamento das condições de saúde dos mesmos, podendo acarretar insuficiência hepática, renal, favorecendo o aumento da dificuldade à adesão terapêutica (CERQUEIRA SR, et al., 2020). A assistência farmacêutica voltada a estes, aperfeiçoa os esquemas terapêuticos beneficiando a melhoria dos efeitos farmacológicos desejados (SILVA AS, 2015).

\section{OBJETIVO}

Revisar a importância e os benefícios alcançados no seguimento farmacoterapêutico a partir da inserção do profissional farmacêutico na atenção voltada aos pacientes portadores de hanseníase associada à comorbidades crônicas (multimorbidades).

\section{REVISÃO BIBLIOGRÁFICA}

Os estudos apontaram que pacientes usuários de medicamentos para HAS, DM e/ou outras doenças crônicas associado com a MDT para a hanseníase apresentaram maiores problemas relacionados a medicamentos, como insuficiência renal, hepática, doenças hepática tóxica entre outros, favorecendo até mesmo o óbito (FERREIRA AF, et al., 2019).

A utilização da polifarmácia contribuiu para o uso incorreto dos medicamentos levando ao agravamento das doenças e aumentando a morbimortalidade. Identificou-se escassez dos estudos voltados à atenção farmacêutica para pacientes portadores de doenças crônicas associadas à hanseníase (SILVA AS, 2015).

Tendo em vista que o profissional farmacêutico possui um papel fundamental na atenção ao paciente em tratamento medicamentoso, a assistência prestada aos pacientes com multimorbidades é de extrema importância, pois é o responsável em verificar a existência de possíveis efeitos adversos e interações que estejam ocorrendo ou que podem vir a acontecer. Ofertando as informações e orientações necessárias que contribuirão diretamente com a melhoria e alcance dos resultados farmacoterapêuticos almejados (CERQUEIRA SR, et al., 2020).

\section{CONSIDERAÇÕES FINAIS}

A correta adesão à farmacoterapia é de extrema importância para que se alcance a melhoria das condições clínicas apresentadas pelo paciente, seja ele portador de comorbidades crônicas ou de qualquer outra doença. Quando se trata de portadores de multimorbidades, a assistência farmacêutica torna-se ainda mais relevante, pois é o farmacêutico quem apresenta habilidades técnicas para exercer orientações sobre o uso racional de medicamentos, podendo favorecer uma melhoria à adesão e eficiência farmacoterapêutica. 


\section{REFERÊNCIAS}

1. CERQUEIRA SR, et al. The interference of polypharmacy and the importance of clinical pharmacy advice in the treatment of leprosy: a case-control study. Revista da Sociedade Brasileira de Medicina Tropical, 2020; 53: e20200114.

2. FERREIRA AF, et al. Mortalidade por hanseníase em contextos de alta endemicidade: análise espaçotemporal integrada no Brasil. Revista Panamericana de Saúde Pública, 2019;43: e87.

3. SILVA AS. A importância da Farmácia Clínica no acompanhamento dos pacientes com hanseníase em uma unidade Básica de Saúde. Hansenologia Internationalis, 2015; 40(1): e9-16. 
RESUMO SIMPLES: Revisão Bibliográfica

TÍTULO: ANÁLISE DAS ALTERAÇÕES COMPORTAMENTAIS EM ANIMAIS INFECTADOS POR

TOXOCARA SPP: UMA REVISÃO DA LITERATURA

Autor/ Coautores: Fernanda Shu Moeller de Carvalho, Luiza Lorençato Vitório, Marcelo Andreetta Corral.

Instituição: Universidade de Santo Amaro (UNISA), São Paulo- SP.

Palavras-chave: Alterações comportamentais, Infecção experimental, Toxocara.

\section{INTRODUÇÃO}

A toxocaríase é causada por parasitos do gênero Toxocara. Cães e gatos são considerados seus hospedeiros naturais. Humanos e alguns roedores se comportam como hospedeiros paratênicos. O homem adquire a parasitose pela ingestão de alimentos contaminados ou até mesmo pelo contato direto das mãos em locais como terra ou areia contaminadas com ovos férteis. As principais formas clínicas são a síndrome da larva migrans visceral, a larva migrans ocular, a toxocaríase oculta e a neurotoxocaríase (MA G, et al., 2017). As alterações comportamentais são frequentemente associadas a esta infecção, portanto, estudos para avaliação das manifestações psíquicas costumam ser realizados em modelos murinos (MELIOU M, et al., 2020).

\section{OBJETIVO}

Realizar uma revisão narrativa sobre as principais alterações comportamentais reportadas em animais infectados por Toxocara spp. Foram pesquisados artigos publicados nos últimos 36 anos no "Pubmed" e "Web of Science" utilizando os descritores "toxocara", "behavior" e "neurotoxocariase".

\section{REVISÃO BIBLIOGRÁFICA}

A toxocaríase é uma parasitose negligenciada. Estudos comportamentais realizados em animais são fundamentais para elucidar o comportamento humano frente aos diferentes agentes infecciosos e estimular a realização de um diagnóstico diferencial. Estudos em animais possibilitam um ambiente com carga parasitária inoculada controlada se permitindo comparar a evolução do processo infeccioso (STRUBE C, et al., 2020).

Neste estudo, 92 trabalhos foram encontrados. Dentre eles, 11 foram selecionados para análise, pois contemplavam alterações comportamentais em camundongos infectados por Toxocara spp. Mais de $70 \%$ dos trabalhos reportaram comprometimento do aprendizado e da memória. Outras alterações como a hiperatividade e a redução do comportamento exploratório foram descritas por cerca de $20 \%$ dos autores. A redução dos estímulos sonoros, alteração no desenvolvimento cognitivo e epilepsia também foram listadas, mas somente por um autor cada. As manifestações clínicas observadas nos estudos experimentais são frequentemente encontradas em crianças, as quais constituem a principal população acometida pelo parasito dada as formas de infecção relacionadas com esta parasitose.

\section{CONSIDERAÇÕES FINAIS}

A análise das manifestações clínicas reportadas nos estudos com animais infectados com Toxocara spp aponta que humanos que apresentam sinais e sintomas semelhantes aos descritos devem realizar diagnóstico diferencial para toxocaríase. É importante observar também que as manifestações clínicas podem ser encontradas de forma isolada ou associadas.

\section{REFERÊNCIAS}

1. MA G, et al. Human toxocariasis. The Lancet Infectious Diseases, 2018; e14-e24.

2. MELIOU M, et al. Toxocariasis of the Nervous System. Acta Parasitologica, 2020; 65, 291-299.

3. STRUBE C, et al. Toxocara-induced neural larva migrans (neurotoxocarosis) in rodent model hosts. Advances in Parasitology, 2020; 109:189-218. 
RESUMOS SIMPLES: Revisão Bibliográfica

TíTULO: DIAGNÓSTICOS DA LEISHMANIOSE VISCERAL (LV): UMA REVISÃO DE LITERATURA

Autor/coautores: Jeremias Guilherme da Silva, Elisangela Melquiades Silva e Thafylla Mendes de Sant' Ana.

Instituição: Uninter Educacional - Pernambuco.

Palavras-chave: Leishmaniose Visceral, Diagnóstico, Zoonose.

\section{INTRODUÇÃO}

Doenças negligenciada, crônica, endêmica, incapacitante e presente em populações de baixa renda, a Leishmaniose Visceral (LV) é uma zoonose de acometimento sistêmico, causada por um protozoário da espécie Leishmania chagasi. (SILVA JAO, et al., 2017). É transmitida ao homem pela picada das fêmeas do mosquito palha (inseto flebotomíneo). Anualmente são registrados cerca de 3.500 casos e o coeficiente de incidência é de 2,0 casos/100.000 habitantes no Brasil. Enfermidade com necessidade médica importante, que se não diagnosticada e tratada adequadamente poderá levar a óbito de até $90 \%$ dos casos (BRASIL, 2016).

\section{OBJETIVO}

Verificar os conteúdos e sintetizar as principais evidências encontradas na literatura sobre os principais meios de diagnóstico da enfermidade denominada Leishmaniose Visceral (LV), também conhecida como calazar, em humanos.

\section{REVISÃO BIBLIOGRÁFICA}

O Diagnóstico inicial da LV é realizado no âmbito ambulatorial e, por se tratar de uma doença de notificação compulsória e com características clínicas de evolução grave, deve ser feito de forma precisa e o mais precocemente possível (SANTOS, 2019). Segundo o Manual de Vigilância e Controle da Leishmaniose Visceral esse diagnóstico pode ser feito pelo quadro clínico por técnicas imunológicas e parasitológicas. No quadro clínico o indivíduo apresenta geralmente febre e esplenomegalia associado ou não à hepatomegalia. O diagnóstico laboratorial (técnicas imunológicas) ocorre por meio da coleta de sangue para exames sorológicos da Imunofluorescência indireta-RIFI (positivas as amostras reagentes a partir da diluição de 1:80), dos testes rápidos imunocromatográficos (positivos quando a linha controle e a linha teste aparecem na fita ou plataforma). O diagnóstico pela técnica parasitológica ocorre uma demonstração do parasita por meio de uma punção esplênica (maior sensibilidade) ou da medula óssea procedimento mais seguro), biópsia hepática e até aspiração de linfonodos (BRASIL, 2016).

\section{CONSIDERAÇÕES FINAIS}

É indispensável o conhecimento e a procura do serviço de saúde assim que aparecerem os principais sintomas da LV, pois quanto mais precocemente for diagnosticada, mais rápido e eficiente será o tratamento. Dessa maneira aumentará o nível de chances de evitar agravos, complicações e mortes.

\section{REFERÊNCIAS}

1. BRASIL. Ministério da Saúde. Manual de Vigilância e Controle da Leishmaniose Visceral, 2016.

2. SANTOS ESM, et al. Aspectos Epidemiológicos da Leishmaniose Visceral. Revista Eletrônica Acervo Saúde, 2019; (23): e959.

3. SILVA JAO, et al. Dinâmica da leishmaniose visceral humana no município de Goiana - PE. Pubvet 2017b; 11(12): 1293-1297. 
RESUMO SIMPLES: Revisão Bibliográfica

TÍTULO: RESISTÊNCIA AOS ANTIMALÁRICOS COMO FATOR PREPONDERANTE CONTRA A ERRADICAÇÃO DA MALÁRIA NO BRASIL: UMA REVISÃO INTEGRATIVA

Autor/coautores: Larissa Santos Carneiro Gomes ${ }^{1}$, Joice Carla Moreira D'angelo ${ }^{1}$, Joyce Santana do Nascimento², Damiana Maria Minhaqui da Conceição², Heytor Victor Pereira da Costa Neco¹.

Instituição: Centro Universitário Maurício de Nassau (UNINASSAU), Recife-PE1; Centro Universitário São Miguel (UNISÃOMIGUEL), Recife-PE².

Palavras-chave: Resistência, Antimaláricos, Malária.

\section{INTRODUÇÃO}

A malária, doença causada por protozoários do gênero Plasmodium e transmitida aos humanos através da picada das fêmeas de mosquitos Anopheles infectadas, é um problema de saúde pública (VIERA VV, et al., 2019). No Brasil, apresenta-se endêmica na Bacia Amazônica e, mesmo havendo tratamento, algumas cepas são resistentes. Assim, a resistência aos antimaláricos pelo $P$. falciparum é a mais preocupante, por essa ser a espécie mais patogênica, provocando maior mortalidade. Portanto, a resistência aos antimaláricos dificultam as estratégias de eliminação da malária no Brasil (FERREIRA MU e CASTRO MC, 2016).

\section{OBJETIVO}

Descrever estudos que respaldam a resistência de $P$. falciparum aos antimaláricos como uma dificuldade de erradicação da malária no Brasil e fatores que podem vir a somar para esta problemática.

\section{MÉTODO}

Foi realizada uma revisão integrativa conduzida nas plataformas Pubmed e Acervomais. Os descritores utilizados foram Drug resistance; Resistance Plasmodium falciparum e Antimalarials, termos localizados na Lista Medical SubjectHeadings (Mesh). A critério de inclusão os estudos selecionados estiveram entre 20152020, em inglês e português, por análises de títulos e resumos, sendo 3 artigos escolhidos por melhor adequação ao assunto abordado. Foram descartados, portanto, aqueles sem apropriação.

\section{REVISÃO BIBLIOGRÁFICA}

A resistência aos antimálaricos em $P$. falciparum no Brasil tem merecido destaque devido à confluência de fatores como a utilização de medicamentos falsificados ou o uso indiscriminado destes que dificultam sua erradicação (MENARD D e DONDORP A, 2017). Logo, um ciclo vicioso se observa ao considerar o surgimento de novas drogas, somado a má conduta em relação ao seu uso (VIERA VV, et al., 2019). No Brasil, o primeiro caso de resistência antimalárica foi pelo quinina, em 1900, e hoje já existem dados de resistência para as demais drogas antimaláricas. Entretanto, ainda que não existam relatos de resistência à atermisinina no país, é importante que a qualidade das terapias combinadas à base de atermisinina (CTAs) e outros antimaláricos sejam monitoradas devido à pressão seletiva do medicamento e monoterapia (VIERA VV, et al., 2019). A natureza focal do $P$. falciparum no Brasil oferece viabilidade para erradicar a Malária (FERREIRA MU e CASTRO MC, 2016). Porém é necessário que haja educação em saúde e campanhas apresentando os perigos da automedicação.

\section{CONSIDERAÇÕES FINAIS}

Fatores que contribuem para a resistência aos medicamentos antimaláricos podem retardar a erradicação da malária no Brasil. Para reverter este panorama, são necessárias mais pesquisas, políticas nacionais e a promoção do uso racional de medicamentos por meio da orientação farmacêutica.

\section{REFERÊNCIAS}

1. FERREIRA UM, CASTRO MC. Challengs for malaria elimination in Brazil. Malaria Journal, 2016; 15:284. 
2. MENARD D, DONDORP A. Antimalarial Drug Resistance: A Threat to Malaria Elimination. Cold Spring Harb Perspect Med 2017;7:a025619.

3. VIEIRA VV, et al. Malaria parasite resistance vicious cycle. Revista Eletrônica Acervo Saúde, 2019; 11(18): e1708. 
RESUMOS SIMPLES: Revisão Bibliográfica

TíTULO: DESAFIOS DO MANEJO MÉDICO NO TRATAMENTO DA TUBERCULOSE: UMA DOENÇA AINDA NEGLIGENCIADA

Autor/coautores: Amanda Gomes Lima Bezerra1; Helen da Silva Sousa1; Ingride de Sousa Araújo Macêdo1; Rafaella Cavalcanti Silva da Costa1; Ricardo Oliveira de Andrade1,2.

Instituição: Centro Universitário Maurício de Nassau (UNINASSAU), Recife-PE1; Centro Universitário Tabosa de Almeida (ASCES/UNITA), Caruaru-PE2.

Palavras-chave: Tuberculose, Doenças Negligenciadas, Tratamento.

\section{INTRODUÇÃo}

Doenças negligenciadas são aquelas causadas por agentes etiológicos infecciosos e parasitas, sendo endêmicas em populações de menor prestígio socioeconômico, além disso, os investimentos no estudo dessas doenças são reduzidos, bem como o seu controle e a produção dos medicamentos. Uma das principais doenças negligenciadas no Brasil e em países em desenvolvimento em todo mundo é a Tuberculose (TB), doença infectocontagiosa, causada pelo Mycobacterium tuberculosis que apresenta grandes desafios desde o seu diagnóstico, que muitas vezes é tardio, até o seu tratamento que, por não ser feito de maneira adequada, resulta na resistência do bacilo às drogas.

\section{OBJETIVO}

Revisar a literatura acerca das dificuldades encontradas ao longo de tratamento da TB, doença infectocontagiosa, negligenciada na atualidade, apesar de acometer um número significativo de pessoas e ser um problema de saúde pública no Brasil.

\section{REVISÃO BIBLIOGRÁFICA}

O tratamento da TB possui uma fase intensiva por 2 meses com: Rifampicina, Isoniazida, Pirazinamida, Etambutol (RHZE) em Dose Fixa Combinada (DFC) e uma fase de manutenção por 4 meses com: Rifampicina, Isoniazida (RH) em DFC (RABAHI MF, et al., 2017). Pacientes relatam dificuldades no tratamento: efeitos colaterais e longo período de tratamento ( 6 meses), interferindo no trabalho e convívio social. O reingresso após abandono do tratamento é uma realidade no Brasil e a proporção de abandono do tratamento é crescente (SANTOS TA e MARTINS MMF, 2018). Um estudo de coorte com amostra de 257 pacientes mostrou que $21 \%$ abandonou o tratamento e que dependência química e ter menos de 8 anos de escolaridade são fatores que corroboram para a interrupção do tratamento (VIANA PVS, et al., 2018). A multimorbidade é fator de risco para abandono do tratamento e óbito de pacientes com TB. Ademais, o consumo de álcool e drogas, vulnerabilidade social, dificuldades de acesso ao tratamento, baixo poder aquisitivo, religião e sensação de cura antes do fim do tratamento influenciam a interrupção do tratamento (VIANA PVS, et al., 2018).

\section{CONSIDERAÇÕES FINAIS}

Depreende-se que a manutenção do tratamento da TB ainda constitui um desafio, devido os diversos fatores que levam a sua interrupção por parte dos pacientes, sendo necessário a adoção de medidas como a compreensão do contexto sociocultural no qual o indivíduo está inserido e a criação de um vínculo com os profissionais que irão acompanhá-lo visando reduzir as taxas de abandono do tratamento e aumento da resistência bacilar.

\section{REFERÊNCIAS}

1. RABAHI MF, et al. Tratamento da tuberculose. Jornal Brasileiro de Pneumologia, 2017, 43(5): 472-486. 2.SANTOS TA, MARTINS MMF. Perfil dos casos de reingresso após abandono do tratamento da tuberculose em Salvador, Bahia, Brasil. Cadernos saúde coletiva, 2018, 26(3): 233-240. 
2. VIANA PVS, et al. Fatores associados ao abandono e ao óbito de casos de tuberculose drogarresistente (TBDR) atendidos em um centro de referência no Rio de Janeiro, Brasil. Cadernos de Saúde Pública, 2018; 5:e00048217. 
RESUMOS SIMPLES: Revisão Bibliográfica

TíTULO: OS SERVIÇOS COMUNITÁRIOS DESENVOLVIDOS PELO FARMACÊUTICO NA PANDEMIA DA

CovID-19

Autor/coautores: Carlos Eduardo Oliveira Santana, Danillo Alencar Roseno.

Instituição: Faculdade Nova Esperança de Mossoró (FACENE), Mossoró-RN.

Palavras-chave: Assistência Farmacêutica, Infecções por Coronavírus, Betacoravírus.

\section{INTRODUÇÃO}

Segundo a Organização Pan-Americana de Saúde (OPAS) a Covid-19 estabelece uma crise de saúde pública mundial manifestando um quadro clínico acompanhado de problemas respiratórios. Pacientes diagnosticados recebem as orientações para tratamentos iniciais, mas nem sempre é possível acompanhar a evolução da doença onde os casos mais leves podem ser tratados em casa com medidas paliativas. Esse cenário modificou paradigmas e os métodos até então estabelecidos, trazendo novos desafios para os profissionais de saúde, inclusive o farmacêutico e os serviços clínicos desenvolvido por este profissional a população (CADOGAN e HUGHES, 2020).

\section{OBJETIVO}

Revisar estudos que apresentam práticas e os serviços comunitários desenvolvidos nas farmácias em tempos de pandemia para prevenção, controle e tratamento na população e promoção do uso racional de medicamentos.

\section{MÉTODO}

Para tanto, foi realizado uma revisão integrativa por meio das bases de dados Pubmed e BVS utilizando a associação dos descritores: assistência farmacêutica, betacoronavirus e serviços comunitários de farmácia. Foram incluídas no estudo artigos em português e inglês publicados nos meses de janeiro a julho de $2020 \mathrm{e}$ como critérios de exclusão aqueles artigos incompletos e que não se enquadraram nos objetivos da pesquisa.

\section{REVISÃO BIBLIOGRÁFICA}

Durante a crise sanitária gerada pela Covid-19, vários sistemas de saúde ao redor do mundo têm entrado em colapso e consequentemente o atendimento restringem-se a indivíduos diagnosticados ou com suspeita de Covid-19, deixando as demais enfermidades sem assistência, mesmo apresentando sintomas leves de fácil resolução. Nesse sentido o farmacêutico tem atuado de forma exemplar e demostrando resultados positivos, sobretudo no que tange a problemas de saúde autolimitado como: tosse, erupção cutânea, distúrbios gastrointestinais e vários outros sintomas que podem ter resolutividade dentro do ambiente da farmácia comunitária por meio de orientações sobre uso racional de medicamentos, avaliando o melhor esquema posológico, testagem rápida para Covid-19, serviço remoto de tele farmácia e orientações básicas em educação e saúde essenciais à população sobre prevenção, tratamento e cuidados que devem ter não só com relação a Covid-19 mas também com outras enfermidades que assolam a população (HEDIMA, et al., 2020).

\section{CONSIDERAÇÕES FINAIS}

Foi possível observar que o farmacêutico pode desempenhar um papel fundamental no fortalecimento de instituições de saúde pública e privada, não só na progressão da Covid-19, mas também de outros acometimentos. O engajamento do farmacêutico na educação em saúde de comunidades, através de orientação, elaboração de protocolo de tratamento e rastreio de infectados, adequa 0 a prática do farmacêutico a realidade atual.

\section{REFERÊNCIAS}

1. CADOGAN CA, HUGHES CM. On the frontline against COVID-19: Community pharmacists' contribution during a public health crisis. Research in Social and Administrative Pharmacy. 2020. 
2. HEDIMA EW, et al. Farmacêuticos Comunitários: Na linha de frente do serviço de saúde contra o COVID19 nos LMICs. Research in Social and Administrative Pharmacy. 2020. 
RESUMOS SIMPLES: Revisão Bibliográfica

TÍTULO: EPIDEMIOLOGIA E FATORES DE RISCO DA ESQUISTOSSOMOSE MANSONI: UMA REVISÃO DE LITERATURA

Autor/coautores: Ingride de Sousa Araújo Macêdo1, Amanda Gomes Lima Bezerra1, Nátalye Maria Barreto da Silva1, Rafaella Cavalcanti Silva da Costa1, Tiago Pereira de Sousa Cavalcante2.

Instituição: Centro Universitário Maurício de Nassau (UNINASSAU), Recife-PE¹; Centro Universitário São Camilo, São Paulo-SP².

Palavras-chave: Esquistossomose, Schistosoma mansoni, Doenças Negligenciadas.

\section{INTRODUÇÃO}

Doenças negligenciadas são aquelas causadas por parasitas ou agentes infecciosos e que recebem poucos incentivos a pesquisa e controle, sendo mais prevalentes nas populações mais carentes. A esquistossomose é uma doença infecto-parasitária, endêmica em algumas regiões rurais e urbanas do Brasil, causada pelo agente etiológico Schistosoma mansoni, que teve sua chegada em meio ao Período Colonial no Brasil e que é associada a fatores biológicos, socioeconômicos, demográficos, políticos e de saneamento básico. Seu contágio se dá por meio do contato do indivíduo com águas contaminadas onde ocorre a penetração ativa da cercaria na pele (JUNIOR AMM e COSTA ABS, 2020).

\section{OBJETIVO}

Revisar a literatura acerca da epidemiologia e dos fatores de risco associados a esquistossomose que é uma doença ainda negligenciada na atualidade, apesar de ser considerada endêmica em algumas regiões do Brasil.

\section{REVISÃO BIBLIOGRÁFICA}

Uma pesquisa realizada no estado de Minas Gerais mostrou que o risco da população rural para esquistossomose é mais significativo que na população urbana e que o grau de escolaridade tem uma relação inversamente proporcional ao número de pessoas com esta doença, quanto maior o nível de escolaridade, menor a proporção de indivíduos acometidos (SILVA JDP e ANDRADE MD, 2019). Outro estudo evidenciou também que um maior acometimento da esquistossomose no sexo masculino pode estar relacionado à menor procura destes os serviços de saúde e que a prevalência maior é na faixa etária entre 20 e 59 anos de idade, indicativo de que a doença está associada à ocupação (GOMES ACL, et al., 2016). A região Nordeste é a mais acometidas por doenças endêmicas, pois a região sofre frequentemente com condições inadequadas de saneamento básico, a população não dispõe de ações educativas em saúde e há um alto índice de pobreza, estes fatores contribuem para a disseminação de formas parasitárias, já que pessoas que são vítimas da desigualdade social e econômica acabam sendo mais suscetíveis a determinados problemas de saúde pública (JUNIOR AMM e COSTA ABS, 2020).

\section{CONSIDERAÇÕES FINAIS}

Diante disso, infere-se que a esquistossomose é mais prevalente em regiões com condições sanitárias precárias, baixo nível de escolaridade e, portanto, com deficiência na prática de ações educativas em saúde. Por tratar-se de um problema de saúde pública, deve ser mais bem abordado o contexto educativo na atenção primária, seja pela busca ativa por meio das visitas domiciliares, seja pelas políticas públicas para melhoria das condições de vida das populações afetadas. 


\section{REFERÊNCIAS}

1. GOMES ACL, et al. Prevalência e carga parasitária da esquistossomose mansônica antes e depois do tratamento coletivo em Jaboatão dos Guararapes, Pernambuco. Revista Epidemiol. Serv. Saúde [online], 2016.

2. JUNIOR AMM, COSTA ABS. Abordagem sobre a Schistosoma Mansoni e seu perfil epidemiológico nos municípios do Rio Grande do Norte/RN. Revista Medicus,2020;2:e.74-6484

3. SILVA JDP, ANDRADE MD. Perfil epidemiológico da esquistossomose mansônica em Minas Gerais. Revista Inova Saúde, 2019. 
RESUMO SIMPLES: Revisão Bibliográfica

TíTULO: SINTOMAS CHAGÁSICOS PODEM SER POTENCIALIZADOS PELA COVID19

Autor/coautores: Damiana Maria Minhaqui da Conceição1, Joyce Santana do Nascimento1, Larissa Santos Carneiro Gomes², Juliana Mendes Correia'.

Instituição: Centro Universitário São Miguel (UNISÃOMIGUEL), Recife-PE'; Centro Universitário Maurício de Nassau (UNINASSAU), Recife-PE2.

Palavras-chave: COVID-19, Doença de Chagas, Pandemia.

\section{INTRODUÇÃO}

A Doença de Chagas (DC) é uma condição crônica que leva aproximadamente $40 \%$ dos indivíduos infectados a desenvolverem sinais de comprometimento cardíaco, como palpitações ou ritmo anormal do coração, dores de cabeça, abdômen, músculos, febre, falta de ar, inchaço indolor ao redor dos olhos ou irritação na pele. Estima-se que em 2020 existam mais de 1 milhão de pessoas infectadas no Brasil. A mortalidade pela DC pode ser ainda maior quando se considera, além da causa básica, causas associadas, tornando-se necessária avaliação do aumento do risco de óbitos durante a pandemia por COVID-19 (MINISTÉRIO DA SAÚDE, 2020).

\section{OBJETIVO}

O designío do estudo é caracterizar os riscos de óbito para portadores da Doença de Chagas Crônica contaminados pela COVID-19, determinando os possíveis sinais de agravamento como forma de prevenir, tratar e reduzir suas complicações.

\section{MÉTODO}

Trata-se de uma revisão integrativa realizada com base nas informações do Ministério da Saúde, Governo Federal e SBMT. Considerou-se artigos publicados nos últimos cinco anos, em português, encontrando-se os descritores: COVID-19, Doença de Chagas, Pandemia. Foram encontrados 14 artigos, desconsiderados 11 que não se enquadraram aos critérios apresentados.

\section{REVISÃO BIBLIOGRÁFICA}

A Doença de Chagas e COVID-19 são patologias com similaridades sintomatológicas. Realizando uma comparação, é possível citar que ambas apresentam dores de cabeça e musculares, além de febre, sendo capaz de evoluir para arritmias, miocardite, complicações trombóticas e problemas respiratórios. Os sintomas específicos poderão distinguir as doenças, porém as duas situações epidemiológicas podem evoluir individualmente para óbito, suscitando preocupação clínica caso um paciente portador de DC seja acometido por COVID-19. A junção da diagnose e duplicação do perfil sintomatológico podem potencializar sintomas comuns e comprometer a saúde do paciente rapidamente (GOVERNO FEDERAL, 2020).

Ressalta-se que pacientes com DC crônica com perda de olfato, paladar, tosse seca e dor de garganta, sinais e sintomas específicos para COVID-19, devem entrar em contato com o centro de Saúde ou com o médico que o acompanha para o diagnóstico e, em caso positivo, seguir imediatamente para o tratamento, principalmente com uso contínuo dos medicamentos antiparasitário ou betabloqueadores (SBMT, 2020).

\section{CONSIDERAÇÕES FINAIS}

É necessário o desenvolvimento de pesquisas e acompanhamento minucioso dos casos confirmados pela COVID-19 nos pacientes acometidos pela doença de Chagas para melhorar o aporte no manejo dos sintomas e conhecimento da evolução do quadro clínico. Por fim, faz-se necessária a inclusão da doença de Chagas na lista do grupo de risco e agravamento para óbito por COVID-19. 


\section{REFERÊNCIAS}

1. GOVERNO FEDERAL. Perguntas e respostas sobre COVID-19 e Chagas, 2020; e1.

2. MINISTÉRIO DA SAÚDE. Secretaria de Vigilância em Saúde. Recomendações para adequações das ações de vigilância e cuidado ao paciente com doença de Chagas frente à situação epidemiológica da COVID19. Departamento de Imunização e Doenças Transmissíveis. Coordenação-Geral de Vigilância de Zoonoses e Doenças de Transmissão Vetorial. Nota Informativa № 9/2020-CGZV/DEIDT/SVS/MS, 2020; e1.

3. SBMT. SOCIEDADE BRASILEIRA DE MEDICINA TROPICAL. COVID-19 e Chagas: Pessoas que vivem com a doença correm o risco de complicações graves, 2020; e1. 
RESUMOS SIMPLES: Revisão Bibliográfica

TÍTULO: HANSENÍASE: UM PROBLEMA DE SAÚDE PÚBLICA

Autor/coautores: Suélen Stefanoni Brandão; Monica Micheli Alexandre; Priscila Luzia Pereira Nunes; Giuliana Zardeto-Sabec.

Instituição: Universidade Paranaense (UNIPAR), Umuarama-Paraná.

Palavras-chave: Mycobacterium leprae, Infectocontagiosa, Baciloscopia.

\section{INTRODUÇÃO}

A hanseníase apresenta como agente etiológico o bacilo Mycobacterium leprae. É uma doença infectocontagiosa, crônica, com alto poder incapacitante por atingir especialmente, as células epiteliais e neuronais. Os pacientes acometidos são classificados quanto ao número de lesões cutâneas, carga bacilar e nível de acometimento dos nervos periféricos (QUARESMA MSM, et al., 2019). O Brasil ocupa o segundo lugar na relação de países com maior número de casos no mundo (SILVA, PSR, 2020). Trata-se de uma enfermidade incluída na Lista Nacional de Notificação Compulsória, tendo a descrição e interpretação dos dados epidemiológicos de fundamental importância para realizar estratégias de prevenção, controle e eliminação (NUNES PS, 2020).

\section{OBJETIVO}

Descrever as características relevantes sobre o tema hanseníase, devido ao fato do país ocupar a segunda posição no mundo em número de casos, se tornando um problema de saúde pública.

\section{REVISÃO BIBLIOGRÁFICA}

No mundo, foram reportados à Organização Mundial da Saúde (OMS) 214.783 casos novos da doença em 2016 (SILVA, PSR, 2020). A transmissão é prevalentemente pelas vias aéreas superiores. É transmitida principalmente por meio do convívio com os doentes do tipo virchowiano ou dimorfo que ainda não foram diagnosticados e tratados (QUARESMA MSM, et al., 2019).

O diagnóstico da hanseníase é clínico, tendo como base os sinais e sintomas e história epidemiológica do paciente e outras provas complementares são os exames de baciloscopia, histopatógico e a prova da histamina (QUARESMA MSM, et al., 2019; SILVA PSR, 2020).

O grande número de casos de hanseníase determina a doença como problema de saúde pública, além disso, seu alto potencial incapacitante pode trazer consequências ao indivíduo em sua vida social e em fase produtiva determinando perdas econômicas e traumas psicoemocionais. Essas incapacidades têm sido responsáveis pelo estigma e discriminação dos doentes, o que afeta diretamente na renda familiar, corroborando com a literatura científica que afirma que a hanseníase predomina em classes menos favorecidas (NUNES PS, 2020).

\section{CONSIDERAÇÕES FINAIS}

Percebe-se que a hanseníase perdura como um problema de saúde pública, sendo necessário um diagnóstico precoce e tratamento adequado para alcançar a cura. Condições socioeconômicas afetam diretamente no sucesso da erradicação da mesma, sendo assim, mais estudos são necessários para alertar a população a respeito da transmissão, do diagnóstico precoce, além da importância do tratamento adequado.

\section{REFERÊNCIAS}

1. NUNES PS, et al. Perfil clínico e epidemiológico dos casos de hanseníase em menores de 15 anos em um município da região metropolitana de Goiânia, Goiás. Revista Eletrônica Acervo Saúde, 2019; 17: e319e319. 
2. QUARESMA MSM, et al. Perfil clínico e epidemiológico dos pacientes portadores de hanseníase em uma unidade de referência no estado do Pará. Revista Eletrônica Acervo Saúde, 2020; 18: e269-e269.

3. SILVA PSR, et al. Perfil clínico-epidemiológico de pacientes portadores de hanseníase em um município do Maranhão. Revista Eletrônica Acervo Saúde, 2020; 12(8): e3468-e3468. 
RESUMOS SIMPLES: Revisão Bibliográfica

TÍTULO: ESTUDOS IN VITRO E IN VIVO UTILIZANDO NANOSSISTEMAS PARA APLICAÇÃO ANTITUBERCULOSE

Autor/coautores: Daniel Charles dos Santos Macêdo, Luana Bastos da Silva; Karlle Tathyana de Almeida Santos; Mariane Cajubá de Britto Lira Nogueira.

Instituição: Laboratório de Imunopatologia Keizo Asami (LIKA), Recife -PE; Universidade Federal de Pernambuco (UFPE), Recife-PE.

Palavras-chave: Nanossistemas, Tuberculose, Mycobacterium tuberculosis.

\section{INTRODUÇÃO}

A tuberculose pulmonar é provocada pelo Mycobacterium tuberculosis (Mtb), causando milhões de mortes ao redor do mundo (VISWANATHAN V, et al., 2018). O tratamento preconizado pela OMS é eficaz, porém a terapia é longa e associada a efeitos adversos graves, promovendo baixa adesão do paciente e consequente surgimento de cepas multirresistentes (PI J, et al., 2019). Uma vez que o Mtb é um parasita intracelular obrigatório, residindo dentro de macrófagos alveolares, esta célula é o principal alvo da terapia anti-Tb. Assim, nanossistemas de superfície modificada com moléculas sinalizadoras têm sido desenvolvidos apresentando como alvo os macrófagos, visando a redução da sobrevivência do Mtb intracelular (VISWANATHAN V, et al., 2018).

\section{OBJETIVO}

Pesquisar publicações que utilizaram nanossistemas na veiculação de ativos visando o tratamento de macrófagos infectados com $M$. tuberculosis em estudos in vitro e in vivo para futura aplicação na terapia antiTb.

\section{REVISÃO BIBLIOGRÁFICA}

Após análise dos artigos, observou-se um consenso entre os autores de que os nanossistemas com superfície modificada são capazes de aumentar a concentração dos ativos encapsulados dentro dos macrófagos (JAHAGIRDAR P, et al., 2020). Pi e colaboradores (2019) desenvolveram nanopartículas de óxido de grafeno revestidas com manose e polietilenoglicol contendo rifampicina (Rif-GO-PEG-MAN). Os autores observaram que a encapsulação proporcionou um aumento na concentração do fármaco dentro dos macrófagos passando de $50 \mathrm{ng}$ para $150 \mathrm{ng} / 10^{6}$ (fármaco/células). Na avaliação da atividade anti-Tb, houve uma redução de 1,75 vezes na contagem das UFC após tratamento com Rif-GO-PEG-MAN comparado ao fármaco livre, revelando maior atividade da rifampicina após sua encapsulação (PI J, et al., 2019).

Em estudos in vivo utilizando ratos swiss, nanopartículas de gelatina revestidas com manose e contendo licorice (LE-MnGNP), extrato obtido da Glycyrrhiza glabra, mantiveram constante a concentração plasmática do ativo durante 22h. Para a atividade anti-Tb, o grupo tratado com LE-MnGNP apresentou redução das UFC $\left(1,6 \log _{10}\right)$ presentes nos pulmões dos ratos comparado ao grupo sem tratamento $\left(\sim 7 \log _{10}\right)$ (VISWANATHAN V, et al., 2018).

\section{CONSIDERAÇÕES FINAIS}

O aumento da concentração dos ativos dentro dos macrófagos a partir da utilização de nanossistemas com superfície modificada ou sítio-específicos é uma estratégia promissora para combater o Mtb intracelular. Além dos trabalhos in vitro, estudos in vivo mostraram que a encapsulação dos fármacos em nanossistemas aumentou a atividade dos respectivos ativos, revelando a importância da nanotecnologia como uma promissora ferramenta no combate à tuberculose. 


\section{REFERÊNCIAS}

1. JAHAGIRDAR $P$, et al. Intramacrophage delivery of dual drug loaded nanoparticles for effective clearance of Mycobacterium tuberculosis. Journal of Pharmaceutical Sciences, 2020; 109 (7): 2262-2270.

2. PI J, et al. Mannosylated graphene oxide as macrophage-targeted delivery system for enhanced intracellular M. tuberculosis killing efficiency. Materials Science and Engineering: C, 2019; 103: 109777.

3. VISWANATHAN V, et al. Mannosylated gelatin nanoparticles of licorice for use in tuberculosis: formulation, in vitro evaluation, in vitro cell uptake, in vivo pharmacokinetics and in vivo anti-tubercular efficacy. Journal of Drug Delivery Science and Technology, 2018; 45: 255-263. 
RESUMO SIMPLES: Revisão Bibliográfica

TÍTULO: HIV-1 SUBTIPO F NO BRASIL: IMPORTÂNCIA NA DISPERSÃO DA EPIDEMIA, PATOGÊNESE E GERAÇÃO DOS RECOMBINANTES BF DO VÍRUS

Autor/coautores: Edson Barbosa de Souza ${ }^{1}$, Aldenize Pimentel de Souza1, Ícaro Pedro do Nascimento ${ }^{1}$, Nicácio de Oliveira Freitas ${ }^{2}$, Kledoaldo Lima ${ }^{1,3}$

Instituição: Hospital das Clínicas, Universidade Federal de Pernambuco, UFPE, Recife-PE1; Secretaria de Educação de Pernambuco, SEE, Recife-PE²; European Virus Bioinformatics Center, Leutragraben 1, 07743 Jena, Germany ${ }^{1,3}$.

Palavras-chave: HIV-1, Epidemiologia Molecular, Resistência Antirretroviral.

\section{INTRODUÇÃO}

A epidemia do HIV-1 no Brasil é causada por múltiplos subtipos do grupo $M$, sendo o $B$ o prevalente, seguido pelo $\mathrm{F}$ e C, além da grande circulação de recombinantes BF. No País, a primeira identificação do subtipo $\mathrm{F}$ aconteceu em quatro amostras coletadas entre 1989-1990 (LOUWAGIE, et al., 1994). A dispersão de subtipos não-B, incluindo o HIV-1 F, tem acometido várias regiões do País, além de, estarem associados a diferenças na patogênese ao serem comparados ao subtipo B (LIMA, et al., 2016). Entretanto, há poucos dados sobre a influência deste subtipo em diversas populações, seu papel na origem de recombinantes $B F \mathrm{e}$ na delimitação de características moleculares desta variante.

\section{OBJETIVO}

Avaliar, atravéz de uma pesquisa bibliográfica nos bancos de dados do Pubmed e Scielo, o papel do HIV$1 \mathrm{~F}$ na epidemia de Aids no Brasil, na patogênese da doença e origem dos recombinantes BF.

\section{REVISÃO BIBLIOGRÁFICA}

A primeira identificação do subtipo F, no Brasil, aconteceu em quatro amostras coletadas entre 1989-1990. Entretanto, o primeiro estudo sobre a história evolucionária desse subtipo estimou que o início desta epidemia ocorreu na década de 1980. Alguns estudos relacionam a presença do subtipo $F$ com a transmissão heterossexual, na demonstração que o mesmo possuía mais mutações relacionadas à alguns antirretrovirais, como para Inibidores de Protease (IPs) do que o subtipo B, no qual é mais frequente nos países ocidentais. Além disso, outros trabalhos relacionam a presença deste subtipo a alguns grupos epidemiológicos e à menor carga viral e maior contagem de células T CD4+ (LIMA, et al. 2016). Na epidemia brasileira do HIV-1, a distribuição do subtipo $F$ é bastante heterogênea. As proporções dos subtipos virais podem variar de acordo com a região genética utilizada na determinação de subtipagem e com a categoria de exposição escolhida para a amostragem (LIMA, et al., 2017). Na Brasil, a prevalência dos recombinantes BF é maior do que o observado para a o subtipo $\mathrm{F}$, indicando a importância destes recombinantes na epidemia do continente.

\section{CONSIDERAÇÕES FINAIS}

Verificou-se o HIV-1 subtipo F, apesar de apresentar um efeito fundador logo no início da epidemia, como demonstrado para outros subtipos, o mesmo não apresentou uma maior dispersão epidêmica no Brasil. Além disso, averiguou-se importantes diferenças quanto à transmissão, resistência antirretroviral e características clínicas em estudos isolados.

\section{REFERÊNCIAS}

1. LIMA K, et al. Increase in human immunodeficiency virus 1 diversity and detection of various subtypes and recombinants in north-eastern Brazil. J Med Microbiol. 2017;66(4):526-535.

2. LIMA K, et al. Epidemiological, Clinical and Antiretroviral Susceptibility Characterization of Human Immunodeficiency Virus Subtypes B and Non-B in Pernambuco, Northeast Brazil [published correction appears in PLoS One. 2016;11(6):e0158192]. PLoS One. 2016;11(5):e0155854. Published 2016 May 24.

3. LOUWAGIE J, et al. Genetic analysis of HIV-1 isolates from Brazil reveals presence of two distinct genetic subtypes. AIDS Res Hum Retroviruses. 1994;10(5):561-567. 
RESUMOS SIMPLES: Revisão Bibliográfica

TÍTULO: DISTRIBUIÇÃO GEOGRÁFICA E ASPECTOS EPIDEMIOLÓGICOS DA FILARIOSE LINFÁTICA: UMA REVISÃO DE LITERATURA

Autor/coautores: Thalles Rodolfo Buarque de Vasconcelos; Fernanda das Chagas Angelo Mendes Tenorio. Instituição: Universidade Federal de Pernambuco (UFPE), Recife-PE.

Palavras-chave: Filariose linfática, Wuchereria bancrofti, Localização geográfica.

\section{INTRODUÇÃO}

As doenças negligenciadas (DNs) compreendem uma série de problemáticas causadas por um determinado agente infeccioso ou parasita, com impactos sócio-economicos e danos físicos, principalmente em comunidades carentes e em áreas de clima tropical e subtropical (GONÇALVES EA, et al., 2019). Dentre estas doenças, destaca-se a filariose linfática que é transmitida para o ser humano através da picada da fêmea do mosquito Culex quinquefasciatus e causada pelo helminto Wuchereria bancrofti. Essa doença por sua vez ataca prioritariamente os vasos linfáticos fazendo-os inchar com a formação de edemas linfáticos e nódulos granulomatosos (OLIVEIRA MM, et al., 2018). Investigar distribuições geográficas da filariose linfática pode contribuir para a implementação de ações de controle.

\section{OBJETIVO}

Analisar as localizações geográficas das incidências dos casos, esclarecer o entendimento do porquê essa doenca seja classificada como negligenciada, e com isso, associar a relação entre os dados apresentados e os locais de acontecimento das infecções.

\section{REVISÃO BIBLIOGRÁFICA}

De acordo com a Organização Mundial de Saúde (OMS), a filariose linfática afeta mais de 120 milhões de de pessoas em 72 países da Ásia, África e das Américas e em 2018 cerca de 893 milhões de pessoas viviam em áreas de risco de contrair a infecção.

A maior incidência de casos da doença ocorre na região do Sudeste Asiático, sobretudo na Índia sendo endêmica em 256 distritos distribuídos em 16 Estados e 5 territórios da União.

Na América os níveis são menos alarmantes atingindo quatro países, República Dominicana, Guiana, Brasil e Haiti, este último com maior prevalência.

No Brasil a filariose linfática foi detectada em quatro municípios do Estado de Pernambuco, Recife, Jaboatão dos Guararapes, Olinda e Paulista.

No período entre 2008 e 2013, foram registrados 516 diagnósticos positivos, Olinda exibiu 48,6\% ( $n=251$ ) dos casos, Recife, 23,1\% ( $n=119)$, Jaboatão dos Guararapes, 24,4\% $(n=126)$ e Paulista, 3,9\% $(n=20)$. Entre 2014 a 2016, não houve registro de novos casos e em 2018, foram examinadas 73.364 pessoas, e não foi encontrado nenhum caso positivo (MINISTÉRIO DA SAÚDE, 2019).

\section{CONSIDERAÇÕES FINAIS}

Infere-se, portanto que a localização geográfica da filariose linfática está correlacionada em áreas que posuem baixos indicadores socio-econômicos e de clima favorável para o desenvolvimento do agente etiológico e para a sua proliferação através do mosquito. Estratégias e medidas de prevenção e controle dessa doença devem ser elaboradas nas regiões endêmicas.

\section{REFERÊNCIAS}

1. GONÇALVES EA, et al. Enfoque da filariose linfática no contexto atual: uma revisão de literatura. Mostra Científica da Farmácia. 2019; 5. 
2. OLIVEIRA MM, et al. Estratégia para controle e eliminação da filariose linfática. Open Journal of Aging Research, 2018; 1.

3. MINISTÉRIO DA SAÚDE (BR). Secretaria de Vigilância em Saúde. Vigilância em saúde no Brasil 2003|2019: Da criação da Secretaria de Vigilância em Saúde aos dias atuais. Boletim Epidemiológico; 2019; 50:1-154. 
RESUMOS SIMPLES: Revisão Bibliográfica

TÍTULO: NOVAS ESTRATÉGIAS PARA A TERAPIA DA LEISHMANIOSE CUTÂNEA: UMA REVISÃO NARRATIVA

Autor/coautor: Vinicius Paz dos Santos ${ }^{1}$, Alane Rafaela de Carvalho Amaral ${ }^{1}$, Kaio Henrique de Freitas ${ }^{1}$, Alan Francisco da Costa Lima Junior ${ }^{2}$, Dênis Roberto da Silva ${ }^{3}$.

Instituição: Universidade Federal de Pernambuco (UFPE), Recife - PE¹; Universidade de Pernambuco (UPE), Serra Talhada - $\mathrm{PE}^{2}$; Raia Drogasil, Recife - $\mathrm{PE}^{3}$.

Palavras-chave: Leishmaniose cutânea, Tratamento, Antimoniato de metilglucamina.

\section{INTRODUÇÃO}

As leishmanioses compreendem um grupo de doenças negligenciadas causadas por protozoários do gênero Leishmania. A Leishmaniose cutânea (LC) é a apresentação mais comum, responsável por mais de $90 \%$ dos casos do Brasil, representando uma das afecções dermatológicas que requer mais atenção devido à magnitude de suas lesões, como o risco de ocorrência de deformidades no ser humano. No país, o fármaco de primeira escolha para o tratamento é o antimoniato de metilglucamina (AM) considerado eficaz, porém, possui alta toxicidade, podendo trazer impactos negativos para o paciente (VASCONCELOS JM, et al., 2018). Logo, é importante a busca de novas estratégias que visem minimizar os efeitos adversos na terapia dessa parasitose.

\section{OBJETIVO}

Revisar estudos primários relatando estratégias de tratamento, as quais possuam eficácia terapêutica visando um menor potencial de efeitos adversos comparadas ao medicamento convencional na terapia da doença e, assim, possibilitando o aumento da adesão pelo paciente.

\section{REVISÃO BIBLIOGRÁFICA}

Devido aos tratamentos convencionais para LC basearem-se na forma de ação sistêmica, alternativas tópicas vêm sendo usadas isoladamente ou associadas ao tratamento convencional a fim de aumentar a adesão e diminuir os efeitos adversos. Amostras de tecido de lesões de hamsters tratados foram avaliadas. Comparado ao grupo sem tratamento, o tratamento tópico com emulsão hidratante com 10\% de Isotionato de Pentamidina (IP) e ácido úsnico apresentou diferença significativa nas medidas de lesões, 20 dias após o tratamento final e $27,37 \%$ de redução. O tratamento tópico com emulsão anidra com $10 \%$ de IP e ácido úsnico mostrou redução da carga parasitária (WYREPKOWSKI CDC, et al., 2017).

Um outro estudo que utilizava o AM, três $(3,37 \%)$ pacientes morreram, $12(13,48 \%)$ relataram reações adversas e o tratamento foi alterado para anfotericina B, e $74(83,14 \%)$ foram curados. As alterações que levaram à substituição do $\mathrm{AM}$ foram febres persistentes. Anfotericina $\mathrm{B}$ e Pentamidina são fármacos de segunda escolha, uma vez que só são usados nos casos não resolutivos ao tratamento convencional (SILVEIRA LJD, et al., 2015).

\section{CONSIDERAÇÕES FINAIS}

Sendo assim, fica em evidência a importância de estudos que têm como objetivo a busca de alternativas para o tratamento de LC, tendo em vista que a sua terapia tradicional dispõe de alta toxicidade e efeitos adversos além de difícil adesão. Para isso, necessita-se de investimentos na área para, assim, possibilitar novas descobertas de tratamento para essa doença que atinge uma grande parte dos brasileiros.

\section{REFERÊNCIAS}

1. SILVEIRA LJD, et al. Historical series of patients with visceral leishmaniasis treated with meglumine antimoniate in a hospital for tropical diseases, Maceio-AL, Brazil. Revista do Instituto de Medicina Tropical de São Paulo, 2015; 1809-4302. 
2. VASCONCELOS JM, et al. American integumentary leishmaniasis: epidemiological profile, diagnosis and treatment. Brazilian Journal of Clinical Analyses, 2018;50(3):221-7.

3. WYREPKOWSKI CDC, et al. Tratamento tópico da leishmaniose cutânea experimental em hamster dourado ( Mesocricetus auratus ) com formulações contendo pentamidina. Acta Amazônica, 2017; 16789946. 
RESUMO SIMPLES: Revisão Bibliográfica

TÍTULO: A INFLUÊNCIA DA EXPRESSÃO GÊNICA NA VIRULÊNCIA DA PARACOCCIDIOIDOMICOSE Autor/coautores: Gabriela Nogueira Motta ${ }^{1}$, Rafisah Sekeff Simão Alencar², Izabely Lima Assunção ${ }^{3}$, Mariana Martins Castro ${ }^{4}$, José Lima Assunção Junior ${ }^{5}$.

Instituição: Universidade Estadual do Maranhão (UEMA), Caxias- MA'; Pontifícia Universidade Católica de Minas Gerais (PUCMG), Poços de Caldas- MG²; Universidade CEUMA (UNICEUMA), São Luís- MA³; Universidade Católica de Brasília (UCB), Brasília- DF"; Instituto Federal do Maranhão (IFMA), São Luís- MA ${ }^{5}$.

Palavras-chave: Paracoccidioidomicose, Virulência, Genes.

\section{INTRODUÇÃO}

A paracoccidioidomicose (PCM) é uma micose sistêmica endêmica mais frequente na América Latina, com alta prevalência no Brasil. A doença é causada pelo fungo do gênero Paracoccidioides spp., cujo grau de virulência é variável pois depende de fatores atribuídos ao hospedeiro e ao fungo (DO AMARAL CC, et al., 2019). Suas manifestações clínicas são caracterizadas por feridas na pele e mucosas, osso e hepatoesplenomegalia, podendo evoluir para lesões nos pulmões e nas vias aéreas. A forma clínica da PCM está relacionada à antecedentes genéticos, idade, sexo, etnia, hábito de fumar, consumo de álcool e imunossupressão celular (MARTINEZ R, 2017).

\section{OBJETIVO}

Revisar a influência da expressão gênica no grau de virulência da paracoccidioidomicose e correlacionar esta variável com as implicações no diagnóstico realizado nos laboratórios e no tratamento terapêutico da doença.

\section{MÉTODO}

Foi realizada uma revisão sistemática de literatura nas plataformas PubMed e BVS utilizando os seguintes descritores e seus entretermos: "Paracoccidioidomicose", "genética" e/ou "virulência". 3 artigos foram selecionados na língua inglesa, publicados entre 2017 e 2019.

\section{REVISÃO BIBLIOGRÁFICA}

Diferenças na virulência entre fungos isolados do gênero Paracoccidioides spp. podem estar relacionadas ao seu conteúdo distinto de vesículas extracelulares de RNA, considerando que as classes de RNA estão envolvidas na modulação da transcrição/tradução em uma variedade de sistemas (PERES DA SILVA R, et al., 2019). Juntamente, proteínas comuns (fosfoglicerato quinase, proteína de ligação ao RNA, gliceraldeído3-fosfato desidrogenase, glutationa redutase, aldolase de frutose-bifosfato, proteína de ligação a ácido nucleico, catalase peroxissômica e aldeído desidrogenase) parecem ser mais abundantes em isolados altamente virulentos do que nos de baixa virulência, demonstrando assim a sua importância para a capacidade de colonização do hospedeiro, sobrevivência em ambiente hostil e fuga do sistema imunológico (DO AMARAL CC, et al., 2019). Além disso, o antígeno C4B * -Q0 do complexo principal de histocompatibilidade classe III foi associado à forma crônica da micose (MARTINEZ R, 2017).

\section{CONSIDERAÇÕES FINAIS}

A paracoccidioimicose é uma doença negligenciada de difícil diagnóstico de maneira que a identificação dos diferentes graus de virulência pode ser um empecilho para a ação terapêutica. Dessa forma, segundo o demonstrado, os papéis das proteínas em diferentes formas clínicas da PCM podem ser utilizados como biomarcadores ou como alvos do tratamento da doença, de modo a aumentar a eficácia dos procedimentos de diagnose e de intervenção. 


\section{REFERÊNCIAS}

1. DO AMARAL CC, et al. Proteomic analysis of Paracoccidioides brasiliensis complex isolates: Correlation of the levels of differentially expressed proteins with in vivo virulence. PLoS ONE, 2019; 14(7): e0218013.

2. MARTINEZ R. New trends in paracoccidioidomycosis epidemiology. Journal of fungi, 2017; 3(1): e3010001.

3. PERES DA SILVA R, et al. Comparison of the RNA Content of Extracellular Vesicles Derived from Paracoccidioides brasiliensis and Paracoccidioides lutzii. Cells, 2019; 8(7). 
RESUMOS SIMPLES: Revisão bibliográfica

TÍTULO: IMPACTO NA SAÚDE MENTAL DA POPULAÇÃO BRASILEIRA CAUSADO PELO DISTANCIAMENTO SOCIAL NO ENFRENTAMENTO A COVID-19

Autor/coautores: Tháfylla Mendes de Sant' Ana, Elisangela Melquiades Silva e Jeremias Guilherme da Silva. Instituição: Grupo Cefapp, Recife - PE.

Palavras-chave: Distanciamento social, Pandemia, Saúde Mental.

\section{INTRODUÇÃO}

Em dezembro de 2019, surgiu uma nova mutação do coronavírus (SARS-CoV-2) em um mercado chinês em Wuhan, com a venda de animais vivos, de onde teria surgido a nova mutação, que se apresenta como uma gripe causando complicações pulmonares. Após as transmissões na cidade, o vírus se expandiu rapidamente, a cada um infectado duas a quatro pessoas são infectadas, resultando na atual pandemia (BAHIANO MA, et al, 2020). Nesse processo, mesmo havendo divergências de opiniões nas esferas governamentais, a medida mais adotada pelos estados brasileiros foi do distanciamento social, visto pela população e mídia como isolamento social, acarretando efeitos negativos como o estresse, depressão, raiva, sensação de solidão e preocupação com a questão financeira.

\section{OBJETIVO}

Compreender a relações entre a saúde mental dos brasileiros com as medidas adotadas para o combate a propagação do novo coronavírus, tais como o distanciamento social.

\section{REVISÃO BIBLIOGRÁFICA}

Para previnir a propagação do vírus, as medidas tomadas em diversos países foi o distanciamento social, que implica na distância de dois metros entre as pessoas quando estão na rua (BAHIANO MA, et al., 2020). A incerteza do término da quarentena causa complicações na saúde mental, gerando insegurança, medo e estresse. De acordo com os dados coletados em um estudo no mês de maio apontou que $41 \%$ dos brasileiros estão sofrendo de ansiedade, 35\% estão se exercitando menos, $26 \%$ sofrem com insônia e $47 \%$ sofrem com transtornos alimentares (Instituto Ipsos, 2020). O governo disponibiliza psicólogos para indivíduos afetados pela crise do coronavíru, mas o Brasil não está preparado para enfrentar a pandemia, o homem desde os primórdios está habituado na convivência com a sociedade e o isolamento social tirou o seu convívio habitual e rotina diária, trazendo impacto na saúde mental da população e na economia do país.

\section{CONSIDERAÇÕES FINAIS}

Esse estudo reune conhecimento para analisar importância da necessidade do cuidado da saúde mental em meio ao surto do novo coronavírus no país, que declarou emergência de saúde pública e trouxe consigo o medo, a insegurança, a raiva e estresse à população brasileira.

\section{REFERÊNCIAS}

1. BAHIANO MA, et al. COVID-19 e saúde mental: a emergência do cuidado. Estud. Psicol; 2020; 37; e20074

2. BEZERRA ACV, et al. Fatores Associados ao comportamento da população durante o isolamento social na pandemia de COVID-19. Ciência \& saúde coletiva, 2020; 25: 2411-2421

3. INSTITUTO IPSOS. More suffering from under exercising, anxiety than other health concerns due to COVID-19: Poll. 2020 


\section{AGRADECIMENTOS}

\section{Patrocinadores}

Interprise produtos laboratoriais

Conselho Federal de Farmácia

Conselho Regional de Farmácia do Estado de Pernambuco

SANARFLIX

SANAR editora

Lume consultoria 